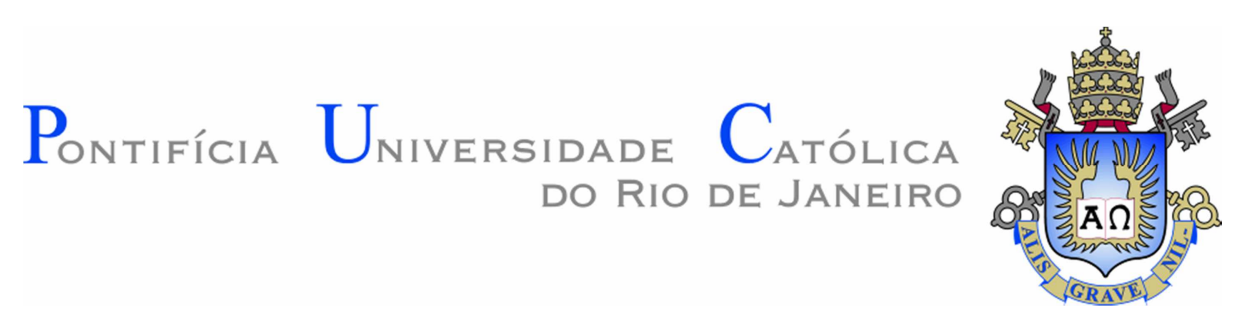

Filipe Meirelles Fonseca

Comportamento não linear, bifurcações e instabilidade de uma treliça hiperelástica

Dissertação de Mestrado

Dissertação apresentada ao Programa de PósGraduação em Engenharia Civil da PUC-Rio como requisito parcial para obtenção do grau de Mestre em Engenharia Civil.

Orientador: Prof. Paulo Batista Gonçalves

Rio de Janeiro

Agosto de 2018 


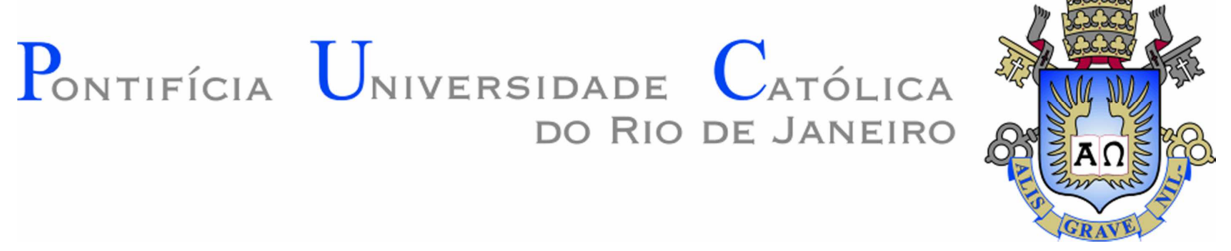

Filipe Meirelles Fonseca

\section{Comportamento não linear, bifurcações e instabilidade de uma treliça hiperelástica}

Dissertação apresentada como requisito parcial para obtenção do grau de Mestre pelo Programa de Pós-Graduação em Engenharia Civil da PUC-Rio. Aprovada pela Comissão Examinadora abaixo assinada.

Prof. Paulo Batista Gonçalves Orientador Departamento de Engenharia Civil e Ambiental - PUC-Rio

Prof. Raul Rosas e Silva Departamento de Engenharia Civil e Ambiental - PUC-Rio

Prof. Diego Orlando Universidade do Estado do Rio de Janeiro - UERJ

Prof. Michèle Schubert Pfeil Universidade Federal do Rio de Janeiro - COPPE-UFRJ

Prof. Márcio da Silveira Carvalho Coordenador Setorial do Centro Técnico Científico - PUC-Rio

Rio de Janeiro, 01 de agosto de 2018. 
Todos os direitos reservados. É proibida a reprodução total ou parcial do trabalho sem autorização da universidade, do autor e do orientador.

\section{Filipe Meirelles Fonseca}

Graduou-se em Engenharia Civil pela Universidade Federal do Rio de Janeiro (UFRJ), em abril de 2015.

Ingressou no mestrado em Engenharia Civil da PUCRio em agosto de 2016, atuando na área de Instabilidade e Dinâmica das Estruturas.

Ficha Catalográfica

Fonseca, Filipe Meirelles

Comportamento não linear, bifurcações e instabilidade de uma treliça hiperelástica / Filipe Meirelles Fonseca; orientador: Paulo Batista Gonçalves. - 2018.

151 f.: il. color. ; $30 \mathrm{~cm}$

Dissertação (mestrado)-Pontifícia Universidade Católica do Rio de Janeiro, Departamento de Engenharia Civil e Ambiental, 2018.

Inclui bibliografia

1. Engenharia civil - Teses. 2. Treliça. 3. Material neo-Hookeano. 4. Bifurcações. 5. Instabilidade estrutural. I. Gonçalves, Paulo Batista. II. Pontifícia Universidade Católica do Rio de Janeiro. Departamento de Engenharia Civil. III. Título. 


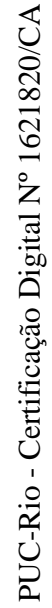

Dedico este trabalho à minha família e à minha namorada 


\section{Agradecimentos}

Minha formação como Engenheiro de Estruturas começa como estudante do curso de Engenharia Civil na Universidade Federal do Rio de Janeiro, onde distintos professores com reponsabilidade e excelência traçaram minha formação.

Meu primeiro emprego como Engenheiro Civil foi na Empresa Beton Stahl Engenharia, onde vivenciei uma grande experiência profissional.

A oportunidade bateu na porta e decidido a desenvolver minha formação, iniciei o mestrado em Engenharia Civil na Pontifícia Universidade Católica do Rio de Janeiro. Aqui, excelentes professores me ajudaram a subir mais um degrau na minha formação.

Em especial, destaca-se o Professor Paulo Batista Gonçalves, que com a recomendação do Professor Ricardo Valeriano, eu já o havia escolhido como orientador desde antes de começar o curso. Ao longo das disciplinas de Instabilidade e Dinâmica das estruturas, com a sua sabedoria ao ensinar, as minhas expectativas foram superadas, ao mesmo tempo, o interesse e o entusiasmo sobre esses temas amadureceram.

No final desta jornada, lembra-se do apoio financeiro do CNPq, assim como do importante papel dos professores da comissão examinadora no julgamento deste trabalho.

Além de tudo isso, o suporte e compreensão das pessoas a quem dediquei este trabalho e dos meus amigos foram essenciais.

E assim, deixo meus sinceros agradecimentos a todos esses que me ajudaram chegar até aqui. 


\section{Resumo}

Fonseca, Filipe Meirelles; Gonçalves, Paulo Batista. Comportamento não linear, bifurcações e instabilidade de uma treliça hiperelástica. Rio de Janeiro, 2018. 151p. Dissertação de Mestrado - Departamento de Engenharia Civil e Ambiental, Pontifícia Universidade Católica do Rio de Janeiro.

Em décadas recentes, renovou-se o interesse no campo da estabilidade estrutural em função das novas aplicações envolvendo estruturas inteligentes e ajustáveis, micro e nano componentes e a mecânica dos metamateriais. Em muito destas estruturas deseja-se um comportamento multiestável, que pode ser obtido por materiais tradicionais ou novos materiais capazes de sofrer grandes deformações elásticas. Neste trabalho o comportamento não linear, estabilidade e vibrações de uma treliça neo-Hookeana que exibe comportamento multiestável é investigada. Neste caso, a teoria de grandes deformações é essencial para modelar as barras da treliça. Muitos trabalhos na literatura investigam a estabilidade de treliças, porém são restritos ao comportamento linear dos materiais. No presente trabalho uma análise paramétrica detalhada de treliças abatidas e não abatidas submetidas à carga estática vertical ou horizontal é realizada, considerando a elasticidade em seu domínio não linear completo para derivar as equações não lineares de equilíbrio e movimento. Imperfeições de carga e geométricas são consideradas. Assim, os caminhos de equilíbrio são obtidos, sua estabilidade é investigada utilizando o princípio da energia potencial mínima, frequências naturais e conceito de bacias de atração. Os resultados demonstram que a presença simultânea da não linearidade do material e geométrica dá origem a novos caminhos de equilíbrio que não são esperados para os materiais elásticos lineares, resultando em várias soluções estáveis e instáveis coexistentes e em uma complexa superfície de energia potencial, esclarecendo a influência do modelo neo-Hookeano nos resultados. Os presentes resultados poderão ajudar no desenvolvimento de novas aplicações na engenharia onde a multiestabilidade é desejada.

\section{Palavras-chave}

Treliça; material neo-Hookeano; bifurcações; instabilidade estrutural. 


\section{Abstract}

Fonseca, Filipe Meirelles; Gonçalves, Paulo Batista (Advisor). Nonlinear behaviour, bifurcations and instability of a hyperelastic truss. Rio de Janeiro, 2018. 151p. Dissertação de Mestrado - Departamento de Engenharia Civil e Ambiental, Pontifícia Universidade Católica do Rio de Janeiro.

Recent decades have seen a renewed interest in the field of structural stability due to new applications involving smart and deployable structures, micro- and nanocomponents and mechanical metamaterials, among others. In many of these structures multistable behaviour is desirable, which can be accomplished by traditional and new materials capable of undergoing large elastic deformations. In this paper the nonlinear behaviour, stability and vibrations of a hyperelastic neo-Hookean truss exhibiting multistable behaviour is investigated. In such case, the large deformation theory is essential to model the truss members. Most papers in the literature dealing with this problem is however restricted to linear material behaviour. In the present work a detailed parametric analysis of shallow and steep trusses under horizontal or vertical loads, considering elasticity in the fully non-linear range is employed to derive the nonlinear equilibrium and motion equations. Then, all equilibrium paths are obtained and their stability is investigated using the minimum energy principle, natural frequencies and the basins of attraction concept. Load and geometric imperfections are considered. The results show that the simultaneous presence of geometric and materials nonlinearities lead to new equilibrium paths which are not expected for linear elastic materials, resulting in several coexisting stable and unstable solutions and a complex potential energy landscape, clarifying the influence of the constitutive hyperelastic model on the results. The present results may help the development of new engineering applications where multistability is wanted.

\section{Keywords}

Truss; neo-Hookean material; bifurcations; strucutral instability. 


\section{Sumário}

1 Introdução 22

1.1. Revisão bibliográfica 23

1.2. Objetivo 31

1.3. Apresentação 31

2 Modelo unidimensional 33

2.1. Modelo neo-Hookeano 33

2.2. Elemento de barra 35

3 Formulação $\quad 39$

3.1. Energia potencial total 41

3.2. Energia cinética 43

3.3. Amortecimento $\quad 45$

4 Análise estática $\quad 46$

4.1. Configurações de equilíbrio da estrutura descarregada 46

4.2. Carga vertical 48

4.2.1. Caminhos de equilíbrio 49

4.2.2. Ângulo limite $\quad 58$

4.2.3. Influência das imperfeições $\quad 61$

4.3. Carga horizontal 69

4.3.1. Caminhos de equilíbrio 70

4.3.2. Influência das imperfeições $\quad 74$

4.4. Análise dimensional 82

5 Frequências naturais de vibração 85

5.1. Equações de movimento

5.2. Frequências naturais $\quad 87$

5.2.1. Modelo perfeito 88

5.2.2. Influência da imperfeição geométrica 90

5.3. Frequências naturais da estrutura carregada estaticamente 93 
5.3.1. Carga vertical 93

5.3.2. Carga horizontal 100

6 Vibrações não lineares 109

6.1. Princípio da conservação da energia 109

6.2. Respostas no tempo 124

6.2.1. Equações de movimento 124

6.2.2. Análise da vibração livre amortecida 126

7 Conclusões e Sugestões 143

8 Referências bibliográficas 147 


\section{Lista de Figuras}

Figura 1.1: Sistemas estruturais analisados. 22

Figura 1.2: Aplicações de metamateriais com ressonadores internos. 27

Figura 1.3: Aplicações de metamateriais. 28

Figura 1.4: Aplicações de elementos multiestáveis. 30

Figura 2.1: Modelo da barra. $\quad 35$

Figura 2.2: Variação de $F / C_{1} A_{0} \operatorname{com} \lambda$. 36

Figura 2.3: Variação de $C_{\lambda} / C_{1} \operatorname{com} \lambda$. 37

Figura 2.4: Curva tensão-deformação de modelos hiperelásticos (Wikipedia, 27/06/2018). 38

Figura 3.1: Modelo da treliça perfeita. 39

Figura 3.2: Carregamento estático. 39

Figura 3.3: Imperfeição de carga. $\quad 40$

Figura 3.4: Modelo genérico. $\quad 40$

Figura 3.5: Imperfeição geométrica. $\quad 41$

Figura 3.6: Modelo para energia cinética da barra $l_{1}$. 43

Figura 4.1: Curvas de nível da energia interna de deformação para treliça com $\theta=15^{\circ}$.

Figura 4.2: Curvas de nível da energia interna de deformação para treliça com $\theta=75^{\circ}$. 47

Figura 4.3: Superfície da energia interna de deformação da treliça. $\quad 47$

Figura 4.4: Configurações de equilíbrio para estrutura descarregada. 48

Figura 4.5: Caminhos de equilíbrio da treliça com carga vertical

e $\theta=0^{\circ}$. 
Figura 4.6: Caminhos de equilíbrio da treliça com carga vertical para $\theta=5^{\circ}, 15^{\circ}$ e $25^{\circ}$.

Figura 4.7: Caminhos de equilíbrio da treliça com carga vertical para $\theta=35^{\circ}, 45^{\circ}$ e $55^{\circ}$.

Figura 4.8: Caminhos de equilíbrio da treliça com carga vertical para $\theta=69^{\circ}, 71^{\circ}$ e $74^{\circ}$.

Figura 4.9: Caminhos de equilíbrio da treliça com carga vertical e $\theta=85^{\circ}$.

Figura 4.10: Caminhos de equilíbrio da treliça com carga vertical e $\theta=15^{\circ}$.

Figura 4.11: Posições críticas para a treliça com carga vertical e $\theta=15^{\circ}$.

Figura 4.12: Caminhos de equilíbrio da treliça com carga vertical e $\theta=75^{\circ}$.

Figura 4.13: Posições críticas para a treliça com carga vertical e $\theta=75^{\circ}$.

Figura 4.14: Caminhos de equilíbrio da treliça com carga vertical e $\theta_{\lim }=70,76^{\circ}$.

Figura 4.15: Variação da carga crítica com o ângulo de abatimento. 59

Figura 4.16: Treliça elástica de von Mises vs. treliça neo-Hookeana. 60

Figura 4.17: Caminhos de equilíbrio da treliça com carga vertical e $\theta=89,9^{\circ}$.

Figura 4.18: Caminhos de equilíbrio da treliça com carga vertical, imperfeição geométrica e $\theta=15^{\circ}$.

Figura 4.19: Sensibilidade à imperfeição geométrica para a treliça com carga vertical e $\theta=15^{\circ}$.

Figura 4.20: Variação da carga limite com o deslocamento em função da imperfeição aplicada (0 a 50\%) para a treliça imperfeita com carga vertical e $\theta=15^{\circ}$. 
Figura 4.21: Caminhos de equilíbrio da treliça com carga vertical, imperfeição de carga e $\theta=75^{\circ}$. 66

Figura 4.22: Bifurcação simétrica instável para a treliça com $\theta=75^{\circ} . \quad 67$

Figura 4.23: Caminhos de equilíbrio da treliça com carga vertical, imperfeição geométrica e $\theta=75^{\circ}$.

68

Figura 4.24: Sensibilidade às imperfeições de carga e geométrica para a treliça com carga vertical e $\theta=75^{\circ}$.

Figura 4.25: Variação da carga limite com o deslocamento em função das imperfeições de carga e geométrica aplicada (0 a 50\%) para treliça imperfeita com carga vertical e $\theta=75^{\circ}$.

Figura 4.26: Caminhos de equilíbrio da treliça com carga horizontal e $\theta=15^{\circ}$.

Figura 4.27: Algumas posições estáticas para a treliça com carga horizontal e $\theta=15^{\circ}$.

Figura 4.28: Caminhos de equilíbrio da treliça com carga horizontal e $\theta=75^{\circ}$.

Figura 4.29: Algumas posições estáticas para a treliça com carga horizontal e $\theta=75^{\circ}$.

Figura 4.30: Projeção $\alpha_{x} \times \alpha_{y}$ dos caminhos de equilíbrio da treliça com carga horizontal para $\theta=15^{\circ}$ e $\theta=75^{\circ}$.

Figura 4.31: Caminhos de equilíbrio da treliça com carga horizontal, imperfeição de carga e $\theta=15^{\circ}$.

Figura 4.32: Posições crítica e pós-critica para a treliça com carga horizontal, imperfeição de carga e $\theta=15^{\circ}$.

Figura 4.33: Caminhos de equilíbrio da treliça com carga horizontal, imperfeição de carga $0,071 Q_{x}$ e $\theta=15^{\circ}$.

Figura 4.34: Caminhos de equilíbrio da treliça com carga horizontal, imperfeição geométrica e $\theta=15^{\circ}$. 
Figura 4.35: Caminhos de equilíbrio da treliça com carga horizontal, imperfeição de carga e $\theta=75^{\circ}$.

Figura 4.36: Caminhos de equilíbrio da treliça com carga horizontal, imperfeição geométrica e $\theta=75^{\circ}$.

Figura 4.37: Treliça com carga vertical e $\theta=15^{\circ}$.

Figura 4.38: Tensões axiais ao longo do caminho de equilíbrio.

Figura 5.1: Frequências naturais para a treliça perfeita em função de $\theta$.

Figura 5.2: Frequências naturais em função de $\theta$ para a treliça descarregada com e sem imperfeição.

Figura 5.3: Caminho das frequências naturais ao quadrado para reliça com carga vertical e $\theta=15^{\circ}$ ao longo das posições de equilíbrio estático.

Figura 5.4: Caminho das frequências naturais ao quadrado para a treliça com carga vertical e $\theta=75^{\circ}$ ao longo das posições de equilíbrio estático.

Figura 5.5: Caminho das frequências naturais ao quadrado da treliça com carga vertical, imperfeição geométrica e $\theta=15^{\circ}$ ao longo das posições de equilíbrio estático.

Figura 5.6: Caminho das frequências naturais ao quadrado da treliça com carga vertical, imperfeição de carga e $\theta=75^{\circ}$ ao longo das posições de equilíbrio estático.

Figura 5.7: Caminho das frequências naturais ao quadrado da treliça com carga vertical, imperfeição geométrica e $\theta=75^{\circ}$ ao longo das posições de equilíbrio estático.

Figura 5.8: Caminho das frequências naturais ao quadrado da treliça com carga horizontal e $\theta=15^{\circ}$ ao longo das posições de equilíbrio estático. 
Figura 5.9: Caminho das frequências naturais ao quadrado da treliça com carga horizontal e $\theta=75^{\circ}$ ao longo das posições de equilíbrio estático.

Figura 5.10: Caminho das frequências naturais ao quadrado da treliça com carga horizontal, imperfeição de carga e $\theta=15^{\circ}$ ao longo das posições de equilíbrio estático.

Figura 5.11: Caminho das frequências naturais ao quadrado da treliça com carga horizontal, imperfeição geométrica e $\theta=15^{\circ}$ ao longo das posições de equilíbrio estático.

Figura 5.12: Caminho das frequências naturais ao quadrado da treliça com carga horizontal, imperfeição de carga e $\theta=75^{\circ}$ ao longo das posições de equilíbrio estático.

Figura 5.13: Caminho das frequências naturais ao quadrado da treliça com carga horizontal, imperfeição geométrica e $\theta=75^{\circ}$ ao longo das posições de equilíbrio estático.

Figura 6.1: Retratos de fase para treliça descarregada, $\theta=15^{\circ}$, posição estática $(0,0,0)$ e dinâmica $(0,0,0,0)$.

Figura 6.2: Retratos de fase para treliça descarregada com imperfeição geométrica, $\theta=15^{\circ}$, posição estática $(0,05,-0,05,0)$ e dinâmica $(0,0,0,0)$.

Figura 6.3: Órbitas dos pontos de sela das treliças descarregada, sem e com imperfeição geométrica e $\theta=15^{\circ}$, para as posições estáticas descarregadas e dinâmicas referentes a cada ponto de sela.

Figura 6.4: Retratos de fase para treliça com carga vertical, $\theta=15^{\circ}$ e posição de equilíbrio estático $(0,0,433,0,042)$ referente à carga limite $\left(P_{L}\right)$.

Figura 6.5: Retratos de fase dos deslocamentos para valores crescentes de carga estática da treliça com carga vertical, $\theta=15^{\circ}$ e posição de acordo com a Tabela 6.2. 
Figura 6.6: Retratos de fase dos deslocamentos para treliça com carga horizontal, $\theta=15^{\circ}$, posição estática do ponto de bifurcação $(1,829,1,3,674)$ e dinâmica $(0,0,0,0)$.

Figura 6.7: Retratos de fase para treliça descarregada, $\theta=75^{\circ}$, posição estática $(0,0,0)$ e dinâmica $(0,0,0,0)$.

Figura 6.8: Retratos de fase para treliça com imperfeição geométrica, $\theta=75^{\circ}$, posição estática $(0,05,-0,05,0)$ e dinâmica $(0,0,0,0)$.

Figura 6.9: Órbitas dos pontos de sela das treliças sem e com imperfeição geométrica e $\theta=75^{\circ}$ para as posições estáticas descarregadas e dinâmicas referentes a cada ponto de sela.

Figura 6.10: Retratos de fase dos deslocamentos para treliça com carga horizontal, $\theta=75^{\circ}$, posição estática do ponto de bifurcação $(4,295,1,0,633)$ e dinâmica $(0,0,0,0)$.

Figura 6.11: Retratos de fase dos deslocamentos para valores crescentes de carga estática da treliça com carga vertical, $\theta=75^{\circ}$ e posições de acordo com a Tabela 6.4.

Figura 6.12: Pontos de atração para a treliça com carga estática vertical.

Figura 6.13: Resposta no tempo da treliça com e sem imperfeição, $\theta=15^{\circ}$, descarregada e $\Delta_{y}=0,5 h_{0}$.

Figura 6.14: Resposta no tempo da treliça com carga vertical, $\theta=15^{\circ}$, posição de equilíbrio estático $(0,0,2,0,031)$ e $\Delta_{y}= \pm 0,05 h_{0}$ e $\Delta_{y}= \pm 0,2 h_{0}$. 128

Figura 6.15: Respostas no tempo da treliça com carga vertical, $\theta=15^{\circ}$, posição de equilíbrio estático $(0,0,25,0,035)$ e $\Delta_{y}=0,1 h_{0}$, $0,3 h_{0}$ e $0,39 h_{0}$.

Figura 6.16: Respostas no tempo da treliça com carga vertical, $\theta=15^{\circ}$, posição de equilíbrio estático $(0,0,2,0,035)$ e $\left(\Delta_{x}, \Delta_{y}\right)=\left(0,06 b_{0}, 0,2 h_{0}\right)$. 
Figura 6.17: Resposta no tempo da treliça com e sem imperfeição, $\theta=75^{\circ}$, descarregada e $\Delta_{x}=1 b_{0}$.

Figura 6.18: Localização da treliça com $\theta=75^{\circ}$ carregada em seu caminho de equilíbrio: posição inicial $(0,0,09,1,054)$.

Figura 6.19: Respostas no tempo da treliça com carga vertical, $\theta=75^{\circ}$, posição de equilíbrio estático $(0,0,09,1,054)$ e $\Delta_{x}=0,5 b_{0}$ e $0,8 b_{0}$.

Figura 6.20: Respostas no tempo da treliça com carga vertical, $\theta=75^{\circ}$, posição de equilíbrio estático $(0,0,09,1,054)$ e $\Delta_{x}=0,82 b_{0}$.

Figura 6.21: Respostas no tempo das treliças sem e com imperfeições (carga e geométrica) para carga vertical $Q_{y}=0,799$, $\theta=75^{\circ}$ e $\Delta_{x}=0,5 b_{0}$.

Figura 6.22: Pontos de atração para a treliça com carga estática horizontal.

Figura 6.23: Respostas no tempo da treliça perfeita, carga horizontal, $\theta=15^{\circ}$ e $\Delta_{y}=0,5 h_{0}$ para diferentes posições de equilíbrio estático.

Figura 6.24: Resposta no tempo da treliça com imperfeição de carga de $0,071 Q_{x}, \theta=15^{\circ}$ e posição de equilíbrio estático $(0,08,0,3,0,933)$.

Figura 6.25: Resposta no tempo da treliça perfeita, $\theta=75^{\circ}$ para as posições de equilíbrio estático $(0,55,0,007,0,113)$ e $(1,55,0,061,0,302)$ diante de uma perturbação $\left(\Delta_{x}, \Delta_{y}\right)=\left(0,5 b_{0}, 0,15 h_{0}\right)$. 


\section{Lista de Tabelas}

Tabela 5.1: Modos de vibração para a treliça perfeita. 89

Tabela 5.2: Frequências naturais da treliça para $\theta=15^{\circ}, 45^{\circ} \mathrm{e} 75^{\circ} . \quad 90$

Tabela 5.3: Modos de vibração para o modelo imperfeito com $\theta=15^{\circ}$.

Tabela 5.4: Modos de vibração para o modelo imperfeito com $\theta=45^{\circ} \mathrm{e} 75^{\circ}$.

Tabela 5.5: Frequências naturais ao quadrado das treliças com carga vertical, $\theta=15^{\circ}$ e $\theta=75^{\circ}$, nas posições descarregadas e críticas.

Tabela 5.6: Frequências naturais ao quadrado e modos de vibração da treliça com carga vertical, sem e com imperfeição, e $\theta=15^{\circ}$ na posição do ponto limite.

Tabela 5.7: Frequências naturais ao quadrado e modos de vibração para a treliça com carga vertical, sem e com imperfeição, e $\theta=75^{\circ}$ na posição da primeira carga crítica.

Tabela 5.8: Frequências naturais ao quadrado e modos de vibração da treliça com carga horizontal, $\theta=15^{\circ}$ e na posição $(1,-2,125,3,438)$.

Tabela 5.9: Frequências naturais ao quadrado e modos de vibração para a treliça com carga horizontal e $\theta=75^{\circ}$ na posição $(1,0,024,0,202)$.

Tabela 5.10: Frequências naturais ao quadrado e modos de vibração da treliça com carga vertical, sem e com imperfeição, e $\theta=15^{\circ}$ na posição estática $\alpha_{x, e}=1$.

Tabela 5.11: Frequências naturais ao quadrado e modos de vibração da treliça com carga vertical, sem e com imperfeição, e $\theta=75^{\circ}$ na posição estática $\alpha_{x, e}=1$. 
Tabela 6.1: Energia dos pontos de sela para treliça com e sem imperfeição geométrica e $\theta=15^{\circ}$.

Tabela 6.2: Posição de equilíbrio estático e energia associada aos pontos de sela para níveis crescentes de carga estática da treliça com $\theta=15^{\circ}$.

Tabela 6.3: Energia dos pontos de sela para treliça com e sem imperfeição geométrica e $\theta=75^{\circ}$.

Tabela 6.4: Posição de equilíbrio estático e energia associada aos pontos de sela para níveis crescentes de carga estática da treliça com $\theta=75^{\circ}$.

Tabela 6.5: Casos de carga estática para as equações de movimento.

Tabela 6.6: Modos de vibração e frequências naturais para a treliça com $\theta=15^{\circ}$. 


\section{Lista de Símbolos}

$a_{i}$, coeficiente proporcionalidade do amortecimento;

A, área transversal indeformada da barra;

$A_{0}$, área transversal deformada da barra;

$b_{0}$, metade do comprimento da base da treliça;

$b_{i}$, comprimento da projeção horizontal da barra da treliça com imperfeição geométrica;

C, energia conservada do sistema;

$C_{i}$, parâmetro experimental de caracterização do modelo hiperelástico;

$C_{\lambda}$, rigidez axial da barra;

c, amortecimento;

E, módulo de elasticidade;

$F$, força axial na barra;

$I_{i}, \quad$ invariante das deformações;

$h_{0}$, altura da treliça perfeita;

K , matriz de rigidez do sistema estrutural;

$L$, função de Lagrange;

$l_{0}$, comprimento indeformado da barra;

$l_{i}$, comprimento indeformado da barra da treliça com imperfeição geométrica;

M, matriz de massa do sistema estrutural;

$N, \quad$ esforço axial na barra;

$n$, modo de flambagem da barra; 
$P_{B i}, \quad$ carga no ponto de bifurcação;

$P_{c r}, \quad$ carga crítica de uma barra neo-Hookeana;

$P_{\text {euler }}$, carga crítica de Euler;

$P_{L}, \quad$ carga no ponto limite;

$p_{i}$, carga estática;

$Q_{i}, \quad$ parâmetro adimensional de carga;

$r_{i}, \quad$ raio de giração da seção transversal da barra;

$r$ razão entre as barras indeformadas da treliça com imperfeição geométrica;

$T$, energia cinética da treliça;

$U_{i}$, energia interna de deformação da treliça;

$V_{i}$, energia potencial das carga externas;

$x$ deslocamento na direção $x$;

$W$, função da energia específica do modelo neo-Hookeano;

w, parâmetro adimensional relativo a frequência natural;

$y, \quad$ deslocamento na direção $y$;

$t$ tempo;

$\alpha$, ângulo de abatimento da treliça na posição deformada;

$\alpha_{i}, \quad$ coordenada adimensional ;

$\varepsilon_{l n}, \quad$ deformação axial logarítmica;

$\mathcal{E}_{d}, \quad$ contração da seção transversal;

$\lambda_{i}$, fator de deformação;

$\mu$, raiz quadrada da razão entre a área deformada e a área indeformada;

$v$, coeficiente de Poisson; 
$\Pi$, energia potencial total do sistema estrutural;

$\theta$, ângulo de abatimento da treliça na posição indeformada;

$\rho$, massa específica do material neo-Hookeano;

$\sigma_{e}$, tensão de engenharia;

$\sigma_{l n}, \quad$ tensão de Cauchy;

$\omega_{i}$, frequência natural;

$\zeta$, coeficiente de amortecimento. 


\section{1}

\section{Introdução}

A instabilidade de treliças planas constituídas por materiais hiperelásticos insere-se em uma nova linha de pesquisa na área de Instabilidade e Dinâmica de Estruturas que envolvem estruturas inteligentes e ajustáveis, micro e nano componentes, sistemas multiestáveis e metamateriais (materiais metaestáveis), entre outras.

As treliças planas, cujo exemplo clássico é a treliça de von Mises, são sistemas estruturais essencialmente biestáveis. A hiperelasticidade aumenta a capacidade da estrutura de deformar-se, permitindo o aparecimento de novas configurações de equilíbrio e, consequentemente, novas trajetórias de equilíbrio.

Neste trabalho, analisa-se a instabilidade estática e as vibrações não lineares de treliças planas constituídas por material hiperelástico descrito pelo modelo neoHookeano. Para tanto, realiza-se uma análise paramétrica para estudar o efeito do ângulo de abatimento no comportamento não linear da estrutura e nas bifurcações, instabilidades e frequências naturais ao longo das distintas trajetórias de equilíbrio. Imperfeições de carga e na geometria da estrutura são consideradas, a fim de esclarecer o comportamento pós-crítico de sistemas estruturais reais, naturalmente imperfeitos.

A Figura 1.1 apresenta um diagrama dos sistemas estruturais analisados para cada ângulo de abatimento.

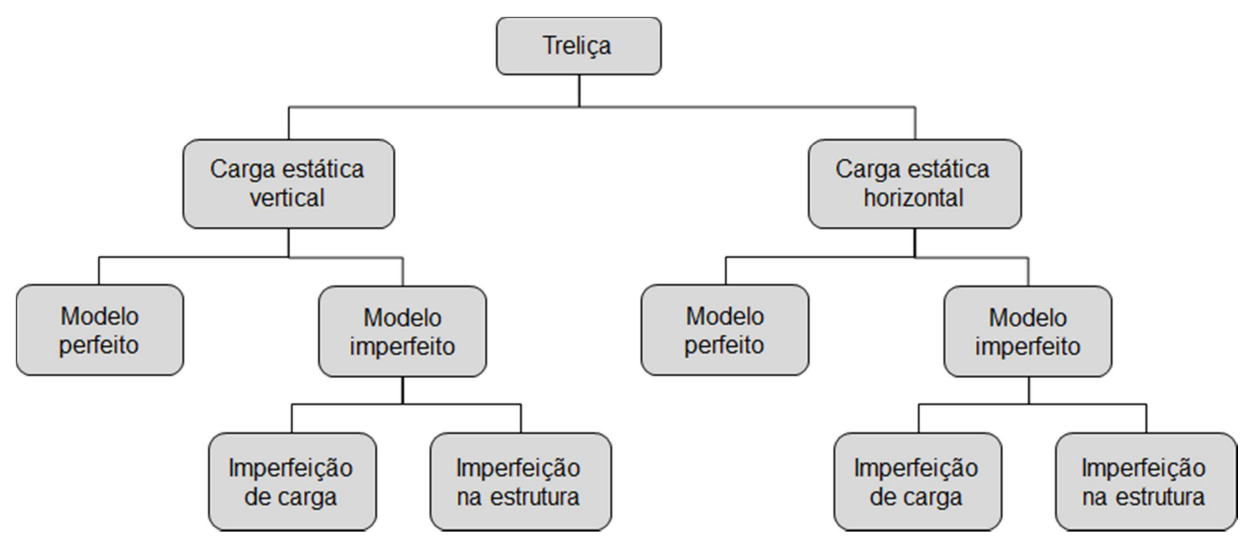

Figura 1.1: Sistemas estruturais analisados. 


\section{1. Revisão bibliográfica}

Von Mises (1923 e 1925) investiga a estabilidade de estruturas constituídas por hastes finas, cujo exemplo mais simples apresentado foi de uma treliça plana. Em seu trabalho, von Mises descreve o caminho fundamental de equilíbrio de uma treliça para diferentes ângulos de inclinação.

Pecknold (1985) analisa uma treliça plana submetida a três condições de carga estática: vertical, horizontal e oblíqua. Utilizando a formulação Lagrangiana, apresenta os comportamentos pré- e pós-crítico presentes no comportamento da treliça e os diferentes tipos de bifurcação. Segundo o autor, apesar destes fenômenos estarem associado às grandes deformações do modelo da estrutura, ele acredita que este simples modelo pode traduzir o comportamento de estruturas mais complexas cujos fenômenos podem acontecer sem a necessidade de grandes deformações.

Kassimali \& Bidhendi (1987) estudaram a resposta dinâmica da treliça de von Mises e de um domo geodésico submetido a três tipos de forças dinâmicas: força constante, impulso triangular e força harmônica, adotando a formulação Euleriana. Por meio das equações de von Mises (1925), classifica as treliças em abatidas e não abatidas, em função da forma que a estrutura perde a estabilidade.

Ario (2004) adotou a equação de Duffing para analisar o comportamento dinâmico não linear da treliça de von Mises, com a massa concentrada em seu nó superior, com foco na estabilidade dinâmica, bifurcações e oscilações não lineares periódicas e não periódicas, incluindo fenômenos caóticos.

Ligarò \& Valvo (2006) generalizaram a análise da treliça de von Mises para 3 dimensões por meio de uma treliça piramidal formada por $n$ barras, analisando a sua estabilidade para condições de carga similares às de Pecknold (1985).

Kwasniewski (2008) estudou os caminhos de equilíbrio de treliças com diferentes ângulos de abatimento e submetidas a uma carga estática vertical. Traçou-se as trajetórias de equilíbrio da treliça com um determinado ângulo de abatimento que possui dois trechos estáveis separados por um trecho instável, esclarecendo o que von Mises (1925) já havia mencionado.

Castro (2014) investigou a instabilidade estática e dinâmica de uma treliça piramidal similar à estudada por Ligarò \& Valvo (2006). Usando ferramentas da 
dinâmica não linear como diagramas de bifurcações e bacias de atração, estudou as vibrações não lineares da pirâmide submetida a cargas estáticas e dinâmicas na direção vertical.

Pascon (2015) implementa em elementos finitos um modelo uniaxial para materiais hiperelastoplásticos considerando grandes deformações com objetivo de analisar estruturas treliçadas. Cinco estruturas são analisadas a fim de validar a formulação proposta.

Apesar dos grandes deslocamentos sempre presentes, apenas o trabalho de Pascon (2015) utilizou uma formulação adequada para grandes deformações. Aliado a isso, von Mises (1925) ressalta que os valores numéricos obtidos na análise de sua treliça para valores relativamente pequenos de abatimento mostram que, no caso de barras feitas de materiais de construção usuais: aço, madeira ou similares, as cargas críticas são muito maiores do que aquelas que o material tolera devido à sua resistência limitada e do que a carga crítica de Euler para um membro individual.

Quanto aos materiais hiperelásticos, Mooney (1940) observou que, baseado em dois resultados experimentais, o corpo de prova de borracha obedece até grandes deformações à lei de Hooke quando cisalhado e que as deformações nestes materiais são produzidas sem consideráveis mudanças de volume. E assim deduziu a função da energia de deformação compostas por duas parcelas, cada uma proporcional a um parâmetro. A fórmula, escrita na forma dos invariantes de Rivlin (Treolar, 1948), é:

$$
W=C_{1}\left(I_{1}-3\right)+C_{2}\left(I_{2}-3\right),
$$

onde $I_{1}$ e $I_{2}$ são os invariantes de deformações e $C_{1}$ e $C_{2}$ são as constantes físicas do material. Em seu trabalho, Mooney (1940) demostrou que os resultados teóricos concordam com o resultado experimental para a borracha analisada num domínio de $400 \%$ de alongamento a 50\% de encurtamento.

Treloar (1947 e 1948) obteve a função de energia a partir da teoria molecular apresentando uma função igual à de Mooney (1940), com o parâmetro $C_{2}$ igual à zero. Esta função ficou conhecida como modelo neo-Hookeano. 
Utilizando a abordagem de invariantes de Rivlin, apresentou uma formulação geral para uma relação não linear entre tensão-deformação em cisalhamento.

Ogden (1972) apresenta uma função cuja compressibilidade da borracha é considerada e com isto distinguem-se dois grupos de modelos hiperelásticos (Schreurs, 2012): os modelos do tipo Mooney-Rivlin para materiais incompressíveis e os modelos de Ogden para materiais compressíveis.

As constantes físicas do material das funções de energia são obtidas experimentalmente. Alguns trabalhos na literatura apresentam ensaios e metodologias utilizadas para a determinação destas constantes.

Selvadurai (2006) analisa as deflexões em uma membrana circular de borracha fixa em seu contorno. Em uma primeira fase realizam-se testes uniaxiais para caracterização do material, utilizando diferentes modelos constitutivos. Em seguida ensaia-se a membrana, registrando-se sua deflexão quando submetida a uma força incremental aplicada por meio de uma esfera. Na etapa final, modela-se a membrana utilizando os diferentes modelos caracterizados. Mesmo com grandes deflexões impostas na membrana, os resultados demonstraram que as deformações ainda estavam em nível moderado $\left(\varepsilon_{0}=70 \%\right)$.

Sasso et al. (2008) realizam três ensaios diferentes para obter as constantes físicas do material hiperelástico. Inicialmente, para determinar os parâmetros do material, realizaram-se ensaios uniaxial e equi-biaxial. Os resultados obtidos são utilizados na caracterização do material por meio da análise por elementos finitos. A fim de verificar os resultados da análise por elemento finitos é realizado um último ensaio de tração axial em um corpo de prova com largura muito maior que sua altura. Os resultados da análise por elementos finitos apresentaram uma boa precisão, até mesmo quando comparado ao último ensaio, no qual o estado de tensões é diferente.

Além de trabalhos dedicados exclusivamente à caracterização destes materiais, há trabalhos que calibram as funções de energia para prosseguir com a análise numérica de certas estruturas.

Lopes (2003) analisa numericamente e experimentalmente o comportamento não linear e possíveis instabilidades de membranas e cascas hiperelásticas submetidas à tração e pressão interna uniforme. As constantes elásticas dos diferentes modelos utilizados são obtidas por meio da comparação entre os 
resultados experimentais e numéricos para o ensaio de tração axial uniforme. Gonçalves et al. (2007) aprofundam a análise destas estruturas, concentrando-se na análise do seu comportamento não linear e de suas instabilidades. Dentro desta linha de pesquisa, destacam-se recentemente os trabalhos de Soares (2009) e Gonçalves et al. (2009), que analisam as vibrações não lineares de membranas circulares hiperelásticas, inicialmente tracionadas, sujeitas à deformações finitas e pressão lateral variável ao longo do tempo.

A nova linha de pesquisa no qual se insere este trabalho investiga a multiestabilidade de estruturas formadas por materiais ou mecanismos com capacidade de sofrer grandes deformações, acompanhadas por diferentes fenômenos de instabilidade. Esta multiestabilidade é explorada com objetivo de criar novos materiais ou estruturas, muitas vezes formados por padrões estruturais, e analisar seu comportamento, explorando suas possíveis aplicações.

Wang et al. (2014) reportam uma nova classe de metamateriais que possui ressonadores acústicos em sua matriz capaz de sintonizar em uma ampla faixa de frequências. Adota-se o modelo neo-Hookeano para descrever o comportamento da matriz. Demonstra-se, numericamente e experimentalmente, que grandes deformações e instabilidades locais podem ser exploradas para efetivamente controlar a resposta destes metamateriais, e também, para ligar ou desligar o gap de energia, abrindo caminhos para o projeto de switches adaptativos.

Schmied et al. (2017) projetam um metamaterial com ressonadores internos para redução de vibração em suportes considerando um domínio com baixas frequências. Utilizam-se elementos finitos para projetar e analisar a resposta das frequências da estrutura e comparam com uma formulação analítica aproximada. Uma análise experimental em um protótipo da estrutura é realizada para validação dos resultados numéricos. Conclui-se que, integrando ressonadores internos na estrutura é possível adicionar graus de liberdade e moldar sua resposta dinâmica.

Nadkarni et al. (2014) investigam a reposta não linear de cadeias de elementos biestáveis, formados por massas conectadas à molas elásticas lineares, cujo arranjo permite grandes deformações e instabilidades por ponto limite. A rigidez negativa deste arranjo produz três diferentes regimes (lineares e não lineares) de propagação de onda no meio periódico que dependem da amplitude da onda. 


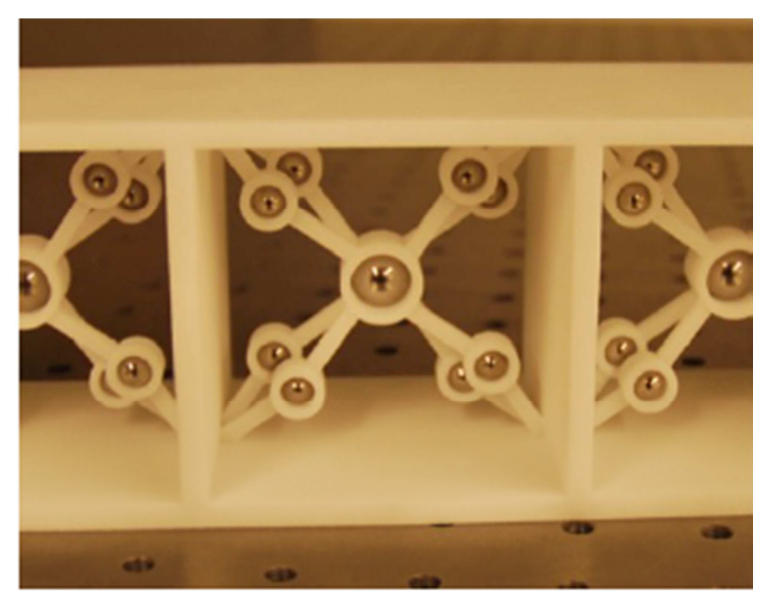

(a) Schmied et al. (2017).

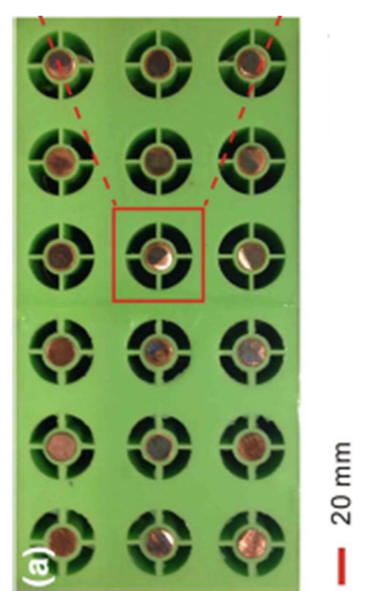

(b) Wang et al. (2014).

Figura 1.2: Aplicações de metamateriais com ressonadores internos.

Florijn et al. (2014) desenvolvem um metamaterial cuja resposta diante de uma compressão axial pode ser programada por um confinamento lateral, permitindo um comportamento monótono, não monótono e histerético. Analisase, experimentalmente e numericamente, utilizando o modelo neo-Hookeano, o metamaterial. Introduz-se um modelo simples que captura a mecânica programável do material, apresentando uma estratégia geral de projeto para estruturas formadas por este material. Finalmente, mostra-se como o confinamento não homogêneo pode ser explorado para criar multiestabilidade e uma grande histerese.

Shan et al. (2015) combinam impressão 3D e análise numérica para desenhar metamateriais capazes de armazenar uma capacidade significante de energia. Realiza-se um ensaio uniaxial de tração em uma única célula para caracterizar o material. Adota-se o modelo neo-Hookeano ligeiramente modificado para incluir a compressibilidade, com um alto módulo de elasticidade volumétrico e, assim sendo, quase incompressível. Resultados do ensaio realizado demonstraram que o modelo neo-Hookeano capturou muito bem o comportamento da célula até uma deformação de aproximadamente 1. Numa fase posterior estas células são arranjadas, formando um metamaterial, e ensaios de compressão com uma taxa quasi-estática de carregamento e via impacto são realizados. Destaca-se que estes materiais podem ser empregados para proteção pessoal, mitigação de impactos em automóveis e aeronaves e na proteção de delicados componentes, considerando estruturas com uma grande variedade de comprimento (micro a macro). 
Rafsanjani et al. (2015) apresentam metamateriais formado por arranjos periódicos de células com diferentes razão entre altura e largura. Analisam, numericamente (modelo neo-Hookeano) e experimentalmente, sua resposta quando submetida à tração. Dependendo da relação entre altura e largura, uma única célula pode apresentar quatro diferentes respostas: monótona, monótona com forma de $S$, com um patamar e snap-trough. Estes desempenhos tornam estes materiais potencialmente adequados para o projeto de estruturas com metamorfose, adaptáveis e implantáveis. A energia dissipada através do fenômeno de snap through pode ser usada para isolamento de vibrações e aplicações em amortecimento.

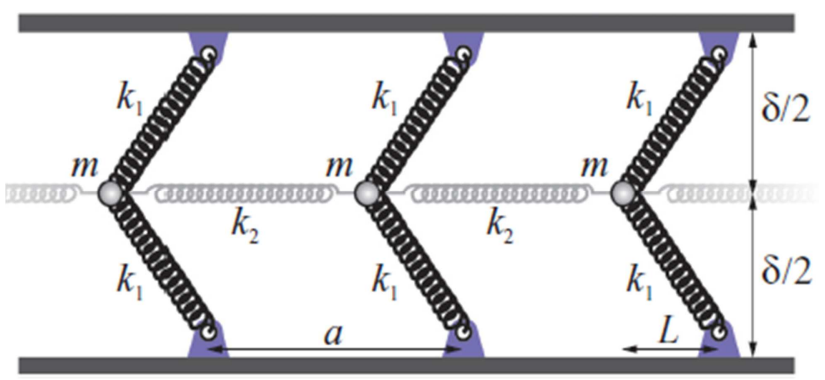

(a) Nadkarni et al. (2014).

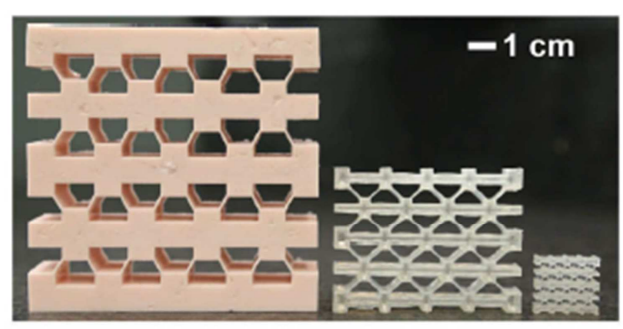

(c) Shan et al. (2015).

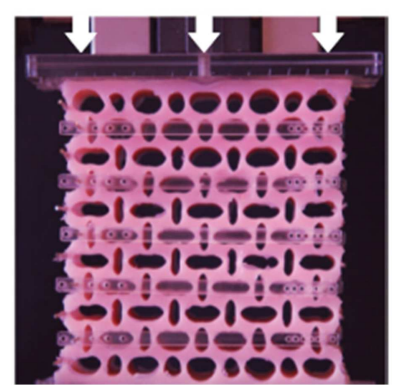

(b) Florijn et al. (2014).

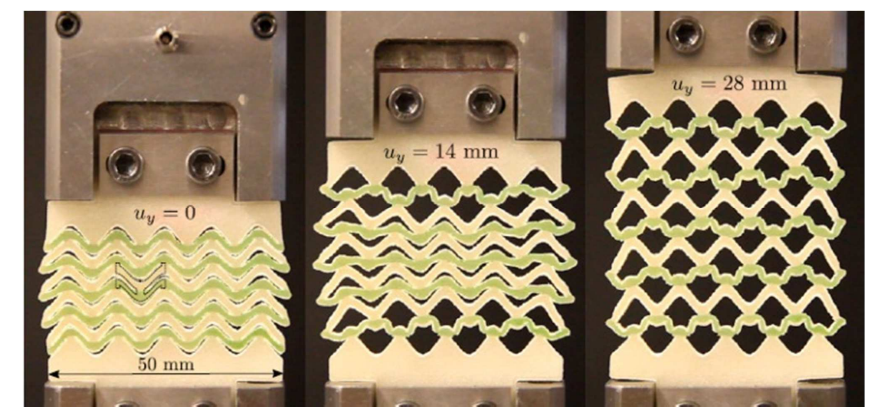

(d) Rafsanjani et al. (2015).

Figura 1.3: Aplicações de metamateriais. 
Coulais et al. (2015) demostram como as não linearidades afetam a flambagem de vigas, analisando uma viga constituídas por metamateriais.

Zirbel et al. (2016) apresentam modelos analíticos e numéricos que são aplicados para prever a biestabilidade e criar mecanismos biestáveis aplicados a materiais não viáveis anteriormente. Mecanismos de pin-puller e cutter release com aplicações espaciais são propostos. Fabricam-se protótipos metálicos, em 3 diferentes materiais, para que sejam compatíveis com projetos espaciais que exigem materiais mais resistentes e menos suscetíveis à fluência e relaxação do que os polímeros.

Schioler \& Pellegrino (2008) apresentam uma nova estrutura biestável, que é rígida em sua configuração estável e necessita apenas uma pequena quantidade de energia para mudar sua configuração. A estrutura é formada por quatro barras articuladas e contraventadas por fitas elásticas. Os autores desenvolveram uma formulação teórica para análise do seu comportamento mecânico e a utilizam como previsão no ensaio experimental, demonstrando-se que a formulação teórica desenvolvida para a estrutura foi capaz de representar o seu comportamento real.

Chen et al. (2017) projetam e verificam dois grupos de estruturas implantáveis. A ativação é realizada utilizando princípios de projeto hierárquico onde um atuador unitário baseado na treliça de von Mises biestável e monolítico atua como o bloco de construção básico. Cada estrutura tem um estado inicial plano e é impresso com uma impressora 3D multimaterial. As análises, numérica e experimental, demonstram que variando o material da junta e o comprimento do atuador, a força de ativação necessária pode ser ajustada. As estruturas analisadas apresentaram capacidade de carga e geometria ativada previsível e são reversíveis e reconfiguráveis.

Outra aplicação para as treliças hiperelásticas seria na construção de placas sanduíches, formando o núcleo. Alguns trabalhos que utilizam treliças com essa função são apresentados a seguir.

Lee et al. (2006) investigam, experimentalmente e numericamente, o comportamento quasi-estático e dinâmico de uma estrutura formada por placas e núcleo com treliças piramidais metálicas. $\mathrm{O}$ autor utiliza uma combinação de técnicas experimentais que permitem identificar e detalhar os diferentes modos de deformação observados no comportamento dessas estruturas. 
Wang et al. (2009) analisam uma placa sanduíche formada por treliças reforçadas de fibra de carbono. A flambagem e a ruína das barras do núcleo são observadas em testes de compressão e cisalhamento sem nenhuma falha nos nós, comum em estruturas sanduíche com núcleo em treliças metálicas. Os resultados previstos mostram que o comportamento mecânico dos painéis com núcleo formado por treliças depende da densidade relativa do núcleo e das propriedades do material das treliças.

A multiestabilidade pode ser explorada também em cascas e placas compósitas, como exemplo têm-se os trabalhos de Giomi \& Mahdevan (2011) e Cui (2015).

cable pass-through
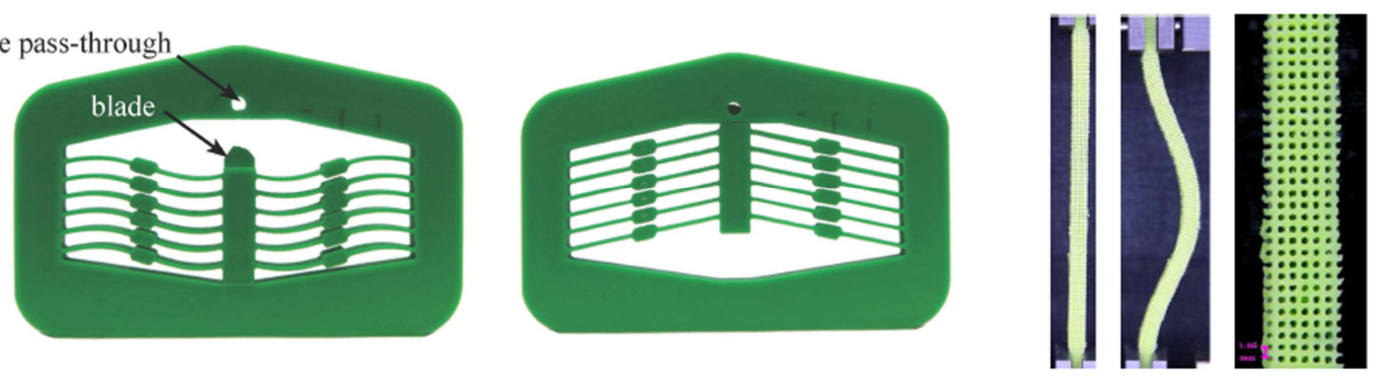

(a) Zirbel et al. (2016).

(b) Coulais et al. (2015).

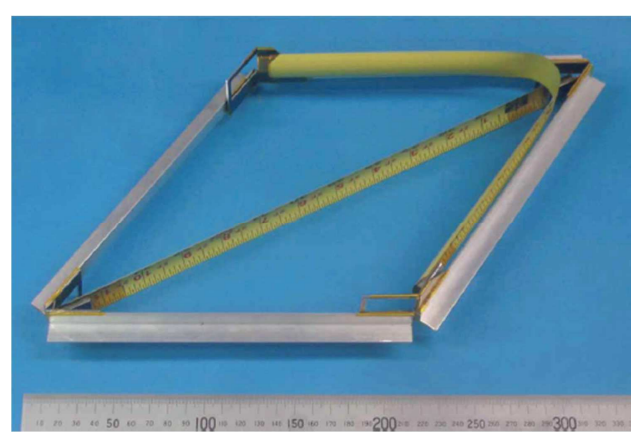

(c) Schioler \& Pellegrino (2008).

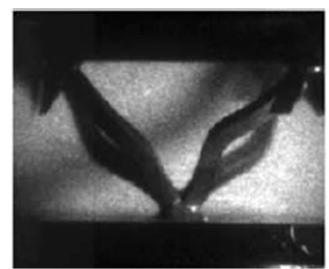

(e) Lee et al. (2006)

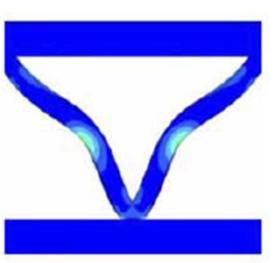

(f) Wang et al. (2009)

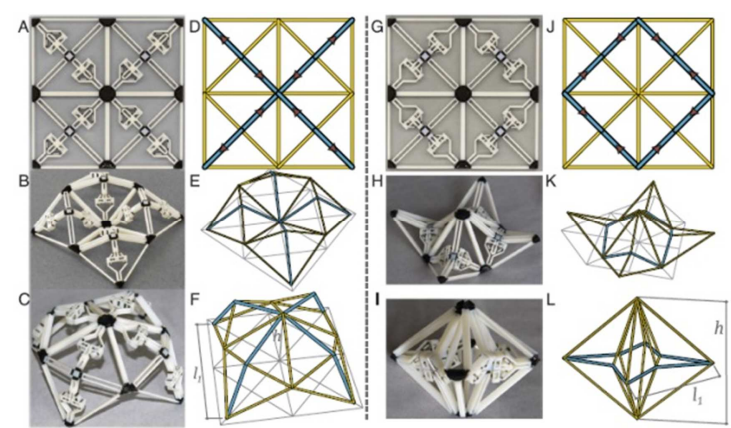

(d) Wang et al. (2014).

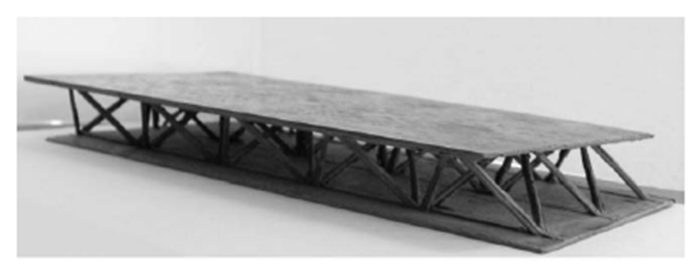

Figura 1.4: Aplicações de elementos multiestáveis. 


\section{2. \\ Objetivo}

Esta dissertação insere-se na linha de pesquisa em Instabilidade e Dinâmica das Estruturas do Departamento de Engenharia Civil e Ambiental da PUC-Rio.

Multiestabilidade em sistemas estruturais é uma nova área de pesquisa em engenharia, ainda restrita a poucos centros de pesquisa (Universidade de Harvard, Universidade de Cambridge e Imperial College London, por exemplo) com possibilidade de aplicações em engenharia civil, aeroespacial e mecânica, além da bioengenharia, envolvendo o desenvolvimento de novos materiais ou estruturas, como os metamateriais, sistemas de controle de vibrações, estruturas ajustáveis, sistemas estruturais com padrão repetitivo, etc.

Em muitas destas aplicações os elementos estruturais estão submetidos a grandes deslocamentos e deformações, sendo importante em sua formulação ou modelagem considerar a não linearidades física e geométrica. Neste contexto, o uso de materiais hiperelásticos encontra um importante campo de aplicação.

Neste trabalho analisa-se a instabilidade estática e as vibrações não lineares de treliças constituídas por barras hiperelásticas (modelo neo-Hookeano), estrutura com potencial para o projeto dessas novas estruturas e um assunto ainda pouco explorado na literatura. Com base neste estudo, deseja-se compreender o comportamento estático e dinâmico não linear dos diferentes sistemas estruturais analisados.

\section{3. Apresentação}

Esta dissertação divide-se em oito capítulos.

No segundo capítulo analisa-se uma barra hiperelástica neo-Hookeana submetida a uma força axial. Introduz-se a função de energia, a deformação adotada e por meio deles derivam-se as tensões e rigidez para o modelo unidimensional.

O Capítulo 3 apresentam os modelos das treliças estudados e deduz-se uma formulação geral baseada em energia. Além das parcelas de energia, apresenta-se o amortecimento adotado na modelagem do sistema. 
No capítulo seguinte, obtêm-se as equações dos caminhos de equilíbrio para os diferentes casos analisados, determina-se pelo princípio da energia potencial mínima sua estabilidade ao longo destas trajetórias, destacando-se os diferentes tipos de bifurcações e instabilidade presentes. Por meio dos modelos com imperfeições verifica-se a sensibilidade das treliças às imperfeições aplicadas. Uma breve análise dimensional encerra este capítulo.

No Capítulo 5 inicia-se a análise dinâmica da treliça. As equações do movimento são obtidas e linearizadas em torno da posição de equilíbrio estático e assim obtêm-se as frequências naturais e os modos de vibração da estrutura ao longo das trajetórias de equilíbrio estático.

Finalmente, no Capítulo 6, utiliza-se o princípio da conservação de energia para obter os retratos de fase para distintos níveis de energia a partir das posições de equilíbrio estático inicial da treliça descarregada e das posições dos pontos críticos. Em seguida adiciona-se o amortecimento nas equações do movimento para análise da vibração não linear livre amortecida da treliça hiperelástica.

As conclusões são apresentadas no Capítulo 7 junto com as sugestões para trabalhos futuros. As referências bibliográficas são exibidas no capítulo seguinte. 


\section{2 \\ Modelo unidimensional}

Para entender a influência da não linearidade do material hiperelástico e posterior análise da treliça, estuda-se inicialmente uma barra constituída por material neo-Hookeano.

\section{1.}

\section{Modelo neo-Hookeano}

Existem na literatura vários modelos que definem as propriedades mecânicas dos materiais, entre eles estão os modelos de materiais hiperelásticos. Estes modelos constitutivos descrevem em geral o comportamento do material através da sua energia interna de deformação, que pode ser escrita em função dos invariantes de deformação, $I_{i}$, que são, em geral, escritos em termos dos fatores de deformações principais do elemento estrutural, $\lambda_{i}$. Na literatura encontram-se várias formas específicas da função energia de deformação, tanto para materiais compressíveis quanto incompressíveis, principalmente isotrópicos.

O modelo constitutivo neo-Hookeano insere-se no grupo dos modelos de Mooney, sendo, entre estes, o modelo mais simples. A função da sua energia específica, $W$, é

$$
W=C_{1}\left(I_{1}-3\right)
$$

sendo o primeiro invariante igual a

$$
I_{1}=\lambda_{1}^{2}+\lambda_{2}^{2}+\lambda_{3}^{2}
$$

Considerando a incompressibilidade do modelo hiperelástico adotado, tem-se a relação $\lambda_{1} \lambda_{2} \lambda_{3}=1$ para os fatores de deformações principais $\lambda_{i}$. 
Para análise de uma barra homogênea e isotrópica, simplifica-se a Equação (2.1), escrevendo-se os fatores de deformações em termos do fator de deformação principal axial, que representa a razão entre o comprimento deformado e indeformado da barra: $\lambda_{1}=\lambda=l / l_{o}$ e $\lambda_{2}=\lambda_{3}=1 / \sqrt{\lambda}$, e assim tem-se a função de energia

$$
W=C_{1}\left(\lambda^{2}+\frac{2}{\lambda}-3\right)
$$

O parâmetro $C_{1}$, característica do material, é obtido experimentalmente. Valores experimentais para este parâmetro são apresentados, para materiais poliméricos, em Selvadurai (2006) e Sasso et al. (2008), dentre outros.

Os materiais hiperelásticos caracterizam-se por sua elevada capacidade de deformação e não linearidade física. Assim, diante de grandes deformações, os tensores adotados para pequenas deformações não são capazes de representar corretamente o comportamento do material. A fim de caracterizar o comportamento de um elemento de barra hiperelástico, adota-se a deformação logarítmica:

$$
\varepsilon_{l n}=\ln (\lambda)
$$

A contração da seção transversal, para um coeficiente de Poisson constante, é dado pela equação:

$$
\varepsilon_{d}=\ln (\mu)=-v \ln (\lambda),
$$

sendo $\mu$, a raiz quadrada da razão entre a área deformada e a área indeformada da seção:

$$
\mu=\sqrt{\frac{A}{A_{0}}} .
$$


Obtém-se assim para área deformada do elemento, a partir das Equações (2.5) e (2.6), a expressão:

$$
A=A_{0} \lambda^{-2 v}
$$

Considerando o material incompressível e desconsiderando fenômenos localizados $(v=0,5)$, a relação entre a área deformada e indeformada da barra torna-se:

$$
A=A_{0} \lambda^{-1}
$$

A tensão de Cauchy é obtida pela variação infinitesimal da energia específica de deformação do material de acordo com a relação a seguir.

$$
d W=\sigma_{l n} d \varepsilon_{l n} \rightarrow \sigma_{l n}=\frac{d W}{d \varepsilon_{l n}}=\frac{d W}{d \lambda} \frac{d \lambda}{d \varepsilon_{l n}}
$$

logo, obtém-se para a tensão:

$$
\sigma_{l n}=2 C_{1}\left(\lambda^{2}-\frac{1}{\lambda}\right)
$$

\section{2. \\ Elemento de barra}

A Figura 2.1 apresenta o modelo de uma barra de material neo-Hookeano.

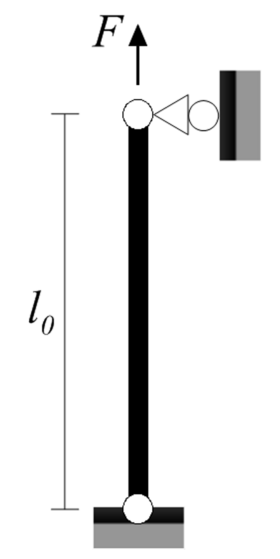

Figura 2.1: Modelo da barra. 
A barra em seu estado indeformado possui comprimento $l_{0}$, área $A_{0}$ e está submetida a uma força axial $F$, que é positiva em caso de tração.

A partir das Equações (2.8) e (2.10), tem-se a relação a seguir.

$$
F=2 C_{1} A_{0}\left(\lambda-\frac{1}{\lambda^{2}}\right)
$$

A Figura 2.2 apresenta a variação do parâmetro adimensional $F / C_{1} A_{0}$ com o parâmetro $\lambda$.

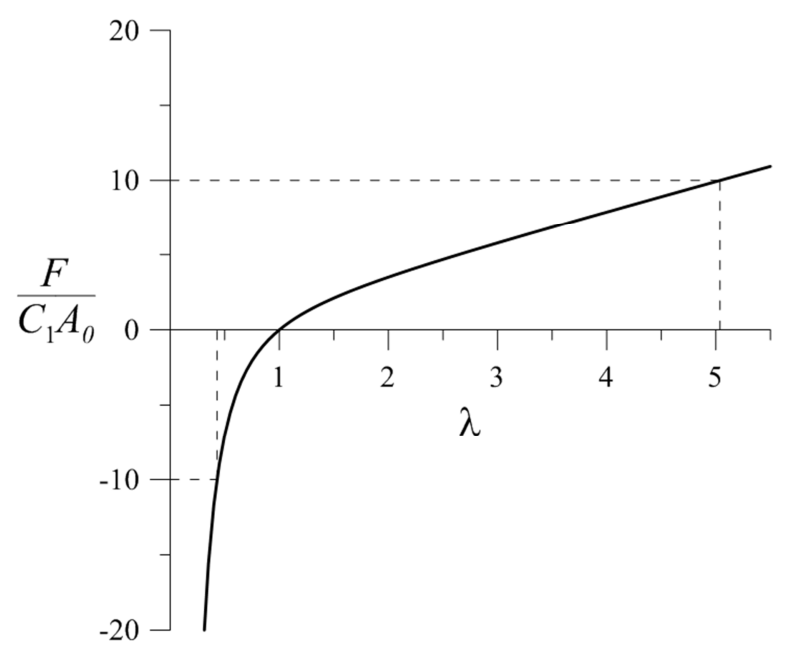

Figura 2.2: Variação de $F / C_{1} A_{0} \operatorname{com} \lambda$.

Observa-se na Figura 2.2, que o comportamento da barra submetida à tração é bastante diferente do seu comportamento em compressão. Para valores iguais de $\left|F / C_{1} A_{0}\right|$, o alongamento da coluna em tração é bem superior ao valor do encurtamento na compressão. Esta diferença tem uma grande importância no comportamento não linear e estabilidade da estrutura, como demonstrado neste trabalho.

Derivando-se a Equação (2.10) em relação ao $\lambda$, obtém-se a rigidez efetiva da barra:

$$
C_{\lambda}=\frac{\partial \sigma_{l n}}{\partial \lambda}=2 C_{1}\left(2 \lambda+\frac{1}{\lambda^{2}}\right)
$$


A relação entre o parâmetro $C_{1}$ e o módulo de elasticidade, $E$, pode ser calculada pelo limite da função da rigidez da barra quando o fator de deformação $\lambda$ tende a 1.

$$
E=\lim _{\lambda \rightarrow 1} \frac{\partial \sigma_{l n}}{\partial \lambda}=6 C_{1}
$$

A Figura 2.3 exibe a variação da rigidez efetiva em função de $\lambda$ para $o$ elemento de barra.

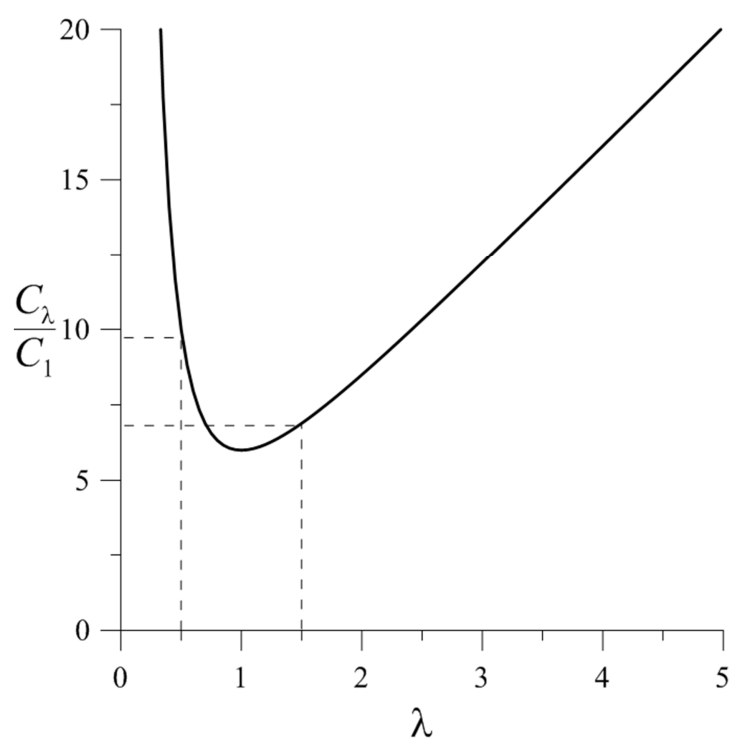

Figura 2.3: Variação de $C_{\lambda} / C_{1} \operatorname{com} \lambda$.

Observa-se na Figura 2.3 que a rigidez efetiva à compressão é superior à rigidez à tração para uma mesma variação de comprimento.

A Figura 2.4 apresenta uma comparação entre diferentes modelos hiperelásticos, realçando a diferença entre o comportamento desses modelos em faixas de deformação superiores a 1 . 


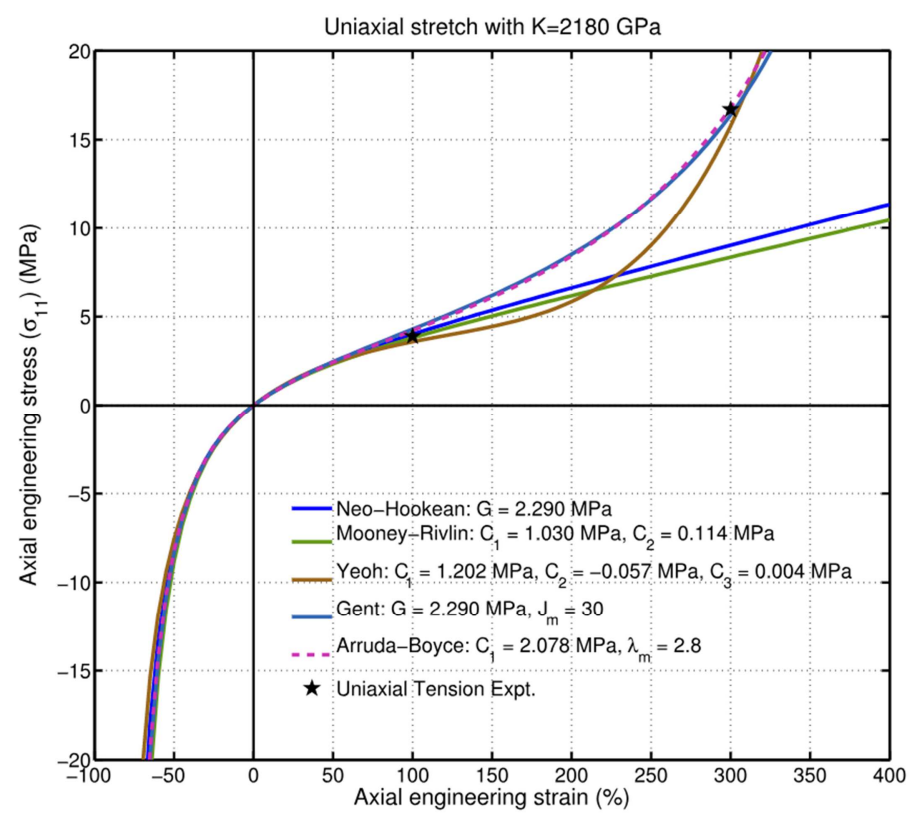

Figura 2.4: Curva tensão-deformação de modelos hiperelásticos (Wikipedia, 27/06/2018). 


\section{3 \\ Formulação}

Apresenta-se neste capítulo a formulação utilizada neste trabalho para análise da instabilidade estática e vibrações da treliça ilustrada na Figura 3.1.

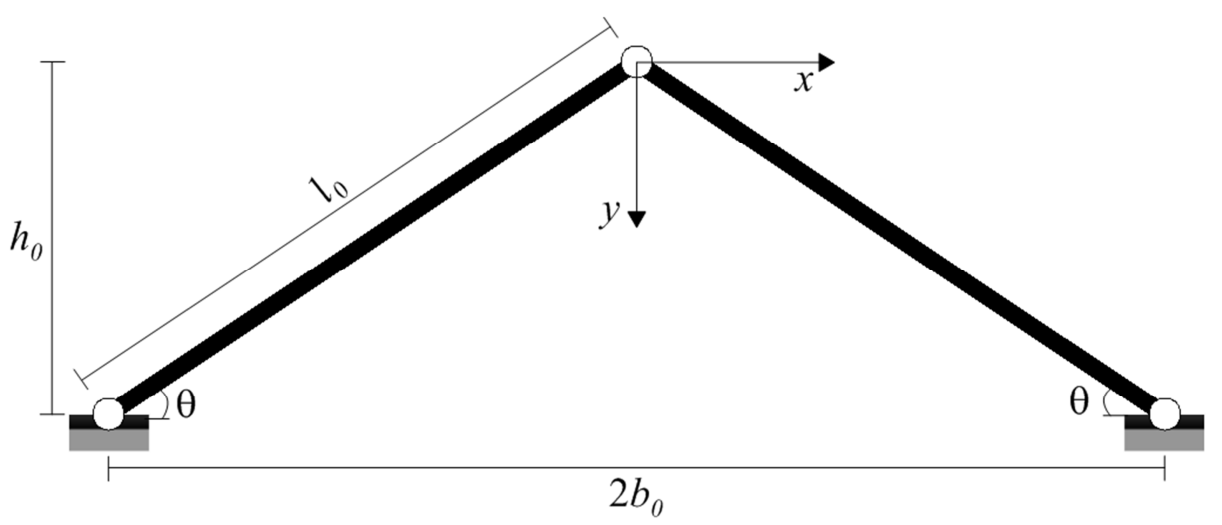

Figura 3.1: Modelo da treliça perfeita.

A treliça perfeita indeformada possui altura $h_{0}$, base $2 b_{0}$ e ângulo de abatimento $\theta$. Suas barras são constituídas por material hiperelástico neoHookeano, têm comprimento inicial $l_{0}$, área $A_{0}$ e massa específica $\rho$. O nó superior, com coordenadas nulas na posição indeformada, possui liberdade para deslocar-se nas direções $x$ e $y$.

Neste trabalho analisa-se o comportamento não linear da treliça submetida a cargas horizontais e verticais. A Figura 3.2 apresenta os dois casos de carregamento, $p_{i}$, considerados.

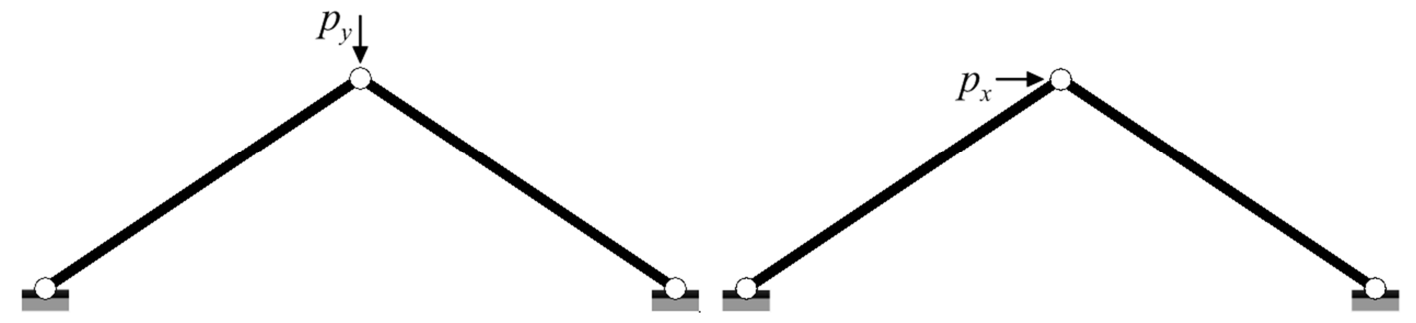

(a) Carga vertical. (b) Carga horizontal.

Figura 3.2: Carregamento estático. 
A fim de avaliar o comportamento da treliça imperfeita, consideram-se imperfeições de carga e na geometria da estrutura para cada situação de carregamento. Para a perturbação do carregamento considera-se uma pequena componente de força perpendicular à carga considerada. A Figura 3.3 ilustra as treliças com imperfeições de carga.

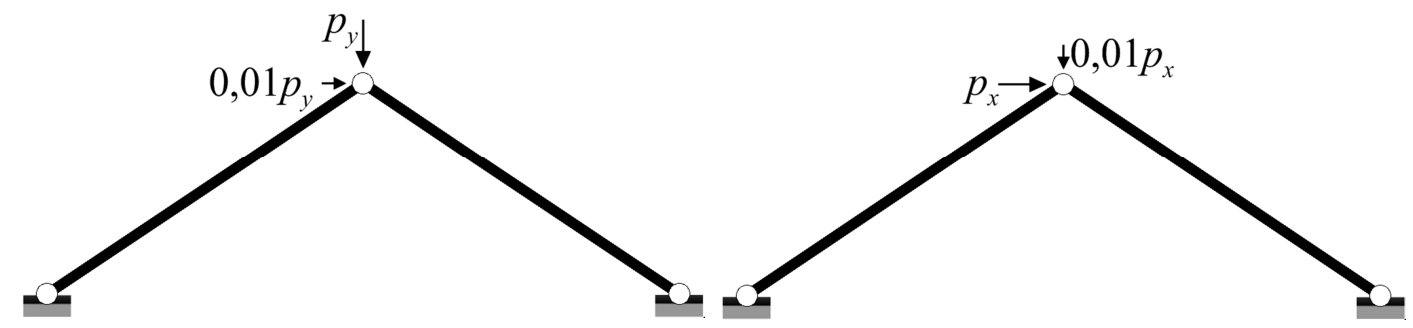

(a) Carga estática vertical.

(b) Carga estática horizontal.

Figura 3.3: Imperfeição de carga.

A Figura 3.4 apresenta a forma como a imperfeição geométrica é considerada, representando uma situação genérica.

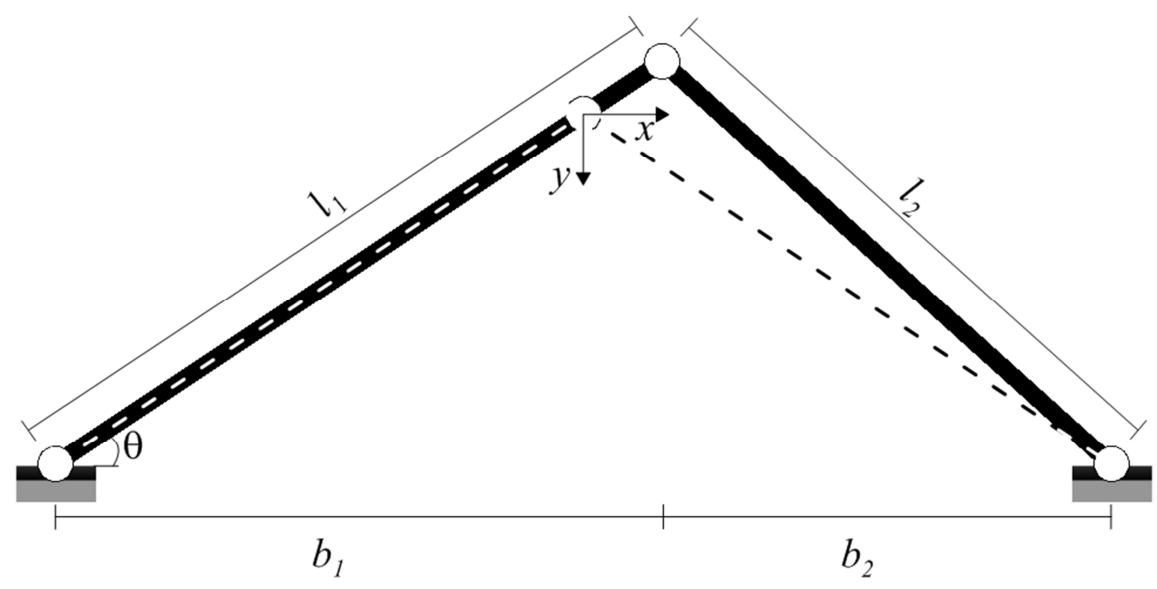

Figura 3.4: Modelo genérico.

Como mostra a Figura 3.4, considera-se na formulação da treliça imperfeita que a inclinação da barra $l_{1}$ mantem-se igual a $\theta$, e os comprimentos das projeções das barras na direção $x$ são alterados em função da imperfeição desejada. A linha tracejada representa a estrutura perfeita em seu estado indeformado. Ressalta-se que a origem dos eixos cartesianos continua no nó superior da treliça perfeita e também que o comprimento total da sua base não foi alterado $\left(b_{1}+b_{2}=2 b_{0}\right)$. 
Introduz-se também uma variável auxiliar $r$, que é a razão entre $l_{1}$ e $l_{2}$, dada por:

$$
r=\frac{l_{1}}{l_{2}}=\frac{\operatorname{sen}\left(\arctan \left(\frac{b_{1}}{b_{2}} \tan (\theta)\right)\right)}{\operatorname{sen}(\theta)} .
$$

A imperfeição geométrica utilizada nos exemplos deste trabalho é exibida na Figura 3.5. Os comprimentos das projeções das barras na direção $x$ são alterados em $5 \%$.

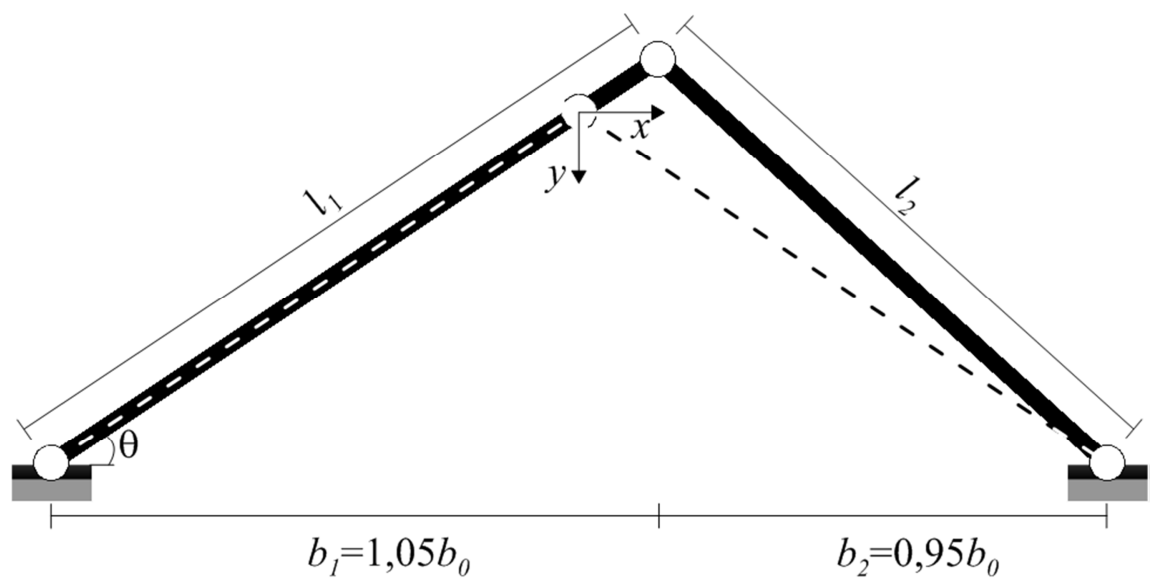

Figura 3.5: Imperfeição geométrica.

\section{1.}

\section{Energia potencial total}

Considera-se a treliça imperfeita (modelo genérico) deformada, com seu nó superior definido pelas coordenadas $(x, y)$.

A energia potencial total do sistema, $\Pi$, é composta pela soma da energia interna devido à deformação das barras da treliça, $U$, e da energia potencial das cargas externas, $V$. 
$\mathrm{Na}$ configuração deformada, obtém-se o fator de deformação $\lambda_{i}$ de cada barra, a saber:

$$
\begin{aligned}
& \lambda_{1}=\frac{1}{l_{1}} \sqrt{\left.\left(h_{0}-y\right)^{2}+\left(b_{0}+x\right)\right)^{2}} ; \\
& \lambda_{2}=\frac{1}{l_{2}} \sqrt{\left.\left(h_{0}-y\right)^{2}+\left(b_{0}-x\right)\right)^{2}} .
\end{aligned}
$$

Assim, a partir da geometria da Figura 3.4 e das Equações (2.3), (3.1) e (3.2) , calcula-se a energia de deformação das barras, sendo esta dada por:

$$
\begin{aligned}
& U=C_{1} A_{0} \frac{b_{1} l_{0}}{b_{0}}\left(\left(\frac{b_{0}}{b_{1}}\right)^{2}\left(\left(\operatorname{sen}(\theta)-\alpha_{y} \operatorname{sen}(\theta)\right)^{2}+\left(\cos (\theta)+\alpha_{x} \cos (\theta)\right)^{2}\right)\right. \\
& \left.+\frac{b_{1}}{b_{0}} \frac{2}{\sqrt{\left(\operatorname{sen}(\theta)-\alpha_{y} \operatorname{sen}(\theta)\right)^{2}+\left(\cos (\theta)+\alpha_{x} \cos (\theta)\right)^{2}}}-3\right) \\
& +C_{1} A_{0} \frac{b_{1} l_{0}}{b_{0} r}\left(\left(\frac{b_{0} r}{b_{1}}\right)^{2}\left(\left(\operatorname{sen}(\theta)-\alpha_{y} \operatorname{sen}(\theta)\right)^{2}+\left(\cos (\theta)-\alpha_{x} \cos (\theta)\right)^{2}\right)\right. \\
& \left.+\frac{b_{1}}{b_{0} r} \frac{2}{\sqrt{\left(\operatorname{sen}(\theta)-\alpha_{y} \operatorname{sen}(\theta)\right)^{2}+\left(\cos (\theta)-\alpha_{x} \cos (\theta)\right)^{2}}}-3\right) ;
\end{aligned}
$$

sendo: $\alpha_{x}=x / b_{0}$ e $\alpha_{y}=y / h_{0}$, variáveis adimensionais e também os graus de liberdade do modelo.

Obtém-se da Equação (3.3) a expressão para a treliça perfeita (Figura 3.1), adotando-se $b_{1}=b_{0}$ e $r=1$.

A energia potencial das cargas $p_{i}$ e das imperfeições de carga $0,01 p_{i}$, para cada situação de carga estática, de acordo com a Figura 3.3, é dada por:

$$
V_{x}=-p_{x} l_{0} \cos (\theta)\left(\alpha_{x}-\left(\frac{b_{1}}{b_{0}}-1\right)\right)-0,01 p_{x} l_{0} \operatorname{sen}(\theta)\left(\alpha_{y}-\left(\frac{b_{1}}{b_{0}}-1\right)\right)
$$




$$
V_{y}=-p_{y} l_{0} \operatorname{sen}(\theta)\left(\alpha_{y}-\left(\frac{b_{1}}{b_{0}}-1\right)\right)-0,01 p_{y} l_{0} \cos (\theta)\left(\alpha_{x}-\left(\frac{b_{1}}{b_{0}}-1\right)\right) .
$$

\section{2.}

\section{Energia cinética}

Considerando-se que um comprimento infinitesimal $d s_{i}$ da barra $l_{i}$ com massa por unidade de comprimento $d m_{i}=\rho A_{0} d s_{i}$ desloca-se de $x_{i}^{\prime}$ e $y_{i}^{\prime}$, como ilustra a Figura 3.6.

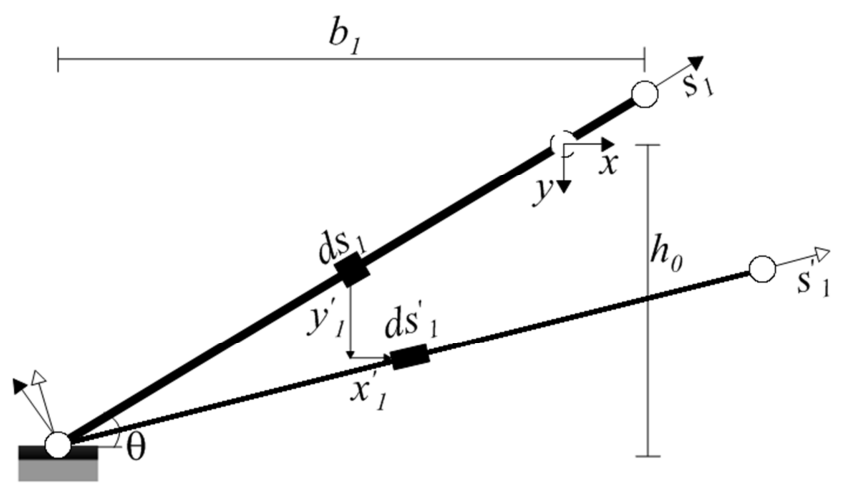

Figura 3.6: Modelo para energia cinética da barra $l_{1}$.

A energia cinética da partícula é dada pela seguinte equação.

$$
d T=\frac{d m_{i}}{2}\left(\dot{x}_{i}^{2}+\dot{y}_{i}^{2}\right)
$$

em que $\ddot{x}_{i}^{\prime} \mathrm{e} \dot{y}_{i}^{\prime}$ são as velocidades referentes aos deslocamentos $x_{i}^{\prime} \mathrm{e} y_{i}^{\prime}$ da massa $d m_{i}$.

Sendo o material neo-Hookeano incompressível, as massas de um elemento infinitesimal deformado e indeformado são iguais, ou seja:

$$
d m_{i}=\rho A_{0} d s_{i}=\rho A_{i} d s_{i}^{\prime}=\rho \frac{A_{0}}{\lambda_{i}} \lambda_{i} d s_{i}
$$


Os deslocamentos $x_{i}^{\prime}$ e $y_{i}^{\prime}$ referentes às barras $l_{1}$ e $l_{2}$ são dados por:

$$
\begin{gathered}
x_{1}^{\prime}=s_{1}\left(\frac{\lambda_{1}\left(b_{1}+x b_{1} / b_{0}\right)}{\lambda_{1} l_{1}}-\frac{b_{1}}{l_{1}}\right) ; \\
y_{1}^{\prime}=s_{1}\left(\frac{h_{0} b_{1} / b_{0}}{l_{1}}-\frac{\lambda_{1}\left(h_{0} b_{1} / b_{0}-y b_{1} / b_{0}\right)}{\lambda_{1} l_{1}}\right) ; \\
x_{2}^{\prime}=s_{2}\left(\frac{b_{2}}{l_{2}}-\frac{\lambda_{2}\left(b_{2}-x b_{1} / b_{0}\right)}{\lambda_{2} l_{2}}\right) ; \\
y_{2}^{\prime}=s_{2}\left(\frac{h_{0} b_{1} / b_{0}}{l_{2}}-\frac{\lambda_{2}\left(h_{0} b_{1} / b_{0}-y b_{1} / b_{0}\right)}{\lambda_{2} l_{2}}\right) .
\end{gathered}
$$

Derivando-se os deslocamentos $x_{i}^{\prime}$ e $y_{i}^{\prime}$ em relação ao tempo, obtém-se para as velocidades $\ddot{x}_{i}^{\prime}$ e $\dot{y}_{i}^{\prime}$ :

$$
\begin{aligned}
& \ddot{x}_{1}^{\prime}=s_{1}\left(\frac{\dot{x}}{l_{0}}\right) ; \\
& \ddot{y}_{1}^{\prime}=s_{1}\left(\frac{\dot{y}}{l_{0}}\right) ; \\
& \ddot{x}_{2}^{\prime}=s_{2}\left(\frac{\dot{x} r}{l_{0}}\right) ; \\
& \ddot{y}_{2}^{\prime}=s_{2}\left(\frac{\dot{y} r}{l_{0}}\right) .
\end{aligned}
$$

A partir das equações (3.5) a (3.8), obtém-se a energia cinética do sistema estrutural imperfeito:

$$
T=\frac{\rho A_{0}}{2 l_{0}{ }^{2}} \int_{0}^{l_{1}} s_{1}^{2} d s_{1}\left(\dot{x}^{2}+\dot{y}^{2}\right)+\frac{\rho A_{0} r^{2}}{2 l_{0}^{2}} \int_{0}^{l_{2}} s_{2}^{2} d s_{2}\left(\dot{x}^{2}+\dot{y}^{2}\right) .
$$


Adotando-se as velocidades adimensionais: $\dot{\alpha}_{x}=\dot{x} / b_{0}$ e $\dot{\alpha}_{y}=\dot{y} / h_{0}$, e integrando-se a Equação (3.9) obtém-se a energia cinética para a treliça:

$$
\begin{aligned}
& T=\frac{m l_{0}^{2}}{6}\left(\frac{b_{1}}{b_{0}}\right)^{3}\left(\dot{\alpha}_{x}^{2} \cos ^{2}(\theta)+\dot{\alpha}_{y}^{2} \operatorname{sen}^{2}(\theta)\right) \\
& +\frac{m l_{0}^{2}}{6 r}\left(\frac{b_{1}}{b_{0}}\right)^{3}\left(\dot{\alpha}_{x}^{2} \cos ^{2}(\theta)+\dot{\alpha}_{y}^{2} \operatorname{sen}^{2}(\theta)\right) .
\end{aligned}
$$

\section{3.}

\section{Amortecimento}

Utiliza-se o amortecimento de Rayleigh, proporcional à massa e à rigidez efetiva linear (matriz de rigidez e matriz geométrica):

$$
c=a_{0} \mathbf{M}+a_{1} \mathbf{K},
$$

para representar a dissipação de energia do sistema. Os coeficientes $a_{0}$ e $a_{1}$ são coeficientes de proporcionalidade. De acordo com Dazio (2013), a utilização do mesmo coeficiente de amortecimento, $\zeta$, para diferentes modos de vibração é razoável. Com isso, os coeficientes $a_{0}$ e $a_{1}$ podem ser escritos em função do coeficiente de amortecimento $\zeta$ e das frequências naturais $\omega_{1,2}$ da seguinte forma:

$$
\begin{aligned}
& a_{0}=\zeta \frac{2 \omega_{1} \omega_{2}}{\omega_{1}+\omega_{2}} ; \\
& a_{1}=\zeta \frac{2}{\omega_{1}+\omega_{2}} .
\end{aligned}
$$




\section{4}

\section{Análise estática}

A análise estática da estabilidade é conduzida utilizando-se o princípio da energia potencial mínima (teorema de Lagrange-Dirichlet) - a configuração de equilíbrio é estável se a energia potencial total do sistema conservativo neste ponto é um mínimo local (critério de estabilidade local).

Assume-se que a carga crítica de Euler da barra da treliça seja superior à carga axial aplicada, não se considerando na presente análise a flambagem local das barras.

\section{1.}

\section{Configurações de equilíbrio da estrutura descarregada}

Utilizando a Equação (3.3), escreve-se a energia interna de deformação da treliça perfeita na forma adimensional como:

$$
\begin{aligned}
& \bar{U}_{P}=2\left(\alpha_{y}{ }^{2}-2 \alpha_{y}-2-\left(\alpha_{y}{ }^{2}-\alpha_{x}{ }^{2}-2 \alpha_{y}\right) \cos ^{2}(\theta)+\right. \\
& \frac{1}{\sqrt{\left(\alpha_{y}-1\right)^{2}-\left(\alpha_{y}^{2}-\alpha_{x}^{2}-2 \alpha_{y}-2 \alpha_{x}\right) \cos ^{2}(\theta)}}+ \\
& \left.\frac{1}{\sqrt{\left(\alpha_{y}-1\right)^{2}-\left(\alpha_{y}^{2}-\alpha_{x}^{2}-2 \alpha_{y}+2 \alpha_{x}\right) \cos ^{2}(\theta)}}\right)
\end{aligned}
$$

onde $\bar{U}_{P}=U_{P} / C_{1} A_{0} l_{0}$.

As Figuras 4.1 a 4.3 apresentam as curvas de nível e as superfícies da energia interna de deformação para treliça descarregada. Observam-se cinco posições de equilíbrio: duas são estáveis (posições 1 e 3 ) que correspondem à dois mínimos e três instáveis (posições 2, 4 e 5) que correspondem à três pontos de sela. Estas posições são ilustradas na Figura 4.4. 
Convém salientar que as posições de equilíbrio 4 e 5 para treliças com $\theta<45^{\circ}$, considerando um domínio de grandes deformações, não existem para materiais elásticos lineares (Kwasnieewski, 2008). Elas são fruto da não linearidade física do material ilustrada na Figura 2.2.

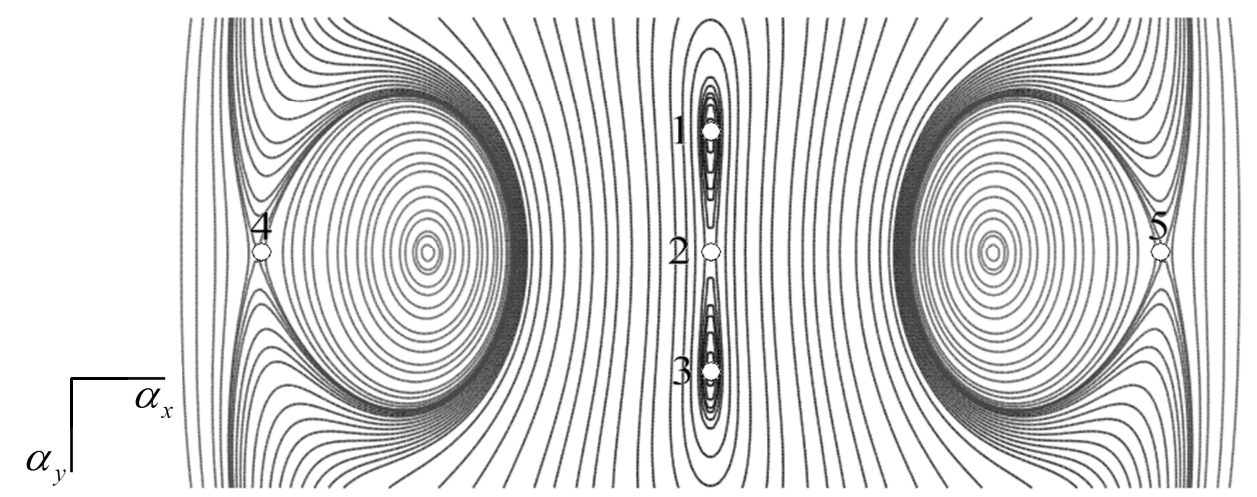

Figura 4.1: Curvas de nível da energia interna de deformação para treliça com $\theta=15^{\circ}$.

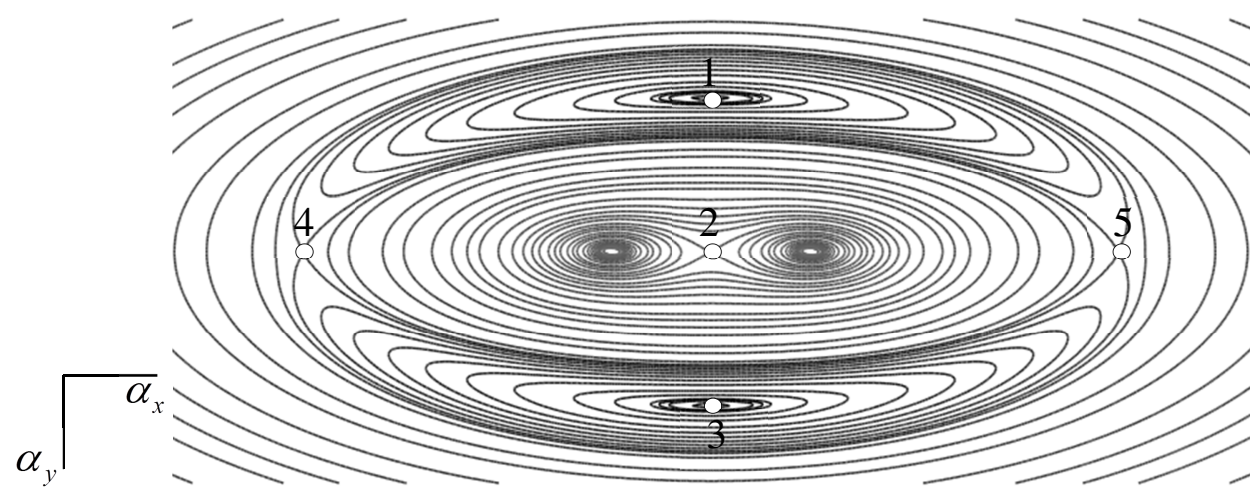

Figura 4.2: Curvas de nível da energia interna de deformação para treliça com $\theta=75^{\circ}$.
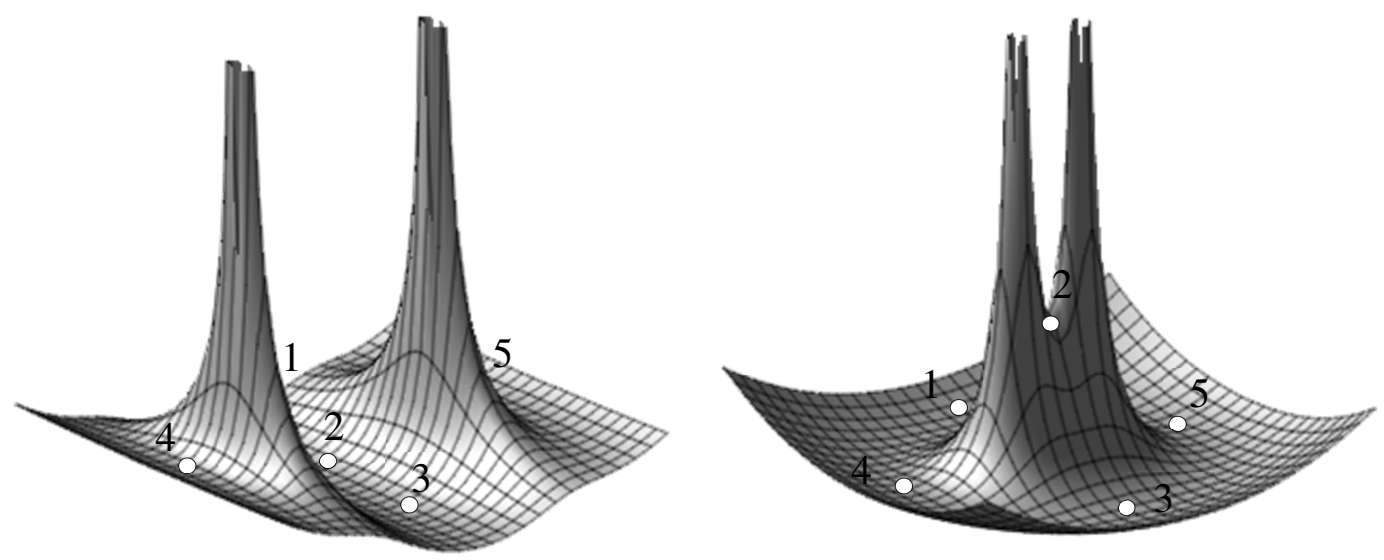

(a) $\theta=15^{\circ}$.

(b) $\theta=75^{\circ}$.

Figura 4.3: Superfície da energia interna de deformação da treliça. 
Observa-se na Figura 4.3, um recorte nos picos da superfície de energia das treliças devido o material neo-Hookeano não possuir um limite de deformação, com isso em certas posições a superfície tende a infinito ( $\lambda$ tende a zero), sendo uma característica das funções de energia deste material.

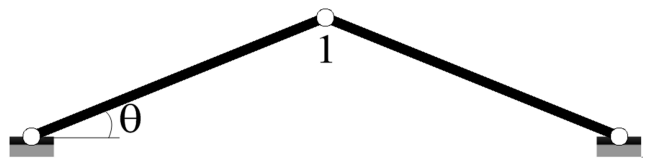

(a) Posição 1.

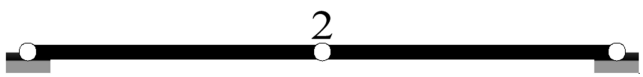

(b) Posição 2.

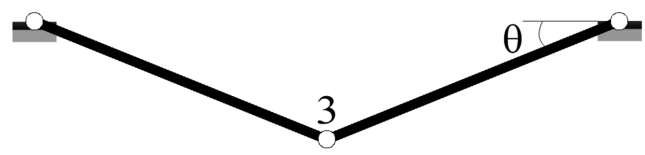

(c) Posição 3.

4

(d) Posição 4.

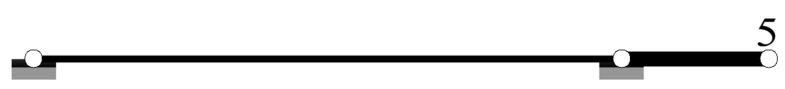

(e) Posição 5.

Figura 4.4: Configurações de equilíbrio para estrutura descarregada.

\section{2.}

Carga vertical

Apresenta-se a seguir a análise da treliça submetida a uma carga estática vertical. Analisam-se três casos: treliça perfeita, com imperfeições de carga e imperfeições geométricas. 


\subsection{1.}

\section{Caminhos de equilíbrio}

A energia potencial total da treliça carregada na direção vertical é dada por

$$
\begin{aligned}
& \bar{\Pi}_{P}=2\left(\alpha_{y}^{2}-2 \alpha_{y}-2-\left(\alpha_{y}^{2}-\alpha_{x}^{2}-2 \alpha_{y}\right) \cos ^{2}(\theta)+\right. \\
& \frac{1}{\sqrt{\left(\alpha_{y}-1\right)^{2}-\left(\alpha_{y}^{2}-\alpha_{x}^{2}-2 \alpha_{y}-2 \alpha_{x}\right) \cos ^{2}(\theta)}}+ \\
& \left.\frac{1}{\sqrt{\left(\alpha_{y}-1\right)^{2}-\left(\alpha_{y}^{2}-\alpha_{x}^{2}-2 \alpha_{y}+2 \alpha_{x}\right) \cos ^{2}(\theta)}}\right)-Q_{y} \alpha_{y} \operatorname{sen}(\theta),
\end{aligned}
$$

sendo: $\bar{\Pi}_{P}=\Pi_{P} / C_{1} A_{0} l_{0}$ e $Q_{y}=p_{y} / C_{1} A_{0}$, o parâmetro de carga.

As equações não lineares de equilíbrio são obtidas derivando-se a energia

potencial total do sistema, $\bar{\Pi}_{P}$, em relação às coordenadas generalizadas, $\alpha_{x}$ e $\alpha_{y}$, sendo dadas na forma adimensional por:

$$
\begin{aligned}
& \operatorname{sen}(\theta)\left(4 \alpha_{y}-4-\frac{2 \alpha_{y}-2}{\left(\left(\alpha_{y}-1\right)^{2}-\left(\alpha_{y}{ }^{2}-\alpha_{x}^{2}-2 \alpha_{y}-2 \alpha_{x}\right) \cos ^{2}(\theta)\right)^{3 / 2}}\right. \\
& \left.-\frac{2 \alpha_{y}-2}{\left(\left(\alpha_{y}-1\right)^{2}-\left(\alpha_{y}{ }^{2}-\alpha_{x}{ }^{2}-2 \alpha_{y}+2 \alpha_{x}\right) \cos ^{2}(\theta)\right)^{3 / 2}}\right)-Q_{y}=0
\end{aligned}
$$

$$
\begin{aligned}
& \cos ^{2}(\theta)\left(4 \alpha_{x}-\frac{2 \alpha_{x}+2}{\left(\left(\alpha_{y}-1\right)^{2}-\left(\alpha_{y}^{2}-\alpha_{x}^{2}-2 \alpha_{y}-2 \alpha_{x}\right) \cos ^{2}(\theta)\right)^{3 / 2}}\right. \\
& \left.-\frac{2 \alpha_{x}-2}{\left(\left(\alpha_{y}-1\right)^{2}-\left(\alpha_{y}^{2}-\alpha_{x}^{2}-2 \alpha_{y}+2 \alpha_{x}\right) \cos ^{2}(\theta)\right)^{3 / 2}}\right)=0 .
\end{aligned}
$$

Observa-se que as duas equações de equilíbrio dependem basicamente do parâmetro de carga $Q_{y}$ e do ângulo $\theta$.

Utiliza-se o método de Newton-Raphson para a resolução desse sistema de equações não lineares e métodos de continuação para obtenção das trajetórias de 
equilíbrio. A estabilidade das configurações de equilíbrio é obtida através da análise da sua forma quadrática: estável se esta é positiva definida, equilíbrio crítico caso seja positiva semi definida e instável nos outros casos.

As Figuras 4.5 a 4.9 apresentam as trajetórias de equilíbrio da treliça submetida à carga vertical para diferentes ângulos de abatimento $\theta$. Os caminhos de equilíbrio estáveis são representados por linhas contínuas e os instáveis por linhas tracejadas, seguindo a convenção adotada internacionalmente.

Para valores de $\theta<70^{\circ}$ a treliça apresenta três trajetórias independentes. A trajetória em vermelho representa o caminho fundamental da estrutura, onde o sistema estrutural mantem sua simetria ao longo do caminho de equilíbrio ( $\alpha_{x}=0$ e $\left.\alpha_{y} \neq 0\right)$. O sistema é inicialmente estável. À medida que a força compressiva cresce, diminui a rigidez efetiva da estrutura até que a rigidez efetiva se torna nula $\left(\partial Q_{y} / \partial \alpha_{y}=0\right)$. Este ponto limite de carga corresponde a uma bifurcação do tipo nó-sela onde, ao atingir a carga limite, a estrutura perde sua estabilidade e salta para uma configuração pós-crítica, estável, em que suas barras estão sujeitas à tração. Ao se descarregar a estrutura e inverter o sentido do carregamento chegase ao outro ponto limite onde a estrutura pula para uma posição de equilíbrio invertida criando um ciclo de histerese. Entre os dois pontos limites o equilíbrio é instável (sela). Este é o comportamento não linear típico de estruturas abatidas. À medida que $\theta$ cresce, aumenta a não linearidade geométrica da treliça e a carga crítica associada ao ponto limite, como será demonstrado mais adiante. Os caminhos azul e verde são simétricos e representam duas trajetórias secundárias de equilíbrio. Eles iniciam nas duas configurações de equilíbrio próprio instáveis (pontos 4 e 5 das Figura 4.1 e 4.4) e são atingidas apenas por meio de controle de deslocamento. Sua inclinação cresce $\operatorname{com} \theta$. Cabe destacar que estes caminhos são devidos à não linearidade física do material hiperelástico. Inicialmente, para pequenos ângulos de abatimento, os três caminhos de equilíbrio são praticamente paralelos no plano $\alpha_{x} \times \alpha_{y}$. A partir de $\theta=25^{\circ}$ começa-se a observar um aumento crescente da curvatura dos caminhos secundários no plano $\alpha_{x} \times \alpha_{y}$, indicando uma relação não linear entre as duas variáveis, enquanto o caminho fundamental permanece com uma projeção linear neste plano e a estrutura mantem sua simetria $\left(\alpha_{x}=0\right)$. À medida que $\theta$ cresce, ou seja, a estrutura se torna menos abatida, os 
dois caminhos secundários se aproximam do caminho fundamental e em um ângulo limite, $\theta_{\lim }$, entre $69^{\circ}$ e $71^{\circ}$, as três trajetórias tangenciam-se e a partir deste ângulo ocorre o cruzamento dos caminhos de equilíbrio, dando origem a dois novos pontos de bifurcação ao longo do caminho fundamental de equilíbrio. A partir de $\theta_{\lim }$ observa-se que as trajetórias de equilíbrio cruzam-se em quatro pontos e quatro trajetórias de equilíbrio são identificadas. Ao longo do caminho fundamental de equilíbrio, a estrutura alcança a carga crítica e perde a instabilidade por bifurcação simétrica instável. A trajetória secundária de equilíbrio (caminho de equilíbrio em azul) é fechada e liga esta configuração a sua simétrica invertida. Após esta bifurcação, a configuração fundamental (vermelha) se torna instável até atingir outro ponto de bifurcação simétrica, representando outra carga crítica da treliça. A partir deste ponto a trajetória fundamental torna-se novamente estável até atingir o ponto limite. Cabe destacar novamente que os caminhos secundários que surgem nestes pontos de bifurcação (verde e roxo) são instáveis e não são observados para estruturas de material elástico linear. Têm-se então quatro trechos estáveis. Estes trechos diminuem à medida que $\theta$ cresce e desaparecem em $\theta=90^{\circ}$, quando a estrutura se torna um mecanismo.

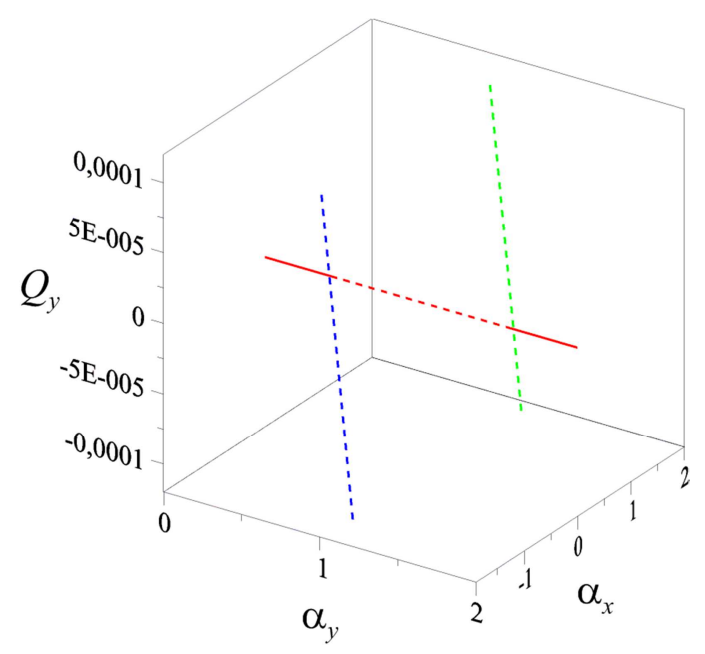

(a) Vista $\alpha_{x} \times \alpha_{y} \times Q_{y}$

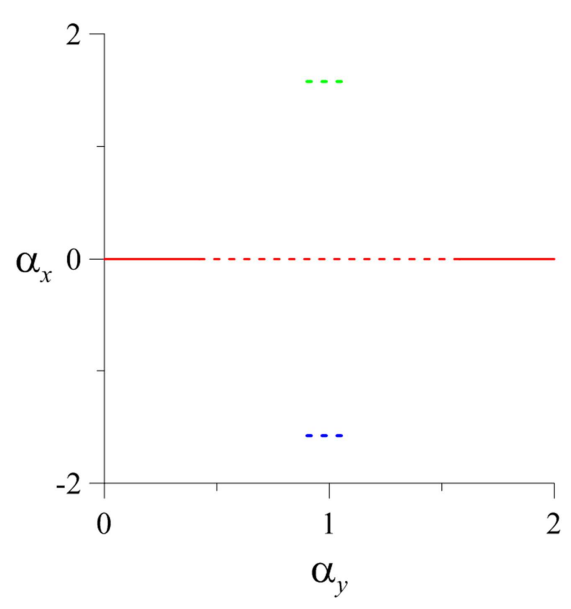

(b) Projeção $\alpha_{x} \times \alpha_{y}$.

Figura 4.5: Caminhos de equilíbrio da treliça com carga vertical e $\theta=0^{\circ}$. 


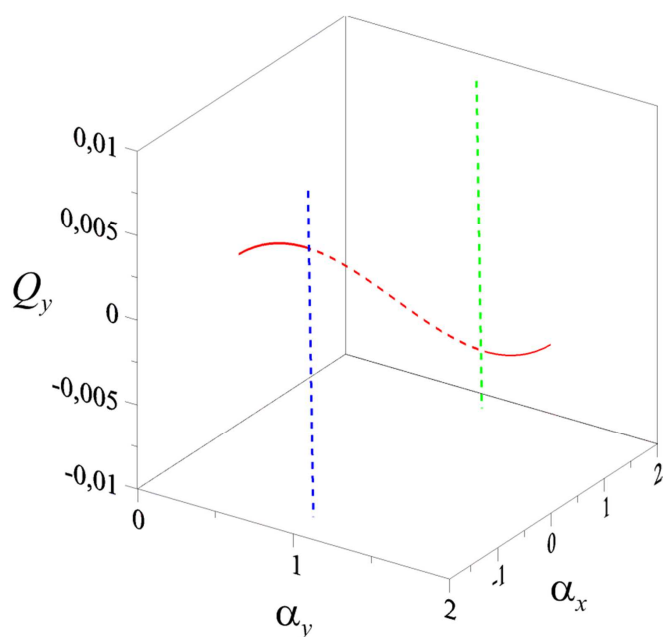

(a) $\theta=5^{\circ}$ : vista $\alpha_{x} \times \alpha_{y} \times Q_{y}$.

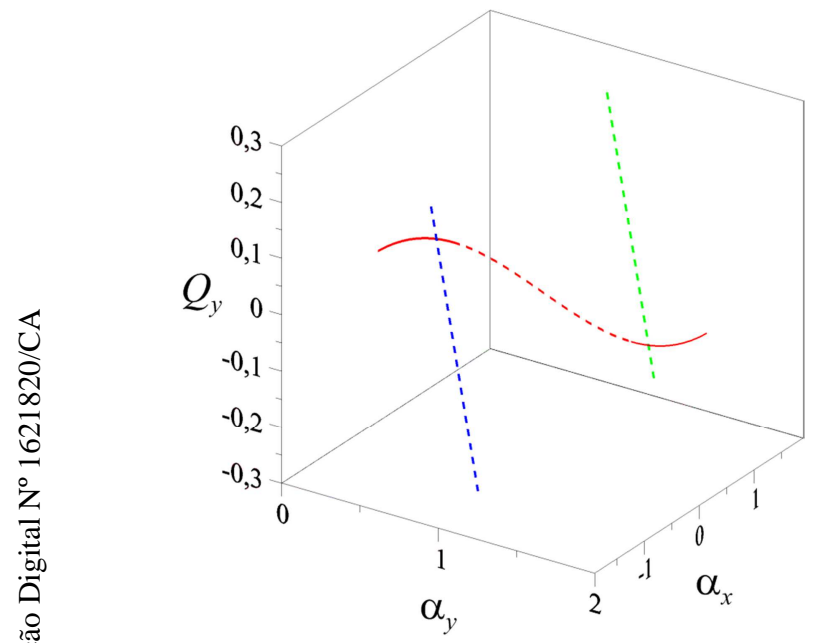

(c) $\theta=15^{\circ}:$ vista $\alpha_{x} \times \alpha_{y} \times Q_{y}$.

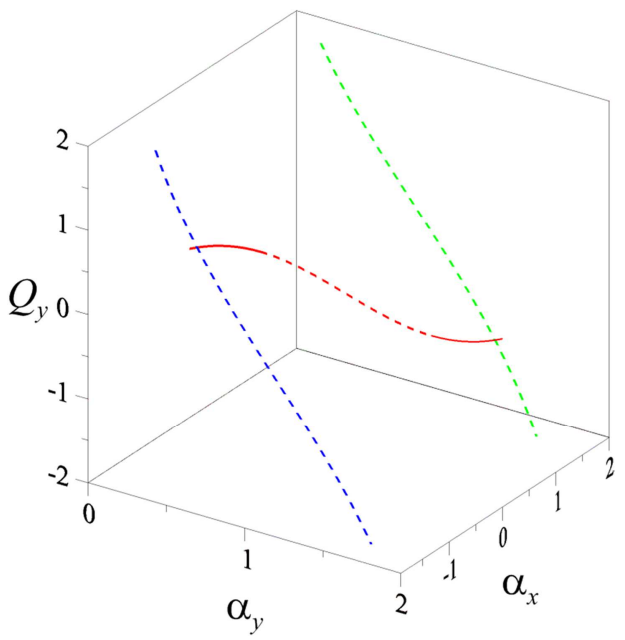

(e) $\theta=25^{\circ}:$ vista $\alpha_{x} \times \alpha_{y} \times Q_{y}$.

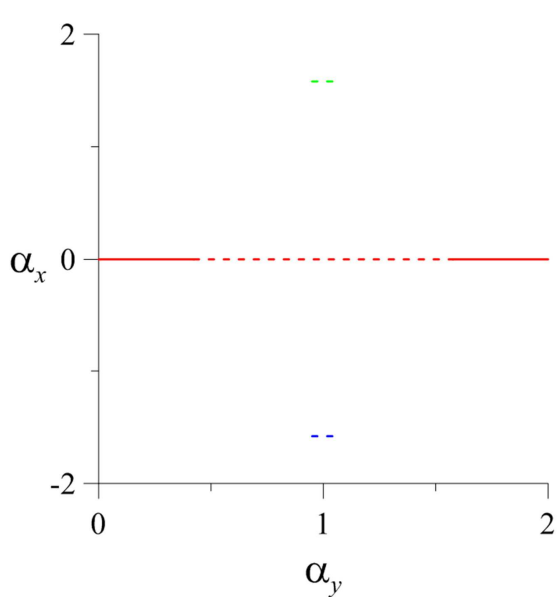

(b) $\theta=5^{\circ}$ : projeção $\alpha_{x} \times \alpha_{y}$.

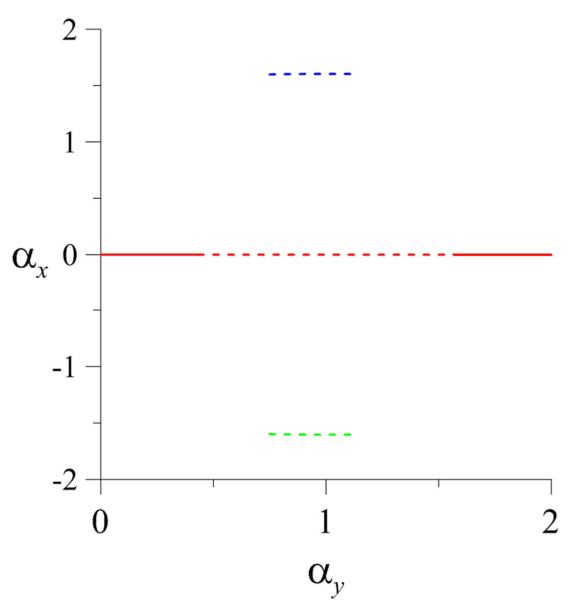

(d) $\theta=15^{\circ}$ : projeção $\alpha_{x} \times \alpha_{y}$.

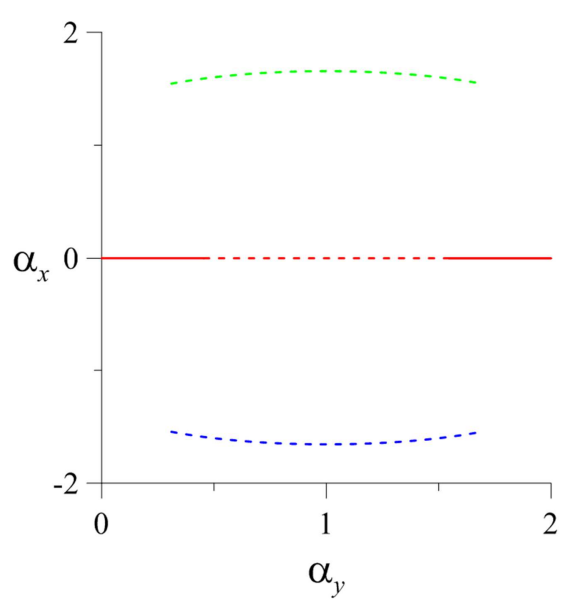

(f) $\theta=25^{\circ}$ : projeção no plano $\alpha_{x} \times \alpha_{y}$.

Figura 4.6: Caminhos de equilíbrio da treliça com carga vertical para $\theta=5^{\circ}, 15^{\circ}$ e $25^{\circ}$. 


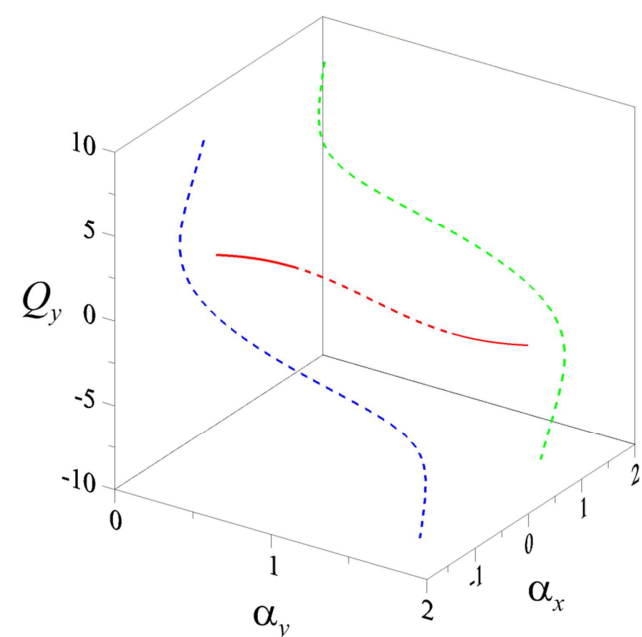

(a) $\theta=35^{\circ}$ : vista $\alpha_{x} \times \alpha_{y} \times Q_{y}$.

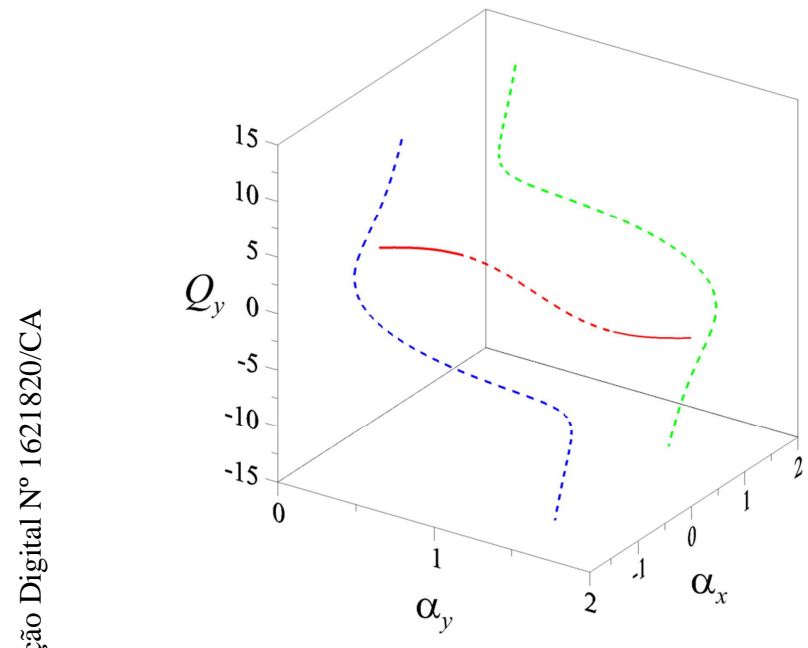

(c) $\theta=45^{\circ}:$ vista $\alpha_{x} \times \alpha_{y} \times Q_{y}$.

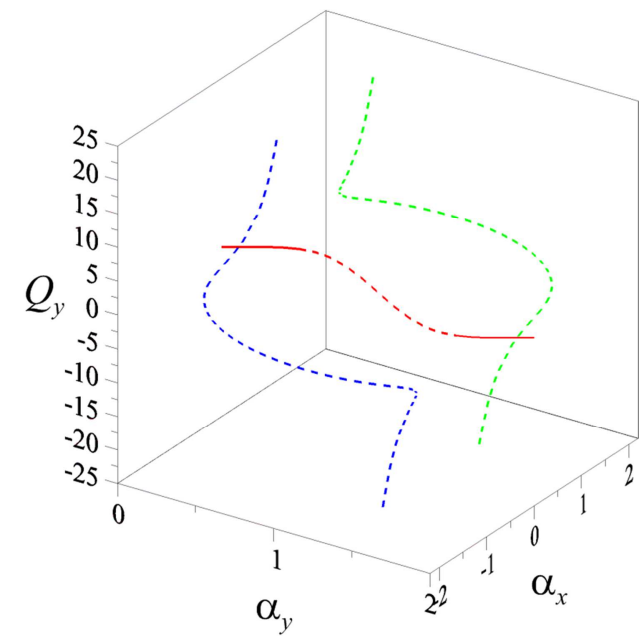

(e) $\theta=55^{\circ}:$ vista $\alpha_{x} \times \alpha_{y} \times Q_{y}$.

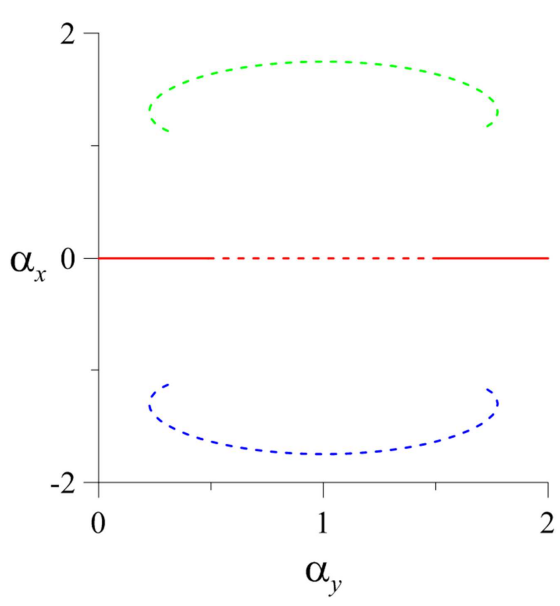

(b) $\theta=35^{\circ}$ : projeção $\alpha_{x} \times \alpha_{y}$.

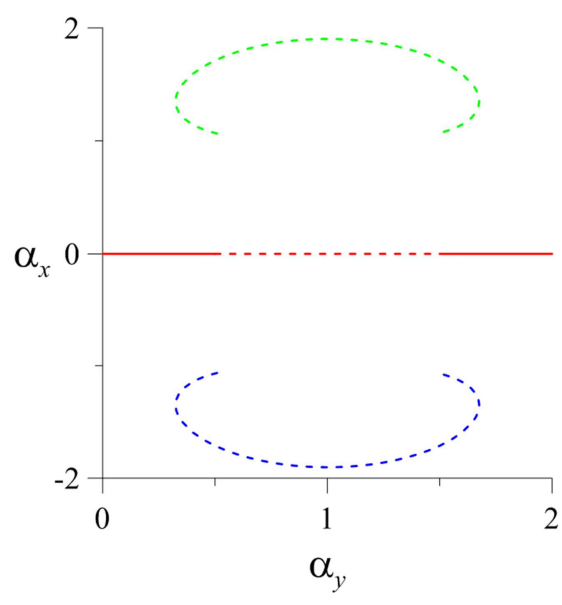

(d) $\theta=45^{\circ}:$ projeção $\alpha_{x} \times \alpha_{y}$.

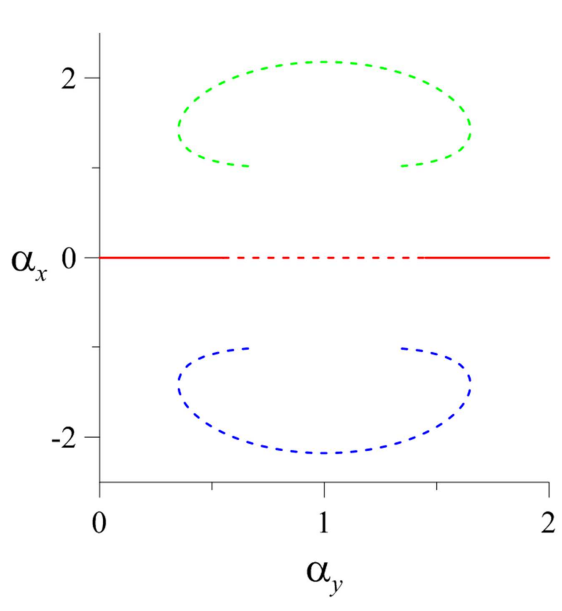

(f) $\theta=55^{\circ}$ : projeção $\alpha_{x} \times \alpha_{y}$.

Figura 4.7: Caminhos de equilíbrio da treliça com carga vertical para $\theta=35^{\circ}, 45^{\circ}$ e $55^{\circ}$. 


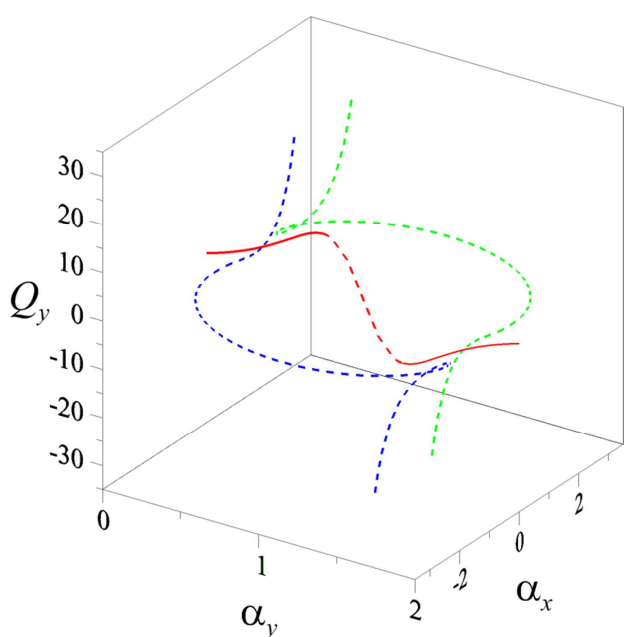

(a) $\theta=69^{\circ}$ : vista $\alpha_{x} \times \alpha_{y} \times Q_{y}$.

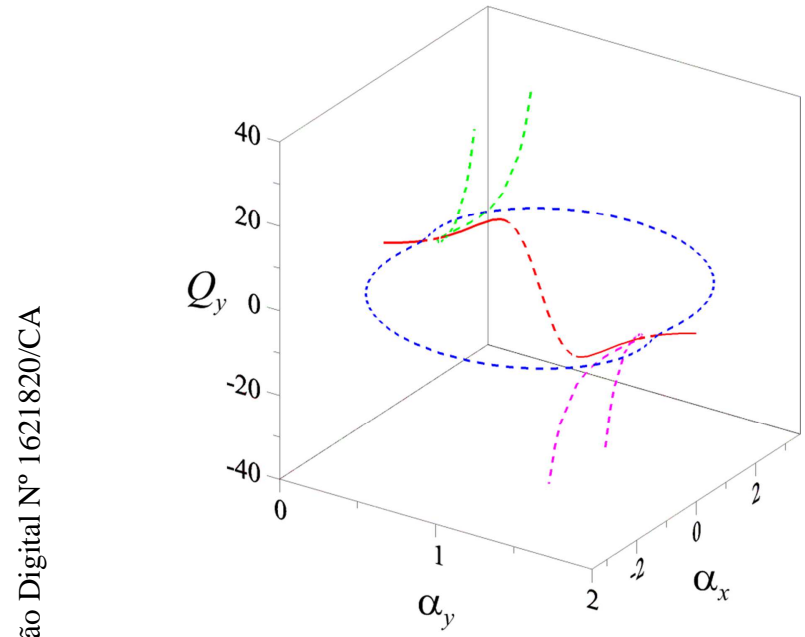

(c) $\theta=71^{\circ}$ : vista $\alpha_{x} \times \alpha_{y} \times Q_{y}$.

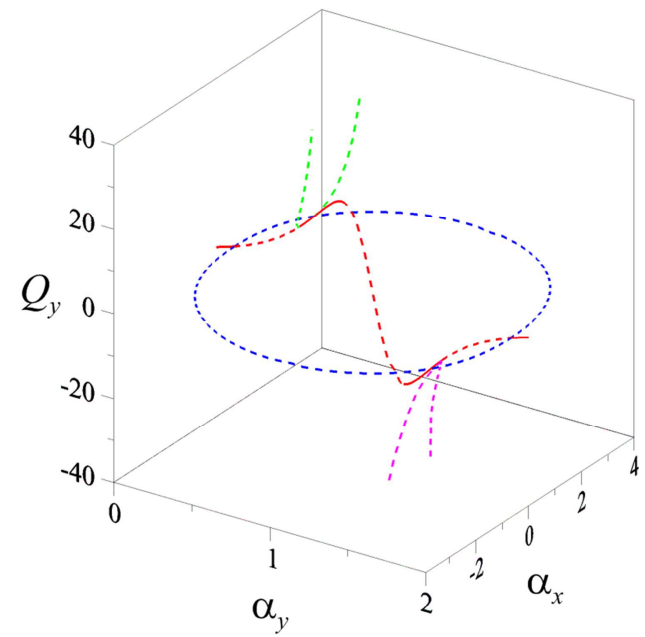

(e) $\theta=74^{\circ}$ : vista $\alpha_{x} \times \alpha_{y} \times Q_{y}$.

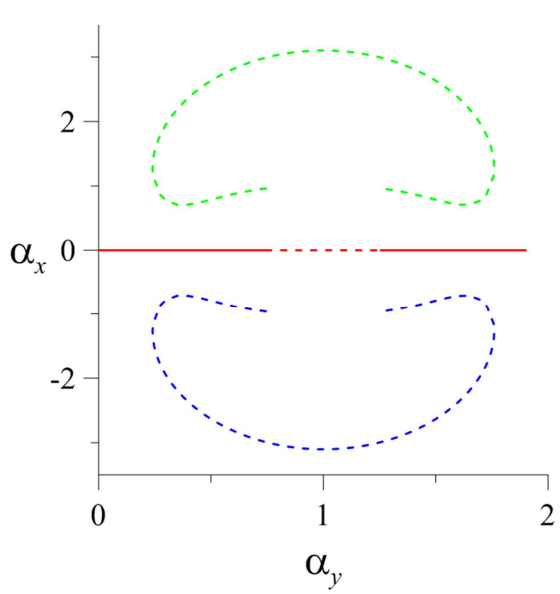

(b) $\theta=69^{\circ}$ : projeção $\alpha_{x} \times \alpha_{y}$.

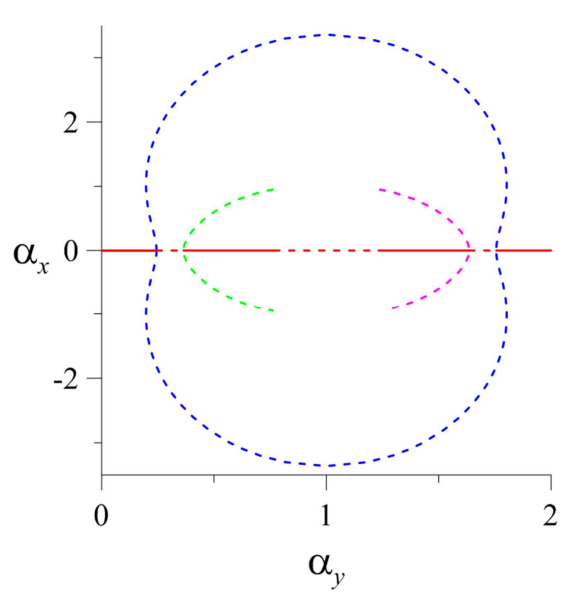

(d) $\theta=71^{\circ}$ : projeção $\alpha_{x} \times \alpha_{y}$.

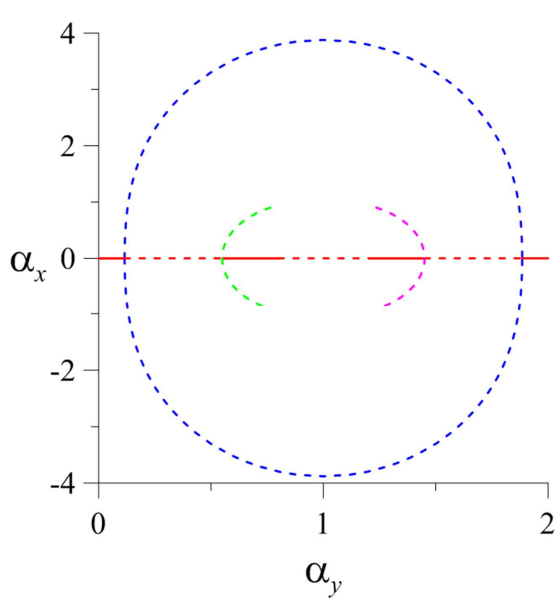

(f) $\theta=74^{\circ}$ : projeção no $\alpha_{x} \times \alpha_{y}$.

Figura 4.8: Caminhos de equilíbrio da treliça com carga vertical para $\theta=69^{\circ}, 71^{\circ}$ e $74^{\circ}$. 


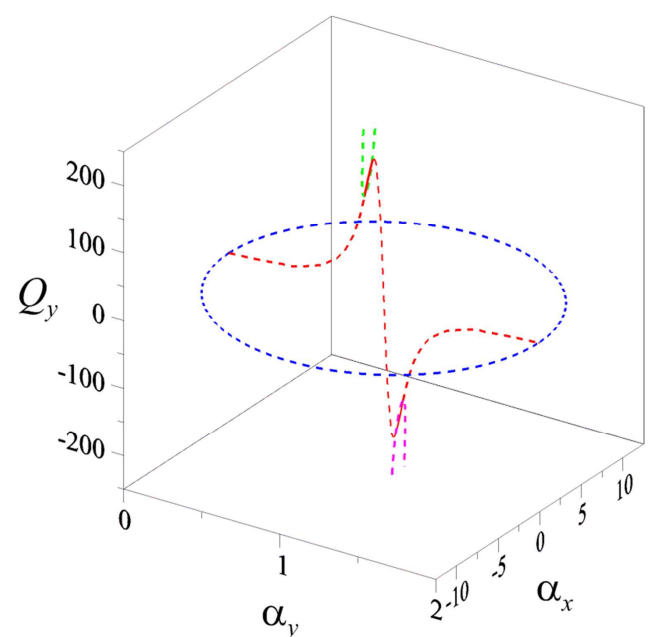

(a) Vista $\alpha_{x} \times \alpha_{y} \times Q_{y}$.

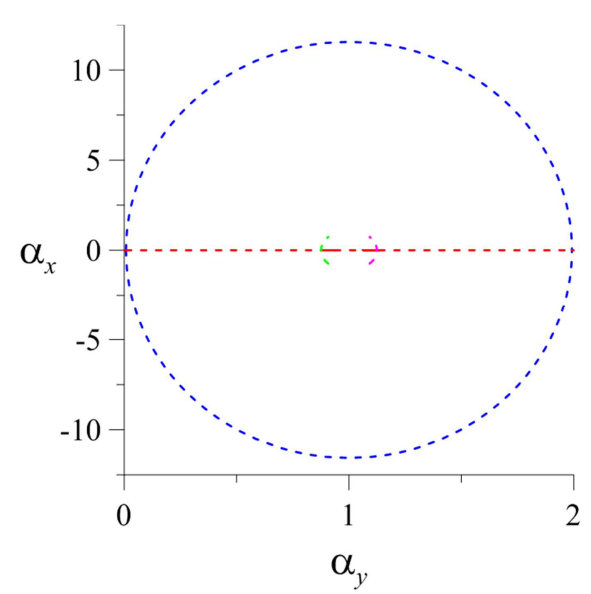

(b) Projeção $\alpha_{x} \times \alpha_{y}$.

Figura 4.9: Caminhos de equilíbrio da treliça com carga vertical e $\theta=85^{\circ}$.

Diante do apresentado, analisam-se a seguir nesta dissertação com mais detalhe as treliças com ângulos de abatimento iguais a $15^{\circ}$ e $75^{\circ}$. Estes ângulos permitem avaliar os dois tipos de cenário observados nas trajetórias de equilíbrio: três caminhos independentes e quatro caminhos que se interceptam, conforme exposto nas Figuras 4.5 a 4.9 .

A Figura 4.10 apresenta quatro projeções dos caminhos de equilíbrio para o ângulo de abatimento igual a $15^{\circ}$ e a Figura 4.12 apresenta quatro projeções dos caminhos de equilíbrio para $\theta=75^{\circ}$.

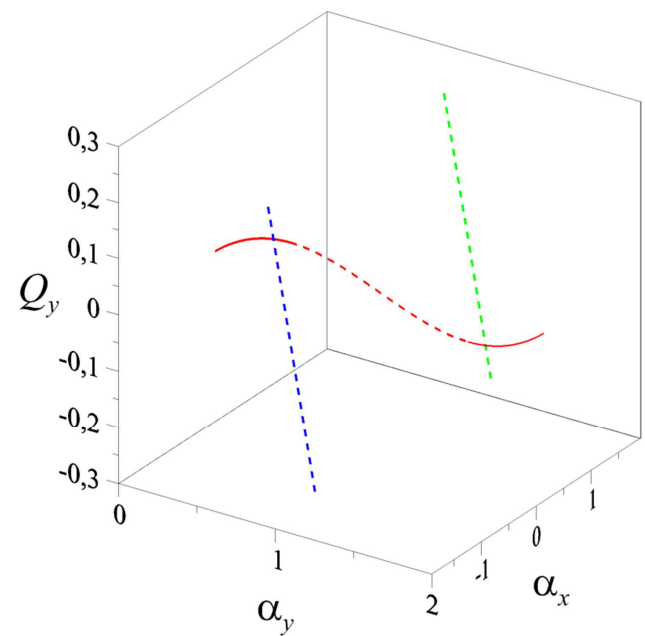

(a) Vista $\alpha_{x} \times \alpha_{y} \times Q_{y}$.

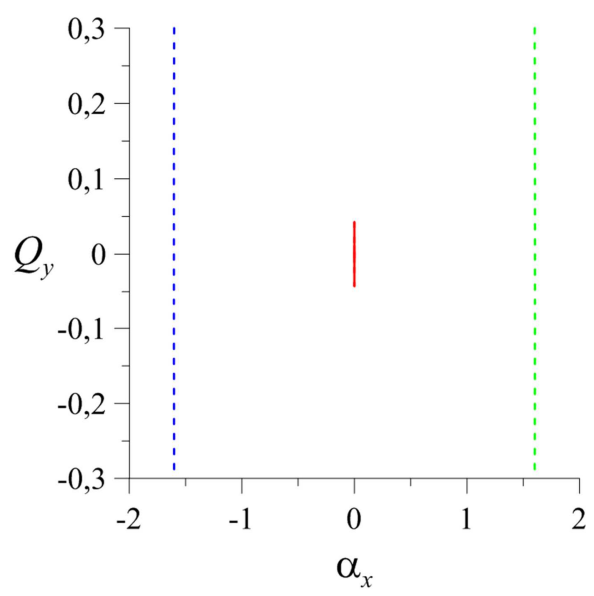

(b) Projeção $\alpha_{x} \times Q_{y}$. 


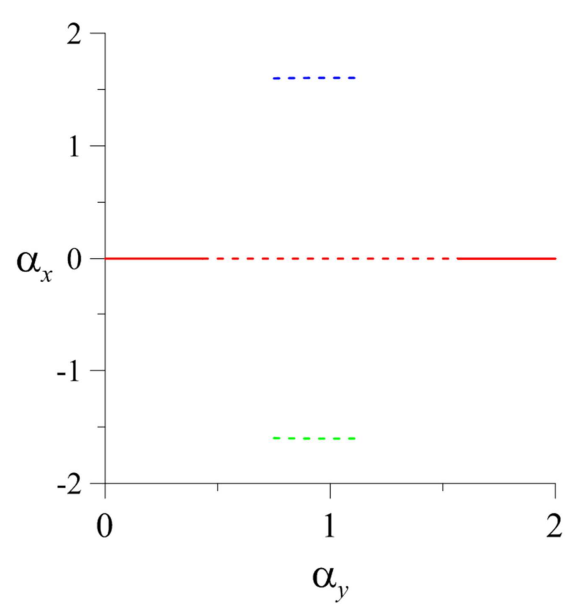

(c) Projeção $\alpha_{x} \times \alpha_{y}$.

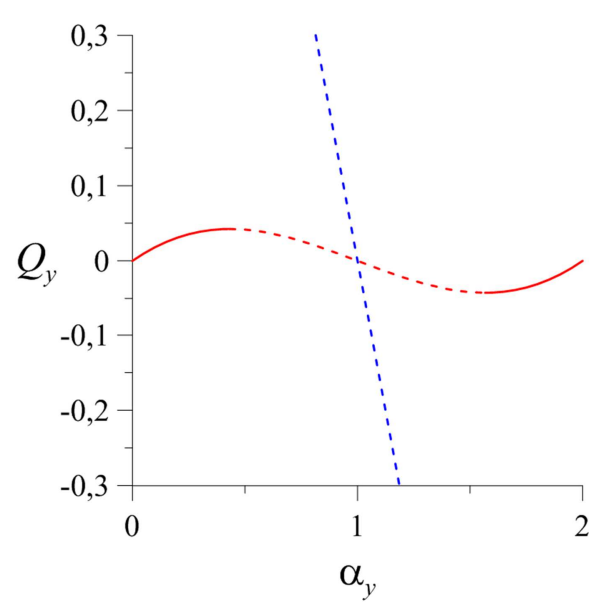

(d) Projeção $\alpha_{y} \times Q_{y}$.

Figura 4.10: Caminhos de equilíbrio da treliça com carga vertical e $\theta=15^{\circ}$.

A Figura 4.11 ilustra as configurações relativas às posições: indeformada, ponto limite $\left(P_{L}\right)$ e pós-crítica $\left(P_{p c r}\right)$ da treliça analisada.

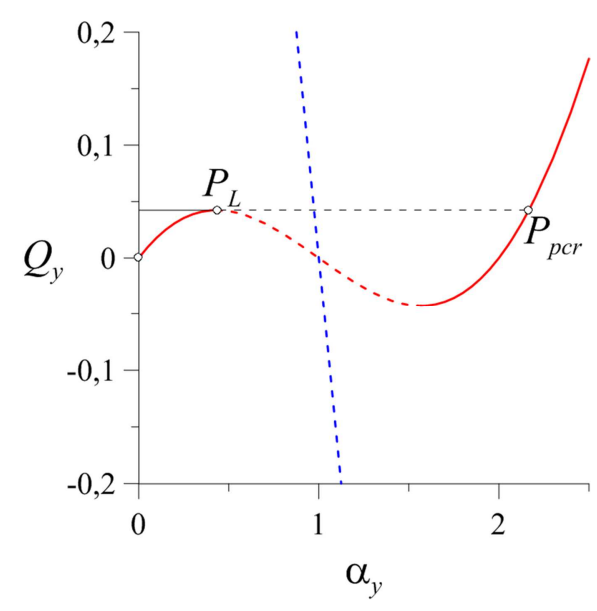

(a) Gráfico $\alpha_{y} \times Q_{y}$.

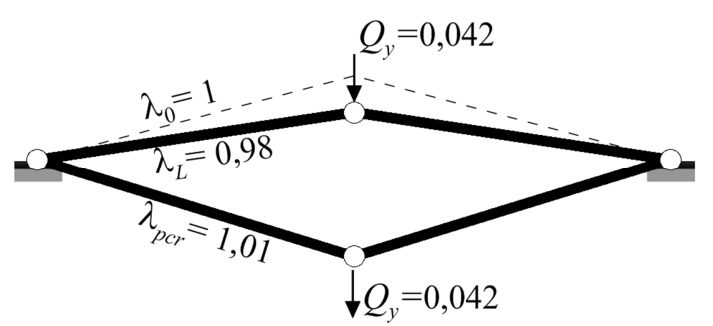

(b) Modelo.

Figura 4.11: Posições críticas para a treliça com carga vertical e $\theta=15^{\circ}$. 


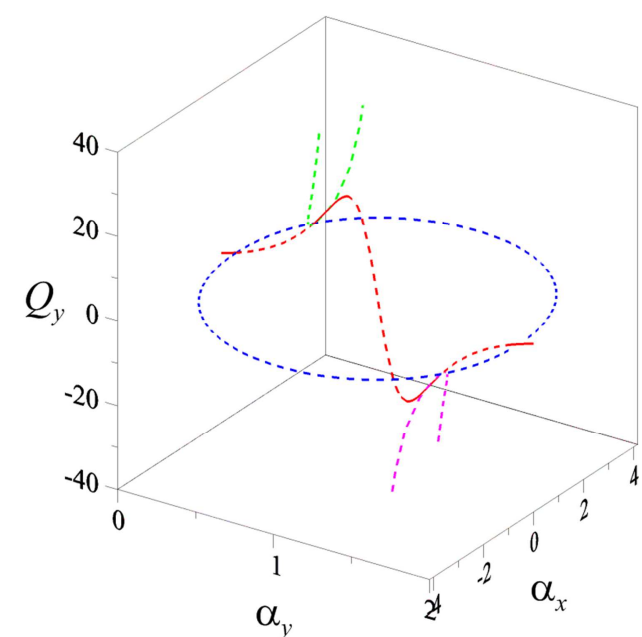

(a) Vista $\alpha_{x} \times \alpha_{y} \times Q_{y}$.

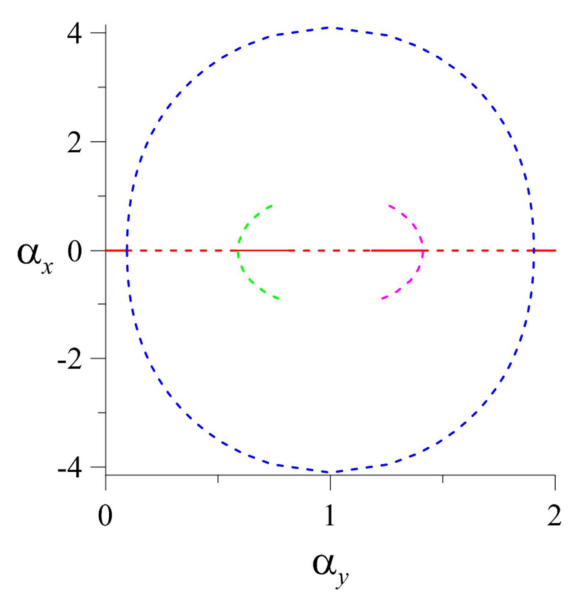

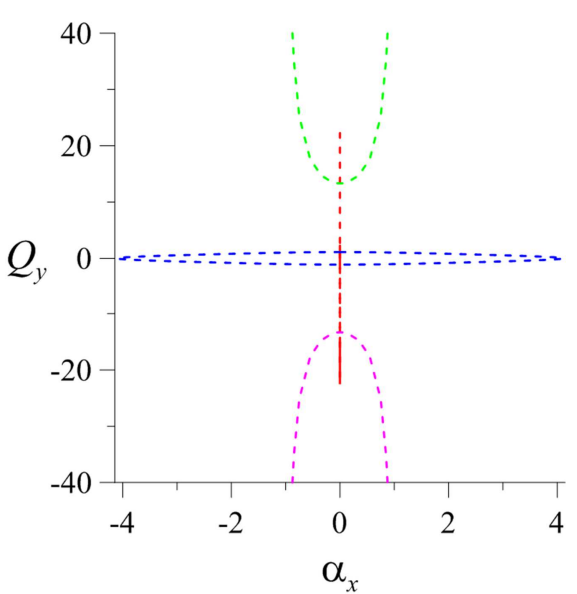

(b) Projeção $\alpha_{x} \times Q_{y}$.

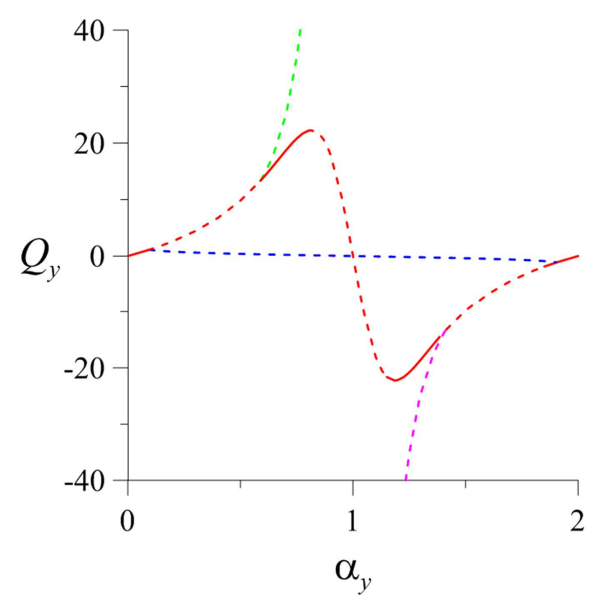

(d) Projeção $\alpha_{y} \times Q_{y}$.

(c) Projeção $\alpha_{x} \times \alpha_{y}$.

Figura 4.12: Caminhos de equilíbrio da treliça com carga vertical e $\theta=75^{\circ}$.

A Figura 4.13 ilustra a treliça nas três posições críticas de sua trajetória fundamental. Estas posições com as respectivas posições pós-críticas são assinaladas no gráfico $\alpha_{y} \times Q_{y}$.

Observa-se nas Figuras 4.11 e 4.13 , que para a treliça com $\theta=15^{\circ}$, as deformações na posição do ponto limite são superiores a sua posição pós-crítica, indicando que a não linearidade da estrutura influencia de forma significativa sua capacidade de carga. Para a treliça com $\theta=75^{\circ}$, comparando-se as deformações na posição crítica $\left(P_{B 1}, P_{B 2}\right.$ e $\left.P_{L}\right)$ e pós-crítica $\left(P_{p c r l}, P_{p c r 2}\right.$ e $\left.P_{p c r 3}\right)$, nota-se a não linearidade do material apresentada no Capítulo 2. 


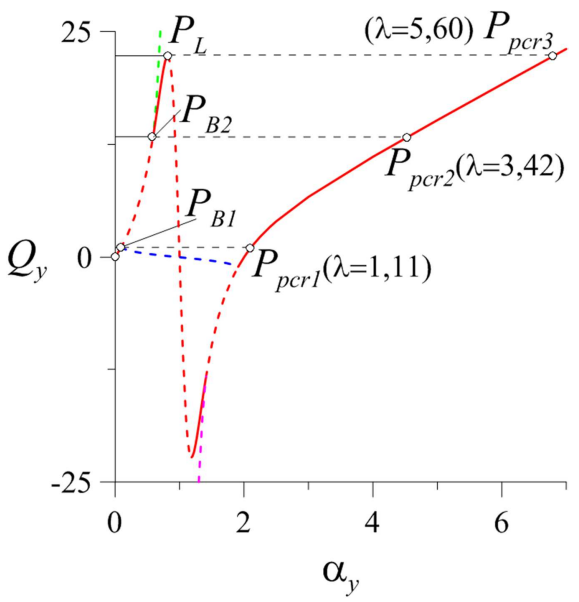

(a) $\alpha_{y} \times Q_{y}$.

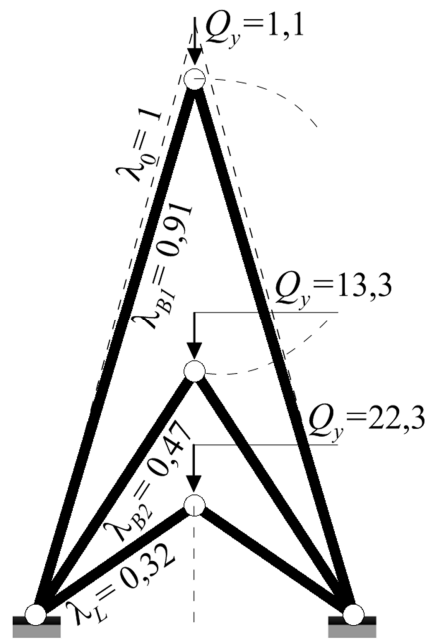

(b) Modelo.

Figura 4.13: Posições críticas para a treliça com carga vertical e $\theta=75^{\circ}$.

\subsection{2.}

\section{Ângulo limite}

Como observado no item anterior, os caminhos de equilíbrio da treliça e a sua forma de perder a estabilidade mudam de forma significativa com o ângulo $\theta$. Há um ângulo específico que estabelece o limite entre a perda de estabilidade por ponto limite ou bifurcação simétrica instável. O ângulo que estabelece essa fronteira para a treliça neo-Hookeana é $\theta_{\lim }=70,76^{\circ}$. A Figura 4.14 apresenta os caminhos de equilíbrio para este ângulo.

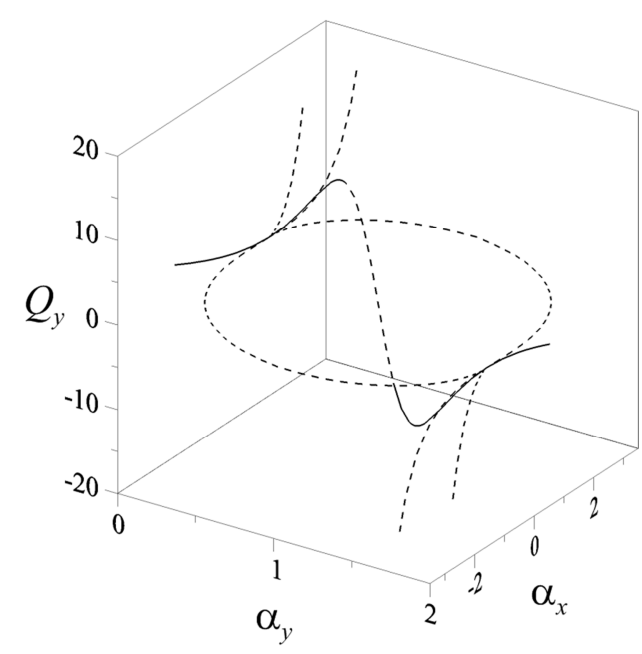

(a) Vista $\alpha_{x} \times \alpha_{y} \times Q_{y}$.

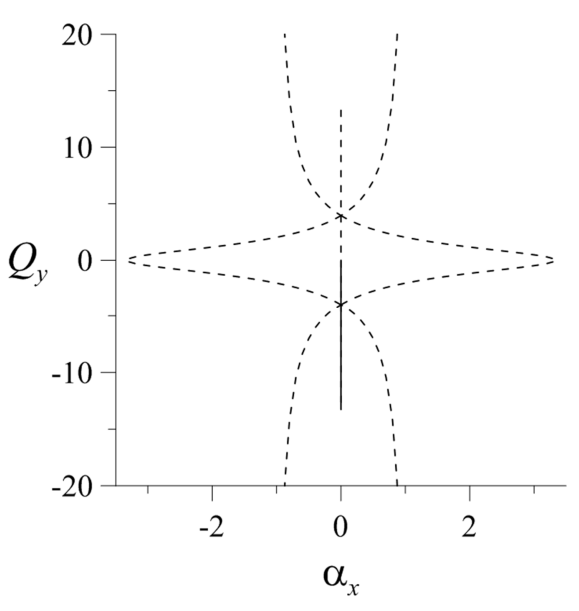

(b) Projeção $\alpha_{x} \times Q_{y}$. 


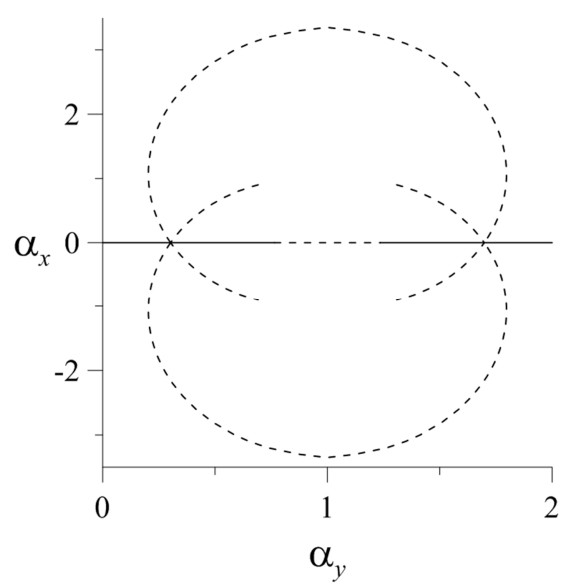

(c) Projeção $\alpha_{x} \times \alpha_{y}$.

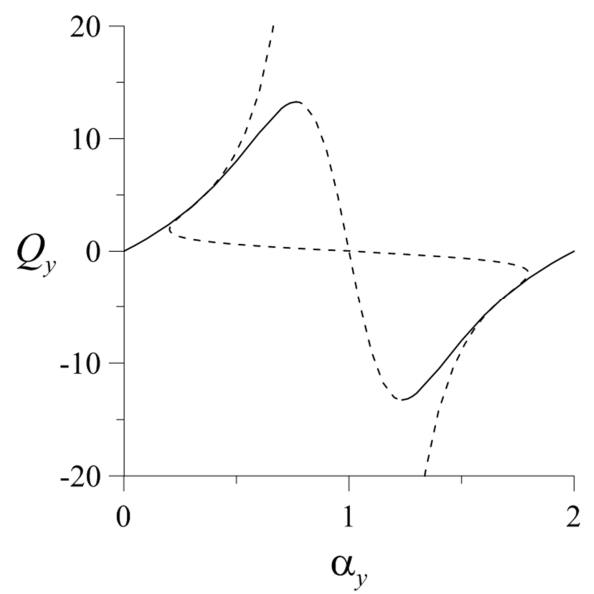

(d) Projeção $\alpha_{y} \times Q_{y}$.

Figura 4.14: Caminhos de equilíbrio da treliça com carga vertical e $\theta_{\lim }=70,76^{\circ}$.

No trabalho de von Mises (1925) encontram-se as equações que descrevem o comportamento não linear da treliça quando submetida à carga estática vertical e a variação das cargas de bifurcação com o ângulo $\theta$.

Aqui neste trabalho, seguindo a mesma metodologia, mostra-se na Figura 4.15 para a treliça de material neo-Hookeano como variam as cargas críticas no caminho fundamental da estrutura em função do seu ângulo de abatimento $\theta$.

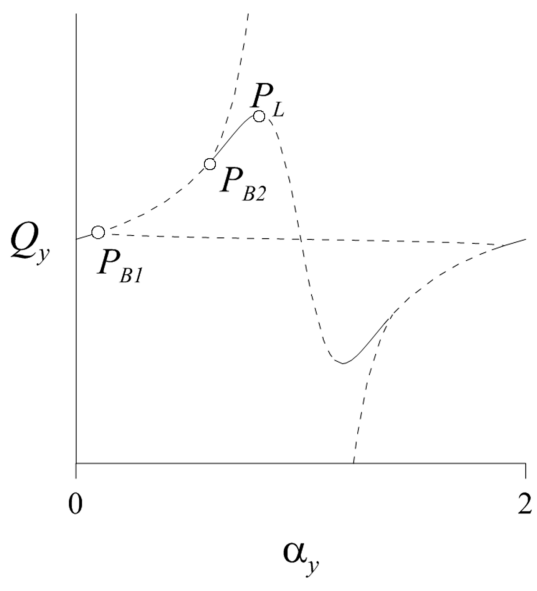

(a) Pontos críticos.

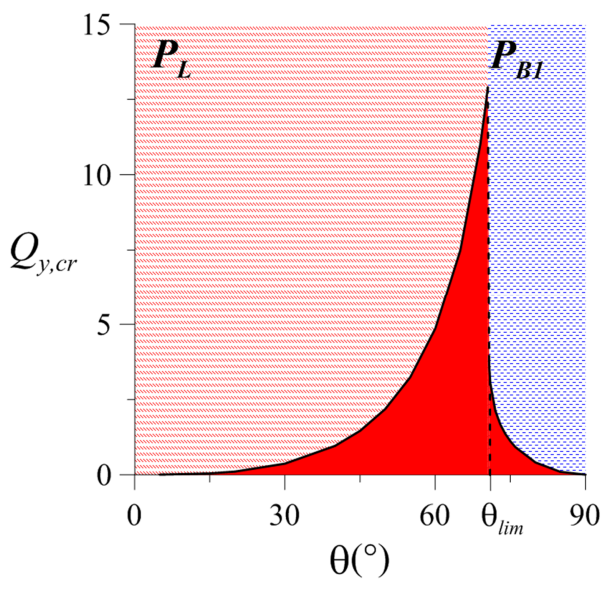

(b) $\theta \times Q_{y, c r}$.

Figura 4.15: Variação da carga crítica com o ângulo de abatimento. 
De acordo com a Figura 4.15, treliças com ângulo de abatimento menor que $\theta_{\lim }$, perdem a estabilidade por ponto limite $\left(Q_{y, c r}=Q\left(P_{L}\right)\right)$, caso contrário, por bifurcação simétrica instável $\left(Q_{y, c r}=Q\left(P_{B I}\right)\right)$. Assim para ângulos inferiores ao $\theta_{\lim }$, os pontos de bifurcação $P_{B 1}$ e $P_{B 2}$ não existem; para $\theta=\theta_{\lim }, P_{B 1} \equiv P_{B 2}$ e para ângulos superiores ao $\theta_{\lim }$, acontece a situação ilustrada na Figura 4.13a. Ressaltase que, para este caso, quanto maior for o ângulo de abatimento, maior será o trecho instável entre $P_{B 1}$ e $P_{B 2}$, com $P_{B 1}$ se aproximando da origem e $P_{B 2}$ de $P_{L}$.

A Figura 4.16 ilustra a solução de von Mises (1925), em preto, para um material elástico linear, comparando com a solução para a treliça hiperelástica, em vermelho.

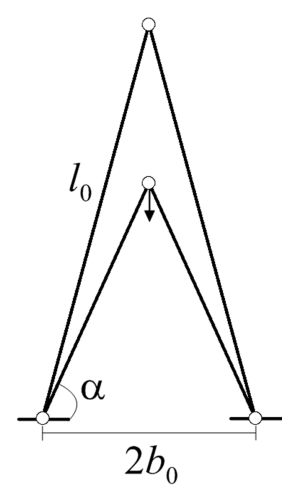

(a) Modelo.

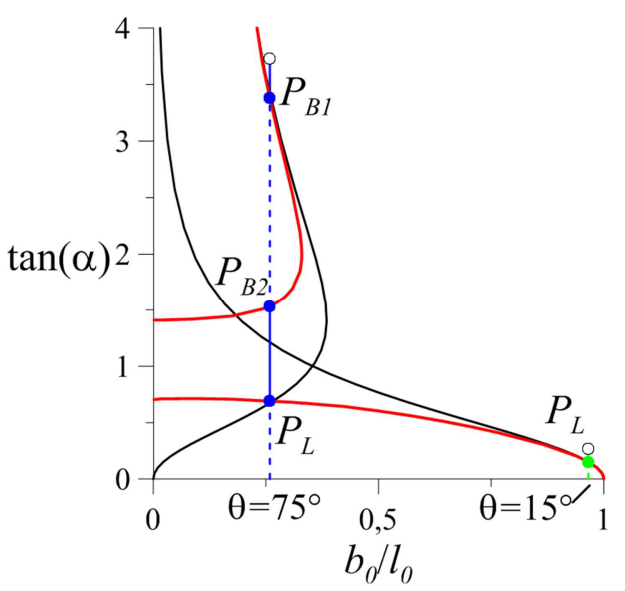

(b) $b_{0} / l_{0} \times \tan (\alpha)$.

Figura 4.16: Treliça elástica de von Mises vs. treliça neo-Hookeana .

Na Figura 4.16, $\alpha$ é o ângulo da treliça na configuração deformada. As funções indicam para cada ângulo $\theta$, os ângulos $\alpha$ no qual a treliça perde a estabilidade. Cada função representa um tipo de instabilidade: ponto limite ou bifurcação. Por exemplo, para o ângulo $\theta=75^{\circ}$ (cor azul): o primeiro ponto em branco indica a posição indeformada do nó superior da treliça, os dois pontos seguintes indicam bifurcação e o último ponto limite. Para a treliça com $\theta=15^{\circ}$ (cor verde) só há esta instabilidade.

$\mathrm{Na}$ Figura 4.16, fica evidente a diferença entre o comportamento de uma treliça elástica e uma hiperelástica, não só em termos das bifurcações, mas também em termos da capacidade de carga. 
Para ângulos próximos de $\theta=90^{\circ}$ o trecho entre a segunda carga crítica e a terceira diminui bastante, quando comparado ao tamanho total do trecho entre o ponto da treliça descarregada e o ponto limite. A Figura 4.17 esclarece isto traçando as trajetórias de equilíbrio da treliça para um ângulo $\theta=89,9^{\circ}$.

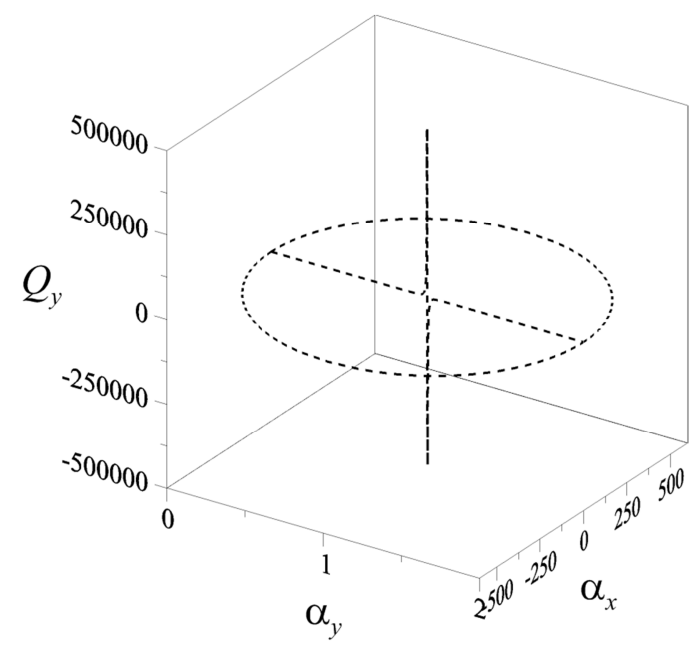

(a) Vista $\alpha_{x} \times \alpha_{y} \times Q_{y}$.

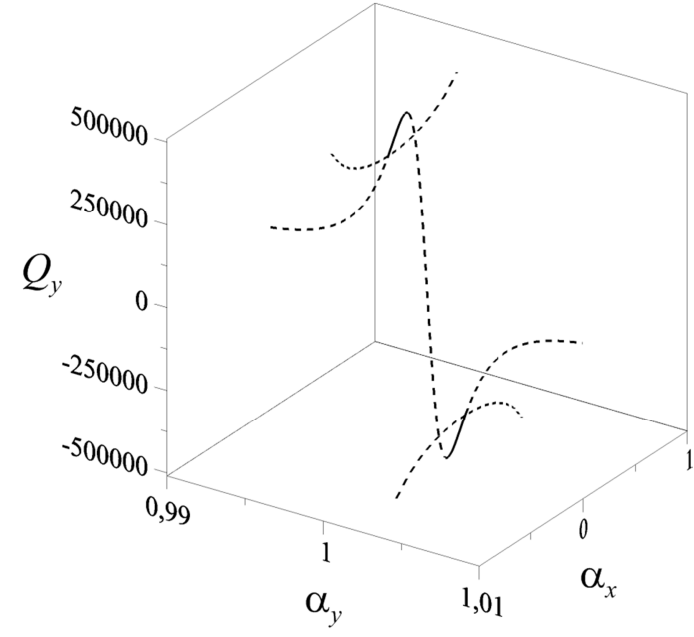

(b) Vista $\alpha_{x} \times \alpha_{y} \times Q_{y}$ ampliada.

Figura 4.17: Caminhos de equilíbrio da treliça com carga vertical e $\theta=89,9^{\circ}$.

\subsection{3.}

\section{Influência das imperfeições}

A presença de imperfeições altera a carga máxima que a estrutura pode suportar e possibilita uma compreensão do comportamento não linear de estruturas reais, naturalmente imperfeitas.

A energia potencial total para a treliça com imperfeição de carga é dada pela seguinte equação:

$$
\begin{aligned}
& \bar{\Pi}_{I C}=2\left(\alpha_{y}{ }^{2}-2 \alpha_{y}-2-\left(\alpha_{y}{ }^{2}-\alpha_{x}^{2}-2 \alpha_{y}\right) \cos ^{2}(\theta)+\right. \\
& \frac{1}{\sqrt{\left(\alpha_{y}-1\right)^{2}-\left(\alpha_{y}^{2}-\alpha_{x}^{2}-2 \alpha_{y}-2 \alpha_{x}\right) \cos ^{2}(\theta)}}+ \\
& \left.\frac{1}{\sqrt{\left(\alpha_{y}-1\right)^{2}-\left(\alpha_{y}^{2}-\alpha_{x}^{2}-2 \alpha_{y}+2 \alpha_{x}\right) \cos ^{2}(\theta)}}\right) \\
& -Q_{y} \alpha_{y} \operatorname{sen}(\theta)-0,01 Q_{y} \alpha_{x} \cos (\theta)
\end{aligned}
$$


As equações não lineares de equilíbrio são dadas por:

$$
\begin{aligned}
& \operatorname{sen}(\theta)\left(4 \alpha_{y}-4-\frac{2 \alpha_{y}-2}{\left(\left(\alpha_{y}-1\right)^{2}-\left(\alpha_{y}{ }^{2}-\alpha_{x}^{2}-2 \alpha_{y}-2 \alpha_{x}\right) \cos ^{2}(\theta)\right)^{3 / 2}}\right)-Q_{y}=0 \\
& \left.-\frac{2 \alpha_{y}-2}{\left(\left(\alpha_{y}-1\right)^{2}-\left(\alpha_{y}{ }^{2}-\alpha_{x}{ }^{2}-2 \alpha_{y}+2 \alpha_{x}\right) \cos ^{2}(\theta)\right)^{3 / 2}}\right) \\
& \cos (\theta)\left(4 \alpha_{x}-\frac{2 \alpha_{x}+2}{\left(\left(\alpha_{y}-1\right)^{2}-\left(\alpha_{y}{ }^{2}-\alpha_{x}{ }^{2}-2 \alpha_{y}-2 \alpha_{x}\right) \cos ^{2}(\theta)\right)^{3 / 2}}\right. \\
& \left.-\frac{2 \alpha_{x}-2}{\left(\left(\alpha_{y}-1\right)^{2}-\left(\alpha_{y}{ }^{2}-\alpha_{x}{ }^{2}-2 \alpha_{y}+2 \alpha_{x}\right) \cos ^{2}(\theta)\right)^{3 / 2}}\right)-0,01 Q_{y}=0
\end{aligned}
$$

A energia potencial total para estrutura com imperfeição geométrica e as equações não lineares de equilíbrio são dadas, respectivamente, por:

$$
\begin{aligned}
& \bar{\Pi}_{I G}=\frac{b_{1}}{b_{0}}\left(\left(\frac{b_{0}}{b_{1}}\right)^{2}\left(\left(\operatorname{sen}(\theta)-\alpha_{y} \operatorname{sen}(\theta)\right)^{2}+\left(\cos (\theta)+\alpha_{x} \cos (\theta)\right)^{2}\right)\right. \\
& \left.+\frac{b_{1}}{b_{0}} \frac{2}{\sqrt{\left(\operatorname{sen}(\theta)-\alpha_{y} \operatorname{sen}(\theta)\right)^{2}+\left(\cos (\theta)+\alpha_{x} \cos (\theta)\right)^{2}}}-3\right) \\
& +\frac{b_{1}}{b_{0} r}\left(\left(\frac{b_{0} r}{b_{1}}\right)^{2}\left(\left(\operatorname{sen}(\theta)-\alpha_{y} \operatorname{sen}(\theta)\right)^{2}+\left(\cos (\theta)-\alpha_{x} \cos (\theta)\right)^{2}\right)\right. \\
& \left.+\frac{b_{1}}{b_{0} r} \frac{2}{\sqrt{\left(\operatorname{sen}(\theta)-\alpha_{y} \operatorname{sen}(\theta)\right)^{2}+\left(\cos (\theta)-\alpha_{x} \cos (\theta)\right)^{2}}}-3\right) \\
& -Q_{y} \alpha_{y} \operatorname{sen}(\theta) ;
\end{aligned}
$$




$$
\begin{aligned}
& \left(\left(\frac{b_{1}}{b_{0}}\right)^{2} \frac{2\left(\operatorname{sen}(\theta)-\alpha_{y} \operatorname{sen}(\theta)\right)}{\left(\left(\operatorname{sen}(\theta)-\alpha_{y} \operatorname{sen}(\theta)\right)^{2}+\left(\cos (\theta)+\alpha_{x} \cos (\theta)\right)^{2}\right)^{3 / 2}}\right. \\
& -\left(\frac{2 b_{0}}{b_{1}}\right)\left(\operatorname{sen}(\theta)-\alpha_{y} \operatorname{sen}(\theta)\right) \\
& +\left(\left(\frac{b_{1}}{b_{0} r}\right)^{2} \frac{2\left(\operatorname{sen}(\theta)-\alpha_{y} \operatorname{sen}(\theta)\right)}{\left(\left(\operatorname{sen}(\theta)-\alpha_{y} \operatorname{sen}(\theta)\right)^{2}+\left(\cos (\theta)-\alpha_{x} \cos (\theta)\right)^{2}\right)^{3 / 2}}\right. \\
& \left.-\left(\frac{2 b_{0} r}{b_{1}}\right)\left(\operatorname{sen}(\theta)-\alpha_{y} \operatorname{sen}(\theta)\right)\right)-Q_{y}=0 \\
& \left(\left(\frac{2 b_{0}}{b_{1}}\right)\left(\cos ^{2}(\theta)+\alpha_{x} \cos ^{2}(\theta)\right)\right. \\
& \left.-\left(\frac{b_{1}}{b_{0}}\right)^{2} \frac{2\left(\cos ^{2}(\theta)+\alpha_{x} \cos ^{2}(\theta)\right)}{\left(\left(\operatorname{sen}(\theta)-\alpha_{y} \operatorname{sen}(\theta)\right)^{2}+\left(\cos (\theta)+\alpha_{x} \cos (\theta)\right)^{2}\right)^{3 / 2}}\right) \\
& +\left(\left(\frac{b_{1}}{b_{0} r}\right)^{2} \frac{2\left(\cos ^{2}(\theta)-\alpha_{x} \cos ^{2}(\theta)\right)}{\left(\left(\operatorname{sen}(\theta)-\alpha_{y} \operatorname{sen}(\theta)\right)^{2}+\left(\cos (\theta)-\alpha_{x} \cos (\theta)\right)^{2}\right)^{3 / 2}}\right. \\
& \left.-\left(\frac{2 b_{0} r}{b_{1}}\right)\left(\cos ^{2}(\theta)-\alpha_{x} \cos ^{2}(\theta)\right)\right)=0 \text {. }
\end{aligned}
$$

A treliça com $\theta=15^{\circ}$ perde a estabilidade por ponto limite e apresenta pequena sensibilidade à imperfeição. A imperfeição de carga (perturbação horizontal de $0,01 p_{y}$ ) apresenta poucas alterações em relação ao modelo perfeito em virtude da magnitude da imperfeição de carga adotada. A Figura 4.18 exibe os caminhos de equilíbrio da treliça com imperfeição geométrica (projeções das barras na direção $x$ são alteradas em 5\% - ver Fig. 3.5). 


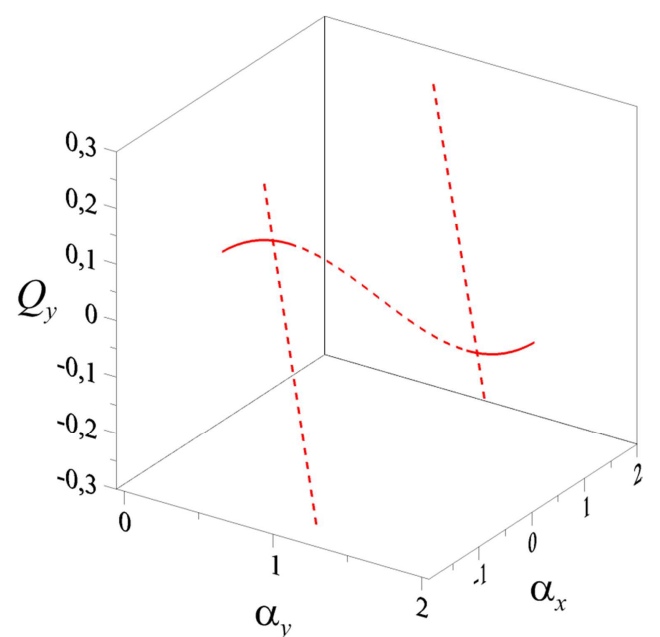

(a) Vista $\alpha_{x} \times \alpha_{y} \times Q_{y}$.

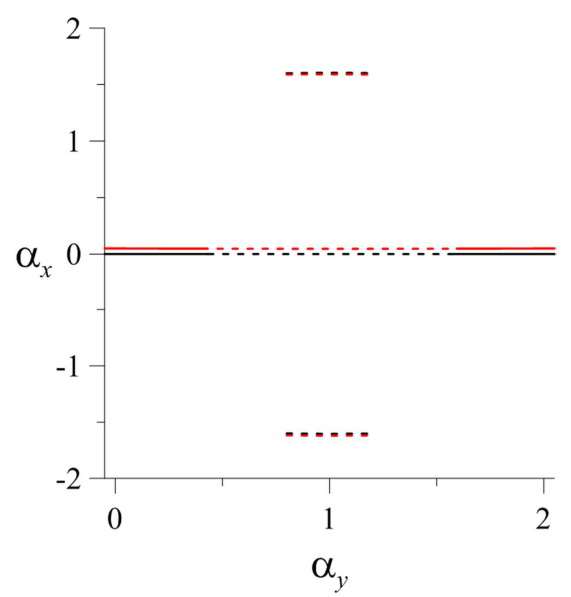

(c) Projeção $\alpha_{x} \times \alpha_{y}$.

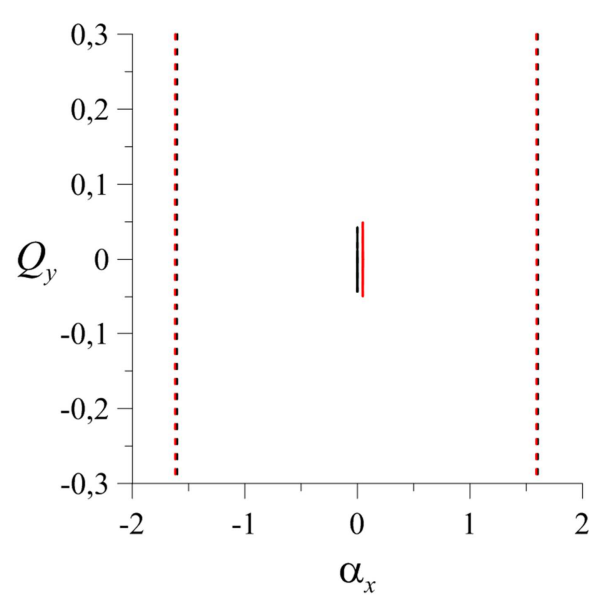

(b) Projeção $\alpha_{x} \times Q_{y}$.

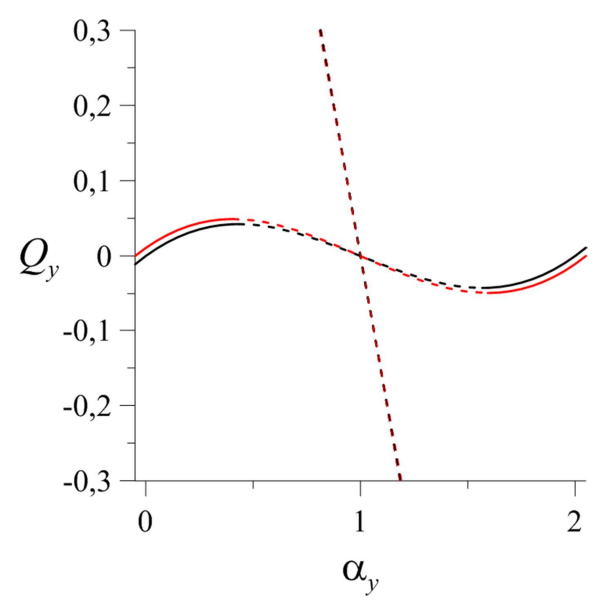

(d) Projeção $\alpha_{y} \times Q_{y}$.

Figura 4.18: Caminhos de equilíbrio da treliça com carga vertical, imperfeição geométrica e $\theta=15^{\circ}$.

A trajetória em preto nas projeções da Figura 4.16 representa o caminho perfeito. Nota-se que o caminho fundamental em vermelho, em forma de "S", distancia-se levemente da trajetória da estrutura perfeita e há um pequeno aumento da carga limite. As trajetórias complementares da treliça imperfeita apresentam também uma pequena alteração em relação às perfeitas. Estas diferenças crescem com o nível da imperfeição.

Como observado por Thompson \& Hunt (1984), perturbações em torno de um ponto limite não modificam o tipo de bifurcação, que continua sendo do tipo nó-sela. Este tipo de bifurcação apresenta pequena sensibilidade a imperfeições. 
A Figura 4.19 apresenta como varia a carga limite em função da imperfeição adotada $\left(\left(b_{1} / b_{0}-1\right) \times 100\right)$, onde se observa um aumento da carga limite.

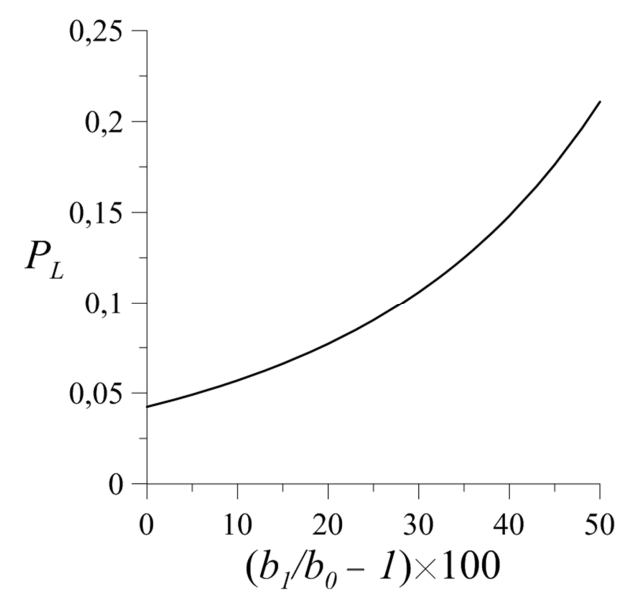

Figura 4.19: Sensibilidade à imperfeição geométrica para a treliça com carga vertical e $\theta=15^{\circ}$.

A Figura 4.20 apresenta a variação da carga limite com os deslocamentos nas direções $x\left(\alpha_{x}-\left(b_{1}-b_{0}\right)\right)$ e $y\left(\alpha_{y}+\left(b_{1}-b_{0}\right)\right)$, ressaltando a não sensibilidade à imperfeição geométrica aplicada para a treliça com $\theta=15^{\circ}$.

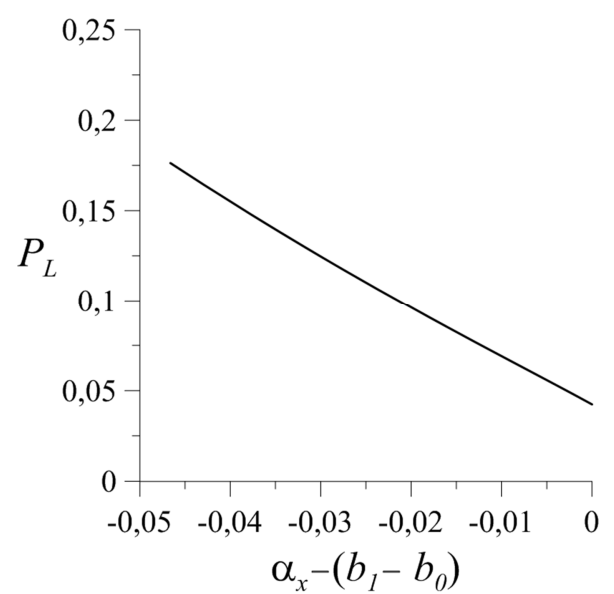

(a) Direção $x$.

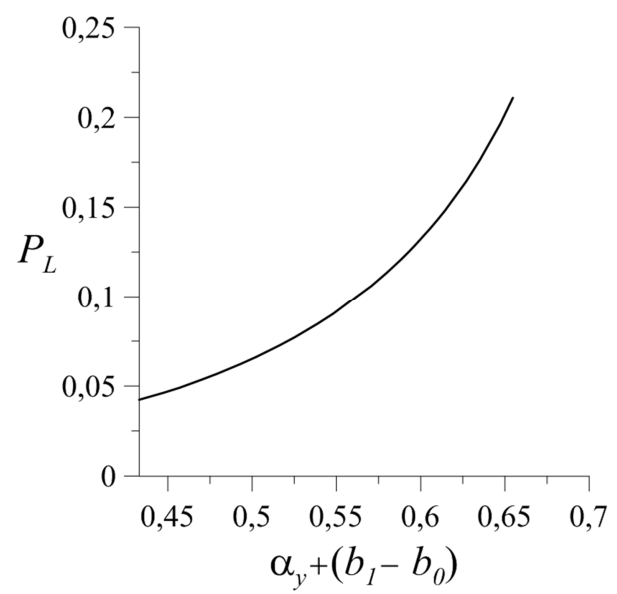

(b) Direção $y$.

Figura 4.20: Variação da carga limite com o deslocamento em função da imperfeição aplicada (0 a 50\%) para a treliça imperfeita com carga vertical e $\theta=15^{\circ}$. 
A Figura 4.21 apresenta as trajetórias de equilíbrio da treliça com imperfeição de carga (perturbação horizontal de $0,01 p_{y}$ ) e $\theta=75^{\circ}$.

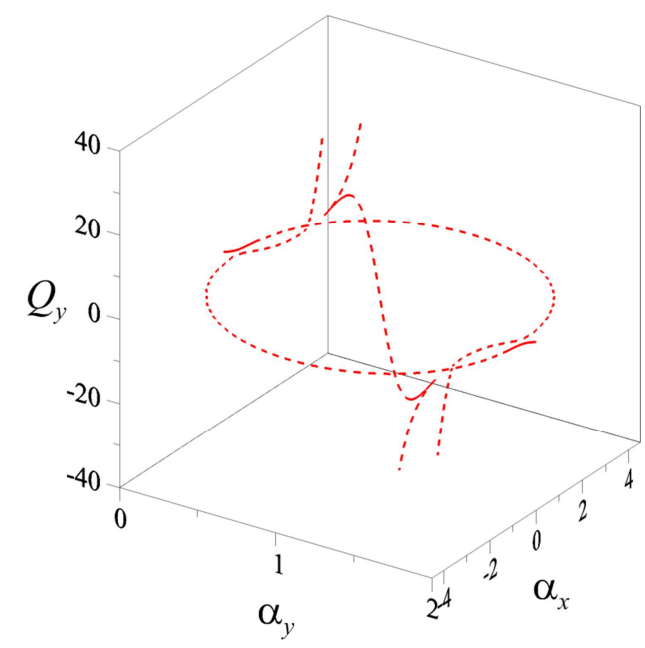

(a) Vista $\alpha_{x} \times \alpha_{y} \times Q_{y}$.

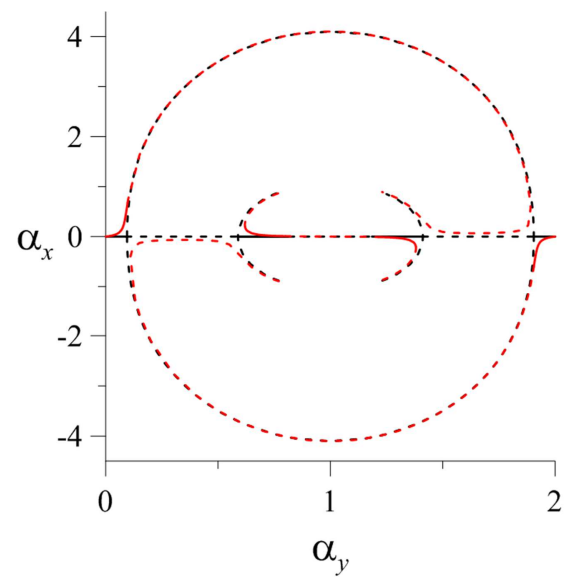

(c) Projeção $\alpha_{x} \times \alpha_{y}$.

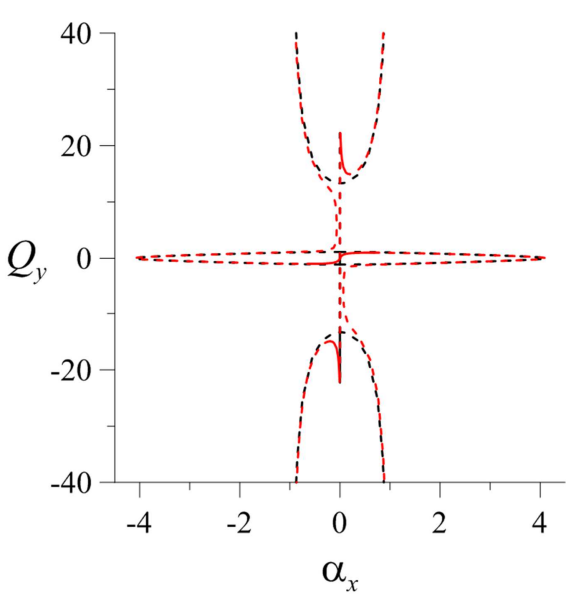

(b) Projeção $\alpha_{x} \times Q_{y}$.

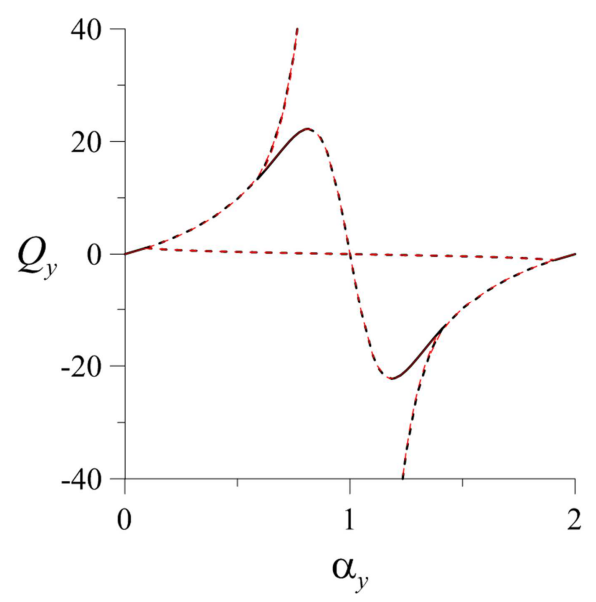

(d) Projeção $\alpha_{y} \times Q_{y}$.

Figura 4.21: Caminhos de equilíbrio da treliça com carga vertical, imperfeição de carga e $\theta=75^{\circ}$.

Observa-se que para o caso perfeito, a treliça com ângulo de abatimento de $75^{\circ}$ perde a estabilidade por bifurcação simétrica instável. Segundo a teoria de Koiter (Croll \& Walker, 1972), a estrutura é sensível à imperfeição e com isso a carga máxima que a estrutura imperfeita suporta é inferior à carga crítica.

Visualizam-se três caminhos de equilíbrio na Figura 4.21. Nota-se que não há mais cruzamento entre as trajetórias e os caminhos imperfeitos margeiam a trajetória perfeita convergindo para esta quando a imperfeição tende a zero. A Figura 4.22 mostra um detalhe da Figura 4.21 na região em torno da bifurcação 
simétrica instável, mostrando o comportamento típico da estrutura imperfeita, que passa agora a perder a estabilidade por ponto limite (Croll \& Walker, 1972). Neste caso houve um decréscimo de 5,6\% na capacidade de carga da estrutura. Observase que o sinal das imperfeições tem influência nas trajetórias de equilíbrio. Caso se modifique o sinal da imperfeição, obtêm-se caminhos de equilíbrio que são o espelho dos caminhos mostrados na Figura 4.21.

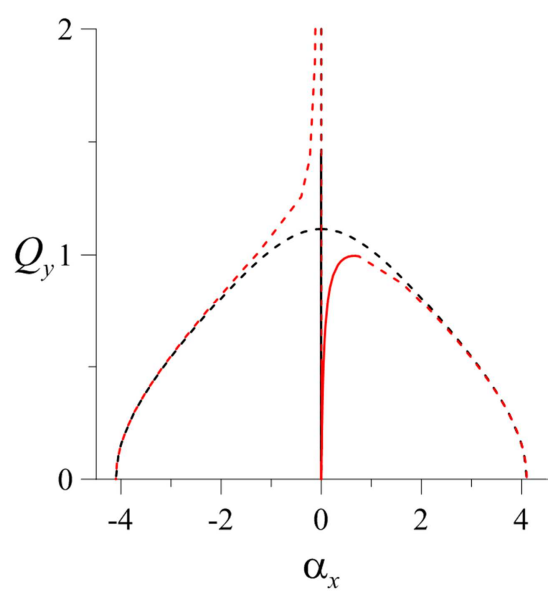

Figura 4.22: Bifurcação simétrica instável para a treliça com $\theta=75^{\circ}$.

A Figura 4.23 apresenta as trajetórias de equilíbrio para a treliça com imperfeição em sua geometria (projeções das barras na direção $x$ são alteradas em $5 \%$ - ver Fig. 3.5) e ângulo de abatimento igual a $75^{\circ}$.

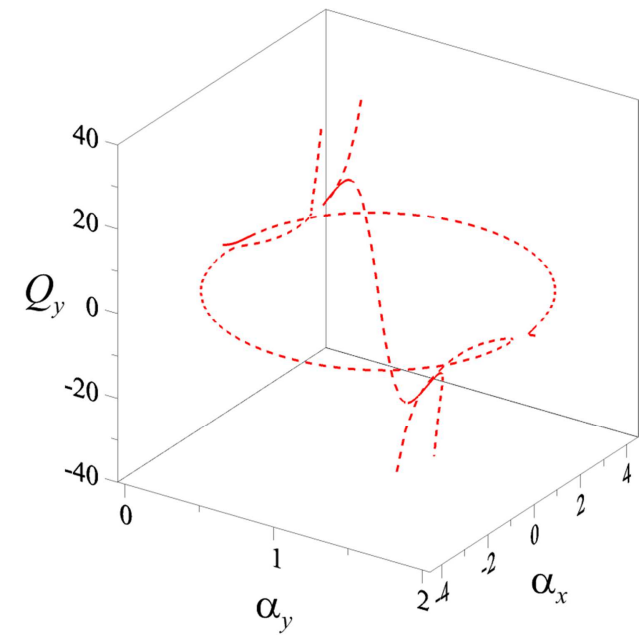

(a) Vista $\alpha_{x} \times \alpha_{y} \times Q_{y}$.

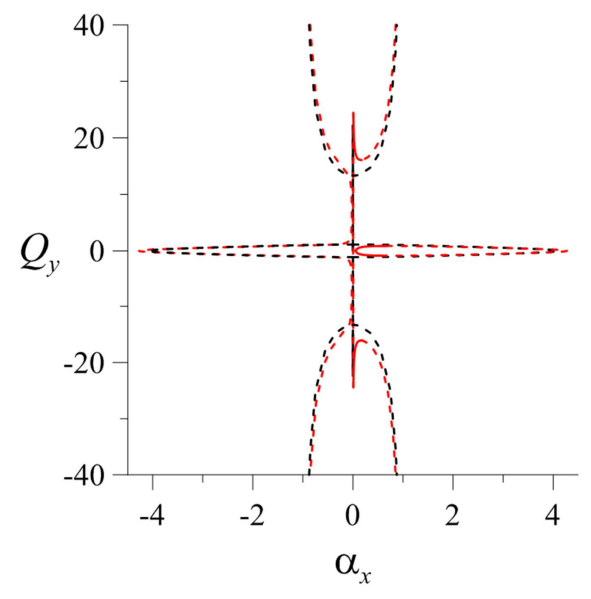

(b) Projeção $\alpha_{x} \times Q_{y}$. 


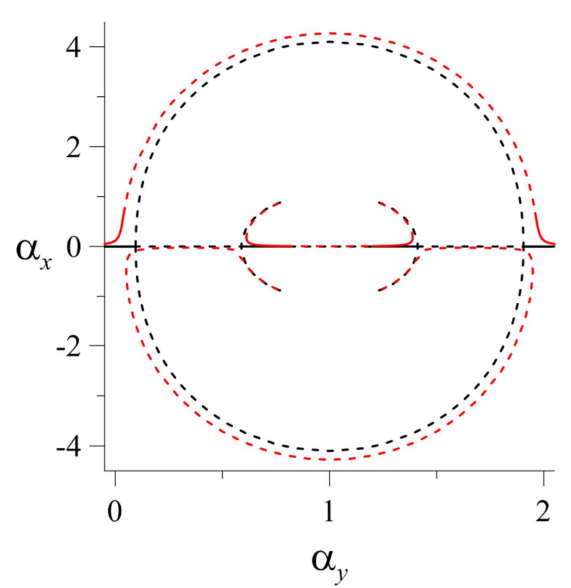

(c) Projeção $\alpha_{x} \times \alpha_{y}$.

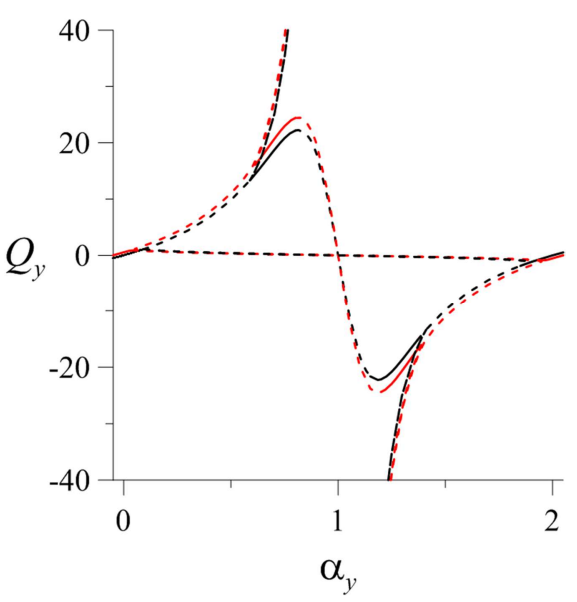

(d) Projeção $\alpha_{y} \times Q_{y}$.

Figura 4.23: Caminhos de equilíbrio da treliça com carga vertical, imperfeição geométrica e $\theta=75^{\circ}$.

Observa-se na Figura 4.23 que a imperfeição geométrica, da mesma forma que a imperfeição de carga, diminui a carga máxima da estrutura em relação ao modelo perfeito, provocando um decréscimo de $17,7 \%$ na capacidade de carga da estrutura. O estudo da sensibilidade à imperfeição é realizado a seguir para a treliça com $\theta=75^{\circ}$.

As Figuras 4.24 e 4.25 apresentam as curvas de sensibilidade da estrutura com $\theta=75^{\circ}$ às imperfeições de carga (vermelho $\left.-P_{B 1} / 100\right)$ e geométrica (azul $\left.\left(b_{1} / b_{0}-1\right) \times 100\right)$ e como variam a carga limite em função do deslocamento do nó da treliça imperfeita em ambas as direções em relação sua posição indeformada.

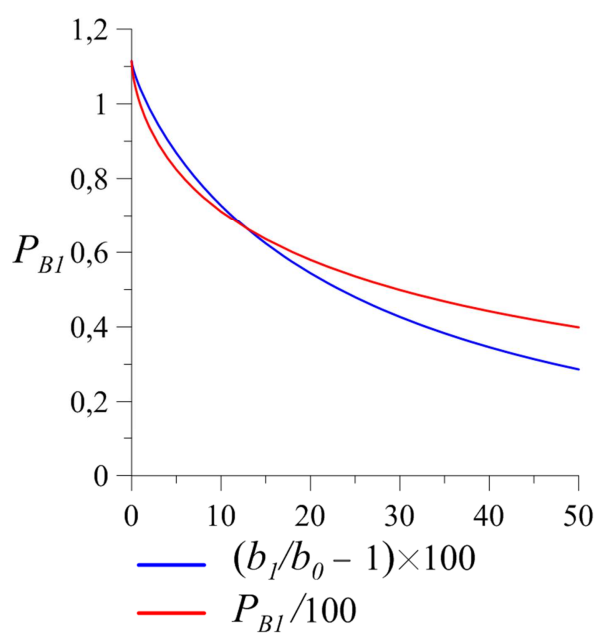

Figura 4.24: Sensibilidade às imperfeições de carga e geométrica para a treliça com carga vertical e $\theta=75^{\circ}$. 


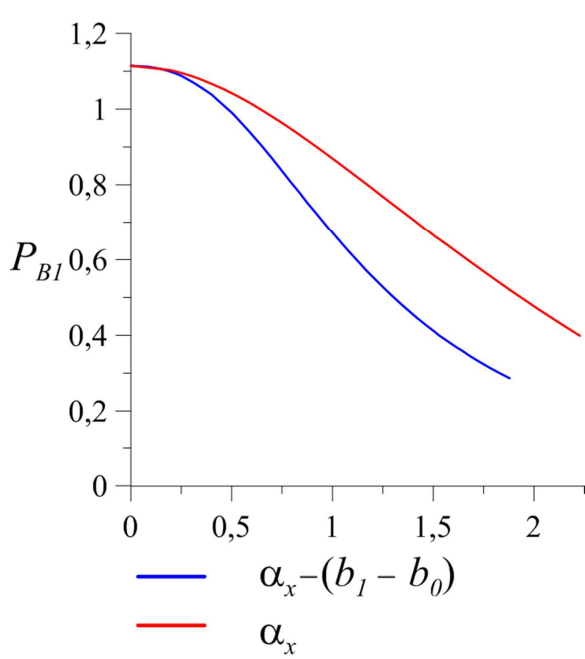

(a) Direção $x$.

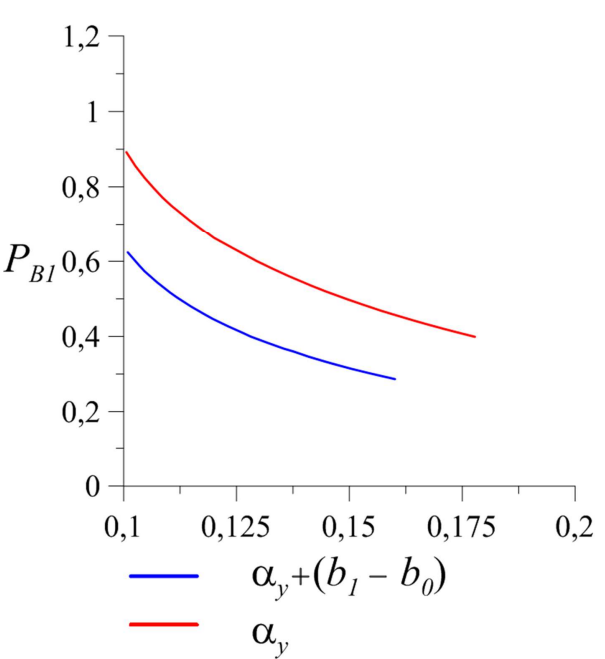

(b) Direção $y$.

Figura 4.25: Variação da carga limite com o deslocamento em função das imperfeições de carga e geométrica aplicada ( 0 a $50 \%$ ) para treliça imperfeita com carga vertical e $\theta=75^{\circ}$.

Salienta-se que os resultados da Figura 4.25, assim como da Figura 4.20, baseiam-se em imperfeições de carga e geométrica de até 50\% de acordo com a Figura 4.24 e Figura 4.19, respectivamente, o que, na realidade, representa uma mudança apreciável no valor e inclinação da carga, no caso de imperfeição de carga, quanto da geometria da treliça, no caso de imperfeição geométrica, levando a uma treliça com grande assimetria.

A partir da Figura 4.25 visualiza-se a influência simultânea da não linearidade do material e geométrica no comportamento não linear para cada caso de imperfeição. Nota-se que a imperfeição geométrica destaca a não linearidade do material nos deslocamentos da direção $x$.

\section{3.}

\section{Carga horizontal}

Analisa-se agora a treliça submetida a uma carga na direção horizontal. Nesta situação há uma completa quebra de simetria do sistema estrutural, tanto devido à carga aplicada como também à não linearidade do material. 


\subsection{1.}

\section{Caminhos de equilíbrio}

A energia potencial total do sistema é dada pela função:

$$
\begin{aligned}
& \bar{\Pi}_{P}=2\left(\alpha_{y}^{2}-2 \alpha_{y}-2-\left(\alpha_{y}^{2}-\alpha_{x}^{2}-2 \alpha_{y}\right) \cos ^{2}(\theta)+\right. \\
& \frac{1}{\sqrt{\left(\alpha_{y}-1\right)^{2}-\left(\alpha_{y}^{2}-\alpha_{x}^{2}-2 \alpha_{y}-2 \alpha_{x}\right) \cos ^{2}(\theta)}}+ \\
& \left.\frac{1}{\sqrt{\left(\alpha_{y}-1\right)^{2}-\left(\alpha_{y}^{2}-\alpha_{x}^{2}-2 \alpha_{y}+2 \alpha_{x}\right) \cos ^{2}(\theta)}}\right)-Q_{x} \alpha_{x} \cos (\theta),
\end{aligned}
$$

sendo o parâmetro de carga $Q_{x}=p_{x} / C_{10} A_{0}$.

As equações não lineares de equilíbrio são dadas por:

$$
\begin{gathered}
\cos (\theta)\left(4 \alpha_{x}-\frac{2 \alpha_{x}+2}{\left(\left(\alpha_{y}-1\right)^{2}-\left(\alpha_{y}{ }^{2}-\alpha_{x}^{2}-2 \alpha_{y}-2 \alpha_{x}\right) \cos ^{2}(\theta)\right)^{3 / 2}}\right)-Q_{x}=0 ; \\
\left.-\frac{2 \alpha_{x}-2}{\left(\left(\alpha_{y}-1\right)^{2}-\left(\alpha_{y}{ }^{2}-\alpha_{x}{ }^{2}-2 \alpha_{y}+2 \alpha_{x}\right) \cos ^{2}(\theta)\right)^{3 / 2}}\right) \\
\operatorname{sen}^{2}(\theta)\left(4 \alpha_{y}-4-\frac{2 \alpha_{y}-2}{\left(\left(\alpha_{y}-1\right)^{2}-\left(\alpha_{y}{ }^{2}-\alpha_{x}{ }^{2}-2 \alpha_{y}-2 \alpha_{x}\right) \cos ^{2}(\theta)\right)^{3 / 2}}\right. \\
\left.-\frac{2 \alpha_{y}-2}{\left(\left(\alpha_{y}-1\right)^{2}-\left(\alpha_{y}{ }^{2}-\alpha_{x}{ }^{2}-2 \alpha_{y}+2 \alpha_{x}\right) \cos ^{2}(\theta)\right)^{3 / 2}}\right)=0 .
\end{gathered}
$$

Assim como para o caso em que a treliça é carregada na direção vertical, a análise foi realizada em detalhe para os ângulos de abatimento iguais a $15^{\circ}$ e $75^{\circ}$.

A Figura 4.26 ilustra as trajetórias de equilíbrio da treliça perfeita com ângulo $\theta=15^{\circ}$. Observa-se a existência de quatro trajetórias de equilíbrio. Uma trajetória estável em vermelho, que corresponde ao caminho inicial de equilíbrio. Este caminho intercepta os caminhos secundários simétricos em azul e roxo no ponto onde o deslocamento horizontal $\alpha_{x}$ atinge um valor máximo. Neste ponto há uma bifurcação simétrica estável, onde os caminhos em azul e roxo mudam a 
estabilidade. Adicionalmente, tem-se um caminho de equilíbrio instável isolado identificado pela cor verde.

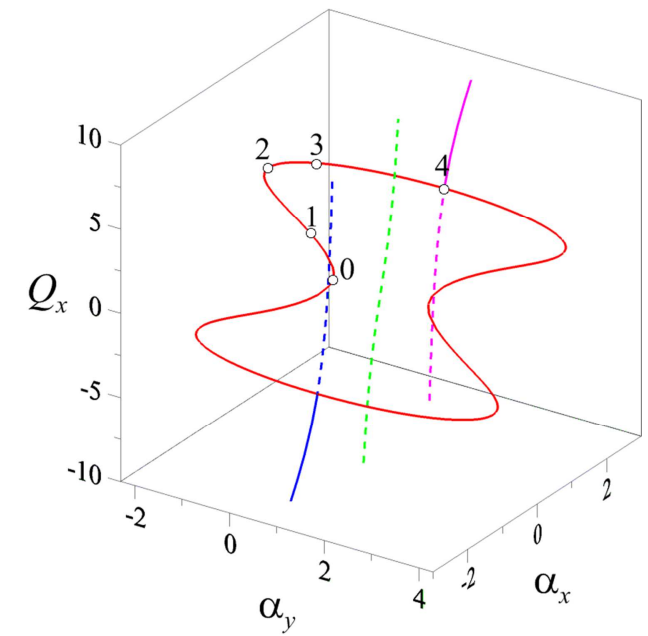

(a) Vista $\alpha_{x} \times \alpha_{y} \times Q_{x}$.

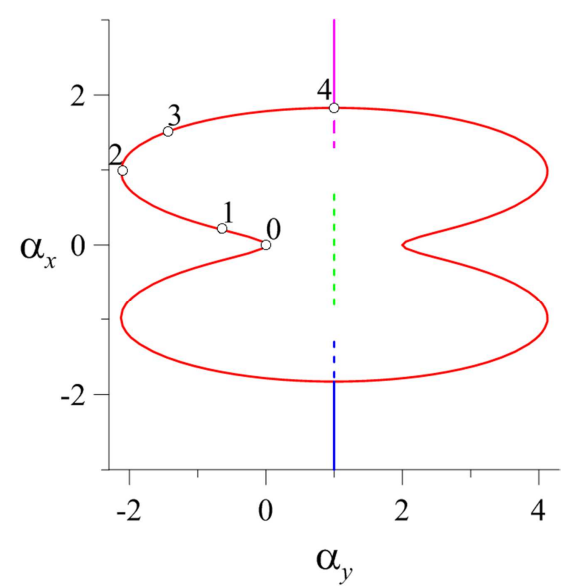

(c) Projeção $\alpha_{x} \times \alpha_{y}$.

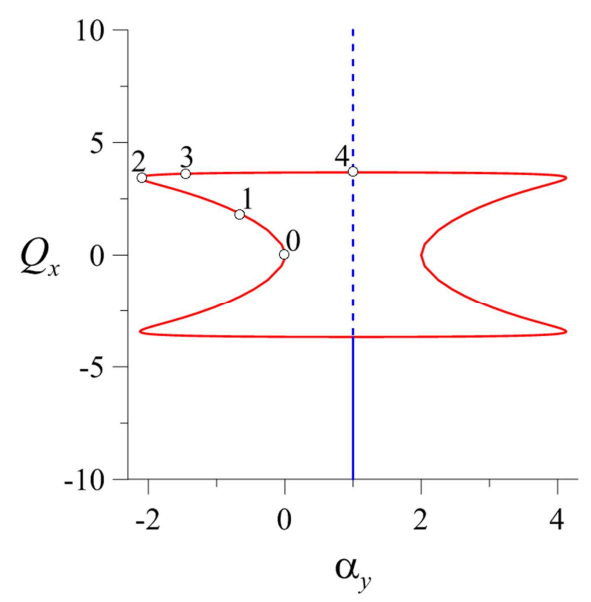

(b) Projeção $\alpha_{y} \times Q_{x}$.

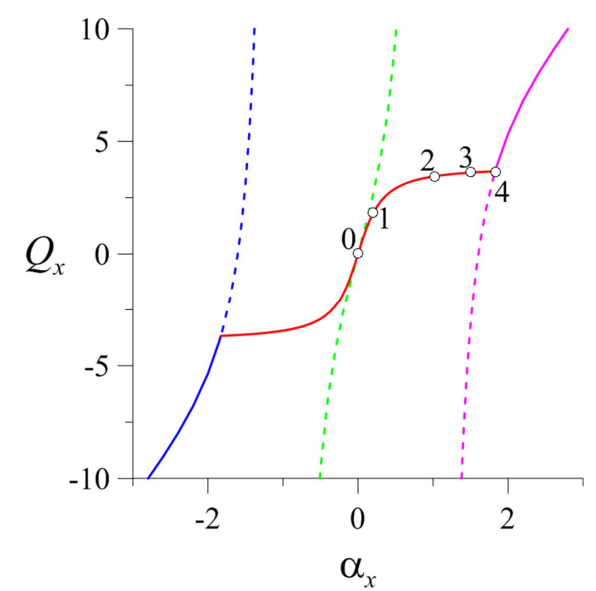

(d) Projeção $\alpha_{x} \times Q_{x}$.

Figura 4.26: Caminhos de equilíbrio da treliça com carga horizontal e $\theta=15^{\circ}$.

Assinala-se na Figura 4.26 a posição inicial para a treliça descarregada e mais quatro posições ao longo da sua trajetória fundamental. Destaca-se uma característica importante do modelo neo-Hookeano apresentada no Capítulo 2: a rigidez da barra à compressão, para uma mesma variação de comprimento, é maior do que sua rigidez à tração, assim a barra tracionada deforma-se mais do que a barra comprimida, o que causa, junto com a capacidade de deformar do material, o deslocamento do nó superior no sentido negativo do eixo y no início da trajetória fundamental. 
Associado a esse comportamento, destaca-se que uma restrição ao deslocamento vertical aumenta a capacidade de carga à ação horizontal da estrutura e altera sua trajetória de equilíbrio, que, assim, perde a estabilidade por ponto limite.

A Figura 4.27 apresenta as configurações da treliça para as posições de 0 a 4 assinaladas na Figura 4.26, mostrando a influência da diferença entre o comportamento da barra em tração e compressão do modelo não linear adotado para o material. Para uma treliça elástica, em seu caminho fundamental, seu nó superior desloca-se entre os seus apoios quando submetida à carga horizontal.

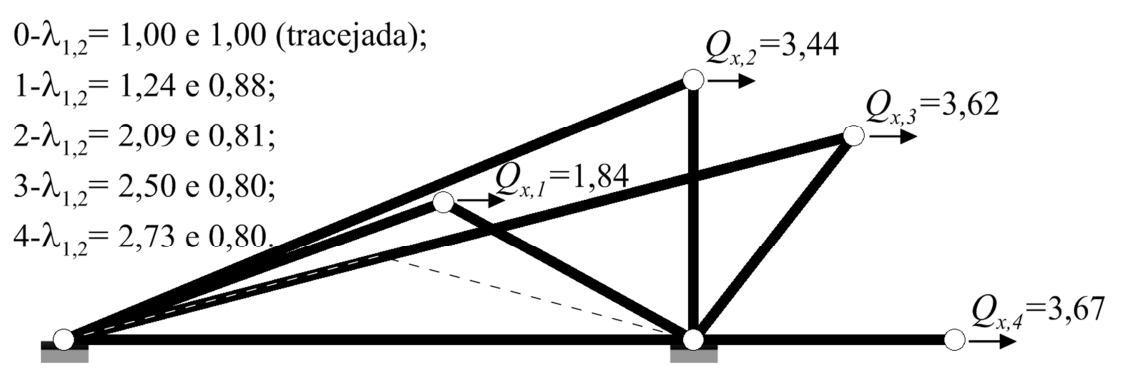

Figura 4.27: Algumas posições estáticas para a treliça com carga horizontal e $\theta=15^{\circ}$.

A Figura 4.28 apresenta as trajetórias de equilíbrio da treliça para $\theta=75^{\circ}$.

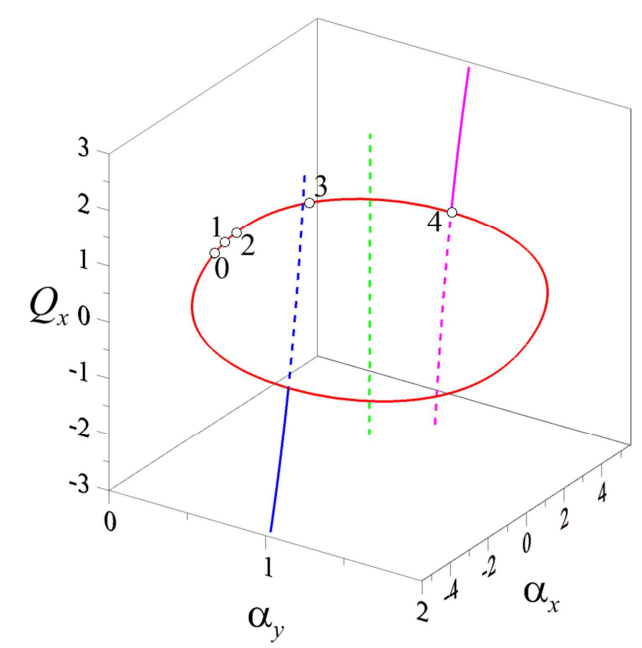

(a) Vista $\alpha_{x} \times \alpha_{y} \times Q_{x}$.

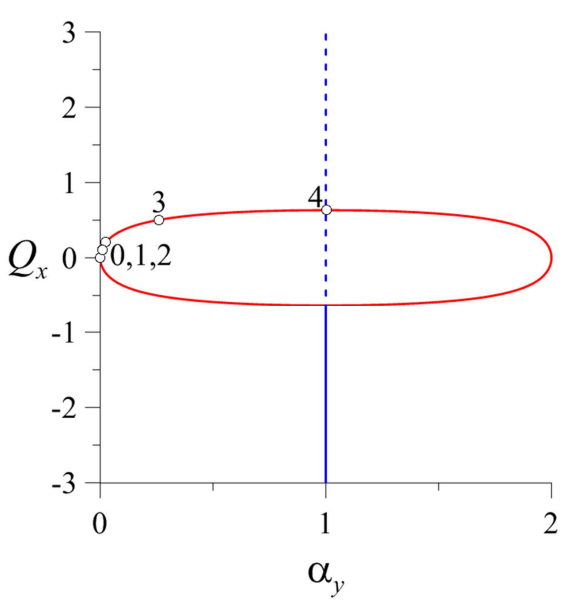

(b) Projeção $\alpha_{y} \times Q_{x}$. 


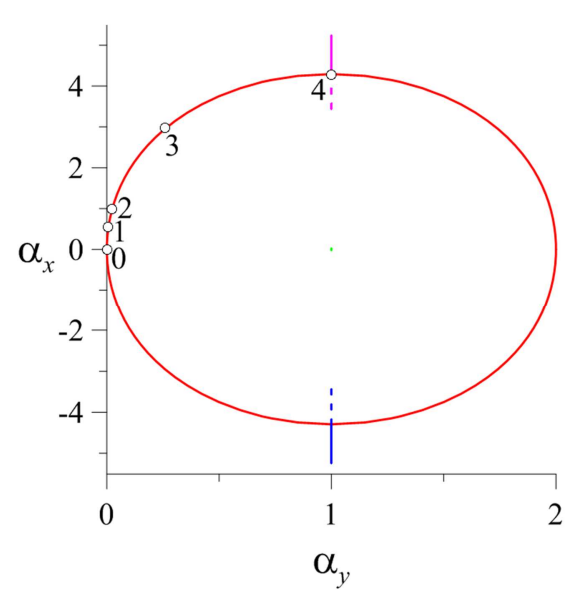

(c) Projeção $\alpha_{x} \times \alpha_{y}$.

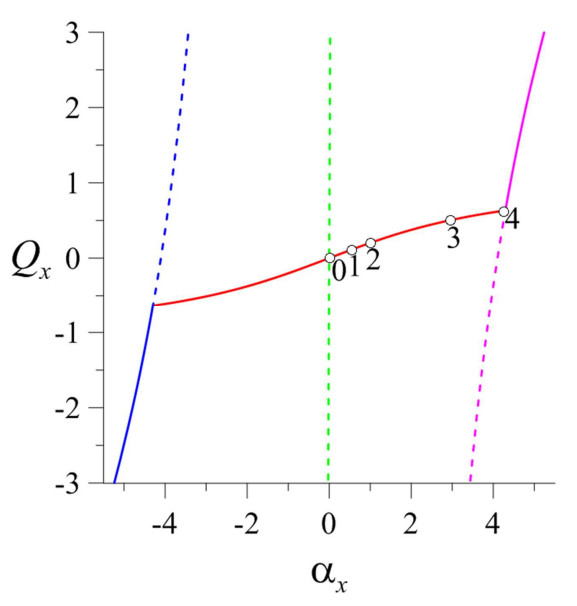

(d) Projeção $\alpha_{x} \times Q_{x}$.

Figura 4.28: Caminhos de equilíbrio da treliça com carga horizontal e $\theta=75^{\circ}$.

O aumento do ângulo de abatimento da estrutura não altera o número nem a estabilidade das trajetórias de equilíbrio, conforme ilustrado na Figura 4.28. A posição qualitativa do ponto bifurcação permanece igual. A diferença da treliça com $\theta=15^{\circ}$ encontra-se apenas no caminho em vermelho onde não há mais deslocamento do seu nó superior no sentido negativo do eixo y. A Figura 4.29 ilustra as posições estáticas assinaladas na Figura 4.28.

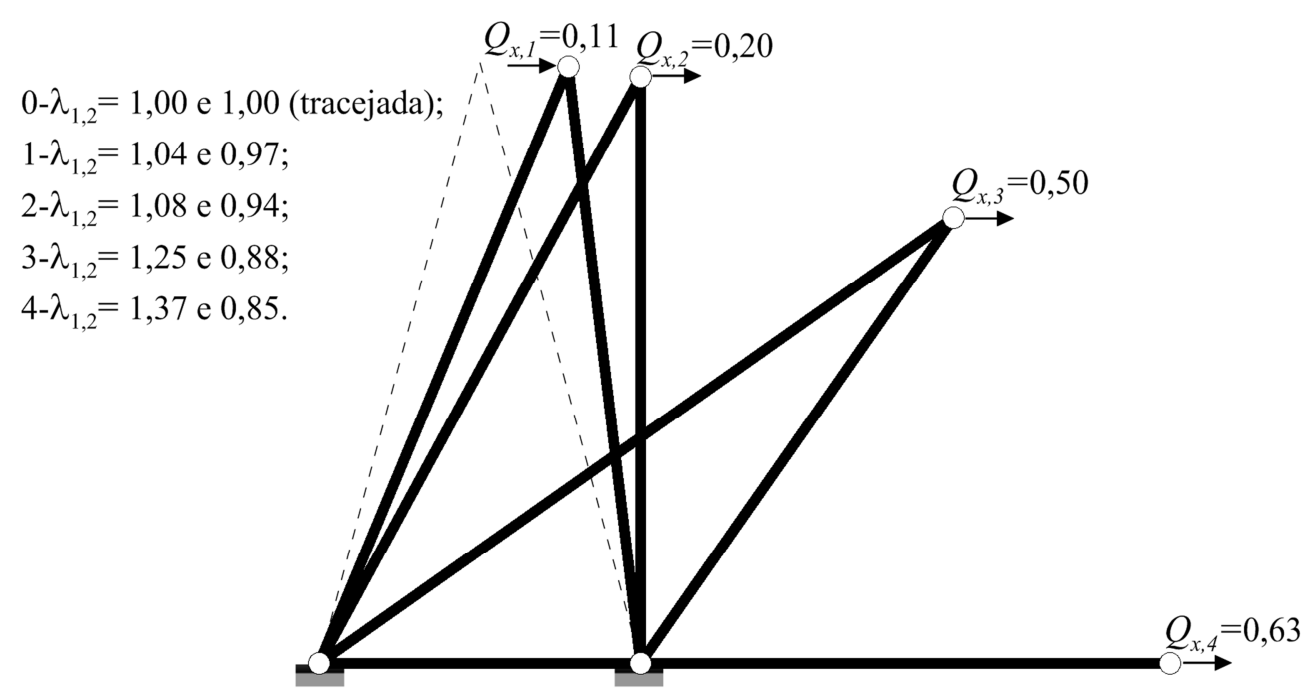

Figura 4.29: Algumas posições estáticas para a treliça com carga horizontal e $\theta=75^{\circ}$. 
A Figura 4.30 mostra uma comparação entre as projeções dos caminhos de equilíbrio no plano $\alpha_{x} \times \alpha_{y}$ para os ângulos de $15^{\circ}$ e $75^{\circ}$.

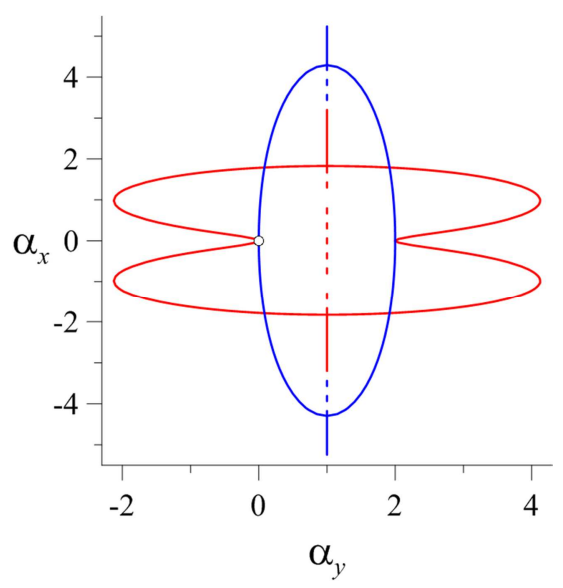

Figura 4.30: Projeção $\alpha_{x} \times \alpha_{y}$ dos caminhos de equilíbrio da treliça com carga horizontal para $\theta=15^{\circ}$ e $\theta=75^{\circ}$.

Nota-se na comparação da Figura 4.30, que existe um ângulo entre $15^{\circ}$ e $75^{\circ}$ que a treliça deixará de apresentar a rigidez negativa presente no caminho de equilíbrio da treliça com $\theta=15^{\circ}$.

\subsection{2.}

\section{Influência das imperfeições}

A seguir, apresentam-se as funções da energia potencial total do sistema imperfeito e as equações que definem suas trajetórias de equilíbrio.

Para a estrutura com imperfeição de carga (perturbação vertical de $0,01 p_{x}$ ) tem-se:

$$
\begin{aligned}
& \bar{\Pi}_{I C}=2\left(\alpha_{y}^{2}-2 \alpha_{y}-2-\left(\alpha_{y}{ }^{2}-\alpha_{x}^{2}-2 \alpha_{y}\right) \cos ^{2}(\theta)+\right. \\
& \frac{1}{\sqrt{\left(\alpha_{y}-1\right)^{2}-\left(\alpha_{y}^{2}-\alpha_{x}^{2}-2 \alpha_{y}-2 \alpha_{x}\right) \cos ^{2}(\theta)}}+ \\
& \left.\frac{1}{\sqrt{\left(\alpha_{y}-1\right)^{2}-\left(\alpha_{y}^{2}-\alpha_{x}^{2}-2 \alpha_{y}+2 \alpha_{x}\right) \cos ^{2}(\theta)}}\right) \\
& -Q_{x} \alpha_{x} \cos (\theta)-0,01 Q_{x} \alpha_{y} \operatorname{sen}(\theta)
\end{aligned}
$$




$$
\begin{aligned}
& \cos (\theta)\left(4 \alpha_{x}-\frac{2 \alpha_{x}+2}{\left(\left(\alpha_{y}-1\right)^{2}-\left(\alpha_{y}{ }^{2}-\alpha_{x}{ }^{2}-2 \alpha_{y}-2 \alpha_{x}\right) \cos ^{2}(\theta)\right)^{3 / 2}}\right)-Q_{x}=0 ; \\
& \left.-\frac{2 \alpha_{x}-2}{\left(\left(\alpha_{y}-1\right)^{2}-\left(\alpha_{y}{ }^{2}-\alpha_{x}{ }^{2}-2 \alpha_{y}+2 \alpha_{x}\right) \cos ^{2}(\theta)\right)^{3 / 2}}\right) \\
& \operatorname{sen}(\theta)\left(4 \alpha_{y}-4-\frac{2 \alpha_{y}-2}{\left(\left(\alpha_{y}-1\right)^{2}-\left(\alpha_{y}{ }^{2}-\alpha_{x}{ }^{2}-2 \alpha_{y}-2 \alpha_{x}\right) \cos ^{2}(\theta)\right)^{3 / 2}}\right. \\
& \left.-\frac{2 \alpha_{y}-2}{\left(\left(\alpha_{y}-1\right)^{2}-\left(\alpha_{y}{ }^{2}-\alpha_{x}{ }^{2}-2 \alpha_{y}+2 \alpha_{x}\right) \cos ^{2}(\theta)\right)^{3 / 2}}\right)-0,01 Q_{x}=0 .
\end{aligned}
$$

Para estrutura com imperfeição na sua geometria (projeções das barras na direção $x$ são alteradas em 5\% - ver Fig. 3.5), tem-se:

$$
\begin{aligned}
& \bar{\Pi}_{I G}=\frac{b_{1}}{b_{0}}\left(\left(\frac{b_{0}}{b_{1}}\right)^{2}\left(\left(\operatorname{sen}(\theta)-\alpha_{y} \operatorname{sen}(\theta)\right)^{2}+\left(\cos (\theta)+\alpha_{x} \cos (\theta)\right)^{2}\right)\right. \\
& \left.+\frac{b_{1}}{b_{0}} \frac{2}{\sqrt{\left(\operatorname{sen}(\theta)-\alpha_{y} \operatorname{sen}(\theta)\right)^{2}+\left(\cos (\theta)+\alpha_{x} \cos (\theta)\right)^{2}}}-3\right) \\
& +\frac{b_{1}}{b_{0} r}\left(\left(\frac{b_{0} r}{b_{1}}\right)^{2}\left(\left(\operatorname{sen}(\theta)-\alpha_{y} \operatorname{sen}(\theta)\right)^{2}+\left(\cos (\theta)-\alpha_{x} \cos (\theta)\right)^{2}\right)\right. \\
& \left.+\frac{b_{1}}{b_{0} r} \frac{2}{\sqrt{\left(\operatorname{sen}(\theta)-\alpha_{y} \operatorname{sen}(\theta)\right)^{2}+\left(\cos (\theta)-\alpha_{x} \cos (\theta)\right)^{2}}}-3\right) \\
& -Q_{x} \alpha_{x} \cos (\theta) ;
\end{aligned}
$$




$$
\begin{aligned}
& \left(\left(\frac{b_{1}}{b_{0}}\right)^{2} \frac{2\left(\operatorname{sen}^{2}(\theta)-\alpha_{y} \operatorname{sen}^{2}(\theta)\right)}{\left(\left(\operatorname{sen}(\theta)-\alpha_{y} \operatorname{sen}(\theta)\right)^{2}+\left(\cos (\theta)+\alpha_{x} \cos (\theta)\right)^{2}\right)^{3 / 2}}\right. \\
& \left.-\left(\frac{2 b_{0}}{b_{1}}\right)\left(\operatorname{sen}^{2}(\theta)-\alpha_{y} \operatorname{sen}^{2}(\theta)\right)\right) \\
& +\left(\left(\frac{b_{1}}{b_{0} r}\right)^{2} \frac{2\left(\operatorname{sen}^{2}(\theta)-\alpha_{y} \operatorname{sen}^{2}(\theta)\right)}{\left(\left(\operatorname{sen}(\theta)-\alpha_{y} \operatorname{sen}(\theta)\right)^{2}+\left(\cos (\theta)-\alpha_{x} \cos (\theta)\right)^{2}\right)^{3 / 2}}\right. \\
& \left.-\left(\frac{2 b_{0} r}{b_{1}}\right)^{2}\left(\operatorname{sen}^{2}(\theta)-\alpha_{y} \operatorname{sen}^{2}(\theta)\right)\right)=0 \\
& \left(\left(\frac{2 b_{0}}{b_{1}}\right)^{\left(\cos (\theta)+\alpha_{x} \cos (\theta)\right)}\right. \\
& \left.-\left(\frac{b_{1}}{b_{0}}\right)^{2} \frac{2\left(\cos (\theta)+\alpha_{x} \cos (\theta)\right)}{\left(\left(\operatorname{sen}(\theta)-\alpha_{y} \operatorname{sen}(\theta)\right)^{2}+\left(\cos (\theta)+\alpha_{x} \cos (\theta)\right)^{2}\right)^{3 / 2}}\right) \\
& +\left(\left(\frac{b_{1}}{b_{0} r}\right)^{2} \frac{2\left(\cos (\theta)-\alpha_{x} \cos (\theta)\right)}{\left(\left(\operatorname{sen}(\theta)-\alpha_{y} \operatorname{sen}(\theta)\right)^{2}+\left(\cos (\theta)-\alpha_{x} \cos (\theta)\right)^{2}\right)^{3 / 2}}\right. \\
& -\left(\frac{2 b_{0} r}{b_{1}}\right)^{\left.\left(\cos (\theta)-\alpha_{x} \cos (\theta)\right)\right)-Q_{x}=0}
\end{aligned}
$$

A Figura 4.31 exibe os caminhos de equilíbrio para a treliça carregada horizontalmente e com imperfeição de carga. Observa-se a existência de três trajetórias de equilíbrio independentes que margeiam os caminhos da estrutura perfeita. Caso se mude o sinal da imperfeição, obtêm-se os caminhos complementares simétricos. 


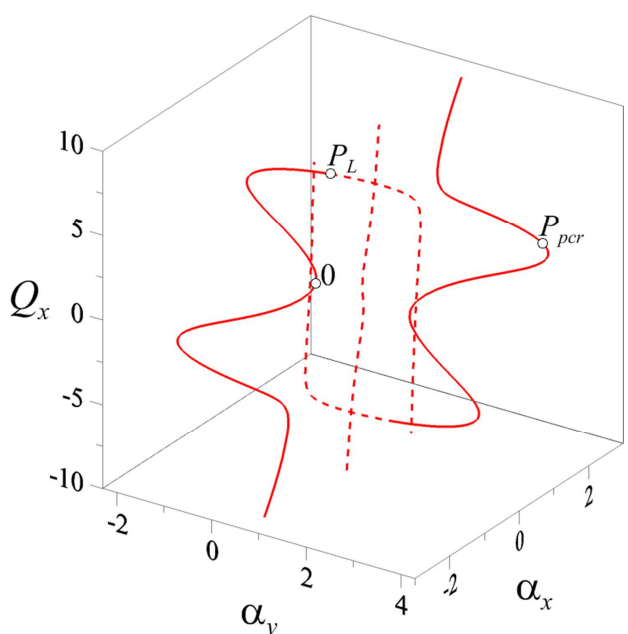

(a) Vista $\alpha_{x} \times \alpha_{y} \times Q_{x}$.

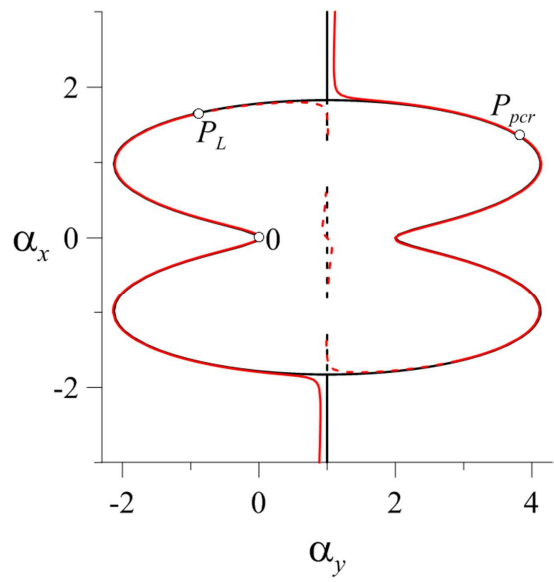

(c) Projeção $\alpha_{x} \times \alpha_{y}$.

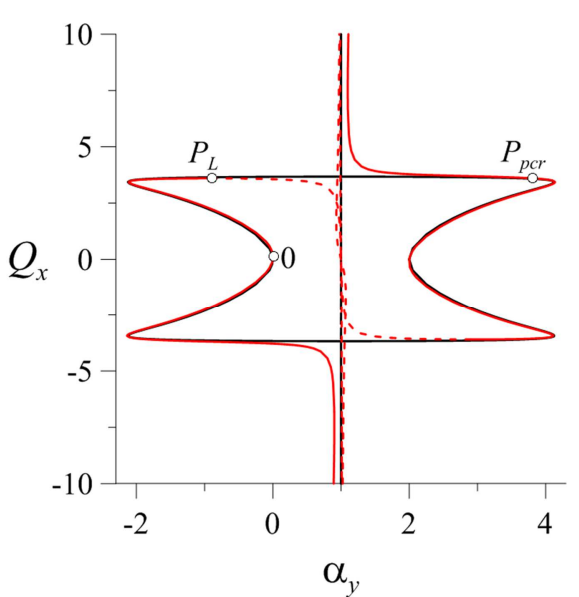

(b) Projeção $\alpha_{y} \times Q_{x}$.

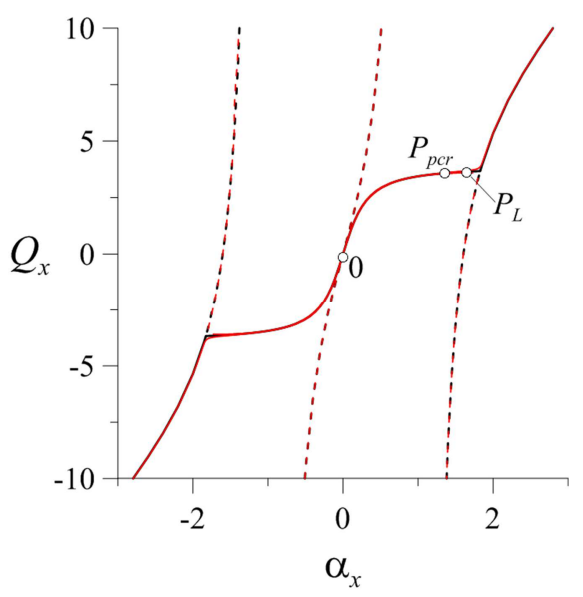

(d) Projeção $\alpha_{x} \times Q_{x}$.

Figura 4.31: Caminhos de equilíbrio da treliça com carga horizontal, imperfeição de carga e $\theta=15^{\circ}$.

Nota-se na Figura 4.31 que para $\alpha_{x}<0$, partindo-se da configuração inicial descarregada, o caminho de equilíbrio é sempre estável e para $\alpha_{x}>0$, a instabilidade acontece por ponto limite, indicado pela posição $\left(P_{L}\right)$ no gráfico 4.31, o que está relacionada com a quebra de simetria gerada pela imperfeição. Neste ponto a estrutura pula para uma configuração deformada pós-crítica em outro caminho de equilíbrio, indicada pela posição $\left(P_{p c r}\right)$ na Figura 4.31. A Figura 4.32 ilustra as configurações crítica e pós-crítica. 


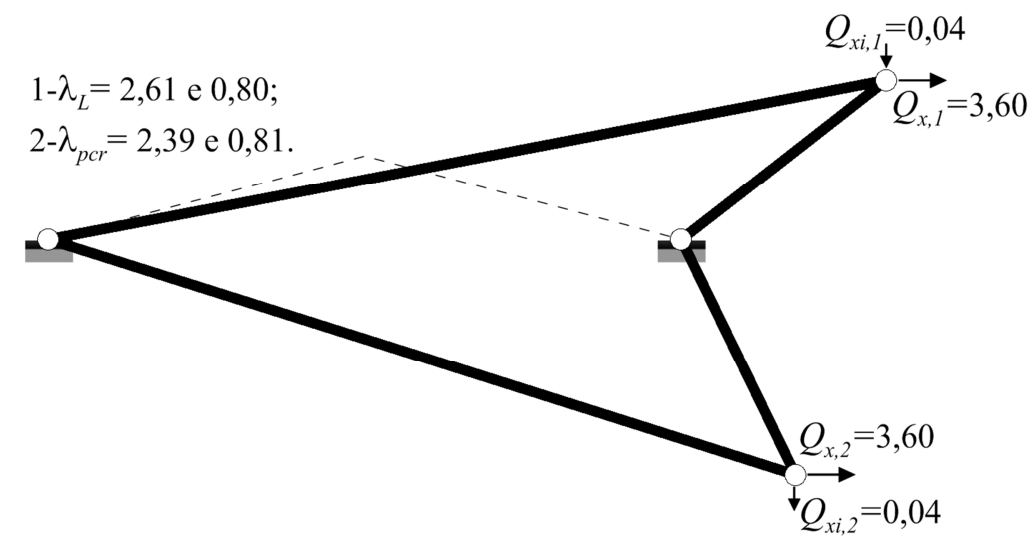

Figura 4.32: Posições crítica e pós-critica para a treliça com carga horizontal, imperfeição de carga e $\theta=15^{\circ}$.

À medida que a imperfeição de carga aumenta (a inclinação da resultante aumenta) os caminhos de equilíbrio se aproximam e, finalmente, a treliça perde a estabilidade por ponto limite saltando entre seus apoios para a configuração póscrítica, como ilustra a Figura 4.33 obtida para uma imperfeição de carga igual a $0,071 Q_{x}$, onde se mostra uma configuração típica de uma bifurcação assimétrica.

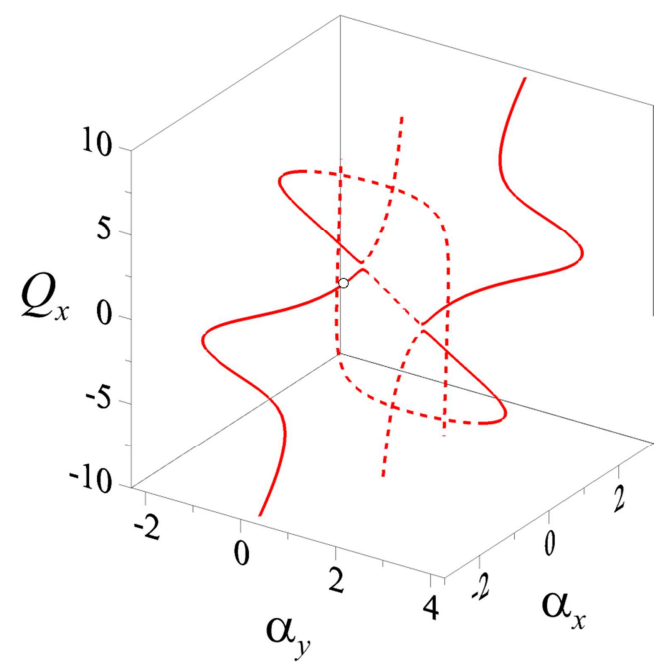

(a) Vista $\alpha_{x} \times \alpha_{y} \times Q_{x}$.

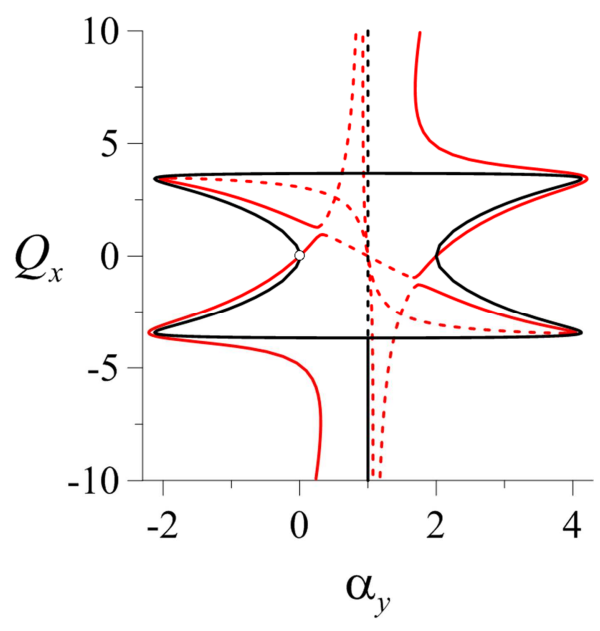

(b) Projeção $\alpha_{y} \times Q_{x}$. 


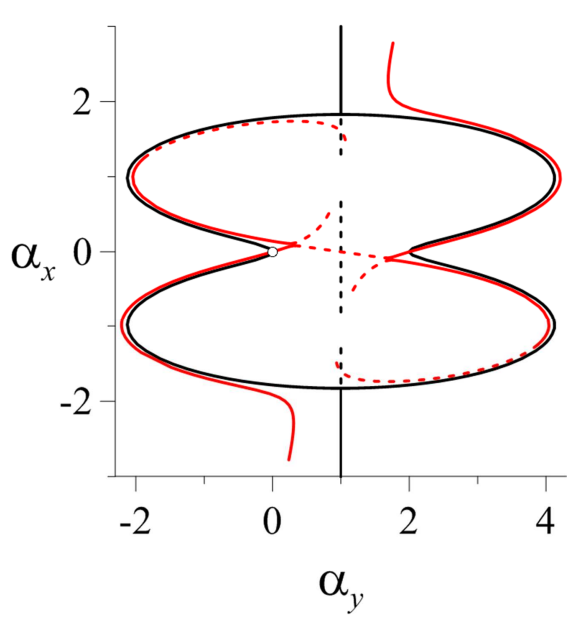

(c) Projeção $\alpha_{x} \times \alpha_{y}$.

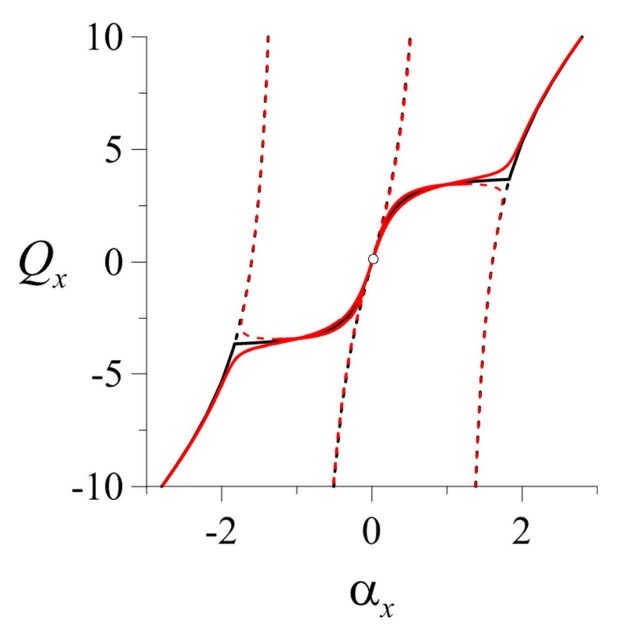

(d) Projeção $\alpha_{x} \times Q_{x}$.

Figura 4.33: Caminhos de equilíbrio da treliça com carga horizontal, imperfeição de carga $0,071 Q_{x}$ e $\theta=15^{\circ}$.

A Figura 4.34 apresenta os caminhos de equilíbrio para o sistema com imperfeição geométrica inicial (assimetria).

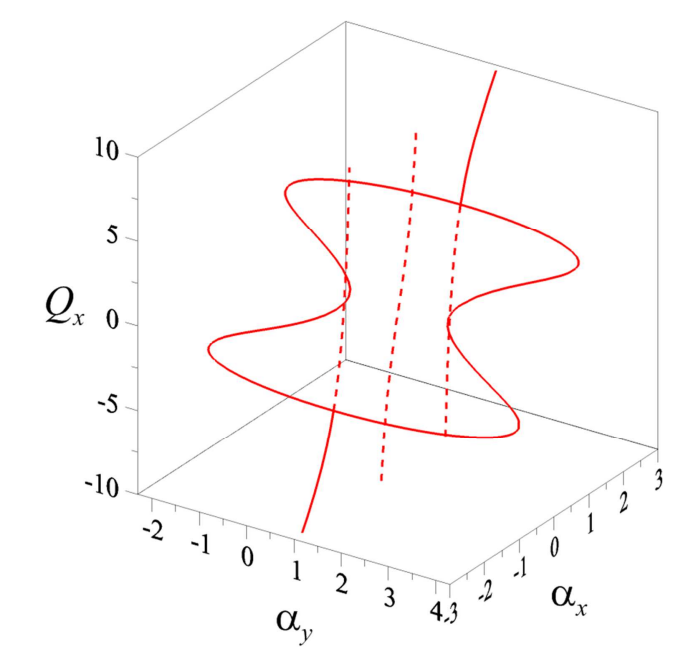

(a) Vista $\alpha_{x} \times \alpha_{y} \times Q_{x}$.

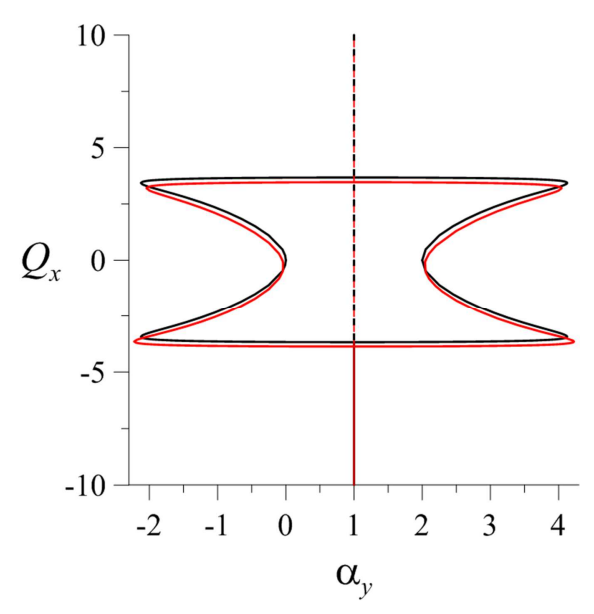

(b) Projeção $\alpha_{y} \times Q_{x}$. 


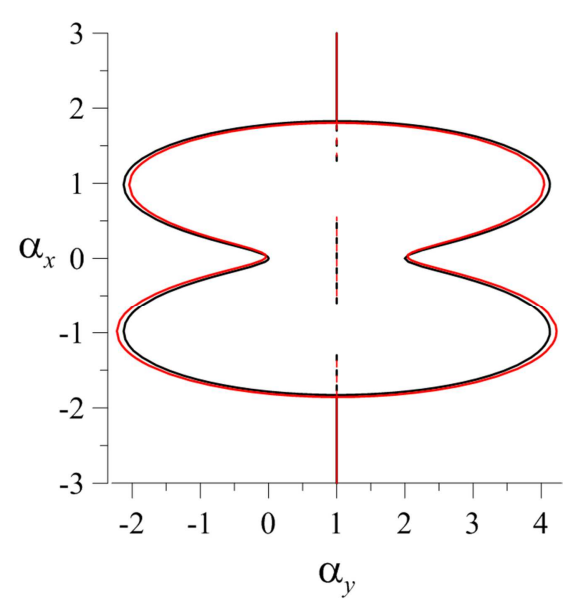

(c) Projeção $\alpha_{x} \times \alpha_{y}$.

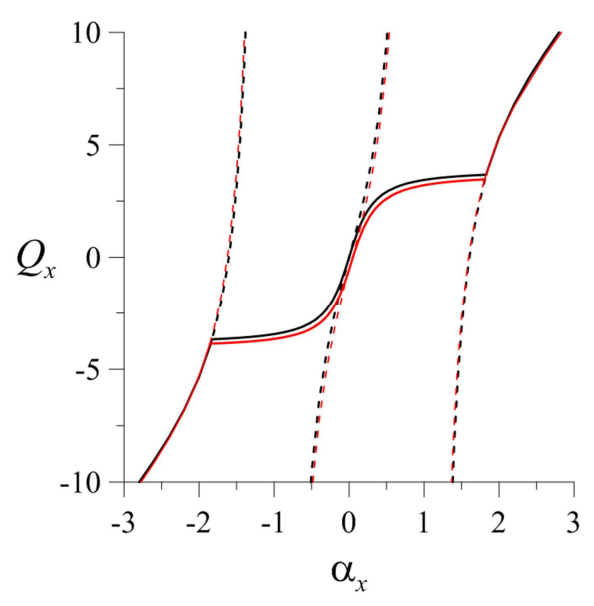

(d) Projeção $\alpha_{x} \times Q_{x}$.

Figura 4.34: Caminhos de equilíbrio da treliça com carga horizontal, imperfeição geométrica e $\theta=15^{\circ}$.

A imperfeição geométrica, de acordo com a Figura 4.34, modifica a rigidez do sistema, mas mantém a forma qualitativa dos caminhos de equilíbrio da estrutura perfeita. Observa-se que, independentemente do sentido da força aplicada, a estrutura mantém seu comportamento, variando levemente as cargas de bifurcação.

As Figuras 4.35 e 4.36 exibem as trajetórias de equilíbrio para a treliça com $\theta=75^{\circ}$ e para as situações de imperfeição de carga e em sua geometria.

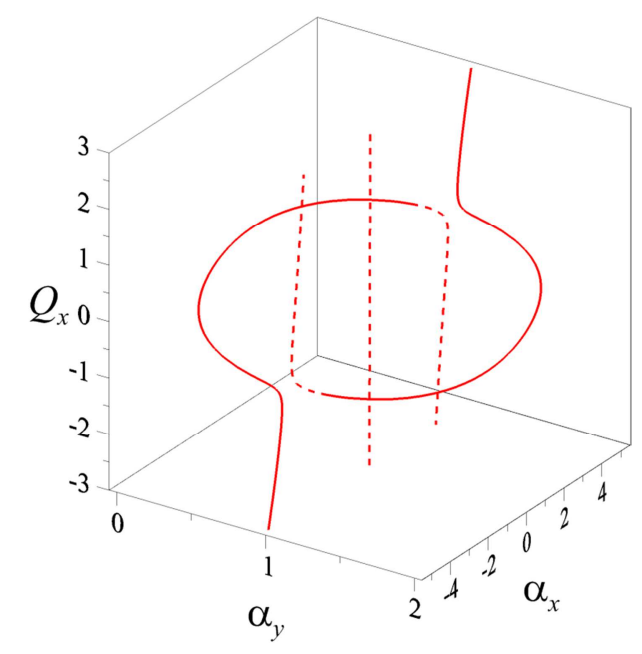

(a) Vista $\alpha_{x} \times \alpha_{y} \times Q_{x}$.

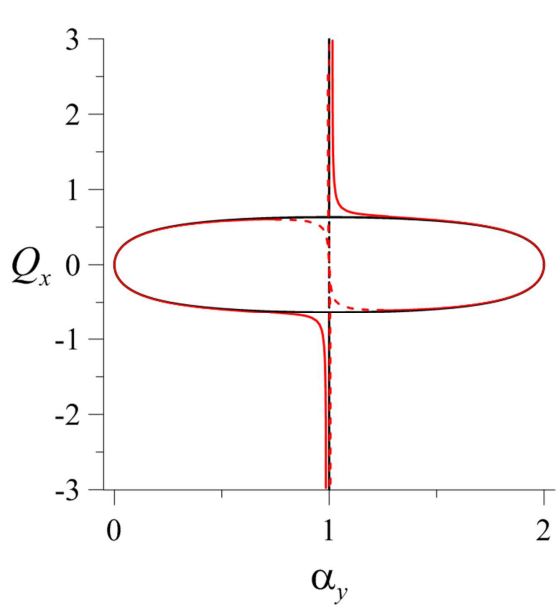

(b) Projeção $\alpha_{y} \times Q_{x}$. 


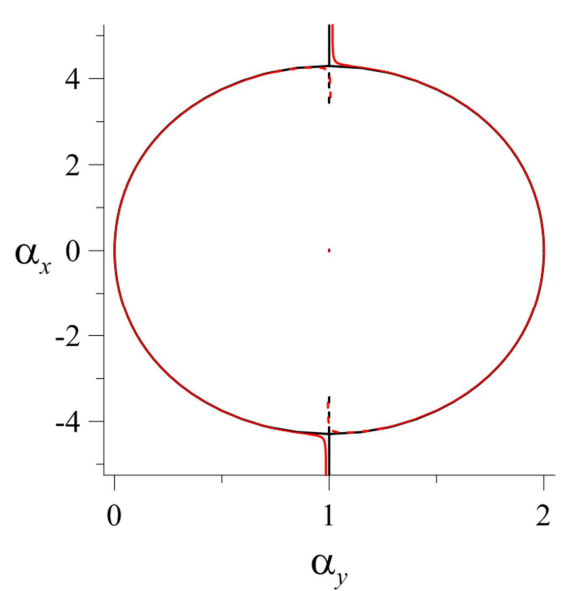

(c) Projeção $\alpha_{x} \times \alpha_{y}$.

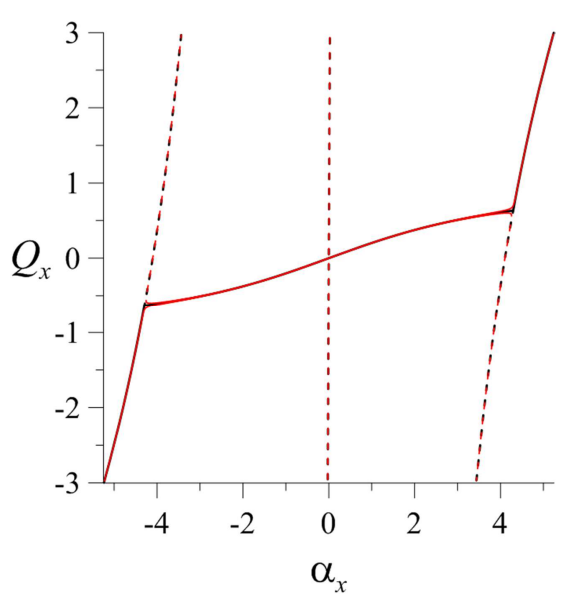

(d) Projeção $\alpha_{x} \times Q_{x}$.

Figura 4.35: Caminhos de equilíbrio da treliça com carga horizontal, imperfeição de carga e $\theta=75^{\circ}$.

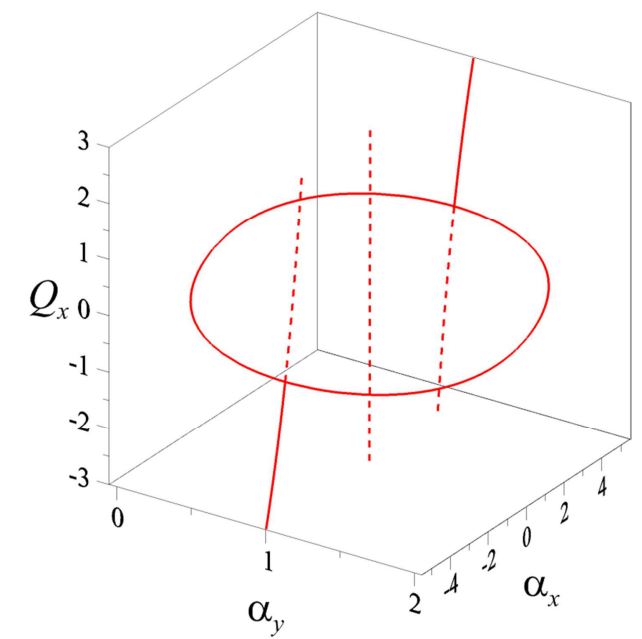

(a) Vista $\alpha_{x} \times \alpha_{y} \times Q_{x}$.

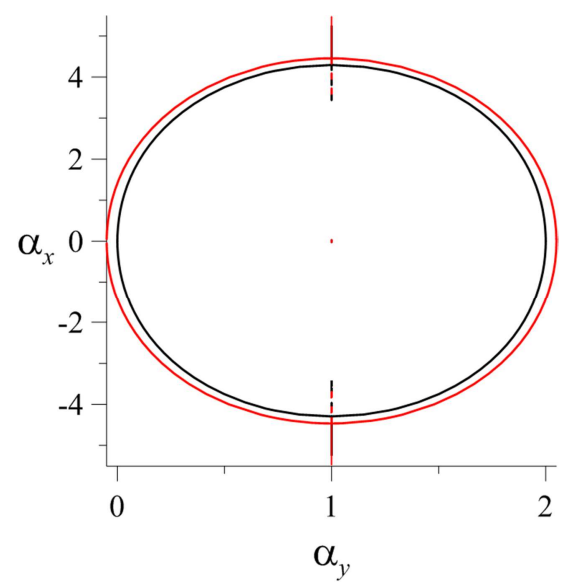

(c) Projeção $\alpha_{x} \times \alpha_{y}$.

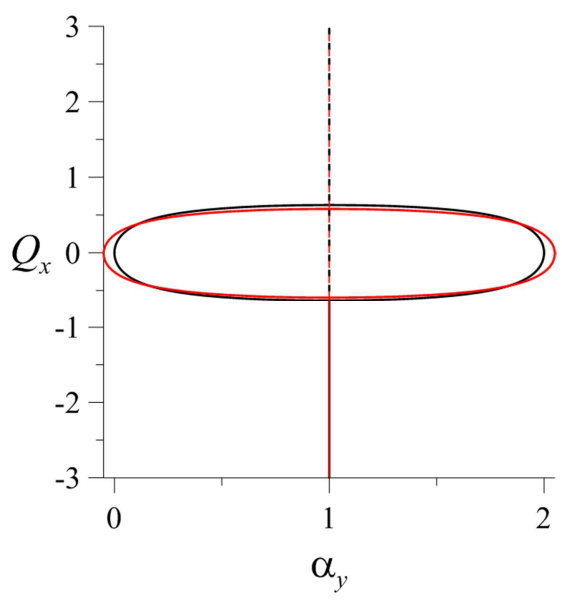

(b) Projeção $\alpha_{y} \times Q_{x}$.

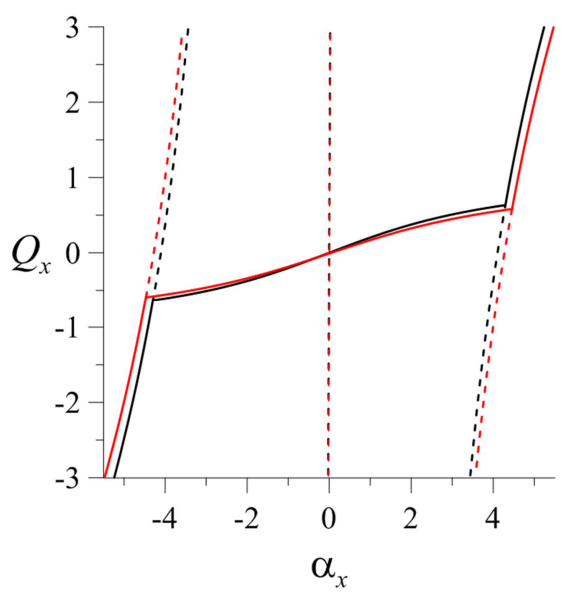

(d) Projeção $\alpha_{x} \times Q_{x}$.

Figura 4.36: Caminhos de equilíbrio da treliça com carga horizontal, imperfeição geométrica e $\theta=75^{\circ}$. 
Nota-se que as imperfeições na treliça com ângulo de abatimento de $75^{\circ}$ (Figuras 4.35 e 4.36), alteram a sua trajetória de equilíbrio da mesma forma que acontece para a treliça imperfeita $\operatorname{com} \theta=15^{\circ}$ : a imperfeição de carga provoca a perda de estabilidade por ponto limite e a geométrica não é sensível à imperfeição. Para este caso, destaca-se que, enquanto para estrutura abatida a imperfeição só diminui a sua carga crítica para $Q_{x}$ positivo, na treliça com $\theta=75^{\circ}$, independentemente do sentido da carga, obtém-se uma carga crítica sempre menor que a do modelo perfeito.

\section{4.}

\section{Análise dimensional}

A análise dimensional apresenta a verificação da estabilidade estática de uma treliça hiperelástica, com dimensões e constante do material conhecidas, para se ter uma certa sensibilidade sobre as tensões e deformações da estrutura.

A carga crítica de uma coluna constituída por material neo-Hookeano submetida a uma carga axial, segundo Attard (2008), é dado por:

$$
P_{c r}=\frac{n^{2} P_{\text {euler }}}{1-\frac{1}{4} \frac{n^{2} P_{\text {euler }}}{E A}\left(1-\frac{r_{y}^{2}}{r_{z}^{2}}\right)}
$$

Onde:

$n:$ modo de flambagem;

$P_{\text {euler }}:$ carga crítica de Euler;

$r_{z}:$ raio de giração relativo à flexão em z;

$r_{y}$ : raio de giração relativo à flexão em $\mathrm{y}$.

Considere a treliça com ângulo de abatimento de $15^{\circ}$ e submetida a uma carga estática vertical. Suas barras possuem comprimento de $1000 \mathrm{~mm}$ e seção quadrada com $170 \mathrm{~mm}$ de lado. Adota-se para constante do material, $C_{1}$, o valor de 0,17 MPa, de acordo Selvadurai (2006). 
Calcula-se a carga de flambagem da barra da treliça, as cargas verticais ao longo do caminho de equilíbrio e com isso a força axial na barra. A Figura 4.37 ilustra o equilíbrio das forças no nó superior de forma esquemática e, em seguida, apresenta os valores calculados destas forças e da carga crítica da barra ao longo do caminho de equilíbrio.

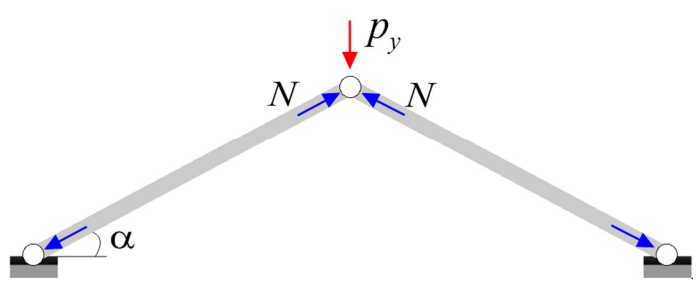

(a) Equilíbrio das forças.

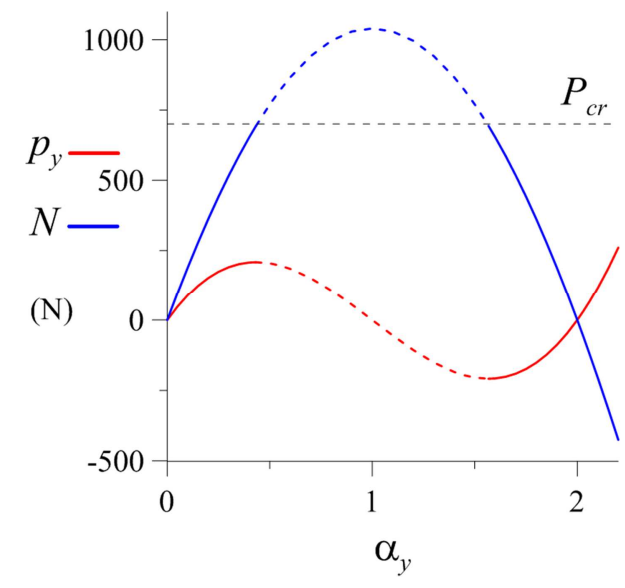

(b) Forças ao longo do caminho de equilíbrio

Figura 4.37: Treliça com carga vertical e $\theta=15^{\circ}$.

A seção transversal da treliça foi escolhida de forma que os fenômenos de instabilidade local da barra e global do sistema estrutural fossem iguais.

As cargas de compressão na barra podem ser obtidas por equilíbrio do nó superior ou a partir das tensões, calculadas de acordo com o Capítulo 2. Neste caso, nota-se que são consideradas as tensões de Cauchy e assim a contração de sua seção deve ser devidamente considerada.

A Figura 4.38 mostra a variação das tensões axiais de Cauchy e de engenharia, cuja formulação considera a área deformada e indeformada, respectivamente, ao longo do caminho de equilíbrio. 


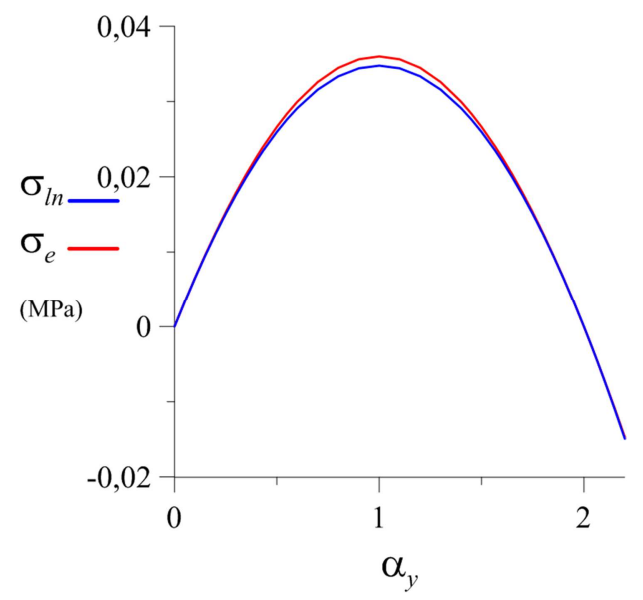

Figura 4.38: Tensões axiais ao longo do caminho de equilíbrio.

A diferença máxima entre as tensões de Cauchy e de Engenharia é 1,7\%. Ressalta-se que neste exemplo as barras da treliça apresentam uma pequena variação máxima de comprimento (aproximadamente 2,3\%). Para grandes deformações essa diferença seria bem maior. 


\section{5}

\section{Frequências naturais de vibração}

As frequências naturais de vibração de uma estrutura caracterizam a relação entre sua rigidez e massa. Como a rigidez efetiva da estrutura é função do carregamento, a estabilidade da treliça pode ser determinada com base nas frequências da estrutura (Croll \& Walker, 1972): se as frequências são todas reais, a treliça é estável (quadrado da frequência positivo), caso pelo menos uma seja imaginária, a estrutura é instável (quadrado da frequência negativo) e para a situação em que uma frequência é nula, tem-se um caso crítico.

\section{1.}

\section{Equações de movimento}

A função de Lagrange, $L=\mathrm{T}-\Pi$, representa a variação da energia da treliça durante o movimento. Considerando a formulação geral, tem-se para a treliça inicialmente descarregada, a função de Lagrange:

$$
\begin{gathered}
L=\frac{m l_{0}^{2}}{6}\left(\frac{b_{1}}{b_{0}}\right)^{3}\left(\dot{\alpha}_{x}^{2} \cos ^{2}(\theta)+\dot{\alpha}_{y}^{2} \operatorname{sen}^{2}(\theta)\right) \\
+\frac{m l_{0}^{2}}{6 r}\left(\frac{b_{1}}{b_{0}}\right)^{3}\left(\dot{\alpha}_{x}^{2} \cos ^{2}(\theta)+\dot{\alpha}_{y}^{2} \operatorname{sen}^{2}(\theta)\right) \\
-C_{10} A_{0} l_{0}\left(\left(\frac{b_{0}}{b_{1}}\right)\left(\left(\operatorname{sen}(\theta)-\alpha_{y} \operatorname{sen}(\theta)\right)^{2}+\left(\cos (\theta)+\alpha_{x} \cos (\theta)\right)^{2}\right)+\right. \\
\left.\left(\frac{b_{1}}{b_{0}}\right)^{2} \frac{2}{\sqrt{\left(\operatorname{sen}(\theta)-\alpha_{y} \operatorname{sen}(\theta)\right)^{2}+\left(\cos (\theta)+\alpha_{x} \cos (\theta)\right)^{2}}}-\frac{3 b_{1}}{b_{0}}\right) \\
-C_{10} A_{0} l_{0}\left(\left(\frac{b_{0} r}{b_{1}}\right)\left(\left(\operatorname{sen}(\theta)-\alpha_{y} \operatorname{sen}(\theta)\right)^{2}+\left(\cos (\theta)-\alpha_{x} \cos (\theta)\right)^{2}\right)+\right. \\
\left(\frac{b_{1}}{b_{0} r}\right)^{2} \frac{3 b_{1}}{\sqrt{\left(\operatorname{sen}(\theta)-\alpha_{y} \operatorname{sen}(\theta)\right)^{2}+\left(\cos (\theta)-\alpha_{x} \cos (\theta)\right)^{2}}}-
\end{gathered}
$$


As equações de movimento são obtidas a partir da equação de EulerLagrange a seguir.

$$
\frac{\mathrm{d}}{\mathrm{dt}}\left(\frac{\partial L}{\partial \dot{\alpha}_{i}}\right)-\frac{\partial L}{\partial \alpha_{i}}=0 .
$$

Aplicado a equação (5.2) para cada coordenada generalizada, obtêm-se as equações não lineares de movimento:

$$
\begin{aligned}
& \ddot{\alpha}_{x}+3 w^{2}\left(\frac{r}{r+1}\right)\left(2\left(\frac{b_{0}}{b_{1}}\right)^{4}\left(1+\alpha_{x}\right)-2 r\left(\frac{b_{0}}{b_{1}}\right)^{4}\left(1-\alpha_{x}\right)\right. \\
& -\left(\frac{b_{0}}{b_{1}}\right) \frac{2\left(1+\alpha_{x}\right)}{\left(\left(\operatorname{sen}(\theta)-\alpha_{y} \operatorname{sen}(\theta)\right)^{2}+\left(\cos (\theta)+\alpha_{x} \cos (\theta)\right)^{2}\right)^{3 / 2}} \\
& \left.+\left(\frac{b_{0}}{b_{1} r^{2}}\right) \frac{2\left(1-\alpha_{x}\right)}{\left(\left(\operatorname{sen}(\theta)-\alpha_{y} \operatorname{sen}(\theta)\right)^{2}+\left(\cos (\theta)-\alpha_{x} \cos (\theta)\right)^{2}\right)^{3 / 2}}\right)=0 ; \\
& \ddot{\alpha}_{y}+3 w^{2}\left(\frac{r}{r+1}\right)\left(-2\left(\frac{b_{0}}{b_{1}}\right)^{4}\left(1-\alpha_{y}\right)-2 r\left(\frac{b_{0}}{b_{1}}\right)^{4}\left(1-\alpha_{y}\right)\right. \\
& +\left(\frac{b_{0}}{b_{1}}\right) \frac{2\left(1-\alpha_{y}\right)}{\left(\left(\operatorname{sen}(\theta)-\alpha_{y} \operatorname{sen}(\theta)\right)^{2}+\left(\cos (\theta)+\alpha_{x} \cos (\theta)\right)^{2}\right)^{3 / 2}} \\
& \left.+\left(\frac{b_{0}}{b_{1} r^{2}}\right) \frac{2\left(1-\alpha_{y}\right)}{\left(\left(\operatorname{sen}(\theta)-\alpha_{y} \operatorname{sen}(\theta)\right)^{2}+\left(\cos (\theta)-\alpha_{x} \cos (\theta)\right)^{2}\right)^{3 / 2}}\right)=0 ;
\end{aligned}
$$

sendo: $w=\sqrt{C_{10} A_{0} / m l_{0}}$.

Considerando a treliça com carregamento estático inicial ou imperfeição geométrica, para que a origem das suas coordenadas generalizadas coincida com os deslocamentos do nó superior, adotam-se as seguintes relações:

$$
\begin{aligned}
& \alpha_{x}=\alpha_{x, d}+\alpha_{x, e} \\
& \alpha_{y}=\alpha_{y, d}+\alpha_{y, e}
\end{aligned}
$$


em que o subscrito $d$ refere-se a dinâmico, indicando os deslocamentos, e o subscrito $e$ a estático, referindo-se a posição de equilíbrio estático inicial do nó da treliça imperfeita, de acordo com o Capítulo 4. Destaca-se que na análise estática tem-se $\alpha_{i}=\alpha_{i, e}$.

\section{2.}

\section{Frequências naturais}

Para obtenção dos coeficientes das matrizes de massa e rigidez, os termos não lineares das equações de movimento são expandidos em séries de Taylor.

A partir das Equações (5.3) e (5.4), utilizando os termos lineares da série de Taylor, obtêm-se as equações de movimento linearizadas na configuração deformada relativa à posição estática de equilíbrio $\left(\alpha_{x, e}, \alpha_{y, e}, Q_{i}\right)$ :

$$
\begin{aligned}
& \ddot{\alpha}_{x, d}+\operatorname{aux}_{11} \alpha_{x, d}+\operatorname{aux}_{12} \alpha_{y, d}=0 ; \\
& \ddot{\alpha}_{y, d}+\operatorname{aux}_{21} \alpha_{x, d}+\operatorname{aux}_{22} \alpha_{y, d}=0 ;
\end{aligned}
$$

cujos termos $a u x_{k l}$ correspondem à:

$$
\begin{aligned}
& a u x_{11}=\frac{6 w^{2} b_{0}}{b_{1}^{4} r(r+1)}\left(\frac{r^{2} \operatorname{var}_{1}\left(b_{0}^{3}(r+1) \operatorname{var}_{2}+b_{1}^{3} \operatorname{var}_{4}\right)+b_{1}^{3} \operatorname{var}_{2} \text { var }_{3}}{\operatorname{var}_{1} \operatorname{var}_{2}}\right) \\
& \operatorname{aux}_{12}=\frac{18 w^{2} b_{0} \operatorname{sen}^{2}(\theta)}{b_{1} r(r+1)}\left(\alpha_{y, e}-1\right)\left(\frac{r^{2}\left(\alpha_{x, e}+1\right) \operatorname{var}_{1}+\left(\alpha_{x, e}-1\right) \operatorname{var}_{2}}{\operatorname{var}_{1} \operatorname{var}_{2}}\right) \\
& \operatorname{aux}_{21}=\frac{18 w^{2} b_{0} \cos ^{2}(\theta)}{b_{1} r(r+1)}\left(\alpha_{y, e}-1\right)\left(\frac{r^{2}\left(\alpha_{x, e}+1\right) \operatorname{var}_{1}+\left(\alpha_{x, e}-1\right) v a r_{2}}{\operatorname{var}_{1} v a r_{2}}\right) \\
& \operatorname{aux}_{22}=\frac{6 w^{2} b_{0}}{b_{1}^{4} r(r+1)}\left(\frac{r^{2} \operatorname{var}_{1}\left(b_{0}^{3}(r+1) \operatorname{var}_{2}-b_{1}^{3} \operatorname{var}_{6}\right)-b_{1}^{3} \operatorname{var}_{2} \operatorname{var}_{5}}{\operatorname{var}_{1} v_{2}}\right)
\end{aligned}
$$

e as variáveis $v a r_{m}$ são:

$$
\operatorname{var}_{1}=\left(\left(\alpha_{x, e}^{2}-\alpha_{y, e}^{2}-2 \alpha_{x, e}+2 \alpha_{y, e}\right) \cos ^{2}(\theta)+\left(\alpha_{y, e}-1\right)^{2}\right)^{5 / 2}
$$




$$
\begin{aligned}
& \operatorname{var}_{2}=\left(\left(\alpha_{x, e}{ }^{2}-\alpha_{y, e}{ }^{2}+2 \alpha_{x, e}+2 \alpha_{y, e}\right) \cos ^{2}(\theta)+\left(\alpha_{y, e}-1\right)^{2}\right)^{5 / 2} ; \\
& \operatorname{var}_{3}=\left(2 \alpha_{x, e}{ }^{2}+\alpha_{y, e}{ }^{2}-4 \alpha_{x, e}-2 \alpha_{y, e}+3\right) \cos ^{2}(\theta)-\left(\alpha_{y, e}-1\right)^{2} ; \\
& \operatorname{var}_{4}=\left(2 \alpha_{x, e}{ }^{2}+\alpha_{y, e}{ }^{2}+4 \alpha_{x, e}-2 \alpha_{y, e}+3\right) \cos ^{2}(\theta)-\left(\alpha_{y, e}-1\right)^{2} ; \\
& \operatorname{var}_{5}=\left(\alpha_{x, e}{ }^{2}+2 \alpha_{y, e}{ }^{2}-2 \alpha_{x, e}-4 \alpha_{y, e}+3\right) \cos ^{2}(\theta)-2\left(\alpha_{y, e}-1\right)^{2} ; \\
& \operatorname{var}_{6}=\left(\alpha_{x, e}{ }^{2}+2 \alpha_{y, e}{ }^{2}+2 \alpha_{x, e}-4 \alpha_{y, e}+3\right) \cos ^{2}(\theta)-2\left(\alpha_{y, e}-1\right)^{2} .
\end{aligned}
$$

Assim, as duas frequências naturais para a estrutura descarregada são dadas por:

$$
\omega_{1,2}^{2}=\frac{\operatorname{aux}_{22}+a u x_{11}}{2} \mp \frac{1}{2} \sqrt{\operatorname{aux}_{11}^{2}-2 a u x_{11} a u x_{22}+4 a u x_{12} \operatorname{aux}_{21}+\operatorname{aux}_{22}{ }^{2}}
$$

e seus correspondentes modos de vibração são:

$$
\begin{aligned}
& \operatorname{modo} 1=\left\{1 \frac{\left(\omega_{1}^{2}+a u x_{11}\right)}{a u x_{12}}\right\}^{T} ; \\
& \operatorname{modo} 2=\left\{1 \frac{\left(\omega_{2}^{2}+a u x_{11}\right)}{a u x_{12}}\right\}^{T} .
\end{aligned}
$$

\subsection{1.}

\section{Modelo perfeito}

A treliça simétrica não apresenta acoplamento entre as direções $x$ e $y$ do seus modos de vibração e suas frequências de vibração nas direções $x$ e $y$ reduzem-se a:

$$
\begin{aligned}
& \omega_{x}=\sqrt{18 w^{2} \cos ^{2}(\theta)} ; \\
& \omega_{y}=\sqrt{18 w^{2} \operatorname{sen}^{2}(\theta)} ;
\end{aligned}
$$

onde $w=\sqrt{C_{10} A_{0} / m l_{0}}$. 
A tabela 5.1 ilustra os modos de vibração da treliça perfeita, que independem do ângulo de abatimento da estrutura.

Tabela 5.1: Modos de vibração para a treliça perfeita.

\begin{tabular}{l} 
Modos \\
$\left\{\begin{array}{l}1 \\
0\end{array}\right\}$ \\
\hline
\end{tabular}

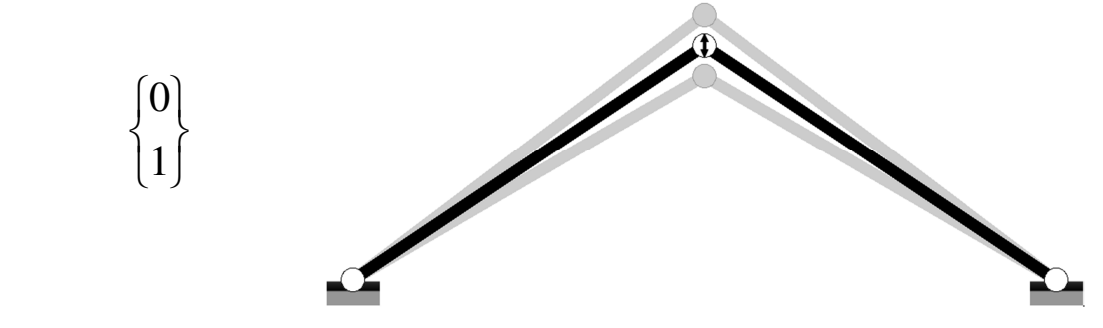

A Figura 5.1 apresenta a variação das frequências em função do ângulo de abatimento da treliça $\theta$.

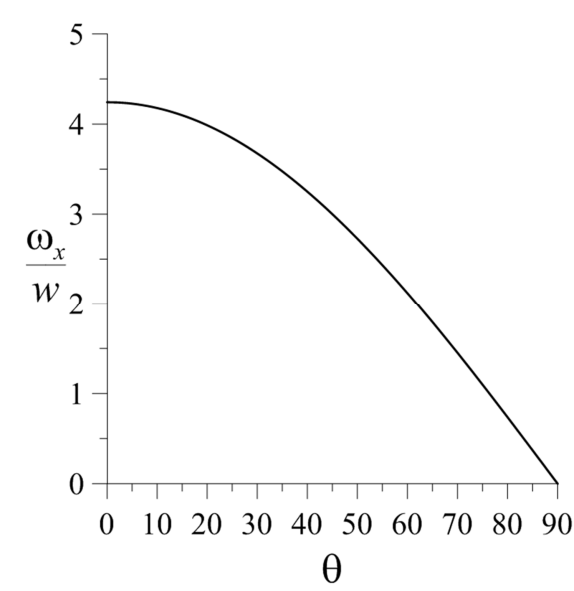

(a) Direção $x$.

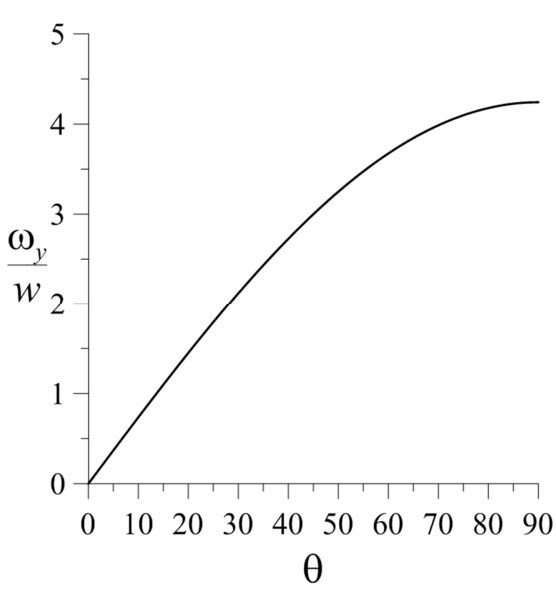

(b) Direção $y$.

Figura 5.1: Frequências naturais para a treliça perfeita em função de $\theta$. 
De acordo com a Figura 5.1, conforme a treliça $\theta$ cresce, a frequência natural na direção $x$ diminui e em $y$ aumenta, sendo iguais quando $\theta=45^{\circ}$, levando a uma possível ressonância interna (Nayfeh, 2000).

\subsection{2.}

\section{Influência da imperfeição geométrica}

As frequências naturais e modos de vibração para a treliça com imperfeição geométrica são obtidos através das Equações (5.8) e (5.9), adotando-se para o nó da treliça imperfeita descarregada do exemplo as coordenadas $\left(\alpha_{x, e}, \alpha_{y, e}, Q_{i}\right)=$ $(0,05,-0,05,0)$.

A Tabela 5.2 compara os valores obtidos para as frequências naturais da estrutura descarregada com e sem imperfeição para os ângulos de abatimento iguais a $\theta=15^{\circ}, 45^{\circ} \mathrm{e} 75^{\circ}$.

Tabela 5.2: Frequências naturais da treliça para $\theta=15^{\circ}, 45^{\circ} \mathrm{e} 75^{\circ}$.

\begin{tabular}{ccc}
\hline$\theta$ & Modelo & Frequências Naturais \\
\hline $15^{\circ}$ & Perfeito & $(\mathrm{y}) 1,10 w ; \times 4,10 w$ \\
& Imperfeito & $(1) 1,09 w ;(2) 3,88 w$ \\
\hline $45^{\circ}$ & Perfeito & $(3,00 w ;$ ( $) 3,00 w$ \\
& Imperfeito & $(1) 2,71 w ;(2) 2,86 w$ \\
\hline $75^{\circ}$ & Perfeito & $(11,10 w ;$ ( $) 4,10 w$ \\
& Imperfeito & $(1) 0,95 w ;(2) 3,74 w$ \\
\hline
\end{tabular}

Nota-se na Tabela 5.2 que, para os três ângulos de abatimento apresentados, as frequências naturais da estrutura com imperfeição geométrica são inferiores as frequências da treliça perfeita.

A Figura 5.2 apresenta a variação da frequência normalizada em relação à $w$ com o ângulo $\theta$ para a estrutura perfeita, em preto, e com imperfeição geométrica, em vermelho. Verifica-se que o cruzamento observado no sistema 
perfeito deixa de existir no caso imperfeito. Entretanto as frequências se tornam muito próximas em torno de $\theta=45^{\circ}$, podendo isto levar a uma interação modal.

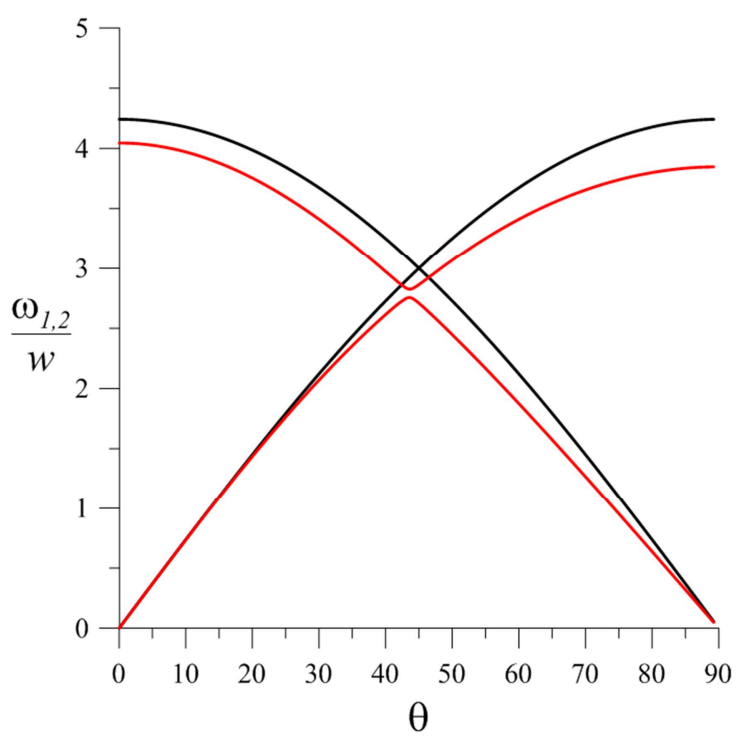

Figura 5.2: Frequências naturais em função de $\theta$ para a treliça descarregada com e sem imperfeição.

As Tabelas 5.3 e 5.4 exibem os modos de vibração para a treliça com imperfeição geométrica e ângulos de abatimento $\theta=15^{\circ}, 45^{\circ} \mathrm{e} 75^{\circ}$.

Tabela 5.3: Modos de vibração para o modelo imperfeito $\operatorname{com} \theta=15^{\circ}$.

$\begin{array}{cc}\theta & \text { Modos }\left\{\begin{array}{c}-0,007 \\ 1,000\end{array}\right\} \\ 15^{\circ} & \text { Representação } \\ 15^{\circ}\left\{\begin{array}{c}1,000 \\ 0,101\end{array}\right\} & \end{array}$


Tabela 5.4: Modos de vibração para o modelo imperfeito com $\theta=45^{\circ} \mathrm{e} 75^{\circ}$.

\begin{tabular}{cc}
$\theta$ & Modos \\
\hline $45^{\circ}$ & $(1)\left\{\begin{array}{c}-1,000 \\
0,209\end{array}\right\}$
\end{tabular}

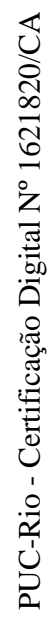

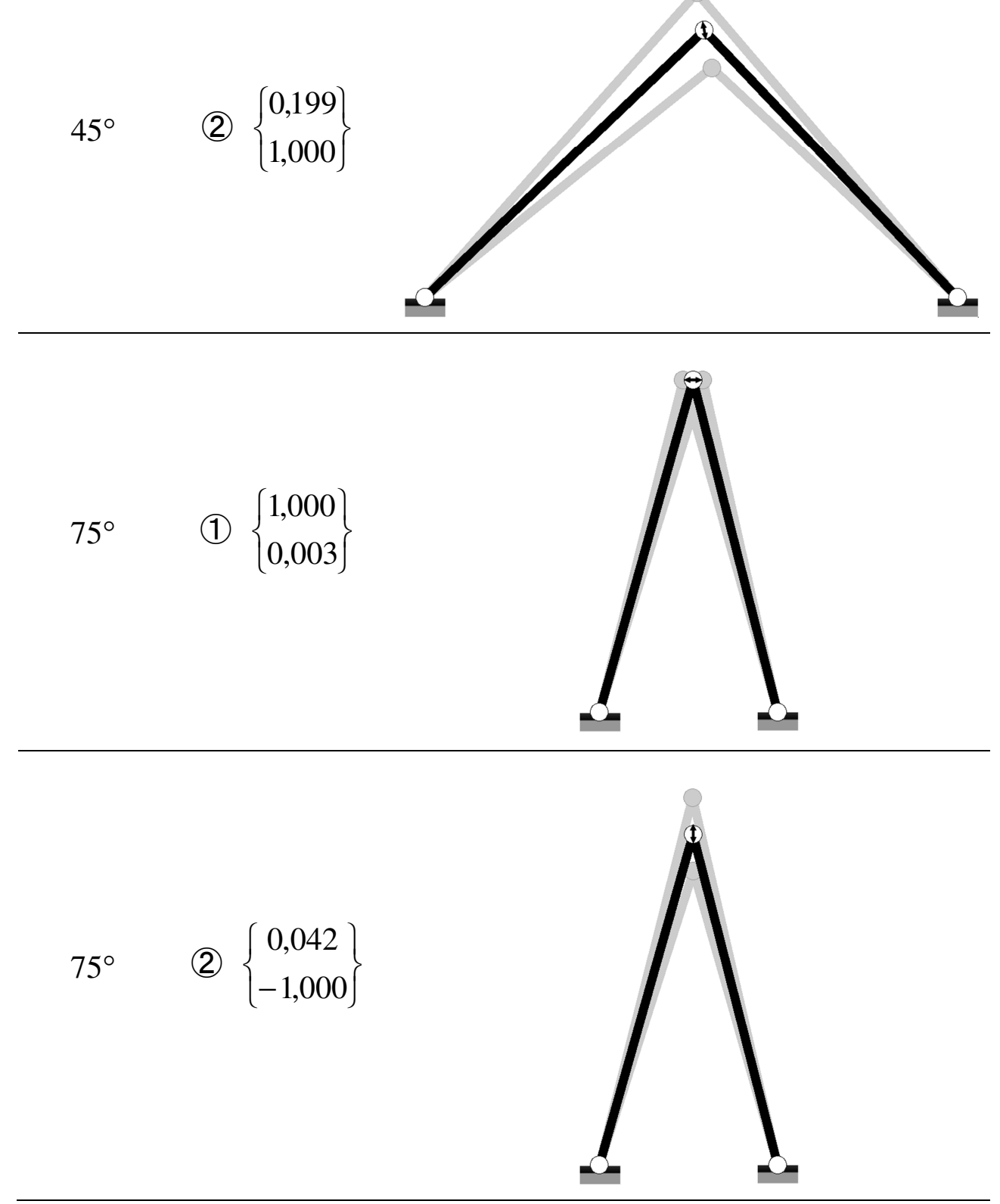


A imperfeição acopla os movimentos nas direções $x$ e $y$ dos modos de vibração da estrutura, conforme apresentado nas Tabelas 5.3 e 5.4. Este acoplamento varia com o ângulo de abatimento da treliça, sendo maior próximo de $\theta=45^{\circ}$, quando as duas frequências naturais estão mais próximas.

\section{3.}

\section{Frequências naturais da estrutura carregada estaticamente}

Na presença de carga, conforme exposto na análise estática, a treliça exibe um comportamento não linear devido ao seu material, em função das grandes deformações, e também da própria geometria, variando sua rigidez ao longo dos caminhos de equilíbrio e, com isso, as suas frequências.

Do mesmo modo que no caso para a treliça com imperfeição geométrica, transfere-se a origem do sistema de coordenadas para a posição de equilíbrio estático. Neste caso a variação da energia potencial total entre a configuração de equilíbrio estático e uma configuração adjacente é dada por:

$$
\Delta \Pi=\Pi\left(\alpha_{x, d}+\alpha_{x, e}, \alpha_{y, d}+\alpha_{y, e}, Q_{i}\right)-\Pi\left(\alpha_{x, e}, \alpha_{y, e}, Q_{i}\right)
$$

Escreve-se a função de Lagrange em termos energia cinética e da variação da energia potencial total. Em seguida, aplica-se a equação de Euler-Lagrange para obter as equações de movimento.

Destaca-se que neste processo as parcelas estáticas das equações de movimento equilibram-se e assim as equações que descrevem a vibração da treliça em torno da posição de equilíbrio estático, $\left(\alpha_{x, e}, \alpha_{y, e}, Q_{i}\right)$, são as mesmas que controlam a vibração livre da treliça imperfeita descarregada.

\subsection{1.}

\section{Carga vertical}

Quando submetida a um carregamento estático, obtêm-se, utilizando as formulações apresentadas no Capítulo 4, coordenadas dos caminhos de equilíbrio, $\left(\alpha_{x, e}, \alpha_{y, e}, Q_{i}\right)$, e a partir das Equações (5.8) e (5.9), as duas frequências naturais para cada posição de equilíbrio estático. Deste modo têm-se duas curvas 
associadas a cada trajetória de equilíbrio estático. A fim de conseguir representar os resultados relativos aos trechos instáveis, plotam-se as frequências elevadas ao quadrado.

\subsubsection{1.}

\section{Modelo perfeito}

Para representar as duas frequências naturais usam-se as mesmas cores das suas respectivas trajetórias de equilíbrio na análise estática apresentadas no Capítulo 4. A Figura 5.3 exibe a variação das frequências naturais da treliça perfeita com carga estática vertical para o ângulo $\theta=15^{\circ}$.
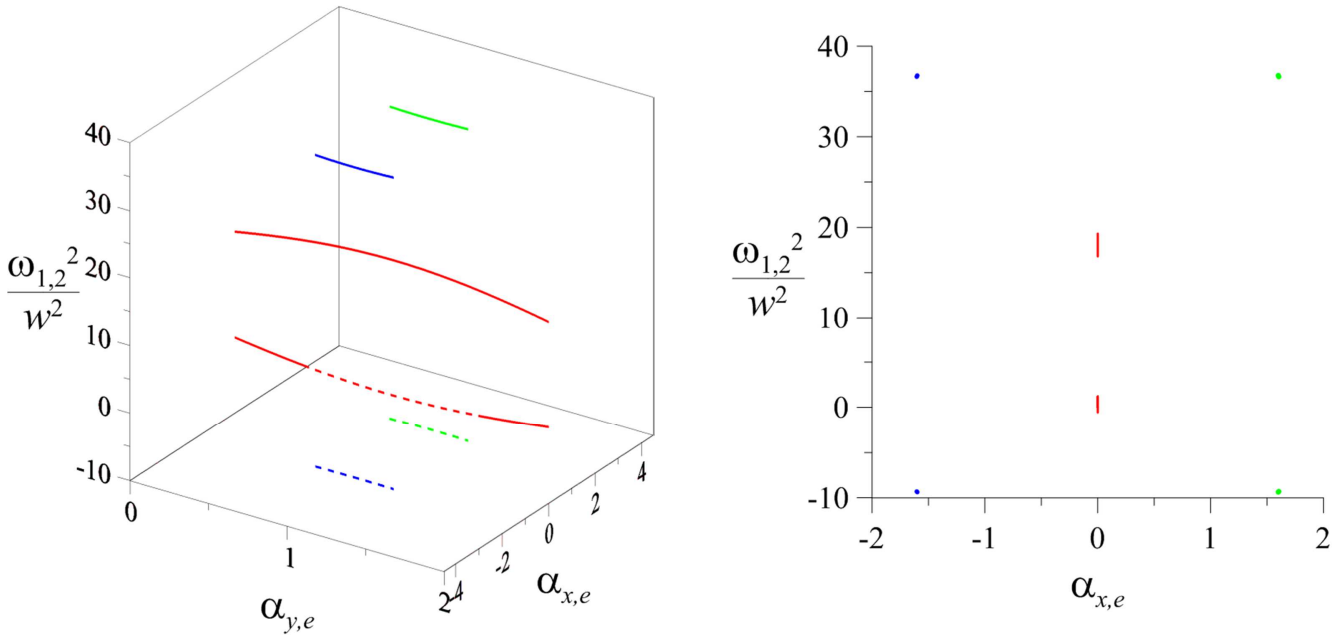

(a) Vista $\alpha_{x, e} \times \alpha_{y, e} \times \omega_{1,2}{ }^{2} / w^{2}$.

(b) Projeção $\alpha_{x, e} \times \omega_{1,2}{ }^{2} / w^{2}$.
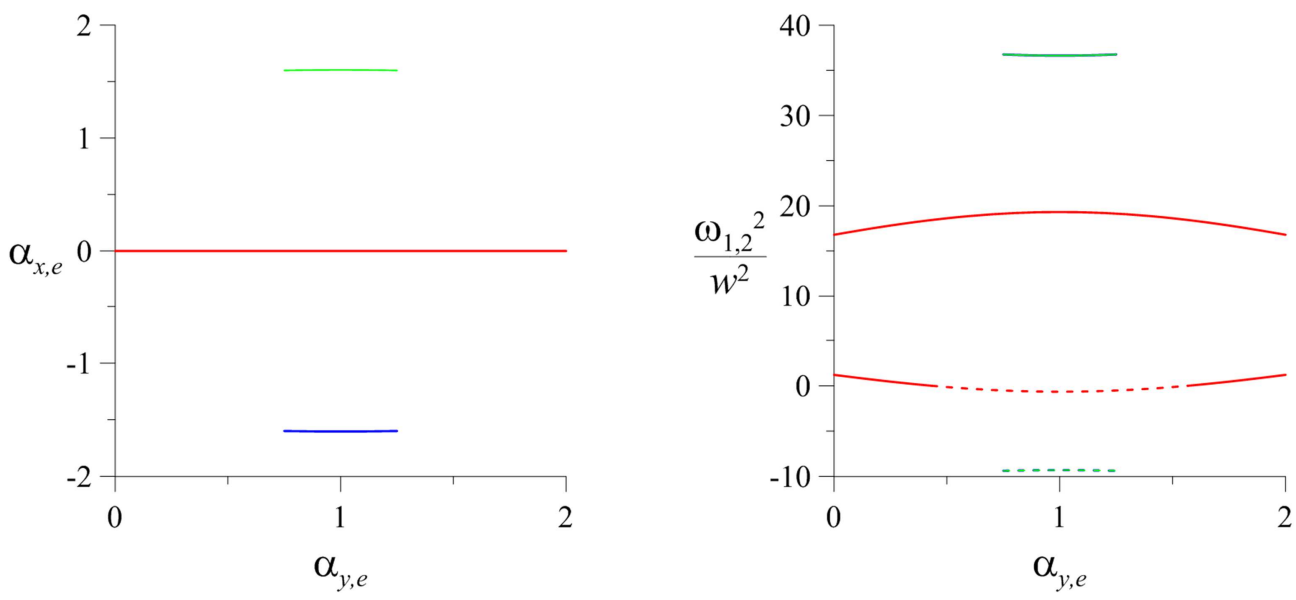

(c) Vista $\alpha_{x, e} \times \alpha_{y, e}$.

(d) Projeção $\alpha_{y, e} \times{\omega_{1,2}}^{2} / w^{2}$.

Figura 5.3: Caminho das frequências naturais ao quadrado para treliça com carga vertical e $\theta=15^{\circ}$ ao longo das posições de equilíbrio estático. 
Para a treliça perfeita com carga estática vertical, ao longo da trajetória fundamental em vermelho, as maiores frequências correspondem ao modo de vibração na direção $x$. À medida que a carga aumenta, a frequência aumenta na direção $x$ e diminui na direção $y$, até tornar-se zero no ponto limite, indicando a perda de estabilidade da treliça. Entre os dois pontos limites o quadrado da menor frequência se torna negativo, indicando instabilidade, em conformidade com os resultados da análise estática. Ao longo dos dois caminhos secundários (em azul e verde), tem-se sempre $\omega_{1}^{2} / w^{2}<0$ e $\omega_{2}^{2} / w^{2}>0$, indicando instabilidade (ponto de sela).

A Figura 5.4 exibe a variação das frequências naturais ao quadrado em função das posições de equilíbrio estático para a treliça com $\theta=75^{\circ}$. Observa-se que nos trechos correspondentes a equilíbrio estável tem-se $\omega_{1,2}{ }^{2} / w^{2}>0$ e, para os trechos instáveis, $\omega_{1}^{2} / w^{2}<0$ e $\omega_{2}^{2} / w^{2}>0$ (pontos de sela). Nos pontos de bifurcação a menor frequência se torna nula, indicando a perda de estabilidade e a bifurcação acopla seus modos de vibração. Observa-se uma grande influência do carregamento estático nas frequências naturais da estrutura. Isto se deve à grande variação da rigidez efetiva que é função das não linearidades físicas e geométricas.
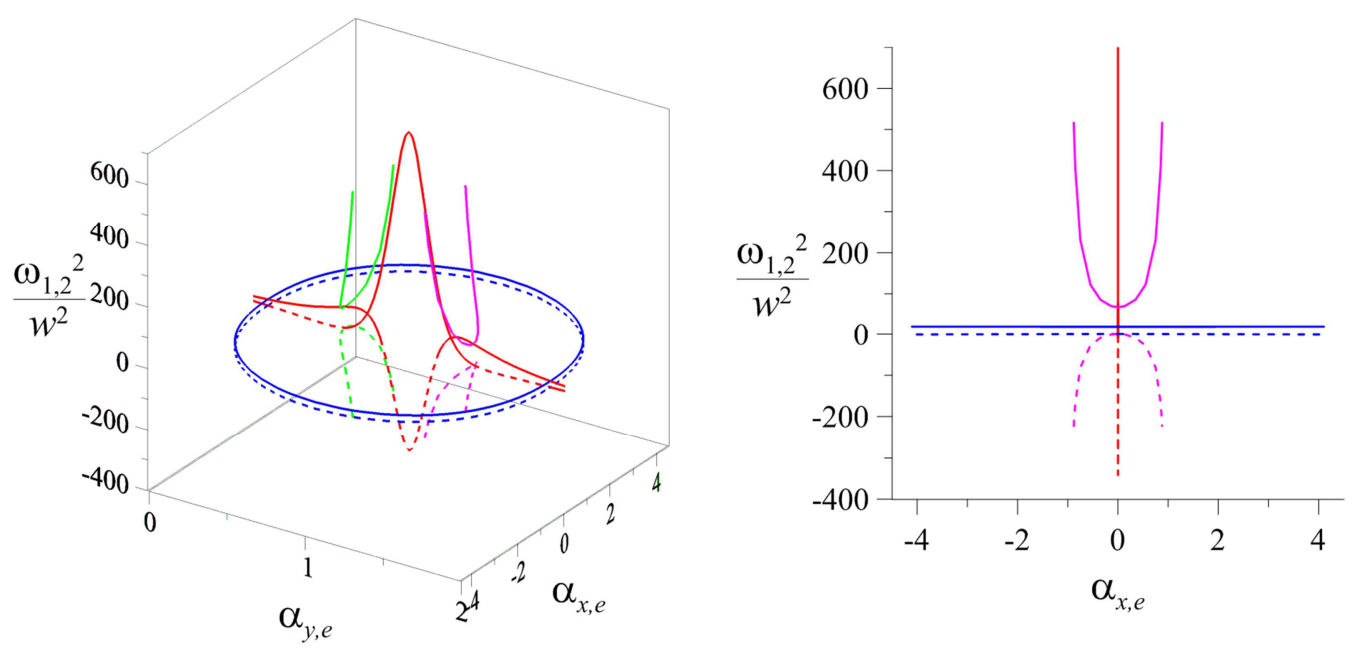
(a) Vista $\alpha_{x, e} \times \alpha_{y, e} \times \omega_{1,2}{ }^{2} / w^{2}$.
(b) Projeção $\alpha_{x, e} \times \omega_{1,2}^{2} / w^{2}$. 


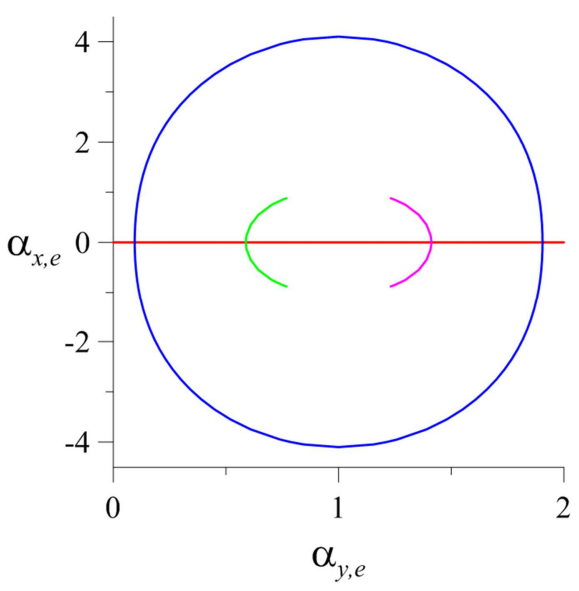

(c) Vista $\alpha_{x, e} \times \alpha_{y, e}$.

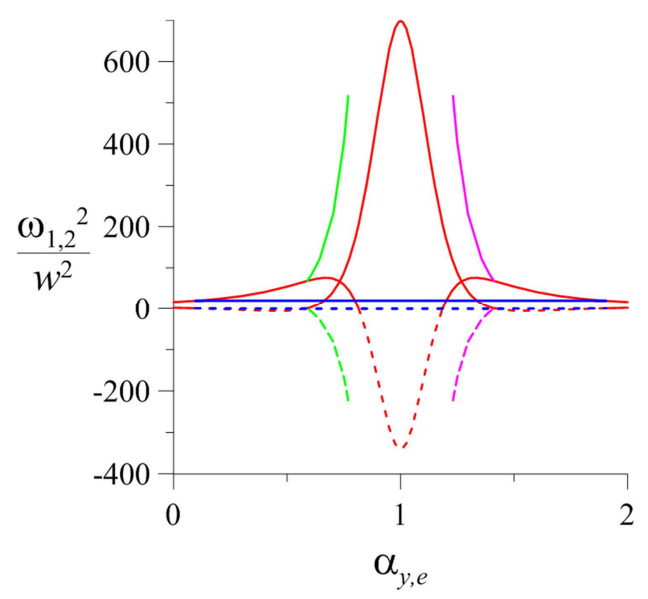

(d) Projeção $\alpha_{y, e} \times \omega_{1,2}{ }^{2} / w^{2}$.

Figura 5.4: Caminho das frequências naturais ao quadrado para a treliça com carga vertical e $\theta=75^{\circ}$ ao longo das posições de equilíbrio estático.

A Tabela 5.5 apresenta os valores das frequências naturais ao quadrado para a treliça descarregada e carregada, com as coordenadas estáticas referentes à carga máxima que a estrutura suporta, que para $\theta=15^{\circ}$ equivale à carga limite e para $\theta=75^{\circ}$, à carga crítica no ponto de bifurcação.

Tabela 5.5: Frequências naturais ao quadrado das treliças com carga vertical, $\theta=15^{\circ} \mathrm{e}$ $\theta=75^{\circ}$, nas posições descarregadas e críticas.

\begin{tabular}{|c|c|c|}
\hline$\theta$ & $\left(\alpha_{x, e}, \alpha_{y, e}, Q_{y}\right)$ & $\omega_{x, y}{ }^{2} / w^{2}$ \\
\hline \multirow{2}{*}{$15^{\circ}$} & $(0,0,0)$ & (У) 1,$21 ; \gtrsim 16,81$ \\
\hline & $(0,0,433,0,042)$ & (y) 0,00 ; $\times 18,43$ \\
\hline \multirow{2}{*}{$75^{\circ}$} & $(0,0,0)$ & × 1,$21 ;$ (У) 16,81 \\
\hline & $(0,0,095,1,114)$ & メ 0,$00 ;$ (У)19,91 \\
\hline
\end{tabular}

Observa-se na Tabela 5.5 o valor das frequências anulando-se quando a treliça atinge a posição crítica. 


\subsubsection{2.}

\section{Influência das imperfeições}

A Figura 5.5 exibe as frequências naturais ao quadrado do sistema estrutural com imperfeição geométrica (projeções das barras na direção $x$ são alteradas em $5 \%$ - ver Fig. 3.5) e $\theta=15^{\circ}$. As trajetórias em vermelho referem-se à estrutura com imperfeição e em preto, à estrutura perfeita. Observa-se pouca influência da imperfeição na menor frequência. Entretanto há um decréscimo sensível do quadrado da segunda frequência, $\omega_{2}^{2} / w^{2}$. A Tabela 5.6 apresenta as frequências naturais da estrutura para a posição de equilíbrio estático referente ao ponto limite.
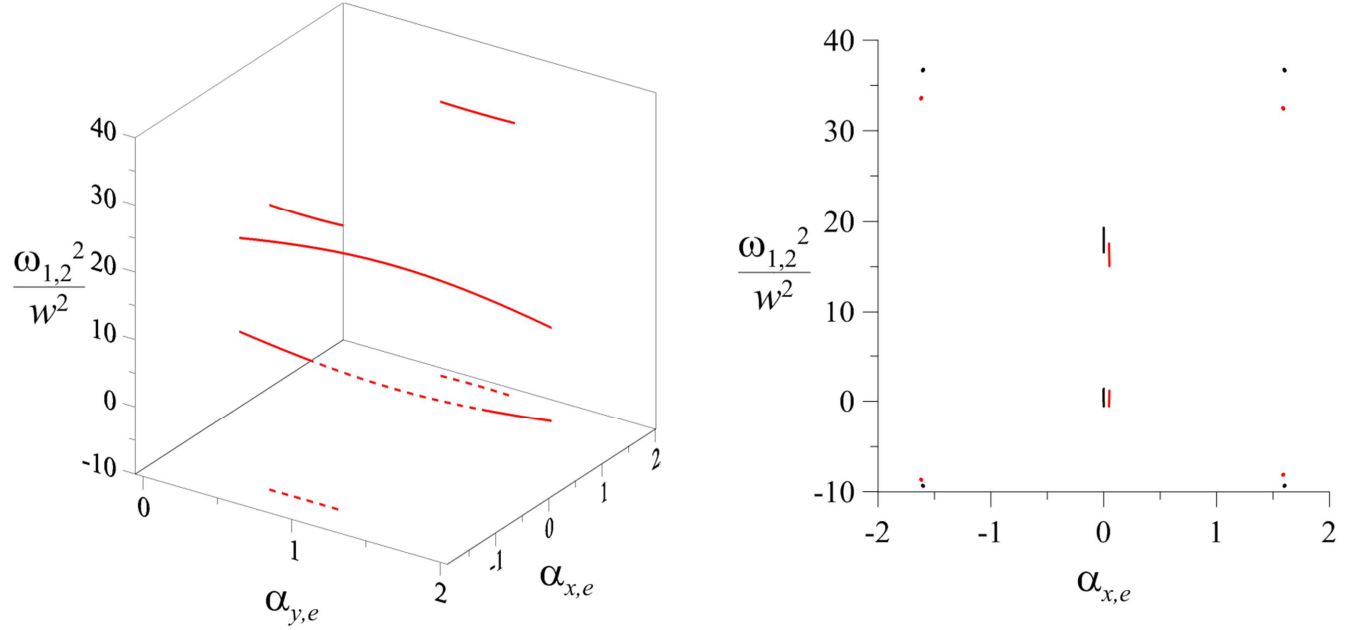

(a) Vista $\alpha_{x, e} \times \alpha_{y, e} \times \omega_{1,2}{ }^{2} / w^{2}$.

(b) Projeção $\alpha_{x, e} \times \omega_{1,2}^{2} / w^{2}$.
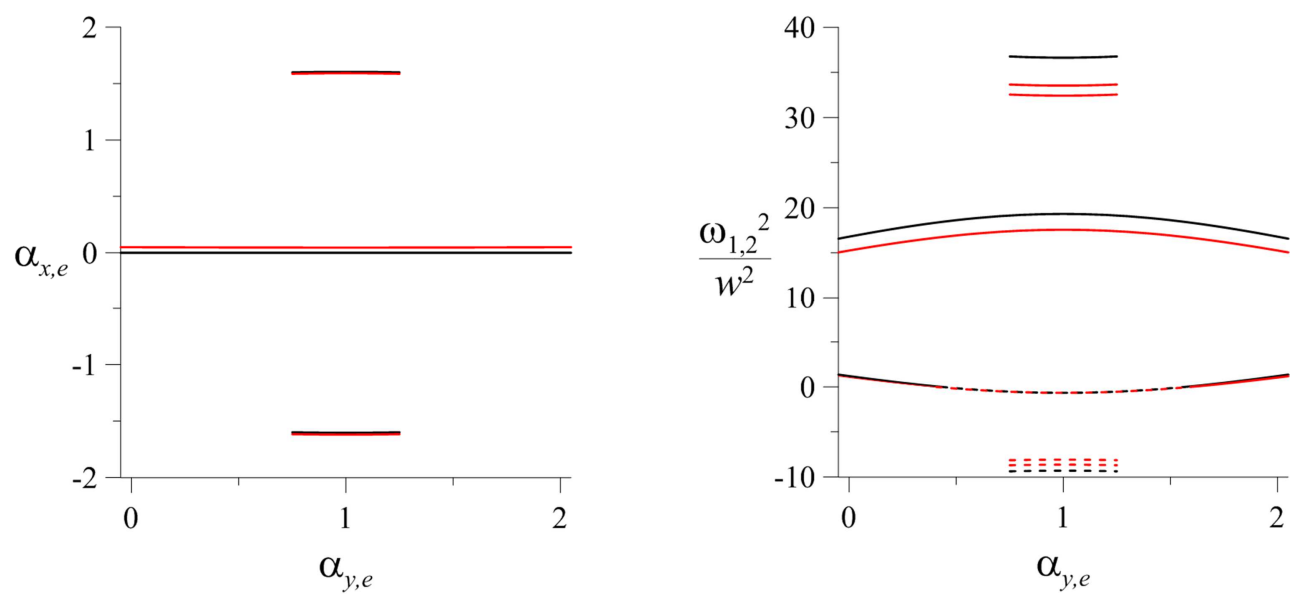

(c) Vista $\alpha_{x, e} \times \alpha_{y, e}$.

(d) Projeção $\alpha_{y, e} \times \omega_{1,2}{ }^{2} / w^{2}$.

Figura 5.5: Caminho das frequências naturais ao quadrado da treliça com carga vertical, imperfeição geométrica e $\theta=15^{\circ}$ ao longo das posições de equilíbrio estático. 
Para o sistema com imperfeição de carga (perturbação horizontal de $0,01 p_{y}$ ), a imperfeição não altera de forma significativa as frequências quando comparado à estrutura perfeita.

Tabela 5.6: Frequências naturais ao quadrado e modos de vibração da treliça com carga vertical, sem e com imperfeição, e $\theta=15^{\circ}$ na posição do ponto limite.

\begin{tabular}{cccc}
\hline Modelo & $\left(\alpha_{x, e}, \alpha_{y, e}, Q_{y}\right)$ & $\omega_{1,2}{ }^{2} / w^{2}$ & Modos de Vibração \\
\hline Perfeito & $(0,0,433,0,042)$ & 0,$00 ; 18,43$ & $\left\{\begin{array}{l}0,000 \\
1,000\end{array}\right\} ;\left\{\begin{array}{l}1,000 \\
0,000\end{array}\right\}$ \\
\hline $\begin{array}{c}\text { Imperfeição } \\
\text { geométrica }\end{array}$ & $(0,048,0,407,0,049)$ & 0,$00 ; 16,68$ & $\left\{\begin{array}{c}-0,004 \\
1,000\end{array}\right\} ;\left\{\begin{array}{c}1,000 \\
0,057\end{array}\right\}$ \\
\hline
\end{tabular}

Por meio da Figura 5.5 e da Tabela 5.6, nota-se a diminuição da maior frequência em relação à estrutura perfeita, que de uma forma geral, correlacionase à rigidez do sistema na direção $x$. Ao mesmo tempo, enquanto o deslocamento diminui na outra direção, a carga limite aumenta, indicando uma maior rigidez do sistema nessa direção.

As Figuras 5.6 e 5.7 ilustram as frequências naturais ao longo das posições de equilíbrio estático para as treliças com imperfeição de carga e geométrica para $\theta=75^{\circ}$.
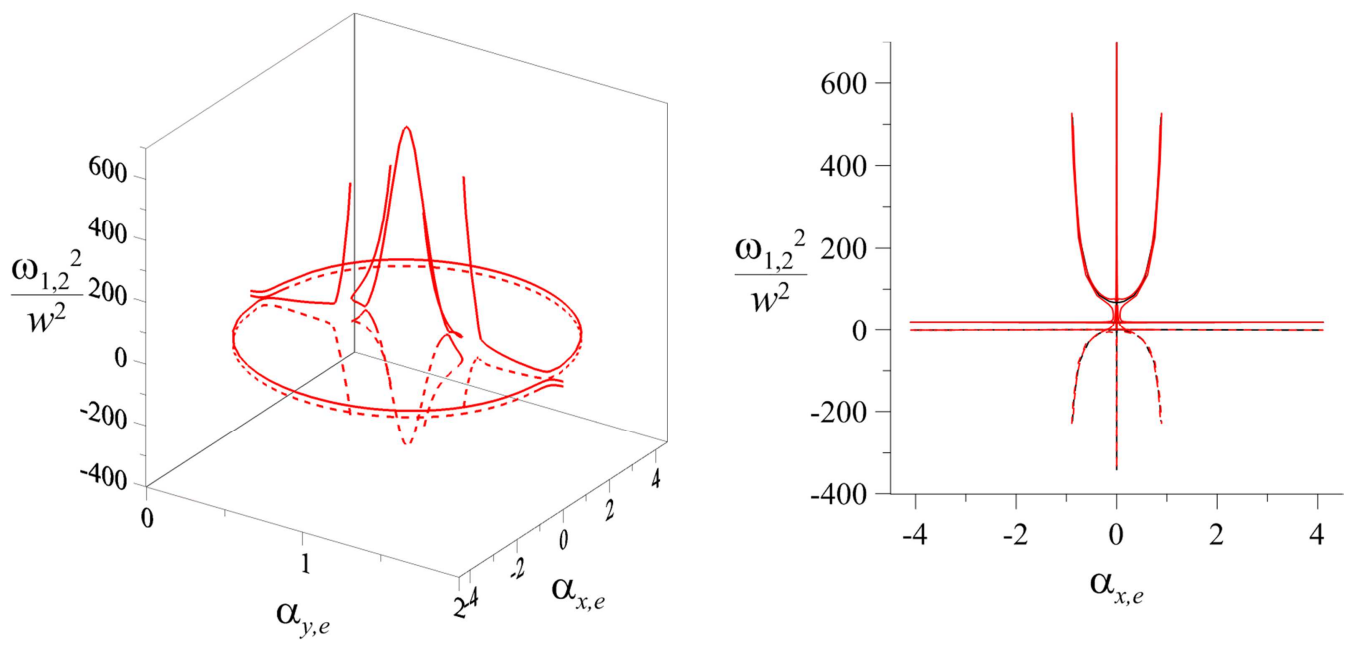
(a) Vista $\alpha_{x, e} \times \alpha_{y, e} \times \omega_{1,2}{ }^{2} / w^{2}$.
(b) Projeção $\alpha_{x, e} \times \omega_{1,2}^{2} / w^{2}$. 


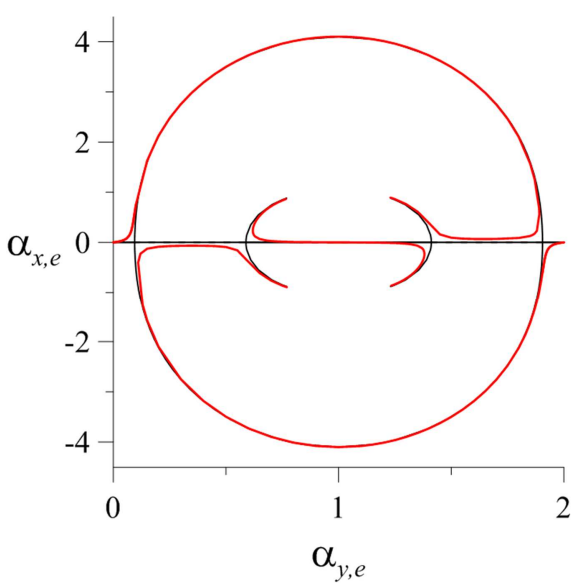

(c) Vista $\alpha_{x, e} \times \alpha_{y, e}$.

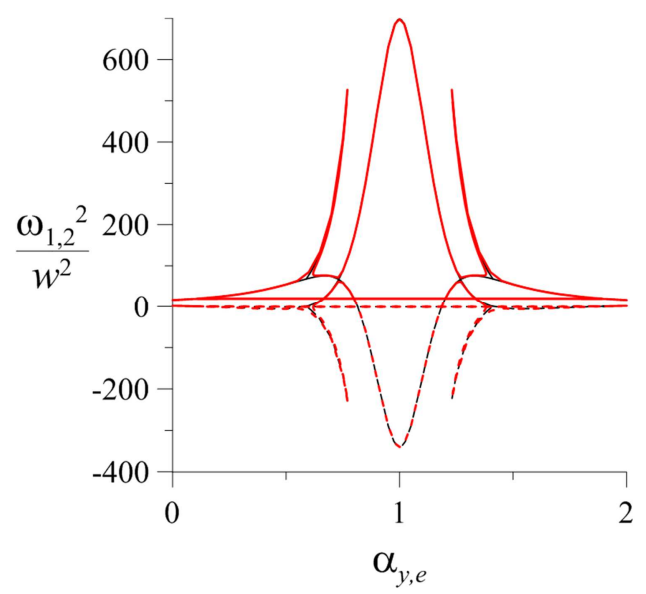

(d) Projeção $\alpha_{y, e} \times \omega_{1,2}{ }^{2} / w^{2}$.

Figura 5.6: Caminho das frequências naturais ao quadrado da treliça com carga vertical, imperfeição de carga e $\theta=75^{\circ}$ ao longo das posições de equilíbrio estático.

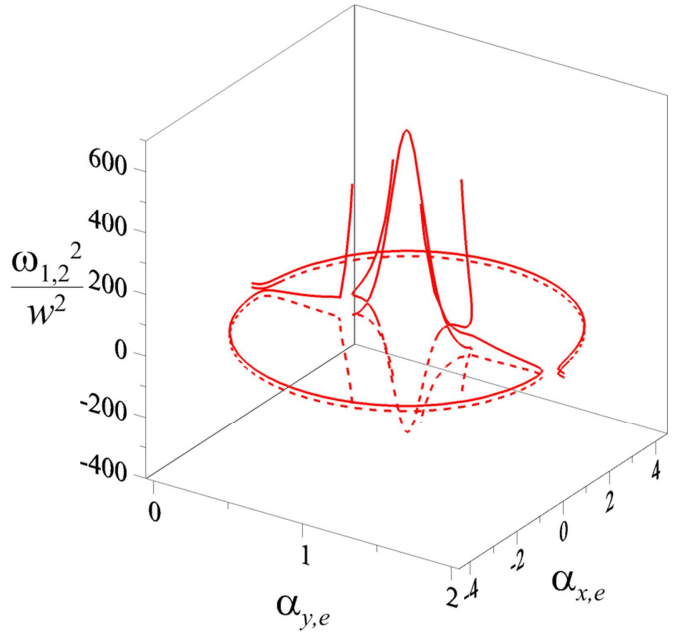

(a) Vista $\alpha_{x, e} \times \alpha_{y, e} \times \omega_{1,2}{ }^{2} / w^{2}$.

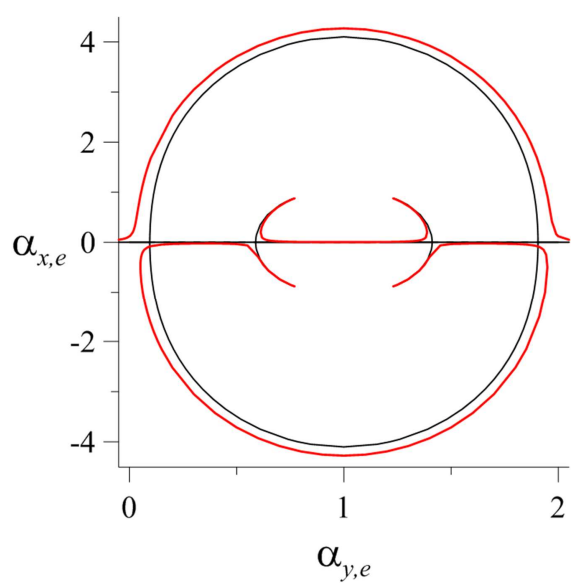

(c) Vista $\alpha_{x, e} \times \alpha_{y, e}$.

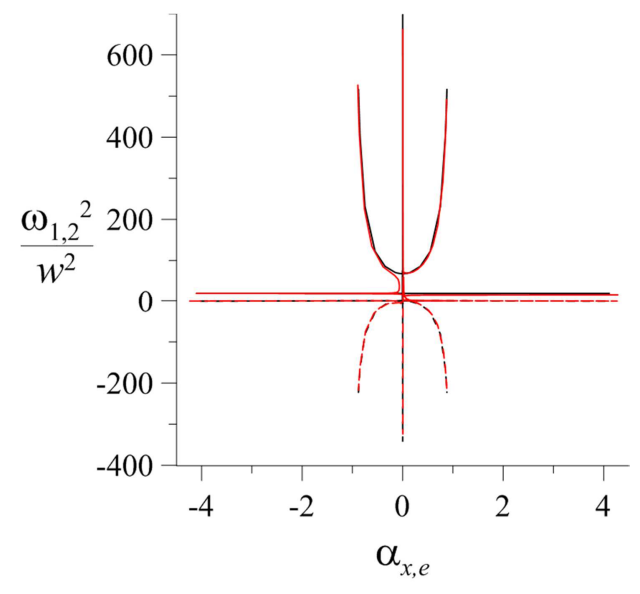

(b) Projeção $\alpha_{x, e} \times \omega_{1,2}^{2} / w^{2}$.

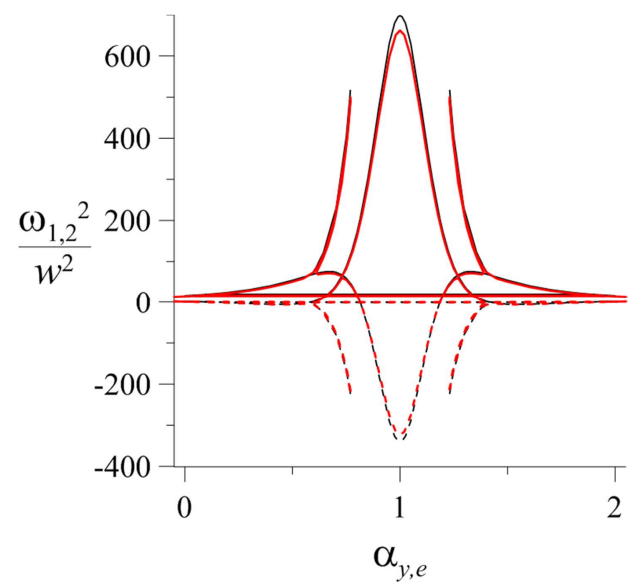

(d) Projeção $\alpha_{y, e} \times \omega_{1,2}{ }^{2} / w^{2}$.

Figura 5.7: Caminho das frequências naturais ao quadrado da treliça com carga vertical, imperfeição geométrica e $\theta=75^{\circ}$ ao longo das posições de equilíbrio estático. 
A Tabela 5.7 apresenta as frequências naturais não lineares da treliça sem e com imperfeições próximas à posição de equilíbrio relativa à primeira carga crítica.

Tabela 5.7: Frequências naturais ao quadrado e modos de vibração para a treliça com carga vertical, sem e com imperfeição, e $\theta=75^{\circ}$ na posição da primeira carga crítica.

\begin{tabular}{cccc}
\hline Modelo & $\left(\alpha_{x, e}, \alpha_{y, e}, Q_{y}\right)$ & $\omega_{1,2}{ }^{2} / w^{2}$ & Modos de vibração \\
\hline Perfeito & $(0,0,095,1,114)$ & 0,$00 ; 19,91$ & $\left\{\begin{array}{l}1,000 \\
0,000\end{array}\right\} ;\left\{\begin{array}{l}0,000 \\
1,000\end{array}\right\}$ \\
\hline $\begin{array}{c}\text { Imperfeição } \\
\text { de carga }\end{array}$ & $(0,461,0,090,0,984)$ & 0,$00 ; 19,71$ & $\left\{\begin{array}{l}0,944 \\
0,033\end{array}\right\} ;\left\{\begin{array}{c}0,485 \\
-1,000\end{array}\right\}$ \\
\hline $\begin{array}{c}\text { Imperfeição } \\
\text { geométrica }\end{array}$ & $(0,752,0,043,0,869)$ & 0,$00 ; 16,12$ & $\left\{\begin{array}{c}0,927 \\
0,037\end{array}\right\} ;\left\{\begin{array}{c}0,563 \\
-1,000\end{array}\right\}$
\end{tabular}

\subsection{2.}

\section{Carga horizontal}

Apresenta-se a seguir a influência da carga estática horizontal na frequência das treliças.

\subsubsection{1. Modelo perfeito}

A Figura 5.8 apresenta a variação não linear das frequências naturais ao quadrado para a treliça perfeita com ângulo de abatimento $\theta=15^{\circ}$. O sistema estrutural perfeito com carga horizontal, conforme apresentado no Capítulo 4 (Figura 4.26), somente torna-se instável ao longo do caminho secundário de equilíbrio que surge o ponto de bifurcação. Deste mesmo modo ao longo do caminho fundamental em vermelho as duas frequências são positivas e sofrem pouca variação ao longo do caminho de equilíbrio (as curvas em vermelho são quase paralelas). Ao longo dos caminhos secundários os quadrados das frequências divergem exponencialmente a partir do ponto de bifurcação. Os resultados para o caminho de equilíbrio isolado em verde confirmam sua instabilidade $\left(\omega_{1}^{2} / w^{2}<0\right.$ e $\left.\omega_{2}^{2} / w^{2}>0\right)$. 

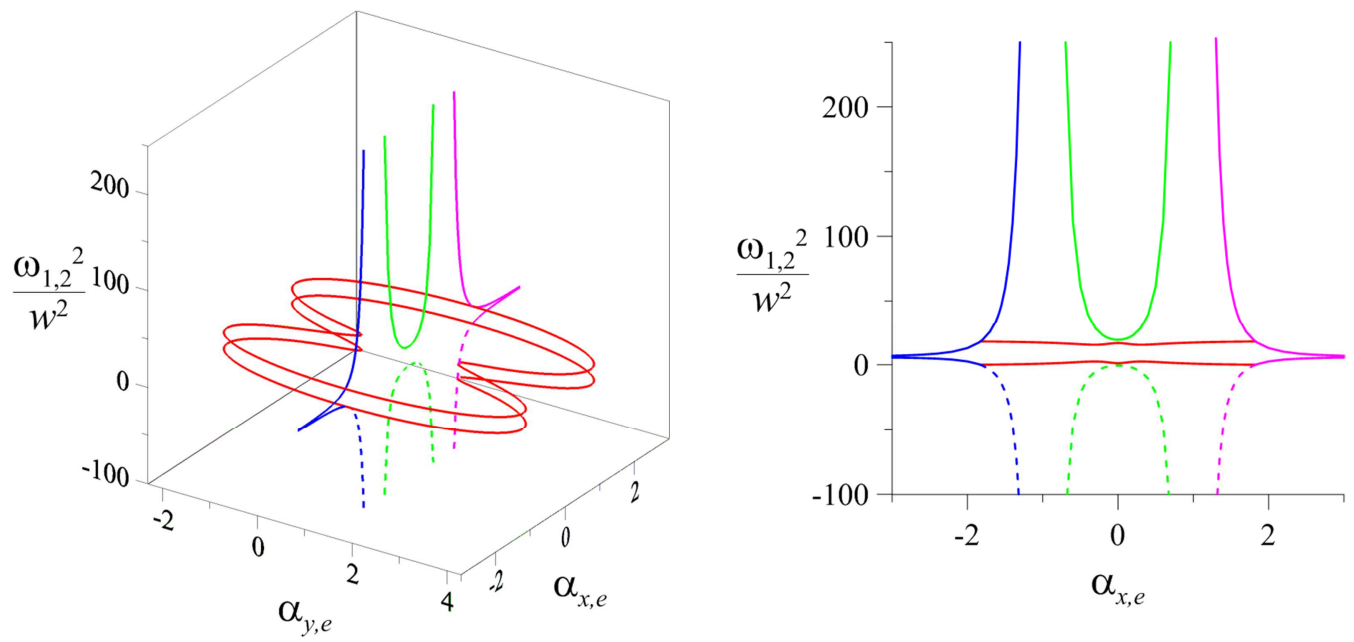

(a) Vista $\alpha_{x, e} \times \alpha_{y, e} \times \omega_{1,2}{ }^{2} / w^{2}$.

(b) Projeção $\alpha_{x, e} \times \omega_{1,2}^{2} / w^{2}$.
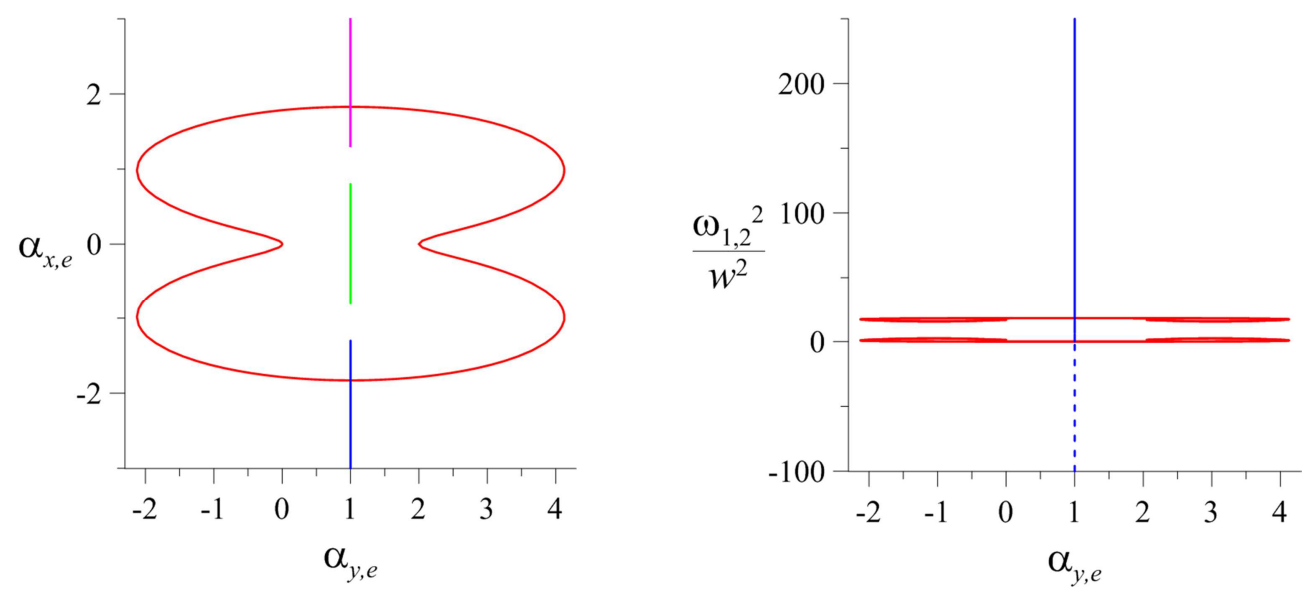

(c) Vista $\alpha_{x, e} \times \alpha_{y, e}$.

(d) Projeção $\alpha_{y, e} \times \omega_{1,2}^{2} / w^{2}$.

Figura 5.8: Caminho das frequências naturais ao quadrado da treliça com carga horizontal e $\theta=15^{\circ}$ ao longo das posições de equilíbrio estático.

A Tabela 5.8 exibe as frequências naturais e os modos de vibração para a posição de equilíbrio estático $(1,-2,125,3,438)$. As linhas tracejadas na Tabela 5.8 referem-se à estrutura indeformada. Para esta posição de equilíbrio, os dois modos de vibração não há praticamente acoplamento entre deslocamentos verticais e horizontais. 
Tabela 5.8: Frequências naturais ao quadrado e modos de vibração da treliça com carga horizontal, $\theta=15^{\circ}$ e na posição $(1,-2,125,3,438)$.

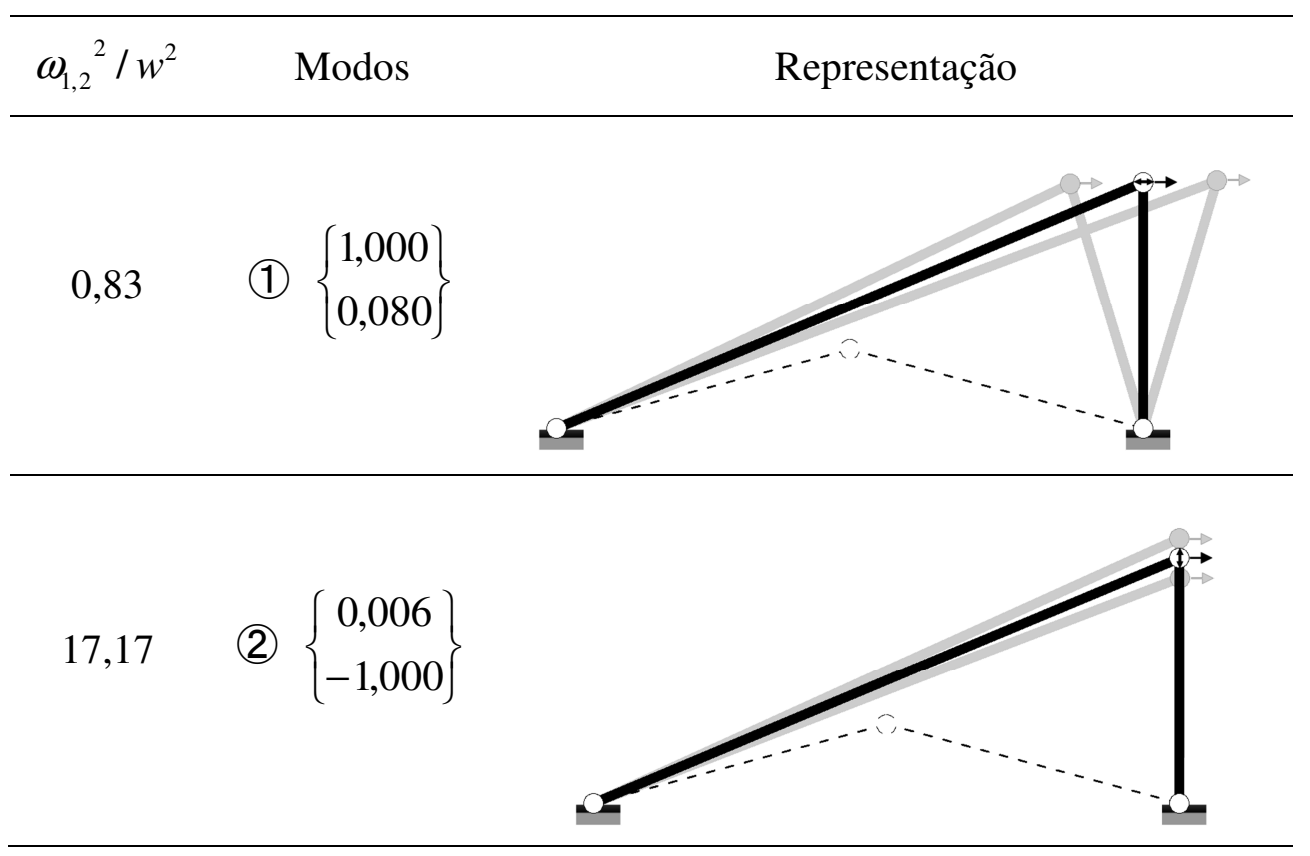

A Figura 5.9 apresenta as frequências naturais para a treliça carregada e $\theta=75^{\circ}$
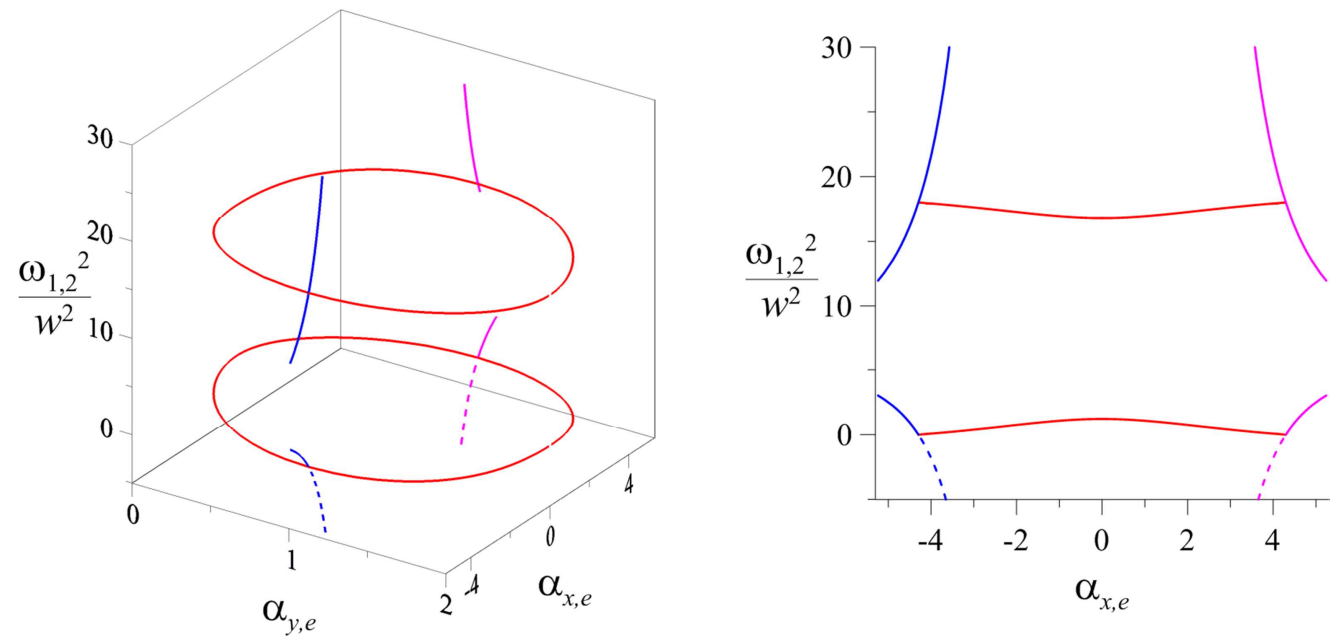
(a) Vista $\alpha_{x, e} \times \alpha_{y, e} \times \omega_{1,2}{ }^{2} / w^{2}$.
(b) Projeção $\alpha_{x, e} \times \omega_{1,2}{ }^{2} / w^{2}$. 


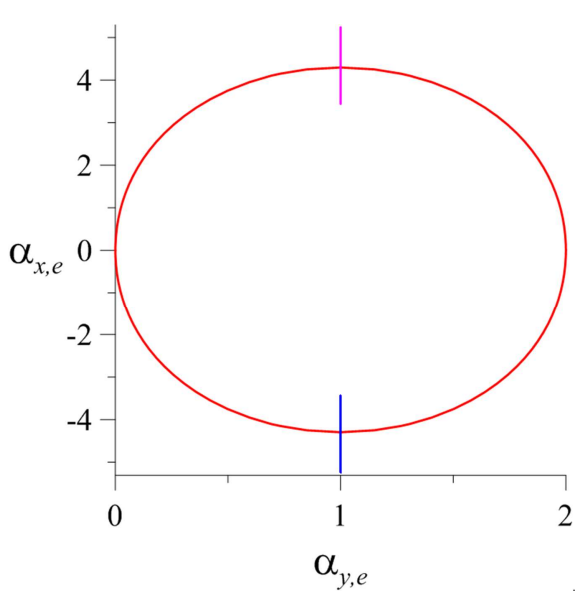

(c) Vista $\alpha_{x, e} \times \alpha_{y, e}$.

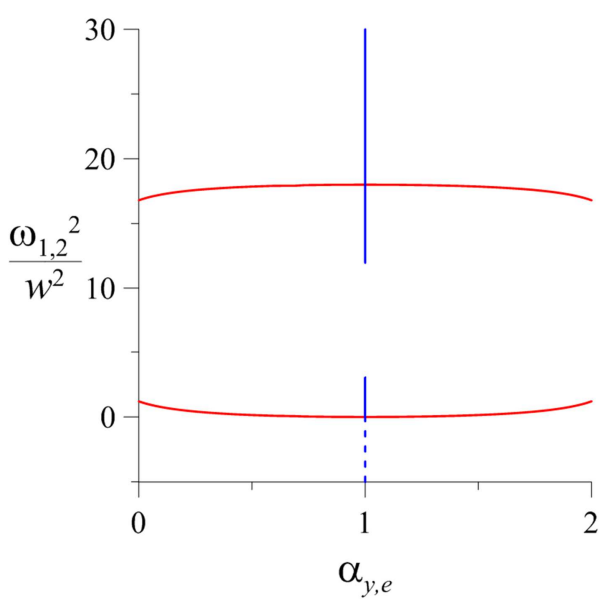

(d) Projeção $\alpha_{y, e} \times \omega_{1,2}^{2} / w^{2}$.

Figura 5.9: Caminho das frequências naturais ao quadrado da treliça com carga horizontal e $\theta=75^{\circ}$ ao longo das posições de equilíbrio estático.

A Tabela 5.9 ilustra as frequências e modos de vibração para posição de equilíbrio estático $(1,0,024,0,202)$. Para este ângulo há um forte acoplamento entre deslocamentos verticais e horizontais no segundo modo de vibração.

Tabela 5.9: Frequências naturais ao quadrado e modos de vibração para a treliça com carga horizontal e $\theta=75^{\circ}$ na posição $(1,0,024,0,202)$.

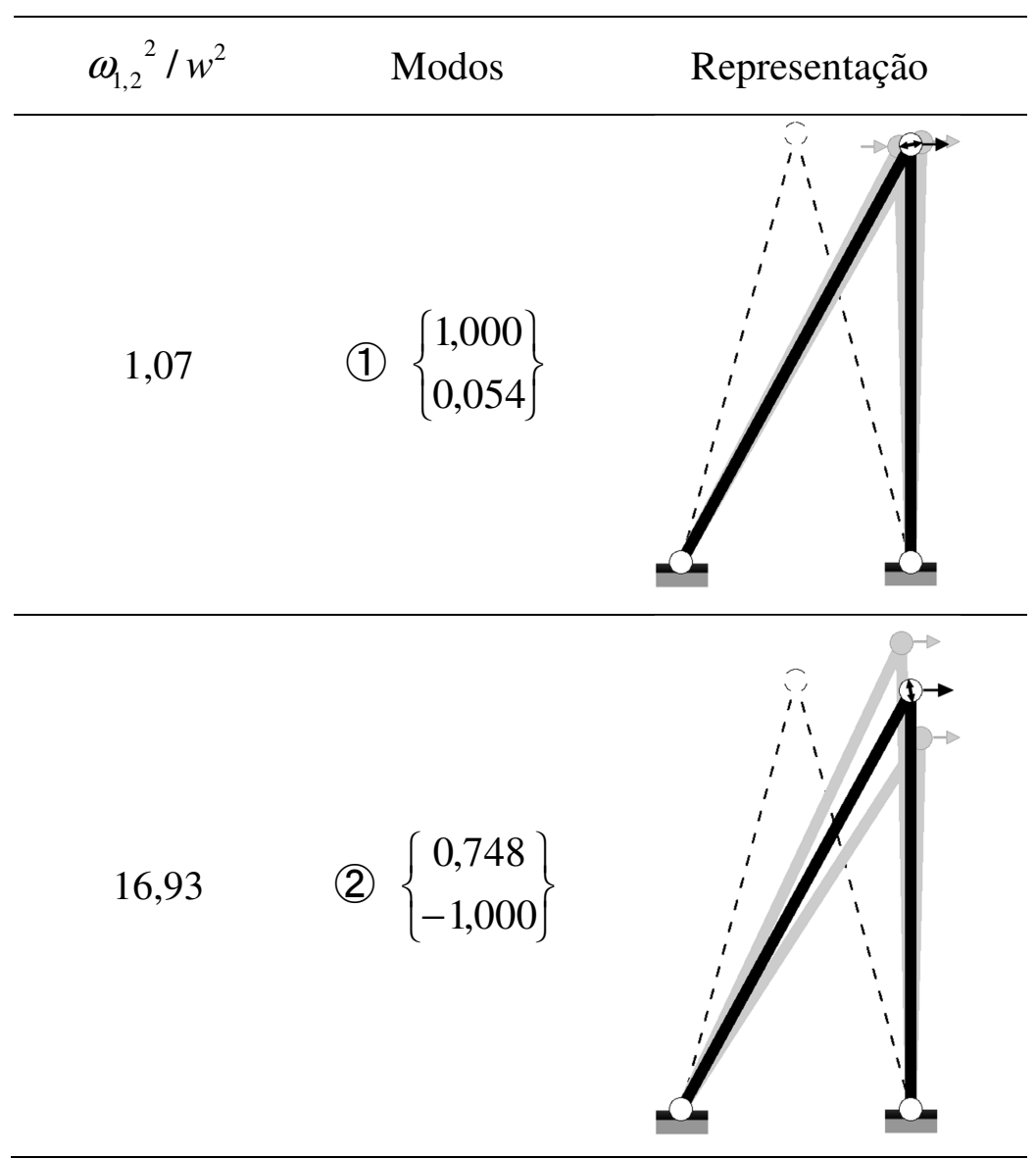


5.3.2.2.

Influência das imperfeições

As Figuras 5.10 e 5.11 exibem os caminhos das frequências naturais não lineares ao quadrado para a treliça abatida com imperfeição de carga e imperfeição geométrica.
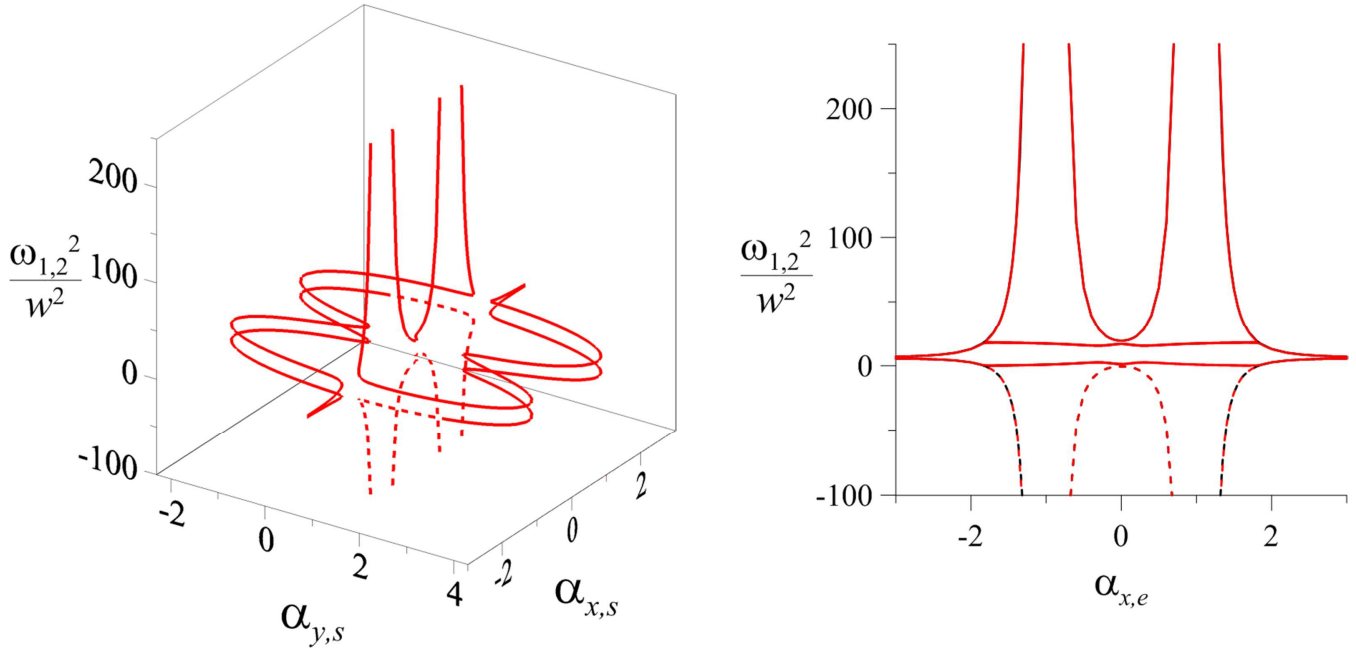

(a) Vista $\alpha_{x, e} \times \alpha_{y, e} \times \omega_{1,2}{ }^{2} / w^{2}$.

(b) Projeção $\alpha_{x, e} \times \omega_{1,2}{ }^{2} / w^{2}$.
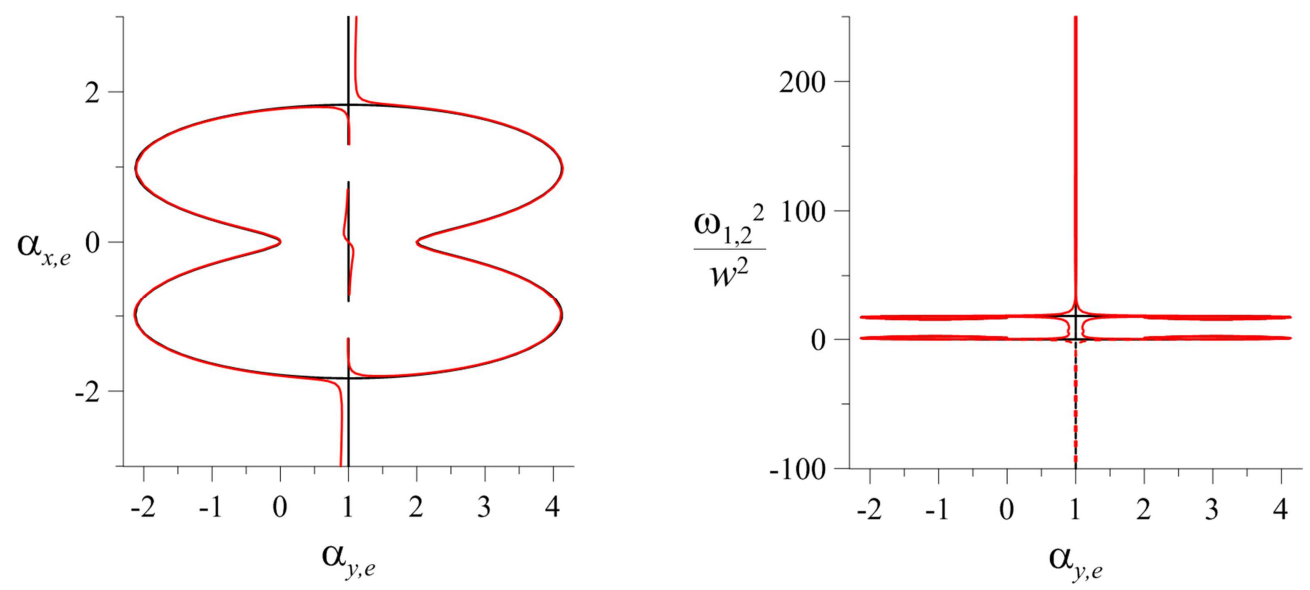

(c) Vista $\alpha_{x, e} \times \alpha_{y, e}$.

(d) Projeção $\alpha_{y, e} \times \omega_{1,2}{ }^{2} / w^{2}$.

Figura 5.10: Caminho das frequências naturais ao quadrado da treliça com carga horizontal, imperfeição de carga e $\theta=15^{\circ}$ ao longo das posições de equilíbrio estático. 

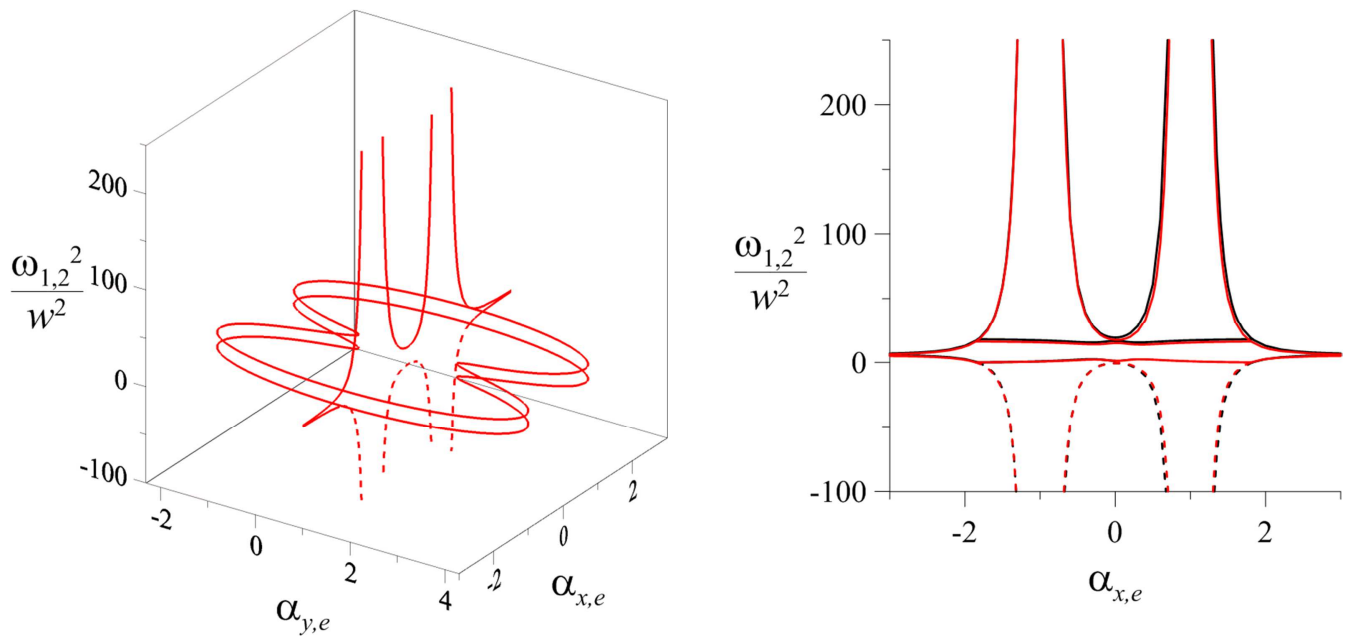

(a) Vista $\alpha_{x, e} \times \alpha_{y, e} \times \omega_{1,2}^{2} / w^{2}$.

(b) Projeção $\alpha_{x, e} \times \omega_{1,2}^{2} / w^{2}$.
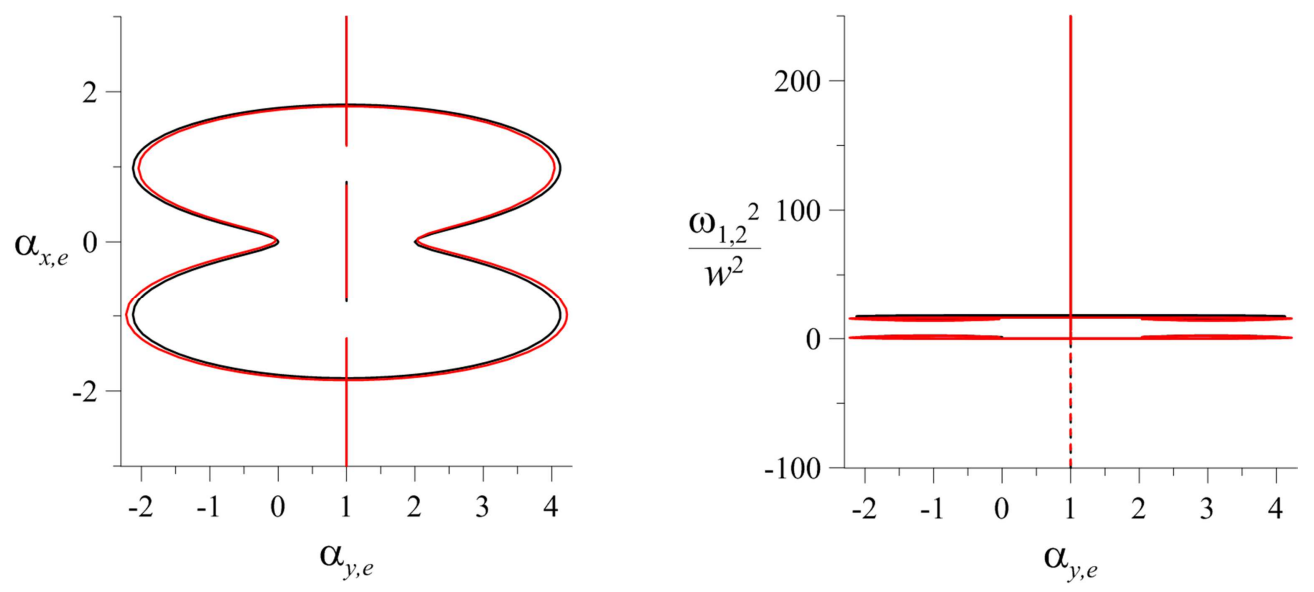

(c) Vista $\alpha_{x, e} \times \alpha_{y, e}$.

(d) Projeção $\alpha_{y, e} \times \omega_{1,2}{ }^{2} / w^{2}$.

Figura 5.11: Caminho das frequências naturais ao quadrado da treliça com carga horizontal, imperfeição geométrica e $\theta=15^{\circ}$ ao longo das posições de equilíbrio estático.

A Tabela 5.10 exibe as frequências naturais para a posição de equilíbrio estático $\alpha_{x, e}=1$.

Tabela 5.10: Frequências naturais ao quadrado e modos de vibração da treliça com carga vertical, sem e com imperfeição, e $\theta=15^{\circ}$ na posição estática $\alpha_{x, e}=1$.

\begin{tabular}{cccc}
\hline Modelo & $\left(\alpha_{x, e}, \alpha_{y, e}, Q_{x}\right)$ & $\omega_{1,2}{ }^{2} / w^{2}$ & Modos de vibração \\
\hline Perfeito & $(1,-2,125,3,438)$ & 0,$83 ; 17,17$ & $\left\{\begin{array}{c}1,000 \\
0,080\end{array}\right\} ;\left\{\begin{array}{c}0,006 \\
-1,000\end{array}\right\}$ \\
\hline $\begin{array}{c}\text { Imperfeição } \\
\text { de carga }\end{array}$ & $(1,-2,112,3,442)$ & 0,$76 ; 17,30$ & $\left\{\begin{array}{c}1,000 \\
0,079\end{array}\right\} ;\left\{\begin{array}{c}0,006 \\
-1,000\end{array}\right\}$ \\
\hline $\begin{array}{c}\text { Imperfeição } \\
\text { geométrica }\end{array}$ & $(1,-2,042,3,211)$ & 0,$84 ; 15,41$ & $\left\{\begin{array}{c}1,000 \\
0,088\end{array}\right\} ;\left\{\begin{array}{c}0,006 \\
-1,000\end{array}\right\}$ \\
\hline
\end{tabular}


Finalmente, as Figuras 5.12 e 5.13 exibem a variação das frequências ao quadrado para a treliça com imperfeição de carga e geométrica e com ângulo $\theta=75^{\circ}$, respectivamente. A Tabela 5.11 quantifica estas frequências para a posição de equilíbrio estático $\alpha_{x, e}=1$ na trajetória fundamental comparando-as com a do modelo sem imperfeição.
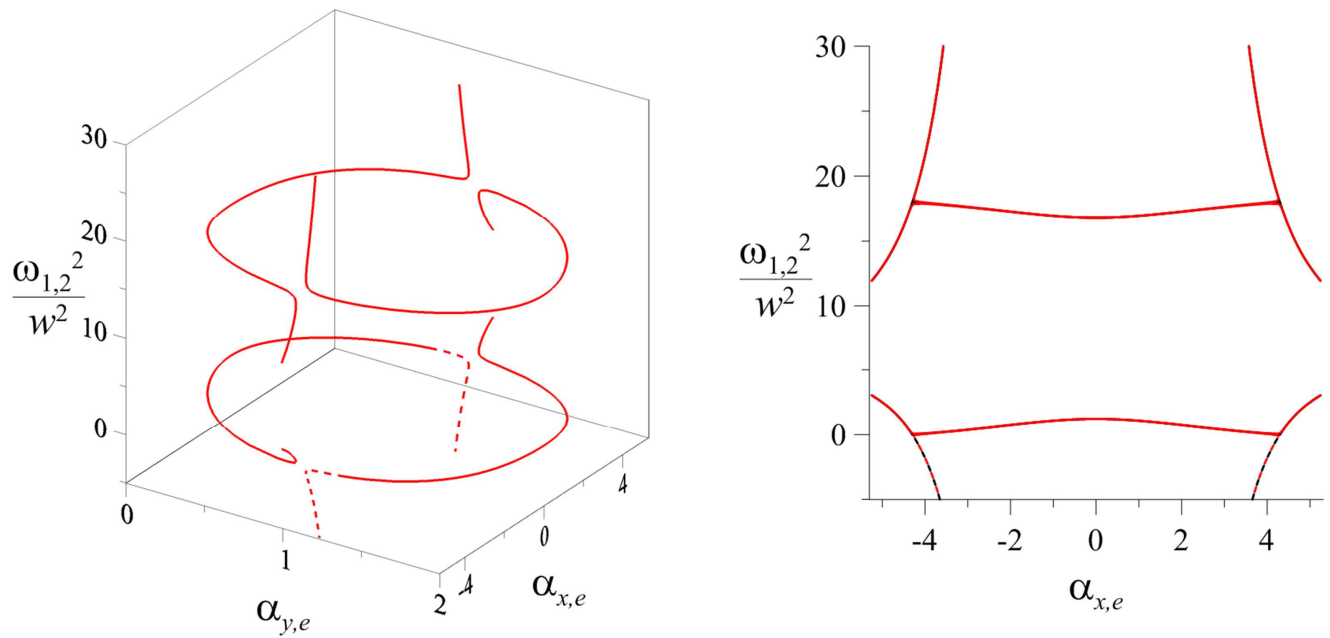

(a) Vista $\alpha_{x, e} \times \alpha_{y, e} \times \omega_{1,2}{ }^{2} / w^{2}$.

(b) Projeção $\alpha_{x, e} \times \omega_{1,2}{ }^{2} / w^{2}$.
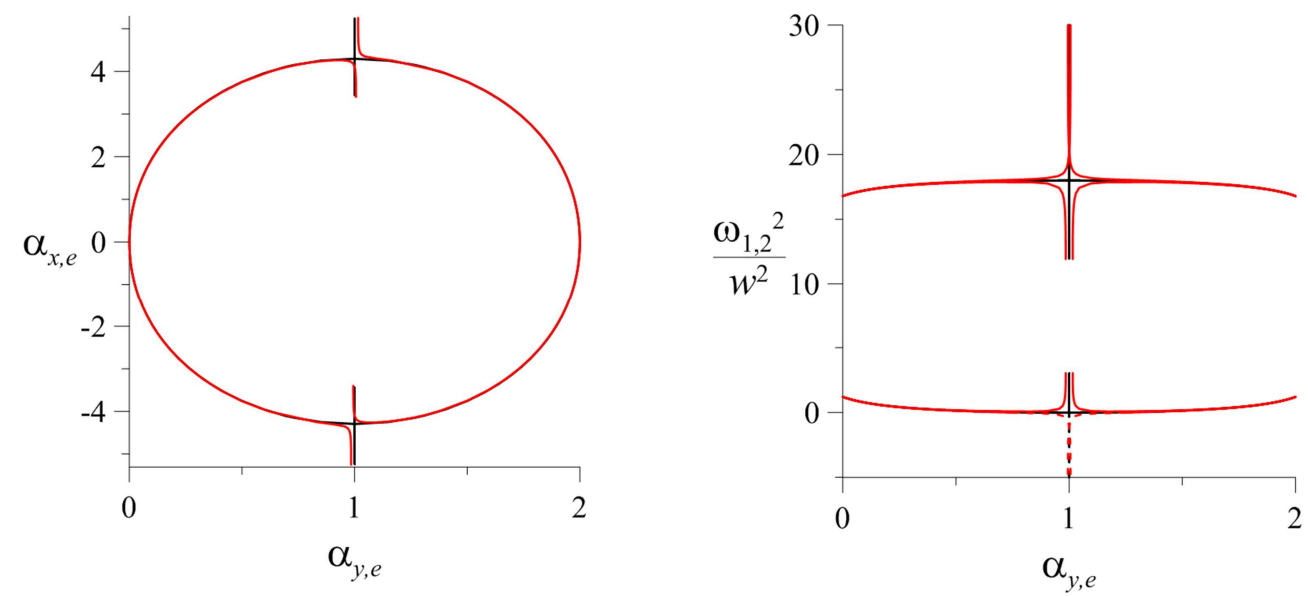

(c) Vista $\alpha_{x, e} \times \alpha_{y, e}$.

(d) Projeção $\alpha_{y, e} \times \omega_{1,2}{ }^{2} / w^{2}$.

Figura 5.12: Caminho das frequências naturais ao quadrado da treliça com carga horizontal, imperfeição de carga e $\theta=75^{\circ}$ ao longo das posições de equilíbrio estático. 

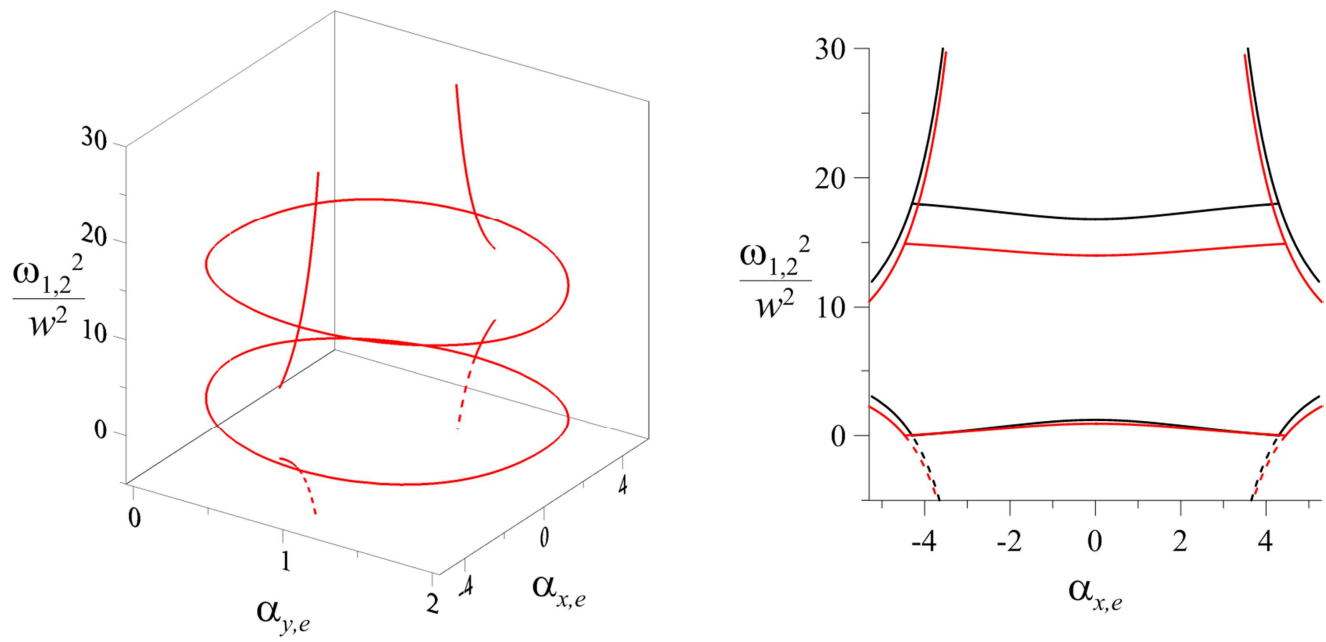

(a) Vista $\alpha_{x, e} \times \alpha_{y, e} \times \omega_{1,2}^{2} / w^{2}$.

(b) Projeção $\alpha_{x, e} \times \omega_{1,2}^{2} / w^{2}$.
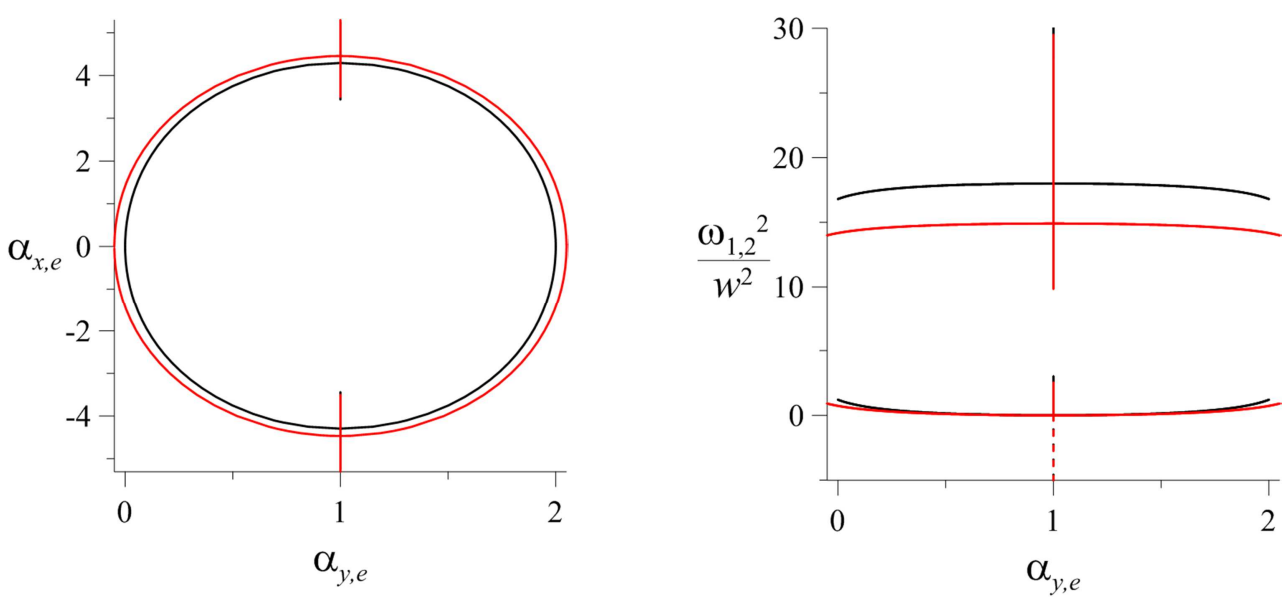

(c) Vista $\alpha_{x, e} \times \alpha_{y, e}$.

(d) Projeção $\alpha_{y, e} \times \omega_{1,2}{ }^{2} / w^{2}$.

Figura 5.13: Caminho das frequências naturais ao quadrado da treliça com carga horizontal, imperfeição geométrica e $\theta=75^{\circ}$ ao longo das posições de equilíbrio estático.

Tabela 5.11: Frequências naturais ao quadrado e modos de vibração da treliça com carga vertical, sem e com imperfeição, e $\theta=75^{\circ}$ na posição estática $\alpha_{x, e}=1$.

\begin{tabular}{cccc}
\hline Modelo & $\left(\alpha_{x, e}, \alpha_{y, e}, Q_{x}\right)$ & $\omega_{1,2}{ }^{2} / w^{2}$ & Modos de vibração \\
\hline Perfeito & $(1,0,024,0,202)$ & 1,$07 ; 16,93$ & $\left\{\begin{array}{l}1,000 \\
0,054\end{array}\right\} ;\left\{\begin{array}{c}0,748 \\
-1,000\end{array}\right\}$ \\
\hline $\begin{array}{c}\text { Imperfeição } \\
\text { de carga }\end{array}$ & $(1,0,025,0,202)$ & 1,$06 ; 16,94$ & $\left\{\begin{array}{l}1,000 \\
0,054\end{array}\right\} ;\left\{\begin{array}{c}0,748 \\
-1,000\end{array}\right\}$ \\
\hline $\begin{array}{c}\text { Imperfeição } \\
\text { geométrica }\end{array}$ & $(1,-0,025,0,168)$ & 0,$82 ; 14,08$ & $\left\{\begin{array}{l}1,000 \\
0,053\end{array}\right\} ;\left\{\begin{array}{c}0,740 \\
-1,000\end{array}\right\}$ \\
\hline
\end{tabular}


Observa-se nas Tabelas 5.10 e 5.11 que as imperfeições aplicadas provocam uma alteração pequena em seus modos de vibração para a posição estática considerada $\left(\alpha_{x, e}=1\right)$.

Os resultados apresentados neste capítulo mostram a grande influência do carregamento estático nas frequências naturais da estrutura e, consequentemente, no seu comportamento dinâmico em vibração livre e forçada, amortecida ou não amortecida, em especial nas regiões de ressonância, servindo de base para estas análises. Os resultados também confirmam a análise da estabilidade das configurações de equilíbrio realizadas no Capítulo 4 usando o princípio da energia potencial mínima. 


\section{6 \\ Vibrações não lineares}

No capítulo anterior analisaram-se as frequências naturais da estrutura com e sem carga estática. Além das frequências, apresentaram-se os seus modos de vibração. Desta forma, é possível predizer o modo em que a estrutura irá vibrar, considerando pequenas perturbações.

Diante de grandes perturbações, a não linearidade do sistema estrutural torna-se importante e seu comportamento torna-se mais complexo e o tipo de resposta da estrutura dependente das condições iniciais, já que existem diversas soluções coexistentes.

Adicionalmente, para análise da instabilidade da treliça, dinamicamente, há a necessidade de considerar o amortecimento da estrutura, assim o sistema deixa de ser conservativo e surgem os pontos de atração.

\section{1. \\ Princípio da conservação da energia}

O princípio da conservação da energia permite analisar o sistema estrutural para níveis específicos de energia e com o tempo de forma implícita.

A partir do princípio da conservação da energia, tem-se que a energia total do sistema conservativo permanece constante durante o movimento, sendo a solução dependente das condições iniciais, ou seja:

$$
T+\Delta U+\Delta V=C
$$

A constante $C$ representa a energia conservada do sistema. Esta energia é função de um conjunto de condições iniciais, ou seja, velocidades e deslocamentos medidos em relação à posição de equilíbrio estático de referência.

Adotando-se um valor para $C$ e escolhendo-se uma posição de equilíbrio estático tem-se um espaço de fase de quatro dimensões: $\alpha_{x, d}, \dot{\alpha}_{x, d}, \alpha_{y, d}$ e $\dot{\alpha}_{y, d}$. Fixando-se valores para duas destas variáveis, diferentes planos de fase são 
possíveis. As soluções em um mesmo plano para diferentes níveis de energia são chamadas de retratos de fase.

As parcelas da energia total da treliça com carga vertical ou horizontal, para as posições de equilíbrio estático são:

$$
\begin{aligned}
& \bar{T}=\frac{1}{6}\left(\frac{b_{1}}{b_{0}}\right)^{3}\left(\dot{\alpha}_{x, d}{ }^{2} \cos ^{2}(\theta)+\dot{\alpha}_{y, d}{ }^{2} \operatorname{sen}^{2}(\theta)\right) \\
& +\frac{1}{6 r}\left(\frac{b_{1}}{b_{0}}\right)^{3}\left(\dot{\alpha}_{x, d}{ }^{2} \cos ^{2}(\theta)+\dot{\alpha}_{y, d}{ }^{2} \operatorname{sen}^{2}(\theta)\right)
\end{aligned}
$$

$$
\begin{aligned}
& \overline{\Delta U}=w^{2}\left(\left(\frac{b_{0}}{b_{1}}\right)\left(\left(\operatorname{sen}(\theta)-\alpha_{y} \operatorname{sen}(\theta)\right)^{2}+\left(\cos (\theta)+\alpha_{x} \cos (\theta)\right)^{2}\right)+\right. \\
& \left.\left(\frac{b_{1}}{b_{0}}\right)^{2} \frac{2}{\sqrt{\left(\operatorname{sen}(\theta)-\alpha_{y} \operatorname{sen}(\theta)\right)^{2}+\left(\cos (\theta)+\alpha_{x} \cos (\theta)\right)^{2}}}-\frac{3 b_{1}}{b_{0}}\right) \\
& +w^{2}\left(\left(\frac{b_{0} r}{b_{1}}\right)\left(\left(\operatorname{sen}(\theta)-\alpha_{y} \operatorname{sen}(\theta)\right)^{2}+\left(\cos (\theta)-\alpha_{x} \cos (\theta)\right)^{2}\right)+\right. \\
& \left.\left(\frac{b_{1}}{b_{0} r}\right)^{2} \frac{2}{\sqrt{\left(\operatorname{sen}(\theta)-\alpha_{y} \operatorname{sen}(\theta)\right)^{2}+\left(\cos (\theta)-\alpha_{x} \cos (\theta)\right)^{2}}}-\frac{3 b_{1}}{b_{0} r}\right) \\
& -w^{2}\left(\left(\frac{b_{0}}{b_{1}}\right)\left(\left(\operatorname{sen}(\theta)-\alpha_{y, e} \operatorname{sen}(\theta)\right)^{2}+\left(\cos (\theta)+\alpha_{x, e} \cos (\theta)\right)^{2}\right)+\right. \\
& \left.\left(\frac{b_{1}}{b_{0}}\right)^{2} \frac{2}{\sqrt{\left(\operatorname{sen}(\theta)-\alpha_{y, e} \operatorname{sen}(\theta)\right)^{2}+\left(\cos (\theta)+\alpha_{x, e} \cos (\theta)\right)^{2}}}-\frac{3 b_{1}}{b_{0}}\right) \\
& -w^{2}\left(\left(\frac{b_{0} r}{b_{1}}\right)\left(\left(\operatorname{sen}(\theta)-\alpha_{y, e} \operatorname{sen}(\theta)\right)^{2}+\left(\cos (\theta)-\alpha_{x, e} \cos (\theta)\right)^{2}\right)+\right. \\
& \left.\left(\frac{b_{1}}{b_{0} r}\right)^{2} \frac{2}{\sqrt{\left(\operatorname{sen}(\theta)-\alpha_{y, e} \operatorname{sen}(\theta)\right)^{2}+\left(\cos (\theta)-\alpha_{x, e} \cos (\theta)\right)^{2}}}-\frac{3 b_{1}}{b_{0} r}\right)
\end{aligned}
$$

onde: $\bar{T}=T / m l_{0}^{2} ; \overline{\Delta U}=\Delta U / m l_{0}^{2} ; \overline{\Delta V}_{i}=\Delta V_{i} / m l_{0}^{2} ; w=1 ; \alpha_{x}=\alpha_{x, d}+\alpha_{x, e} \mathrm{e}$ $\alpha_{y}=\alpha_{y, d}+\alpha_{y, e}$. 
Aplicando-se o princípio da conservação de energia, apresentam-se a seguir para níveis crescentes de energia, os retratos de fase associados aos distintos planos referentes a determinados conjuntos de condições iniciais.

A Figura 6.1 apresenta quatro distintos retratos de fase para a treliça com ângulo de abatimento de $15^{\circ}$ com as seguintes condições iniciais: posição de equilíbrio estático $(0,0,0)$, deslocamentos e velocidades iniciais nulos, $(0,0,0,0)$.

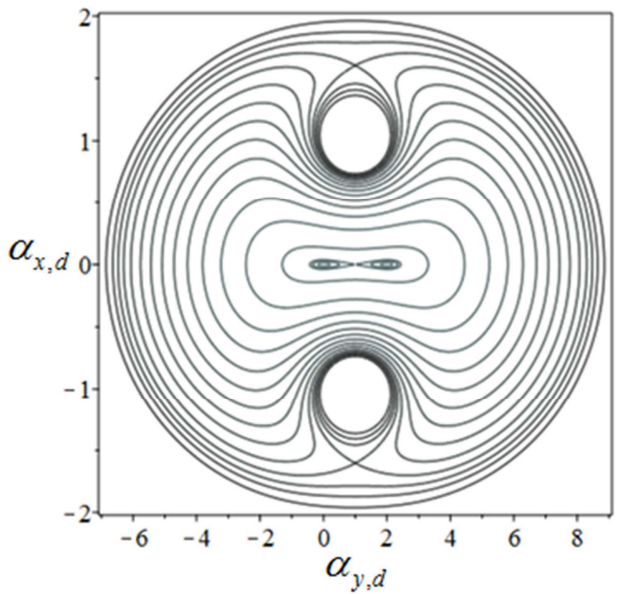

(a) Plano $\alpha_{x, d} \times \alpha_{y, d}$.

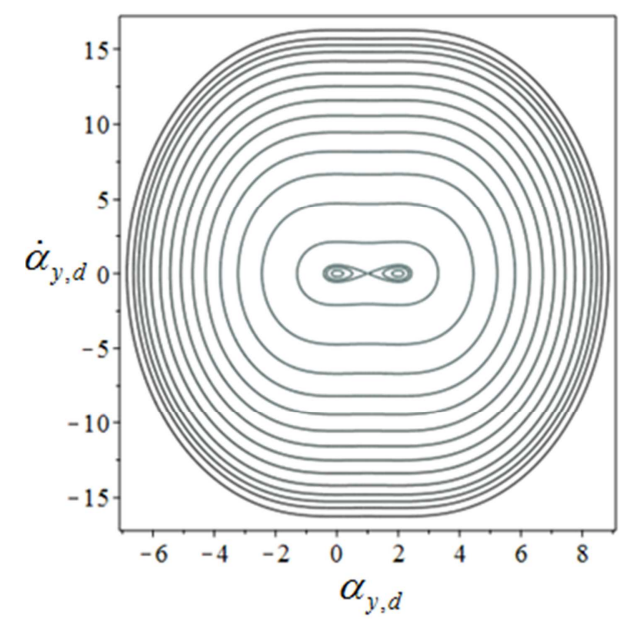

(c) Plano $\alpha_{y, d} \times \dot{\alpha}_{y, d}$.

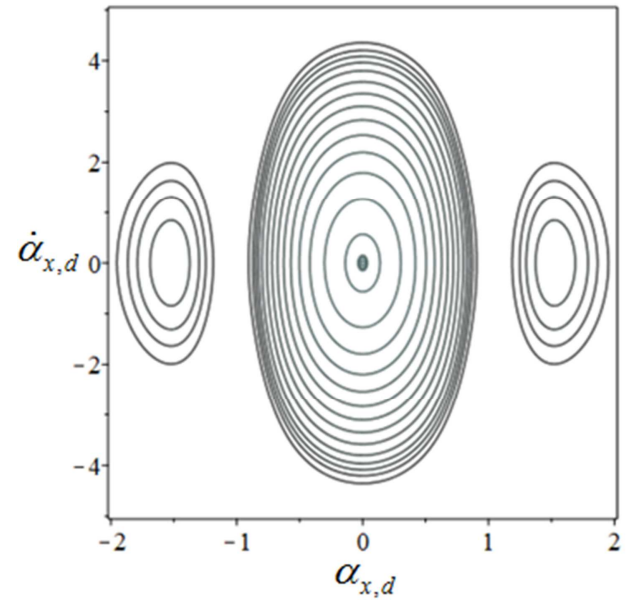

(b) Plano $\alpha_{x, d} \times \dot{\alpha}_{x, d}$.

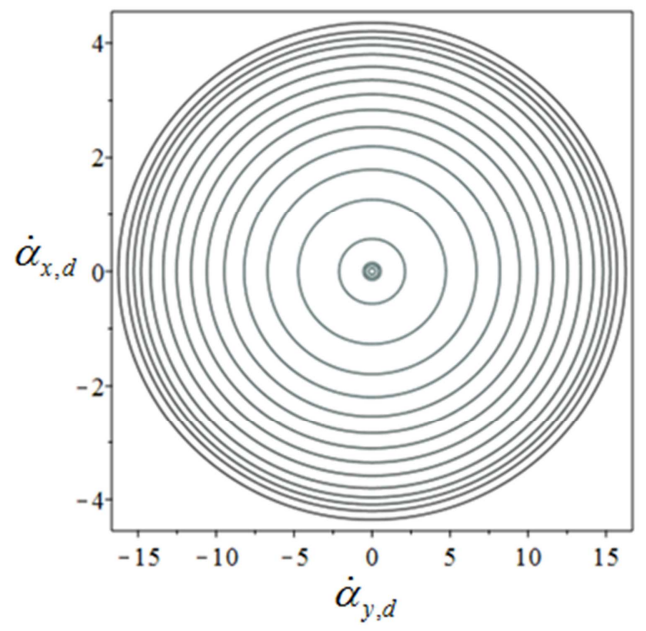

(d) Plano $\dot{\alpha}_{x, d} \times \dot{\alpha}_{y, d}$.

Figura 6.1: Retratos de fase para treliça descarregada, $\theta=15^{\circ}$, posição estática $(0,0,0)$ e dinâmica $(0,0,0,0)$.

Observa-se no retrato de fase dos deslocamentos da Figura 6.1, cinco pontos fixos: três pontos de sela e dois centros. Da análise estática, tem-se que cada ponto 
de sela pertence a uma trajetória de equilíbrio e os centros, à trajetória fundamental de equilíbrio.

Para cada nível de energia surgem órbitas fechadas chamadas de centro, e trajetórias que contêm os pontos de sela. Os centros representam movimentos periódicos em torno da posição de equilíbrio estático estável e as trajetórias das selas possuem soluções não periódicas dividindo os centros em famílias de soluções. Cada família de soluções forma uma bacia de atração conservativa que são envolvidas pelas trajetórias das selas. No plano dos deslocamentos (Figura 6.1), as órbitas que contêm os pontos de sela separam seis famílias de soluções distintas.

A Figura 6.2 apresenta a influência da imperfeição geométrica (projeções das barras na direção $x$ são alteradas em 5\% - ver Fig. 3.5) nos retratos de fase para a treliça com ângulo de abatimento de $15^{\circ}$ e condições iniciais: posição de equilíbrio estático $(0,05,-0,05,0)$, deslocamentos e velocidades iniciais nulos, $(0,0,0,0)$.

No plano dos deslocamentos (Figura 6.2), em virtude da imperfeição geométrica surge uma nova família de solução entre as órbitas dos pontos de sela de maior energia.

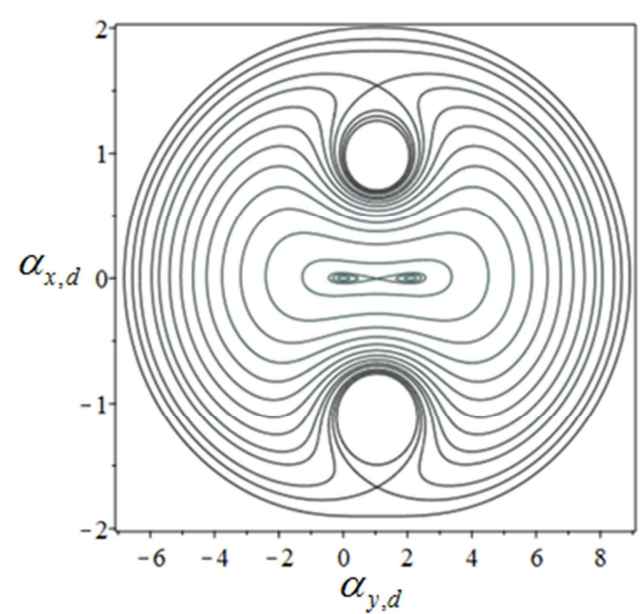

(a) Plano $\alpha_{x, d} \times \alpha_{y, d}$.

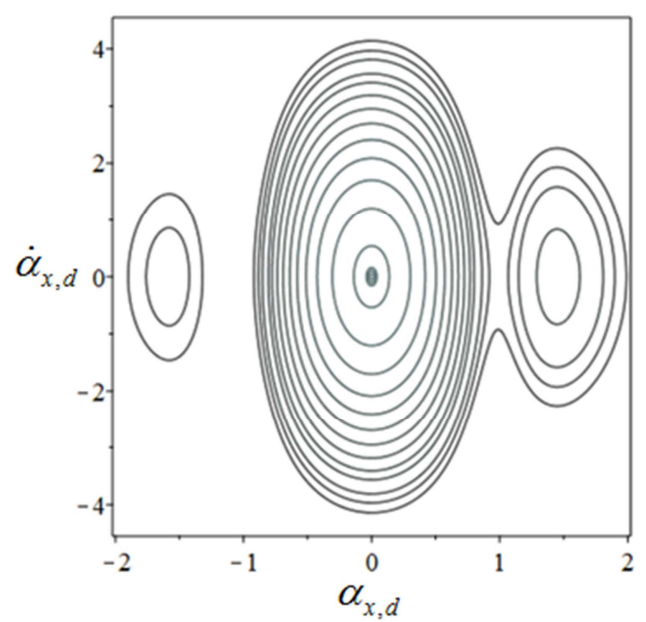

(b) Plano $\alpha_{x, d} \times \dot{\alpha}_{x, d}$. 


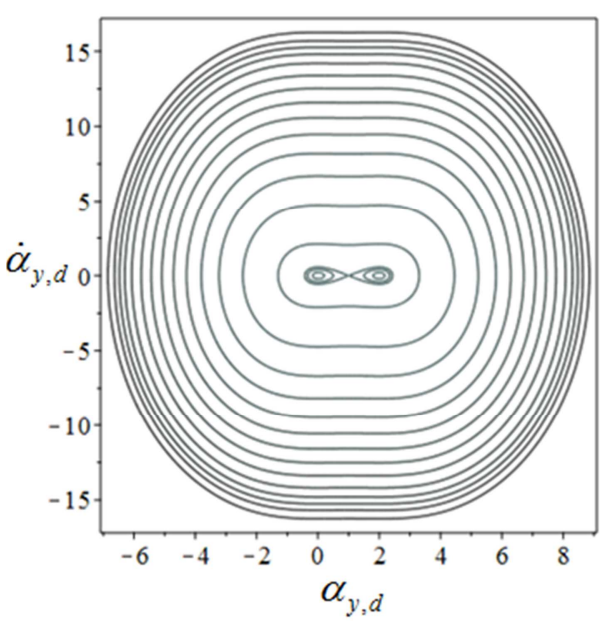

(c) Plano $\alpha_{y, d} \times \dot{\alpha}_{y, d}$.

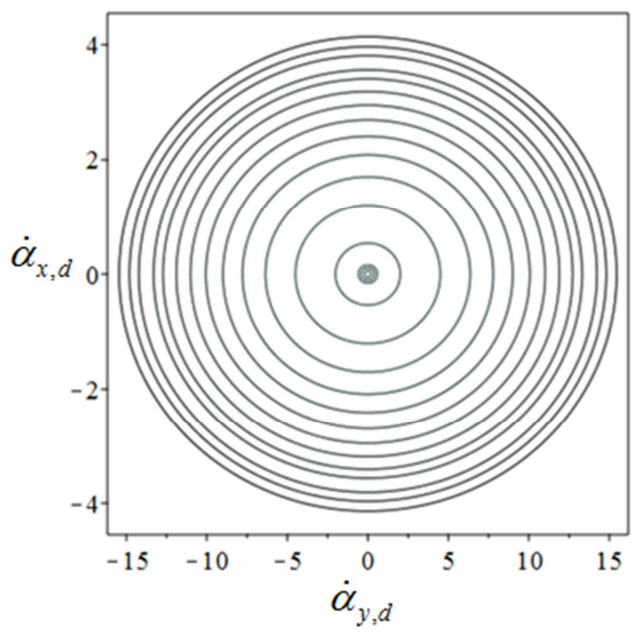

(d) Plano $\dot{\alpha}_{x, d} \times \dot{\alpha}_{y, d}$.

Figura 6.2: Retratos de fase para treliça descarregada com imperfeição geométrica, $\theta=15^{\circ}$, posição estática $(0,05,-0,05,0)$ e dinâmica $(0,0,0,0)$.

A Figura 6.3 destaca as órbitas associadas aos pontos de sela dos modelos perfeitos e com imperfeição geométrica. Estas órbitas são obtidas usando-se as coordenadas dinâmicas (deslocamentos) de cada ponto de sela. Ressalta-se, na Figura 6.3, que cada cor se refere a pontos de sela diferentes e suas coordenadas bem como o valor da constante $C$ são apresentadas na Tabela 6.1.

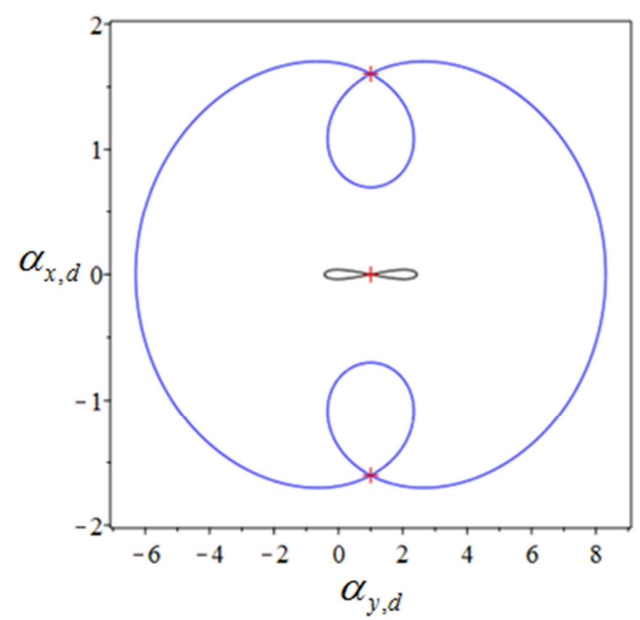

(a) Perfeito: plano $\alpha_{x, d} \times \alpha_{y, d}$.

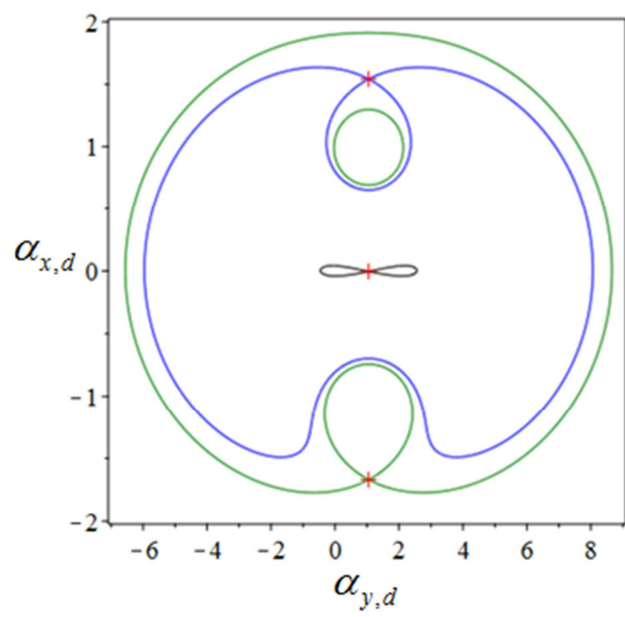

(b) Imperfeito: plano $\alpha_{x, d} \times \alpha_{y, d}$. 


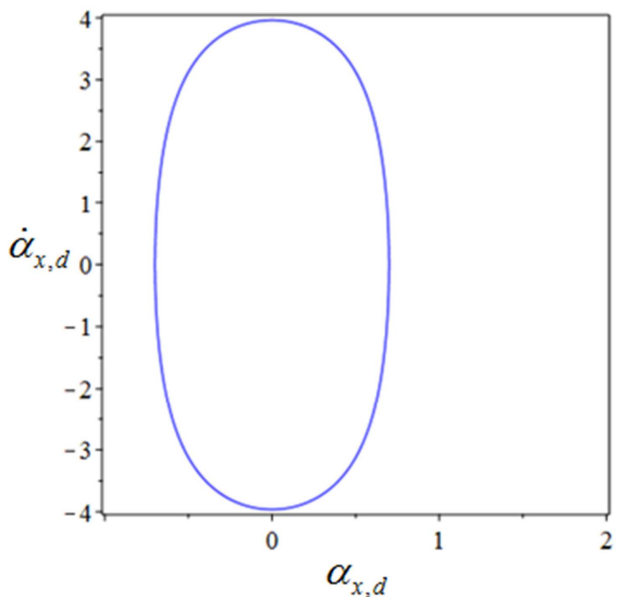

(c) Perfeito: plano $\alpha_{x, d} \times \dot{\alpha}_{x, d}$.

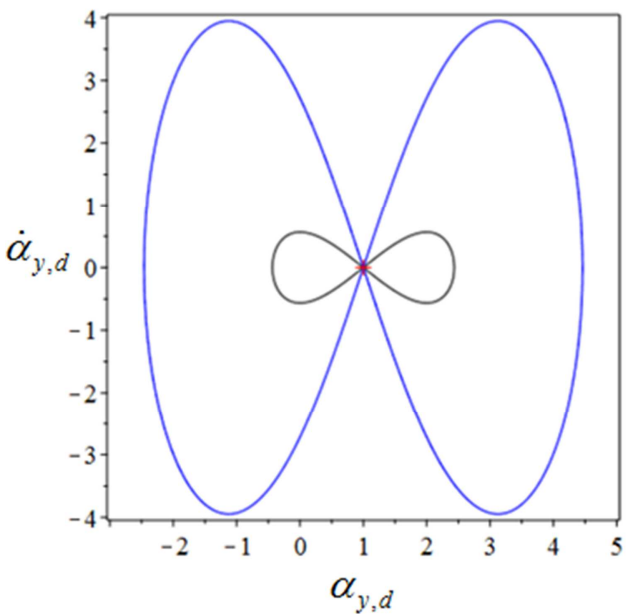

(e) Perfeito: plano $\alpha_{y, d} \times \dot{\alpha}_{y, d}$.

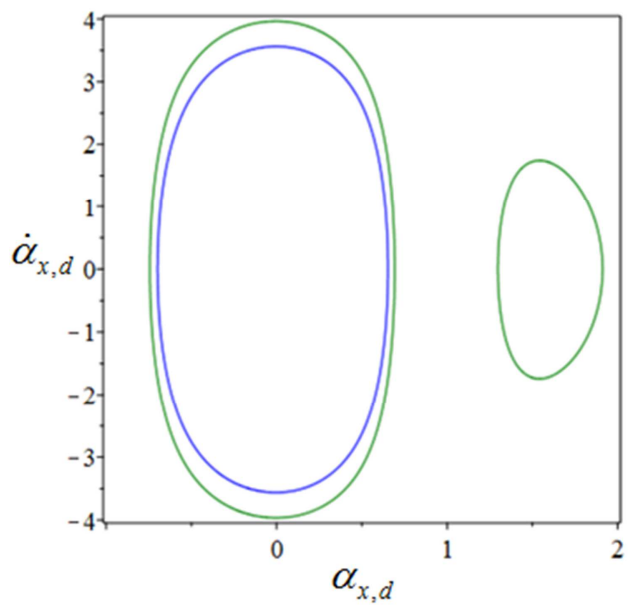

(d) Imperfeito: plano $\alpha_{x, d} \times \dot{\alpha}_{x, d}$.

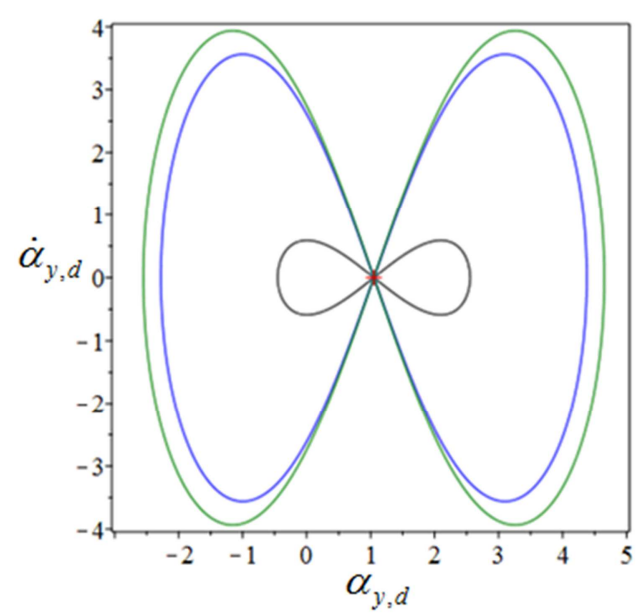

(f) Imperfeito: plano $\alpha_{y, d} \times \dot{\alpha}_{y, d}$.

Figura 6.3: Órbitas dos pontos de sela das treliças descarregada, sem e com imperfeição geométrica e $\theta=15^{\circ}$, para as posições estáticas descarregadas e dinâmicas referentes a cada ponto de sela.

As trajetórias que contêm os pontos de sela podem ser classificadas como órbitas homoclínicas, quando associadas a um único ponto de sela, ou órbitas heteroclínicas, quando a trajetória está associada com dois pontos de sela distintos. Por exemplo, no plano dos deslocamentos do modelo perfeito (Figura 6.3) têm-se quatro órbitas homoclínicas e duas órbitas heteroclínicas, já no plano $\alpha_{y, d} \times \dot{\alpha}_{y, d}$ para a mesma treliça observam-se apenas as quatro órbitas homoclínicas.

Nota-se na Figura 6.3 que a falta de simetria do modelo com imperfeição geométrica altera o espaço de fase, as trajetórias heteroclínicas somem, indicando que não existem mais duas selas com o mesmo nível de energia. 
A Tabela 6.1 lista a energia associada a cada ponto de sela, tendo como referência a posição de equilíbrio estático $(0,0,0)$ do modelo perfeito e a posição estática $(0,05,-0,05,0)$ do modelo com imperfeição geométrica.

Tabela 6.1: Energia dos pontos de sela para treliça com e sem imperfeição geométrica e $\theta=15^{\circ}$.

\begin{tabular}{cccc}
\hline Modelo & $\left(\alpha_{x, e}, \alpha_{y, e}, Q\right)$ & $\left(\alpha_{x, d}, \alpha_{y, d}, \dot{\alpha}_{x, d}, \dot{\alpha}_{y, d}\right)$ & $C$ \\
\hline Perfeito & $(0,0,0)$ & $(0,1,0,0)$ & 0,0071 \\
\cline { 2 - 4 } & $(0,0,0)$ & $( \pm 1,604,1,0,0)$ & 4,8902 \\
\hline Imperfeição & $(0,05,-0,05,0)$ & $(-0,004,1,05,0,0)$ & 0,0087 \\
\cline { 2 - 4 } Geométrica & $(0,05,-0,05,0)$ & $(1,542,1,05,0,0)$ & 4,3746 \\
\cline { 2 - 4 } & $(0,05,-0,05,0)$ & $(-1,670,1,05,0,0)$ & 5,4184 \\
\hline
\end{tabular}

Na Tabela 6.1, a perda da simetria do modelo com imperfeição geométrica pode ser visualizada nos dois pontos de sela de maior energia. Nota-se o aumento da região segura do ponto de sela do caminho fundamental de equilíbrio em relação ao ponto de sela da estrutura perfeita. Este aumento da energia do ponto sela de menor energia provoca um ganho da capacidade de carga da treliça com imperfeição geométrica (aumento da barreira de energia que o sistema precisa ultrapassar para se tornar instável), quando submetida à carga vertical, conforme apresentado nos capítulos anteriores.

Os retratos de fase já apresentados referem-se à configuração inicial de equilíbrio da treliça descarregada. A fim de avaliar o impacto da carga estática nos retratos de fase das treliças com $\theta=15^{\circ}$, mostram-se nas Figuras 6.4 e 6.5 os retratos de fase dos deslocamentos para a treliça com carga vertical e na Figura 6.6 para situação de carga horizontal.

Os retratos de fase da Figura 6.4 referem-se à posição estática de equilíbrio do ponto limite com coordenadas $(0,0,433,0,042)$. 


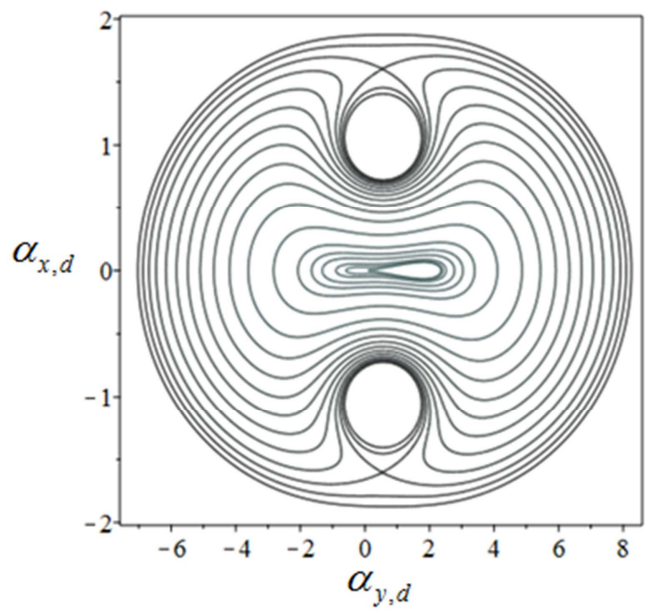

(a) Plano $\alpha_{x, d} \times \alpha_{y, d}$.

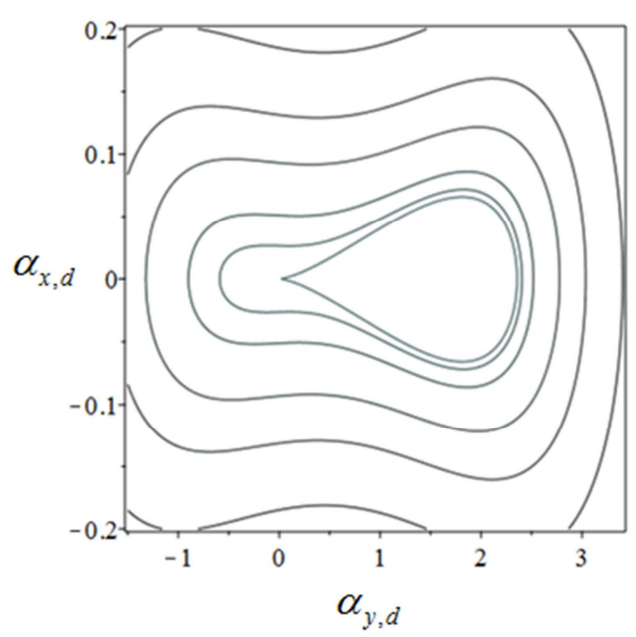

(b) Plano $\alpha_{x, d} \times \alpha_{y, d}$ ampliado.

Figura 6.4: Retratos de fase para treliça com carga vertical, $\theta=15^{\circ}$ e posição de equilíbrio estático $(0,0,433,0,042)$ referente à carga limite $\left(P_{L}\right)$.

Como mostra a Figura 6.4, a carga vertical provoca uma perturbação local no sistema para pequenos níveis de energia, visível próximo à órbita do ponto de sela de menor energia. Os centros, circunscritos pelas órbitas homoclínicas da Figura 6.1, não existem mais, e o ponto limite representa a situação crítica em que o centro se une à sela e a estrutura perde a estabilidade, divergindo. A Figura 6.5 exibe o decréscimo das bacias conservativas para valores de carga estática entre zero e a carga do ponto limite.

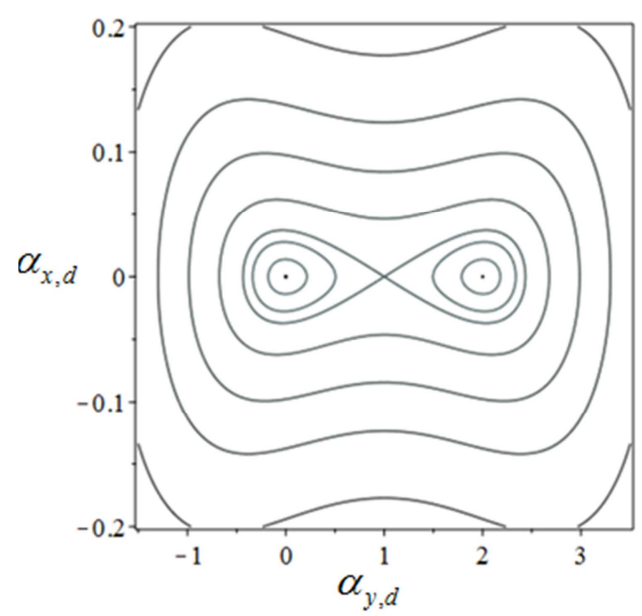

(a) $0,0 \times P_{L}$

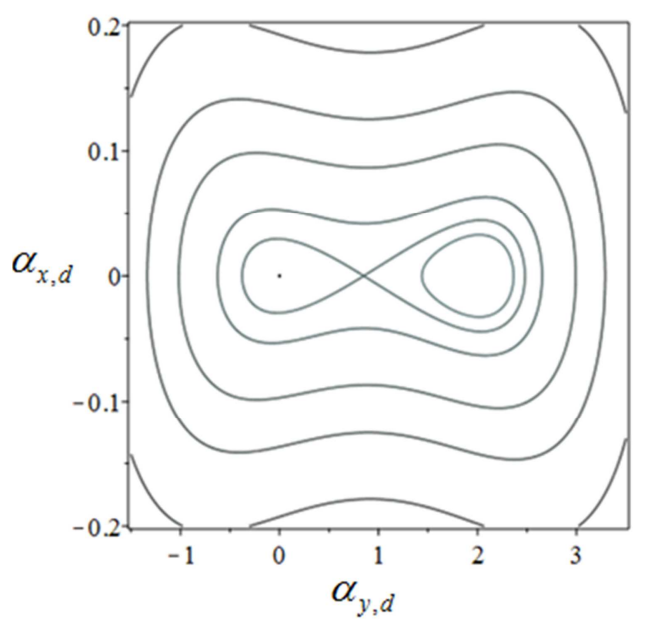

(b) $0,25 \times P_{L}$ 


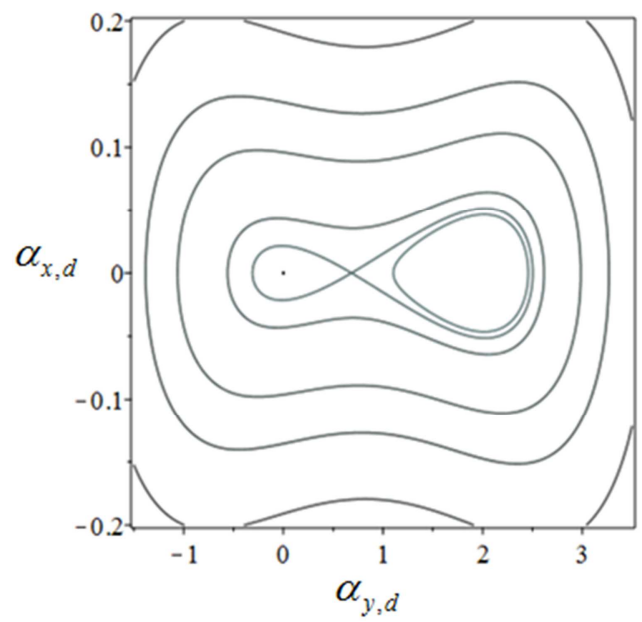

(c) $0,50 \times P_{L}$

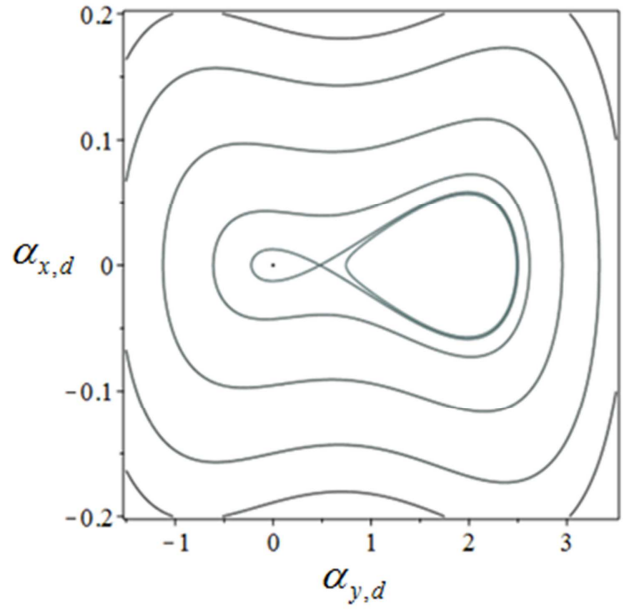

(d) $0,75 \times P_{L}$

Figura 6.5: Retratos de fase dos deslocamentos para valores crescentes de carga estática da treliça com carga vertical, $\theta=15^{\circ}$ e posição de acordo com a Tabela 6.2.

A Tabela 6.2 apresenta a posição de equilíbrio estático, os deslocamentos e energia associados aos pontos de sela das Figuras 6.4 e 6.5.

Tabela 6.2: Posição de equilíbrio estático e energia associada aos pontos de sela para níveis crescentes de carga estática da treliça com $\theta=15^{\circ}$.

\begin{tabular}{cccc}
\hline$\% P_{L}$ & $\left(\alpha_{x, e}, \alpha_{y, e}, Q_{y}\right)$ & $\left(\alpha_{x, d}, \alpha_{y, d}, \dot{\alpha}_{x, d}, \dot{\alpha}_{y, d}\right)$ & $C$ \\
\hline $0,0 \times P_{L}$ & $(0,0,0)$ & $(0,1,0,0)$ & 0,0071 \\
\hline $0,25 \times P_{L}$ & $(0,0,055,011)$ & $(0,0,851,0,0)$ & 0,0046 \\
\hline $0,50 \times P_{L}$ & $(0,0,121,0,021)$ & $(0,0,684,0,0)$ & 0,0025 \\
\hline $0,75 \times P_{L}$ & $(0,0,209,0,032)$ & $(0,0,477,0,0)$ & 0,0009 \\
\hline $1,0 \times P_{L}$ & $(0,0,433,0,042)$ & $(0,0,0,0)$ & 0 \\
\hline
\end{tabular}

Para a estrutura com carga horizontal, adota-se como referência a posição estática do ponto de bifurcação $(1,829,1,3,674)$. A carga horizontal modifica completamente o retrato de fase do sistema estrutural. Este movimento lateral da treliça até o ponto de bifurcação necessita de mais energia que a energia da sela $(1,604,1,0)$ na Tabela 6.1. Com isso, no retrato da Figura 6.6, observa-se a presença do centro da posição do ponto de bifurcação e de dois pontos de sela. 


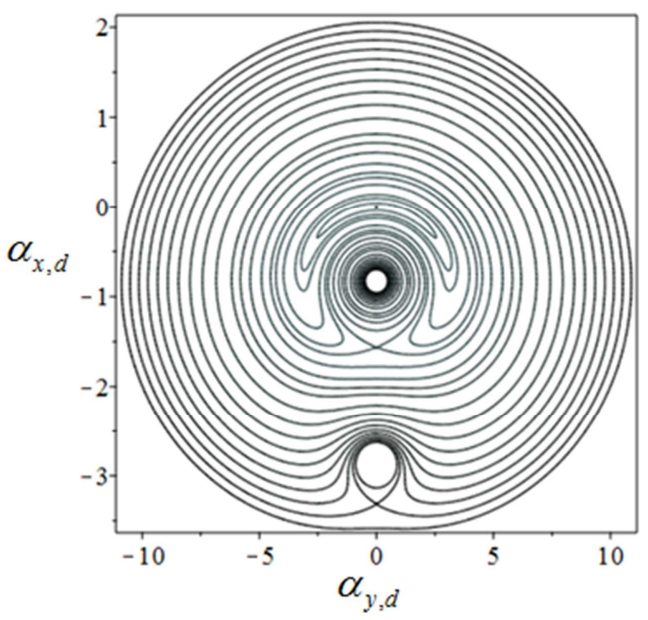

Figura 6.6: Retratos de fase dos deslocamentos para treliça com carga horizontal, $\theta=15^{\circ}$, posição estática do ponto de bifurcação $(1,829,1,3,674)$ e dinâmica $(0,0,0,0)$.

A Figura 6.7 apresenta o retrato de fase para a treliça com ângulo de $75^{\circ} \mathrm{em}$ relação à posição inicial descarregada para condições iniciais de deslocamento e velocidade nulas.

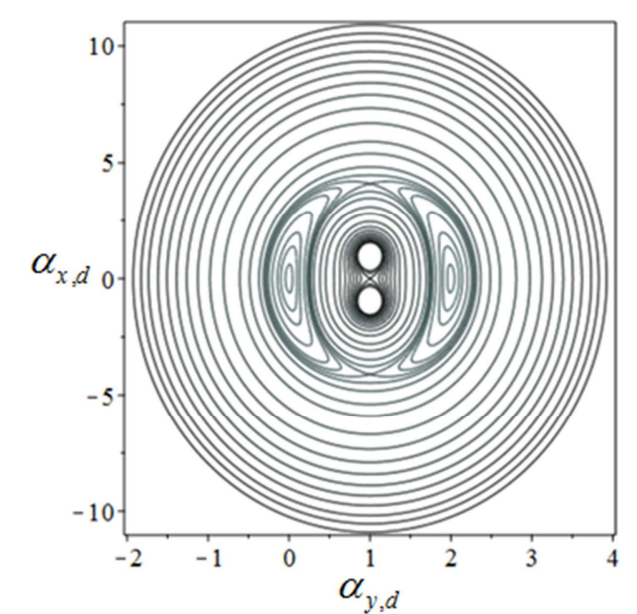

(a) Plano $\alpha_{x, d} \times \alpha_{y, d}$.

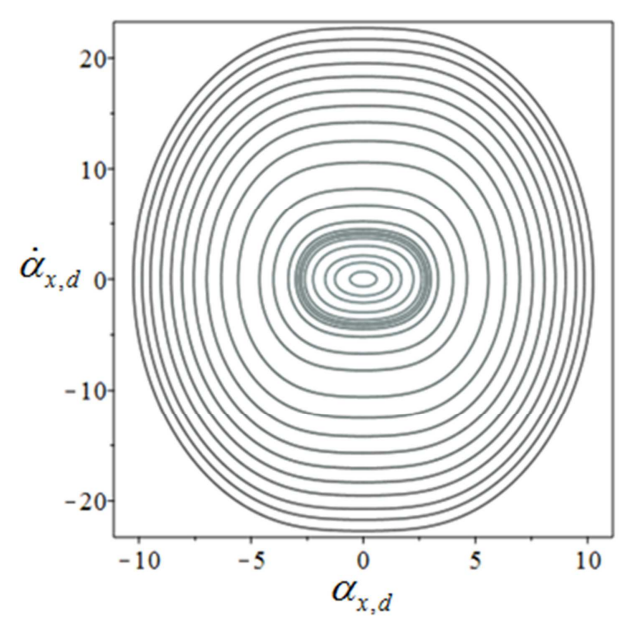

(b) Plano $\alpha_{x, d} \times \dot{\alpha}_{x, d}$. 


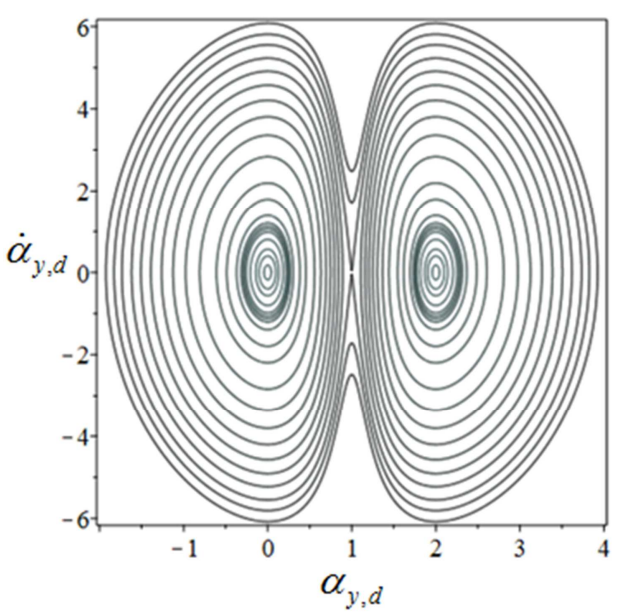

(c) Plano $\alpha_{y, d} \times \dot{\alpha}_{y, d}$.

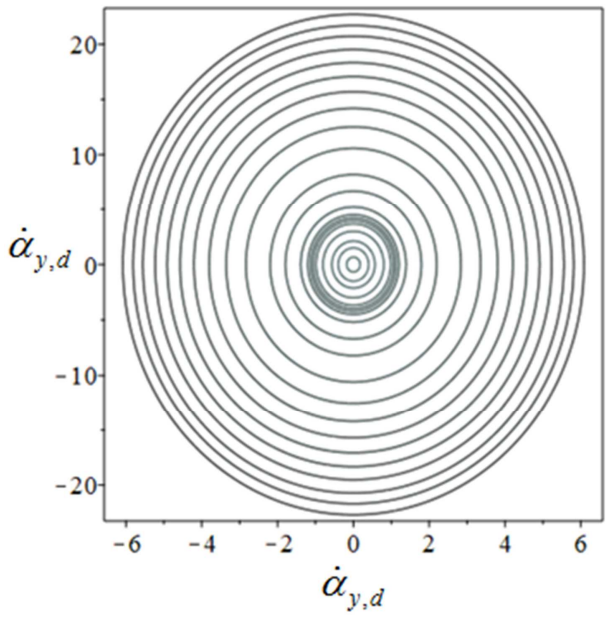

(d) Plano $\dot{\alpha}_{x, d} \times \dot{\alpha}_{y, d}$.

Figura 6.7: Retratos de fase para treliça descarregada, $\theta=75^{\circ}$, posição estática $(0,0,0)$ e dinâmica $(0,0,0,0)$.

Conforme exposto no Capítulo 4, o número de pontos fixos para a treliça hiperelástica descarregada independe do seu ângulo de abatimento, assim, têm-se os mesmos cinco pontos fixos para a treliça com $\theta=75^{\circ}$. Para este ângulo, no caso de carga estática vertical, a instabilidade da treliça está associada aos pontos de sela de coordenadas $\alpha_{x, d}$ não nulas do retrato de fase dos deslocamentos da Figura 6.7. Neste retrato nota-se a diferença entre as órbitas relativas às posições de equilíbrio estável para ambos os ângulos de abatimento, sendo possível associá-las aos diferentes tipos de instabilidade presentes: ponto limite e bifurcação simétrica instável.

A Figura 6.8 apresenta os retratos de fase para a treliça com imperfeição geométrica e $\theta=75^{\circ}$ em relação a posição de equilíbrio estático da treliça descarregada. A Figura 6.9 destaca as órbitas que contêm os pontos de sela do modelo com imperfeição geométrica comparando com o modelo perfeito para a treliça com $\theta=75^{\circ}$, destacando que cada cor refere-se a um ponto de sela diferente. 

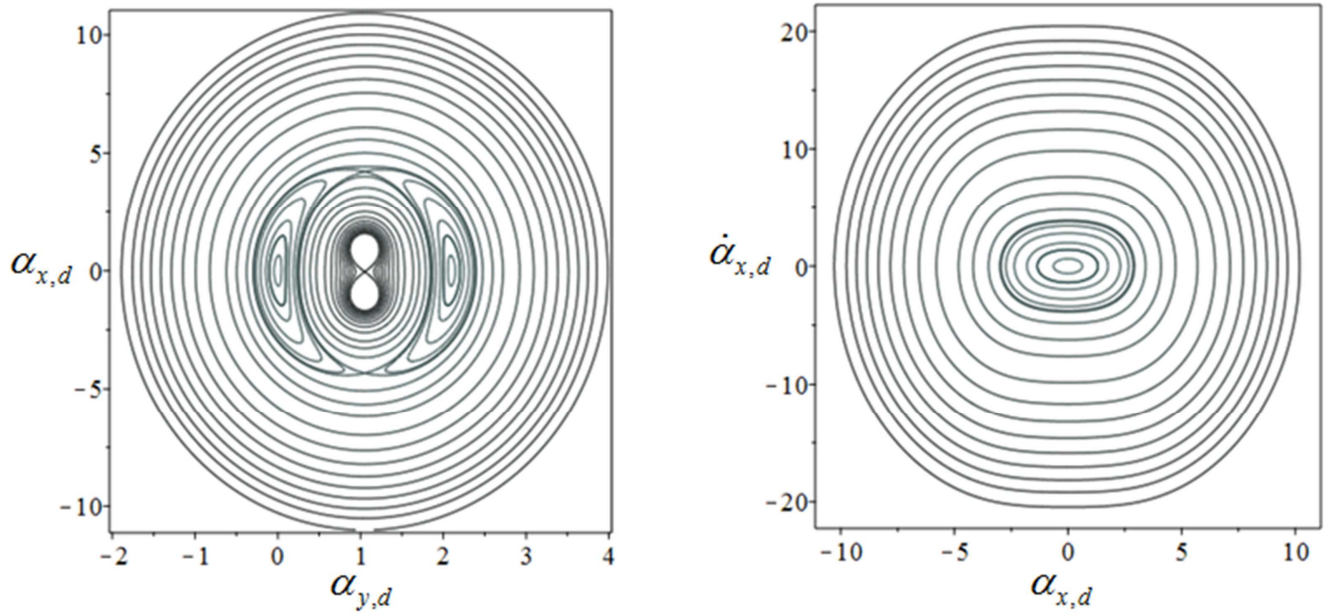

(a) Plano $\alpha_{x, d} \times \alpha_{y, d}$.

(b) Plano $\alpha_{x, d} \times \dot{\alpha}_{x, d}$.
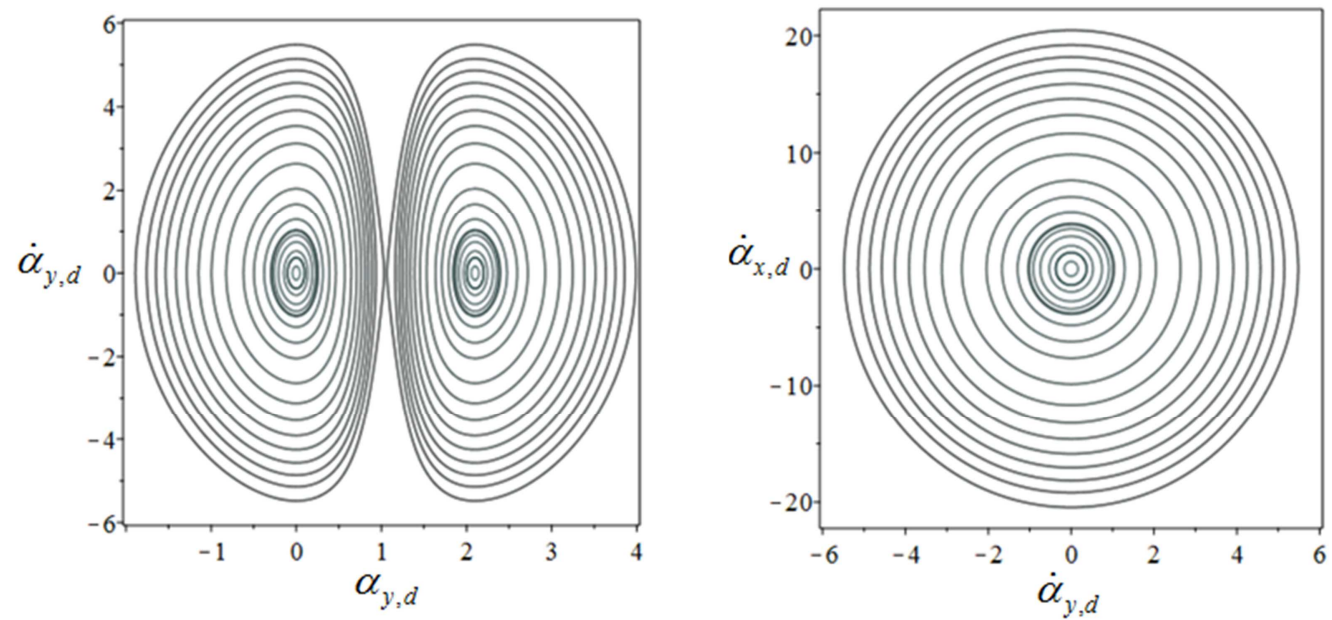

(c) Plano $\alpha_{y, d} \times \dot{\alpha}_{y, d}$.

(d) Plano $\dot{\alpha}_{x, d} \times \dot{\alpha}_{y, d}$.

Figura 6.8: Retratos de fase para treliça com imperfeição geométrica, $\theta=75^{\circ}$, posição estática $(0,05,-0,05,0)$ e dinâmica $(0,0,0,0)$.

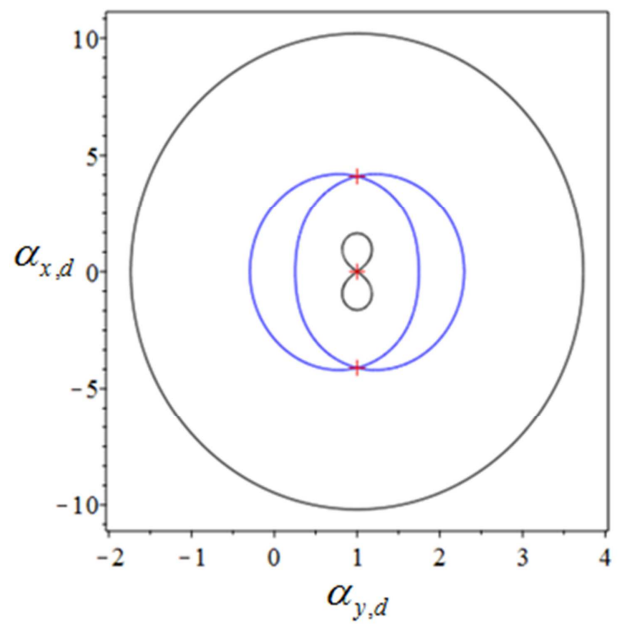

(a) Perfeito: plano $\alpha_{x, d} \times \alpha_{y, d}$.

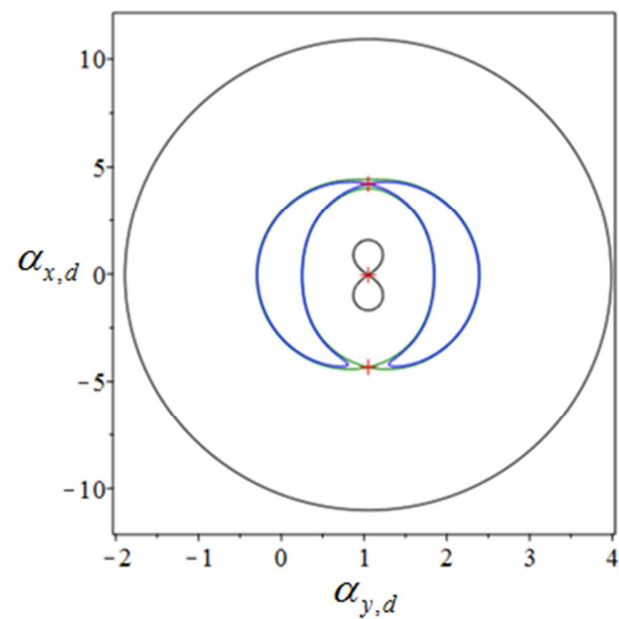

(b) Imperfeito: plano $\alpha_{x, d} \times \alpha_{y, d}$. 


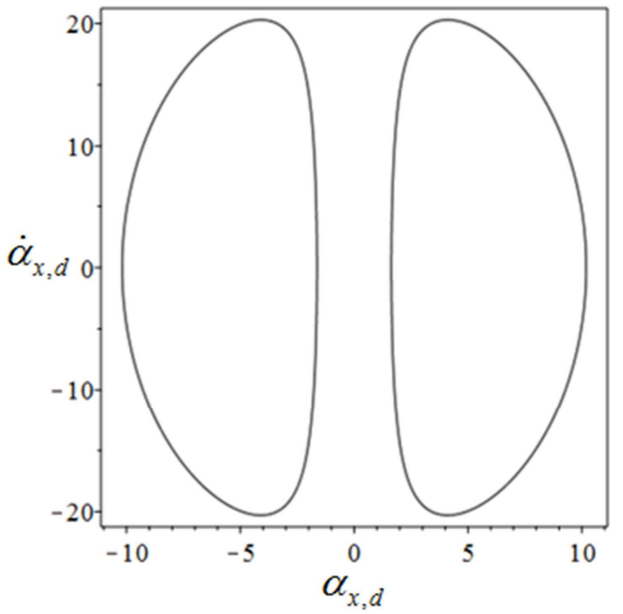

(a) Perfeito: plano $\alpha_{x, d} \times \dot{\alpha}_{x, d}$.

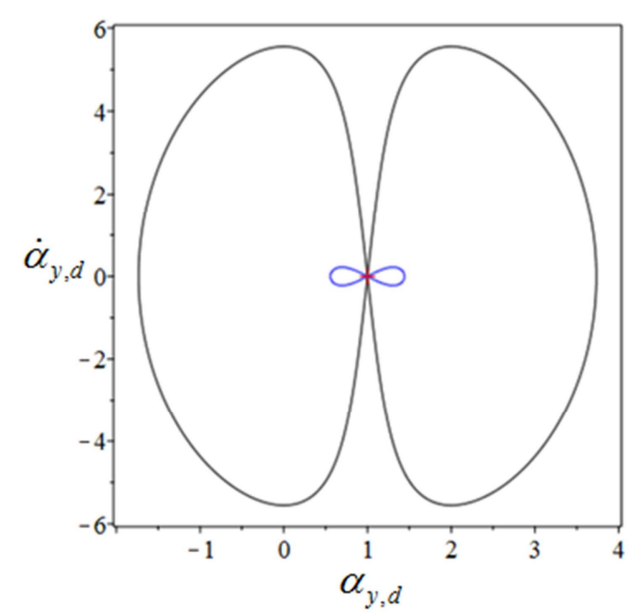

(a) Perfeito: plano $\alpha_{y, d} \times \dot{\alpha}_{y, d}$.

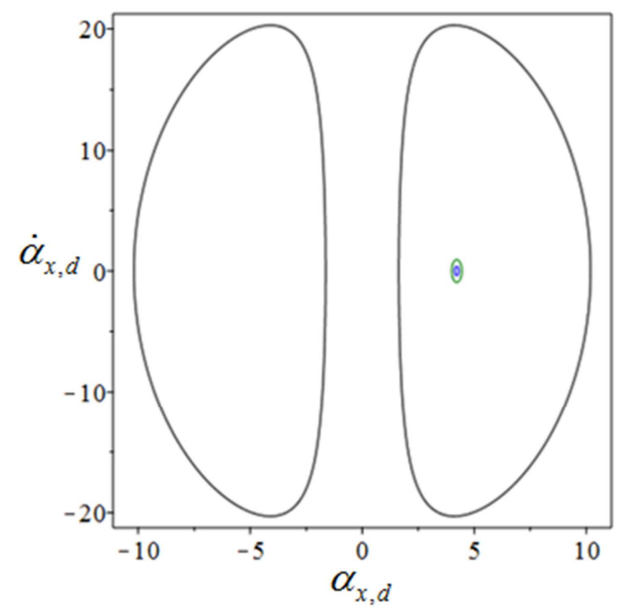

(b) Imperfeito: plano $\alpha_{x, d} \times \dot{\alpha}_{x, d}$.

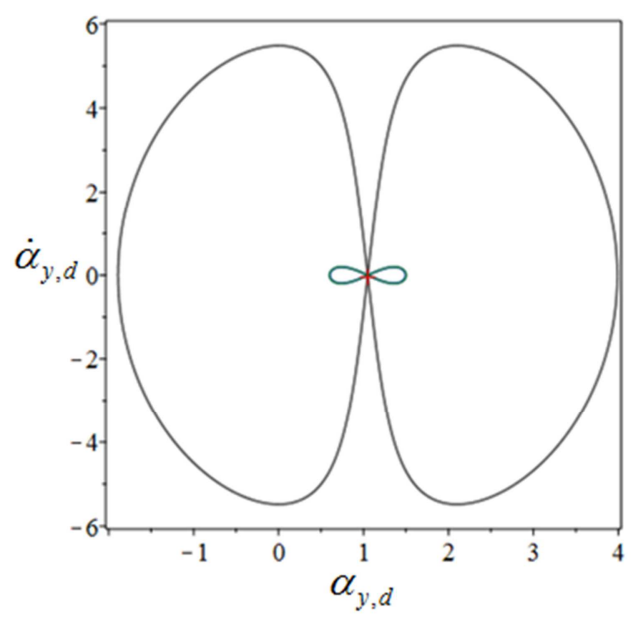

(b) Imperfeito: plano $\alpha_{y, d} \times \dot{\alpha}_{y, d}$.

Figura 6.9: Órbitas dos pontos de sela das treliças sem e com imperfeição geométrica e $\theta=75^{\circ}$ para as posições estáticas descarregadas e dinâmicas referentes a cada ponto de sela.

Observam-se, no plano dos deslocamentos (Figura 6.9a), quatro trajetórias heteroclínicas conectando os pontos de sela de menor energia e duas órbitas homoclínicas associadas ao ponto de sela de maior energia. A Tabela 6.3 apresenta a energia de cada ponto de sela para os modelos com e sem imperfeição geométrica, tendo como referência a posição inicial de equilíbrio estático da estrutura perfeita $(0,0,0)$ e a posição inicial de equilíbrio estático da estrutura imperfeita $(0,05,-0,05,0)$ respectivamente. 
Tabela 6.3: Energia dos pontos de sela para treliça com e sem imperfeição geométrica e $\theta=75^{\circ}$.

\begin{tabular}{cccc}
\hline Modelo & $\left(\alpha_{x, e}, \alpha_{y, e}, Q\right)$ & $\left(\alpha_{x, d}, \alpha_{y, d}, \dot{\alpha}_{x, d}, \dot{\alpha}_{y, d}\right)$ & $C$ \\
\hline \multirow{2}{*}{ Perfeito } & $(0,0,0)$ & $( \pm 4,103,1,0,0)$ & 0,3940 \\
\cline { 2 - 4 } & $(0,0,0)$ & $(0,1,0,0)$ & 9,5888 \\
\hline Imperfeição & $(0,05,-0,05,0)$ & $(4,222,1,05,0,0)$ & 0,3677 \\
\cline { 2 - 4 } Geométrica & $(0,05,-0,05,0)$ & $(-4,327,1,05,0,0)$ & 0,3864 \\
\cline { 2 - 4 } & $(0,05,-0,05,0)$ & $(-0,047,1,05,0,0)$ & 10,7824 \\
\hline
\end{tabular}

A Figura 6.10 apresenta o retrato de fase dos deslocamentos para a treliça com carga horizontal e $\theta=75^{\circ}$, na posição estática do ponto de bifurcação $(4,295,1,0,633)$. A Figura 6.11 exibe os retratos dos deslocamentos para níveis crescentes de carga estática entre zero e o valor carga de bifurcação $\left(P_{B I}\right)$. A Tabela 6.4 lista as posições e energia dos pontos de sela com menor energia, quantificando o decréscimo da região segura.

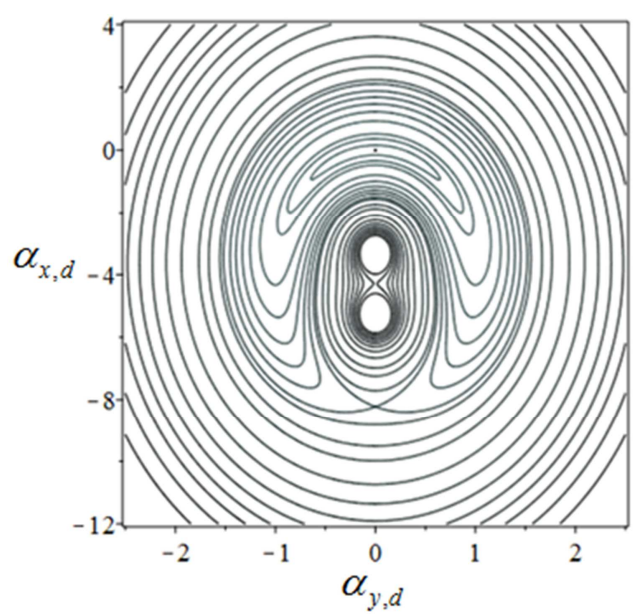

Figura 6.10: Retratos de fase dos deslocamentos para treliça com carga horizontal, $\theta=75^{\circ}$, posição estática do ponto de bifurcação $(4,295,1,0,633)$ e dinâmica $(0,0,0,0)$. 

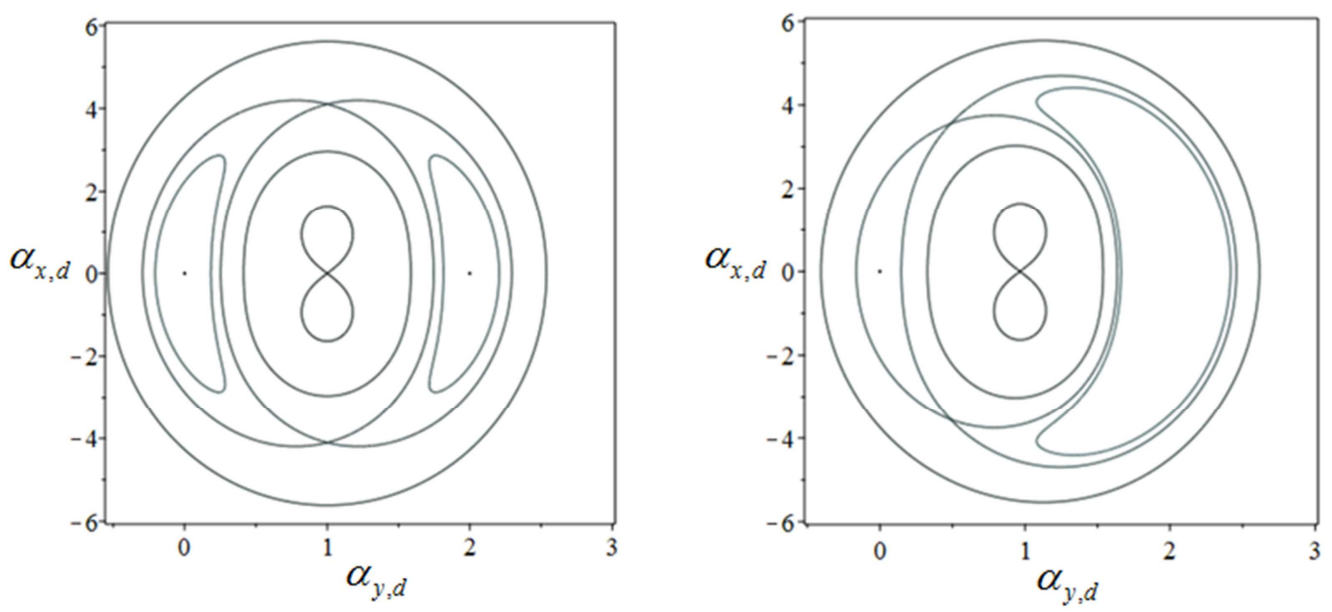

(a) $0,0 \times P_{B 1}$

(b) $0,33 \times P_{B 1}$
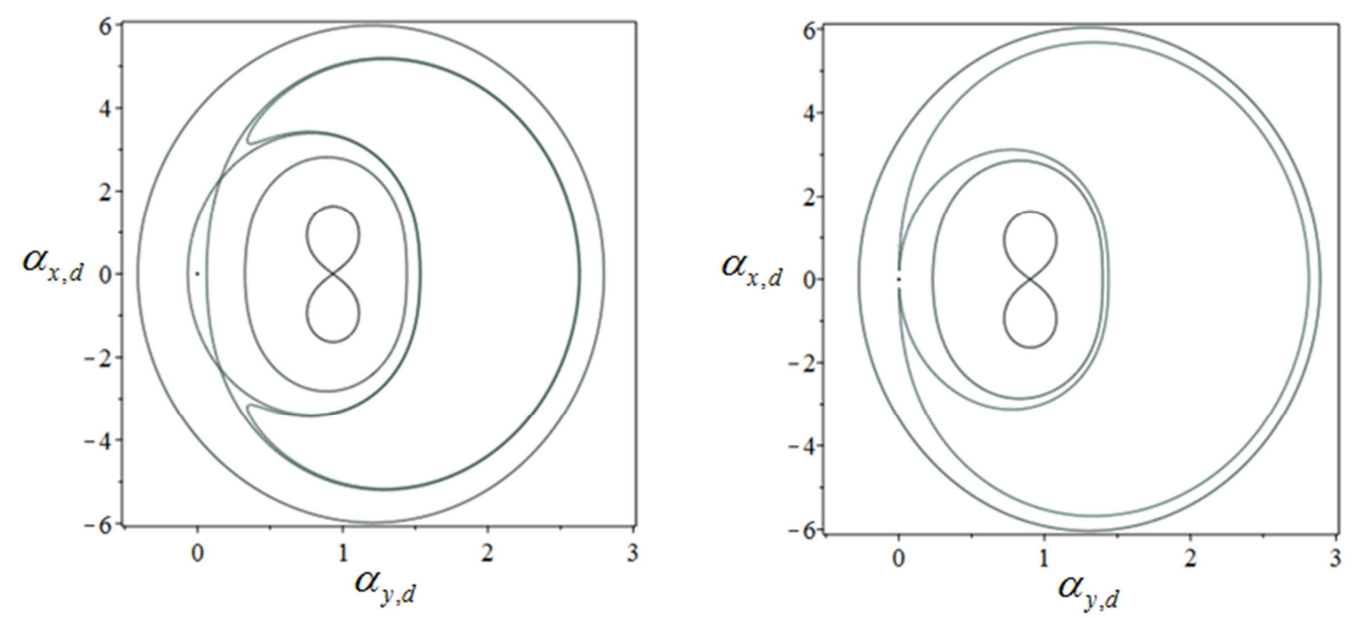

(c) $0,66 \times P_{B 1}$

(d) $1,00 \times P_{B 1}$

Figura 6.11: Retratos de fase dos deslocamentos para valores crescentes de carga estática da treliça com carga vertical, $\theta=75^{\circ}$ e posições de acordo com a Tabela 6.4.

Tabela 6.4: Posição de equilíbrio estático e energia associada aos pontos de sela para níveis crescentes de carga estática da treliça com $\theta=75^{\circ}$.

\begin{tabular}{cccc}
\hline$\% P_{B 1}$ & $\left(\alpha_{x, e}, \alpha_{y, e}, Q_{y}\right)$ & $\left(\alpha_{x, d}, \alpha_{y, d}, \dot{\alpha}_{x, d}, \dot{\alpha}_{y, d}\right)$ & $C$ \\
\hline $0,0 \times P_{B 1}$ & $(0,0,0)$ & $( \pm 4,103,1,0,0)$ & 0,3940 \\
\hline $0,33 \times P_{B 1}$ & $(0,0,033,368)$ & $( \pm 3,551,0,488,0,0)$ & 0,1334 \\
\hline $0,66 \times P_{B 1}$ & $(0,0,064,0,736)$ & $( \pm 2,298,0,158,0,0)$ & 0,0248 \\
\hline $1,0 \times P_{B 1}$ & $(0,0,095,1,114)$ & $(0,0,0,0)$ & 0 \\
\hline
\end{tabular}




\section{2.}

\section{Respostas no tempo}

O princípio da conservação de energia possibilitou visualizar as famílias de centros e as selas e como suas formas variam para diferentes níveis de energia. Abordaram-se de forma conveniente os termos bacias conservativas e barreiras de energia do sistema ideal conservativo. Entretanto os sistemas estruturais apresentam amortecimento, mesmo que pequeno. Este amortecimento influencia de forma significativa o comportamento do sistema não linear. Adota-se neste caso o amortecedor de Rayleigh, apresentado no Capítulo 3, com um coeficiente de amortecimento $\zeta=0,05$ para as análises a seguir.

\subsection{1.}

\section{Equações de movimento}

As equações de movimento para a treliça com amortecimento e para as diferentes situações de carga estática são dadas por:

$$
\begin{aligned}
& \frac{m l_{0}{ }^{2} b_{1}{ }^{3} \cos ^{2}(\theta)}{3 b_{0}{ }^{3}}\left(\frac{r+1}{r}\right) \ddot{\alpha}_{x}+a_{0} \frac{m l_{0}{ }^{2} b_{1}{ }^{3} \cos ^{2}(\theta)}{3 b_{0}{ }^{3}}\left(\frac{r+1}{r}\right) \dot{\alpha}_{x} \\
& +a_{1} C_{10} A_{0} l_{0}\left(\frac{2 \cos ^{2}(\theta)}{b_{1} b_{0}{ }^{2} r^{2}}\left(\frac{\left(b_{0}^{3}(r+1) \operatorname{var}_{2}+b_{1}^{3} \text { var }_{4}\right) r^{2} \operatorname{var}_{1}+b_{1}^{3} \text { var }_{2} \text { var }_{3}}{\text { var }_{1} \text { var }_{2}}\right) \dot{\alpha}_{x}\right. \\
& \left.+\frac{6 b_{1}^{2} \operatorname{sen}^{2}(\theta) \cos ^{2}(\theta)\left(\alpha_{y, e}-1\right)}{b_{0}{ }^{2} r^{2}}\left(\frac{r^{2}\left(\alpha_{x, e}+1\right) \operatorname{var}_{1}+\left(\alpha_{x, e}-1\right) \operatorname{var}_{2}}{\operatorname{var}_{1} v^{2} r_{2}}\right) \dot{\alpha}_{y}\right) \\
& +C_{10} A_{0} l_{0}\left(\frac{2 b_{0}}{b_{1}}\left(1+\alpha_{x}\right) \cos ^{2}(\theta)-\frac{2 b_{0} r}{b_{1}}\left(1-\alpha_{x}\right) \cos ^{2}(\theta)\right. \\
& -\left(\frac{b_{1}}{b_{0}}\right)^{2} \frac{2\left(1+\alpha_{x}\right) \cos ^{2}(\theta)}{\left(\left(\operatorname{sen}(\theta)-\alpha_{y} \operatorname{sen}(\theta)\right)^{2}+\left(\cos (\theta)+\alpha_{x} \cos (\theta)\right)^{2}\right)^{3 / 2}} \\
& \left.+\left(\frac{b_{1}}{b_{0} r}\right)^{2} \frac{2\left(1-\alpha_{x}\right) \cos ^{2}(\theta)}{\left(\left(\operatorname{sen}(\theta)-\alpha_{y} \operatorname{sen}(\theta)\right)^{2}+\left(\cos (\theta)-\alpha_{x} \cos (\theta)\right)^{2}\right)^{3 / 2}}\right)=\text { par }_{1} ;
\end{aligned}
$$




$$
\begin{aligned}
& \frac{m l_{0}{ }^{2} b_{1}^{3} \operatorname{sen}^{2}(\theta)}{3 b_{0}{ }^{3}}\left(\frac{r+1}{r}\right) \ddot{\alpha}_{y}+a_{0} \frac{m l_{0}^{2} b_{1}^{3} \operatorname{sen}^{2}(\theta)}{3 b_{0}{ }^{3}}\left(\frac{r+1}{r}\right) \dot{\alpha}_{y} \\
& +a_{1} C_{10} A_{0} l_{0}\left(\frac{6 b_{1}^{2} \operatorname{sen}^{2}(\theta) \cos ^{2}(\theta)\left(\alpha_{y, e}-1\right)}{b_{0}{ }^{2} r^{2}}\left(\frac{r^{2}\left(\alpha_{x, e}+1\right) \operatorname{var}_{1}+\left(\alpha_{x, e}-1\right) \operatorname{var}_{2}}{\operatorname{var}_{1} v a r_{2}}\right) \dot{\alpha}_{x}\right. \\
& \left.+\frac{2 \operatorname{sen}^{2}(\theta)}{b_{1} b_{0}{ }^{2} r^{2}}\left(\frac{\left(b_{0}^{3}(r+1) v a r_{2}+b_{1}^{3} \operatorname{var}_{6}\right) r^{2} \operatorname{var}_{1}-b_{1}^{3} \operatorname{var}_{2} \operatorname{var}_{5}}{\operatorname{var}_{1} v a r_{2}}\right) \dot{\alpha}_{y}\right) \\
& +C_{10} A_{0} l_{0}\left(-\frac{2 b_{0}}{b_{1}}\left(1-\alpha_{y}\right) \operatorname{sen}^{2}(\theta)-\frac{2 b_{0} r}{b_{1}}\left(1-\alpha_{y}\right) \operatorname{sen}^{2}(\theta)\right. \\
& +\left(\frac{b_{1}}{b_{0}}\right)^{2} \frac{2\left(1-\alpha_{y}\right) \operatorname{sen}^{2}(\theta)}{\left(\left(\operatorname{sen}(\theta)-\alpha_{y} \operatorname{sen}(\theta)\right)^{2}+\left(\cos (\theta)+\alpha_{x} \cos (\theta)\right)^{2}\right)^{3 / 2}} \\
& \left.+\left(\frac{b_{1}}{b_{0} r}\right)^{2} \frac{2\left(1-\alpha_{y}\right) \operatorname{sen}^{2}(\theta)}{\left(\left(\operatorname{sen}(\theta)-\alpha_{y} \operatorname{sen}(\theta)\right)^{2}+\left(\cos (\theta)-\alpha_{x} \cos (\theta)\right)^{2}\right)^{3 / 2}}\right)=\operatorname{par}_{2} .
\end{aligned}
$$

\begin{tabular}{|c|c|c|c|}
\hline Modelo & Carga & par & $\mathrm{par}_{2}$ \\
\hline \multirow{2}{*}{ Perfeito } & vertical & - & $p_{y} l_{0} \operatorname{sen}(\theta)$ \\
\hline & horizontal & $p_{x} l_{0} \cos (\theta)$ & - \\
\hline \multirow{2}{*}{$\begin{array}{l}\text { Imperfeição } \\
\text { geométrica }\end{array}$} & vertical & - & $p_{y} l_{0} \operatorname{sen}(\theta)$ \\
\hline & horizontal & $p_{x} l_{0} \cos (\theta)$ & - \\
\hline \multirow{2}{*}{$\begin{array}{c}\text { Imperfeição } \\
\text { de carga }\end{array}$} & vertical & $0,01 p_{y} l_{0} \cos (\theta)$ & $p_{y} l_{0} \operatorname{sen}(\theta)$ \\
\hline & horizontal & $p_{x} l_{0} \cos (\theta)$ & $0,01 p_{x} l_{0} \operatorname{sen}(\theta)$ \\
\hline
\end{tabular}

em que as parcelas par $_{1}$ e $p a r_{2}$ são os parâmetros de carga para cada situação de carregamento conforme apresentado na Tabela 6.5.

Tabela 6.5: Casos de carga estática para as equações de movimento.

Os sistemas não lineares amortecidos são complexos e não é possível resolvê-los analiticamente. As soluções são obtidas por métodos numéricos por meio do programa de álgebra simbólica Maple. Nesta dissertação utiliza-se o método de Runge-Kutta-Felhberg para integração numérica das equações não lineares de movimento. 


\subsection{2.}

\section{Análise da vibração livre amortecida}

A não linearidade e deformabilidade do material hiperelástico permite a aplicação de grandes perturbações ao nó superior e, com isso, respostas com grandes deslocamentos podem ser considerados.

Segundo Lyapunov, define-se a estabilidade da treliça hiperelástica amortecida por meio da análise da sua resposta diante de uma pequena perturbação inicial. Se após esta perturbação, para $t \rightarrow \infty$, a treliça convergir para a posição de equilíbrio estático original diz-se que esta posição é um atrator e é assim assintoticamente estável. Cabe lembrar que o conceito de Lyapunov é local. Quando se consideram grandes perturbações, deve-se aplicar o conceito de bacias de atração. Para uma dada configuração geométrica e nível de carregamento estático inicial tem-se um determinado número de configurações estáveis (atratores) e o espaço de condições iniciais é dividido em subconjuntos, onde as respostas para todas as condições iniciais em um dado subconjunto convergem para uma dada configuração de equilíbrio estável, sendo denominada bacia de atração desta configuração de equilíbrio. Desta forma a estrutura em sua posição de equilíbrio estático quando perturbada irá procurar os pontos de atração. Há situações em que a resposta não converge para nenhum atrator, mas diverge para infinito.

Uma previsão dos possíveis pontos de atração para a estrutura submetida à carga vertical e com ângulos de abatimento de $15^{\circ}$ e $75^{\circ}$ é apresentado na Figura 6.12 .
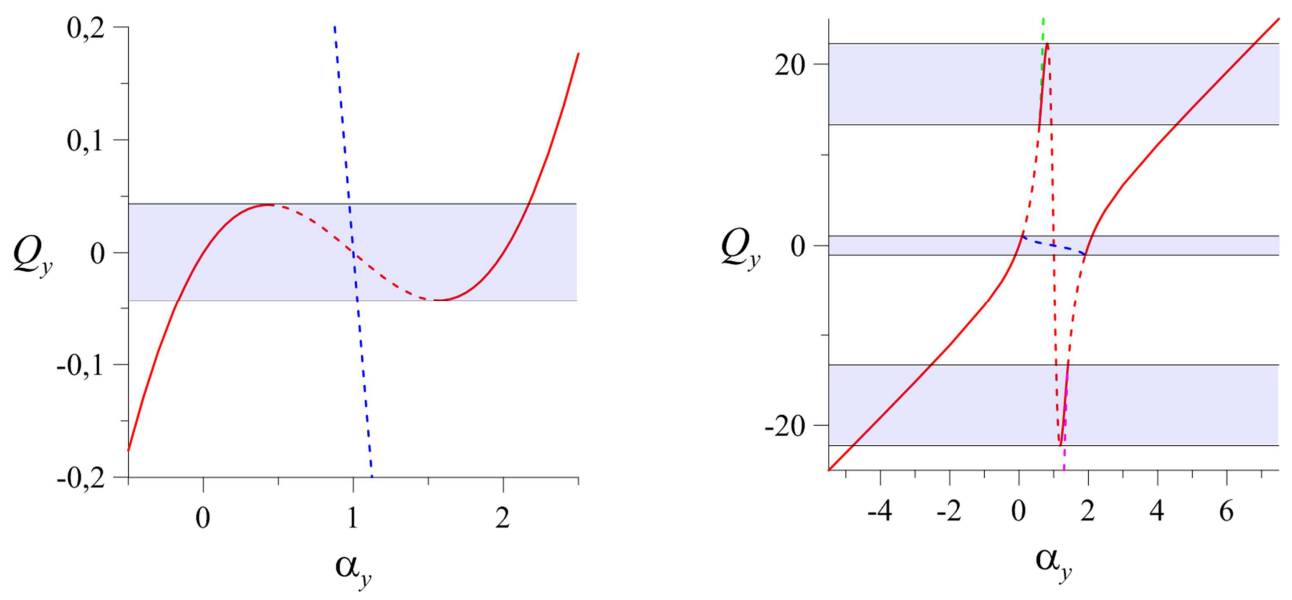

(a) $\theta=15^{\circ}$.

(b) $\theta=75^{\circ}$.

Figura 6.12: Pontos de atração para a treliça com carga estática vertical. 
A Figura 6.12 apresenta os caminhos de equilíbrio da treliça dividido em faixas. As faixas hachuradas em azul representam os trechos com duas posições estáveis para o mesmo nível de carga, sendo estes, os possíveis pontos de atração. As demais faixas apresentam apenas uma posição estável.

Apresenta-se a seguir a análise das respostas no tempo de forma gradual, considerando diferentes perturbações nos distintos sistemas estruturais.

Inicia-se a análise com a treliça com $\theta=15^{\circ}$ descarregada com e sem imperfeição em sua estrutura. A Figura 6.13 exibe a reposta ao longo do tempo destas treliças quando submetida a uma perturbação na direção $y$, de valor $\Delta_{y}$.

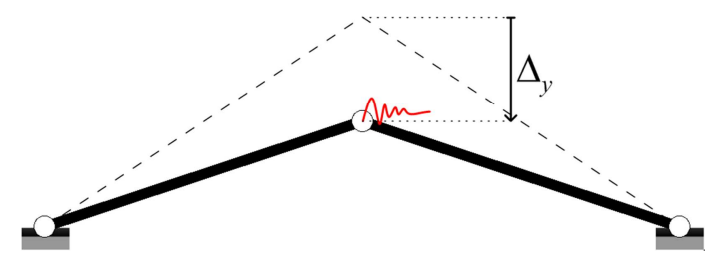

(a) Modelo perfeito.

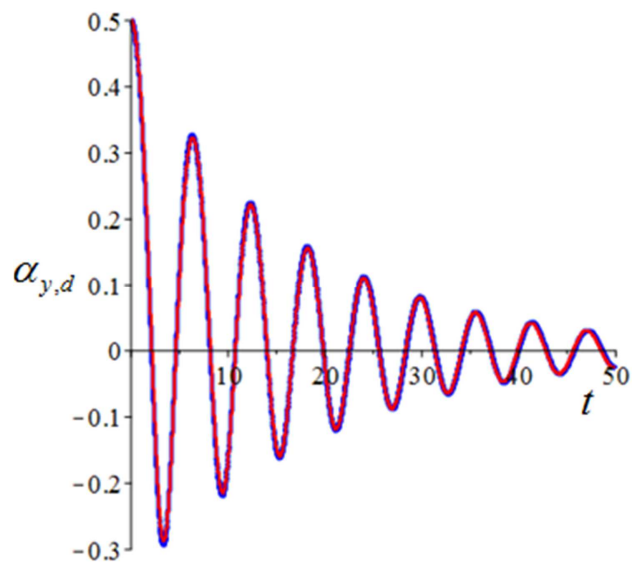

(c) Resposta $t \times \alpha_{y, d}$.

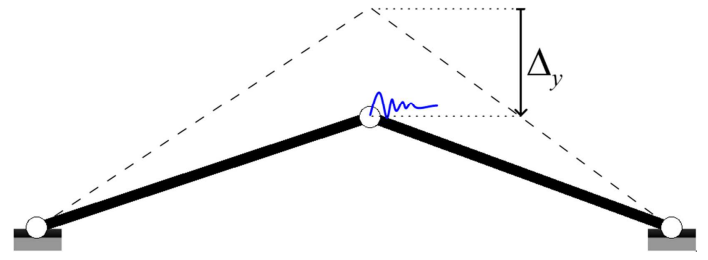

(b) Modelo imperfeito.

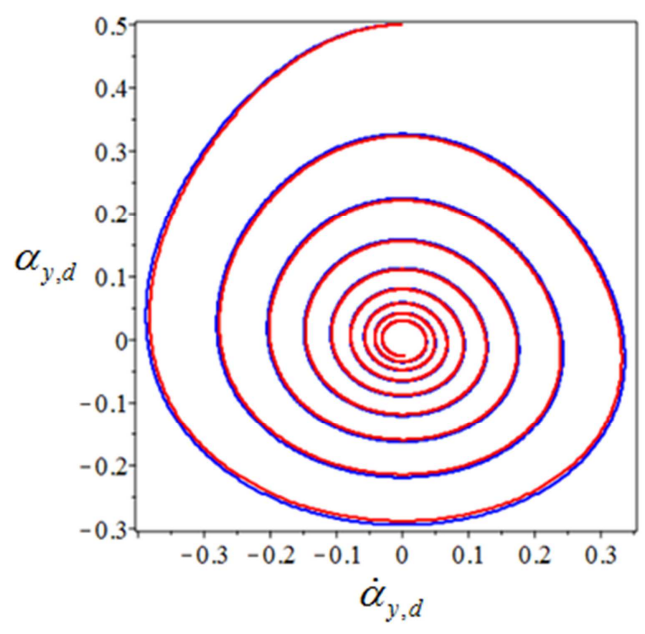

(d) Plano $\alpha_{y, d} \times \dot{\alpha}_{y, d}$.

Figura 6.13: Resposta no tempo da treliça com e sem imperfeição, $\theta=15^{\circ}$, descarregada e $\Delta_{y}=0,5 h_{0}$.

As linhas tracejadas (Figura 6.13a,b) representam a posição inicial da treliça. Nota-se que a imperfeição da estrutura aumenta levemente a sua rigidez, provocando uma pequena defasagem entre as duas respostas, quase que imperceptível. Depois de perturbada, as amplitudes decaem e a resposta converge 
para a posição de equilíbrio original e o período converge para o período do sistema linearizado.

Em seguida na treliça perfeita carregada, aplica-se uma perturbação $\Delta_{y}$ em ambos os sentidos a partir da sua posição de equilíbrio estático $(0,0,2,0,031)$. Duas condições iniciais de deslocamento são impostas: $\Delta_{y}= \pm 0,05 h_{0}$ e $\pm 0,2 h_{0}$. A Figura 6.14 apresenta a resposta no tempo para ambas às condições iniciais impostas.

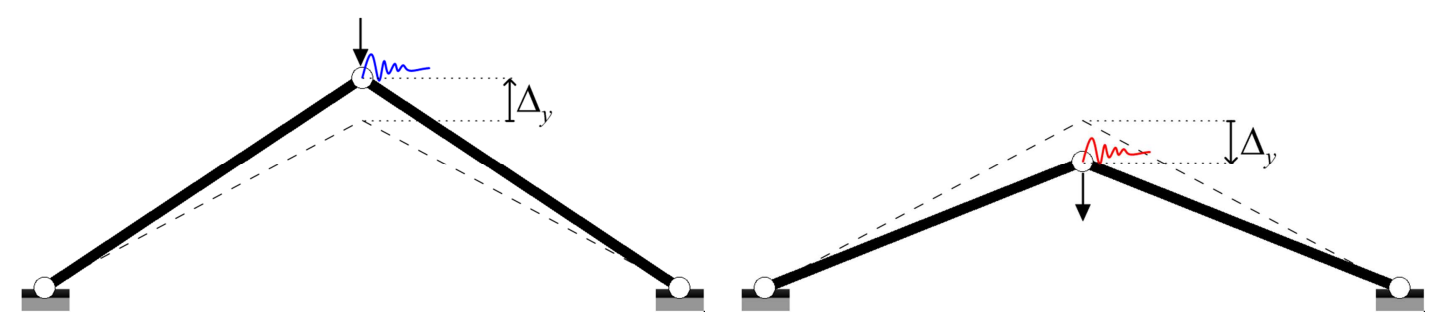

(a) Deslocamento negativo.

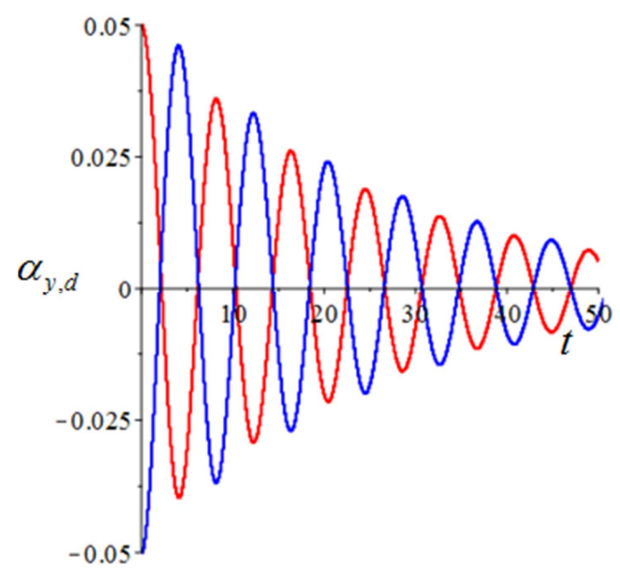

(c) Resposta $t \times \alpha_{y, d}: \Delta_{y}= \pm 0,05 h_{0}$ (b) Deslocamento positivo.

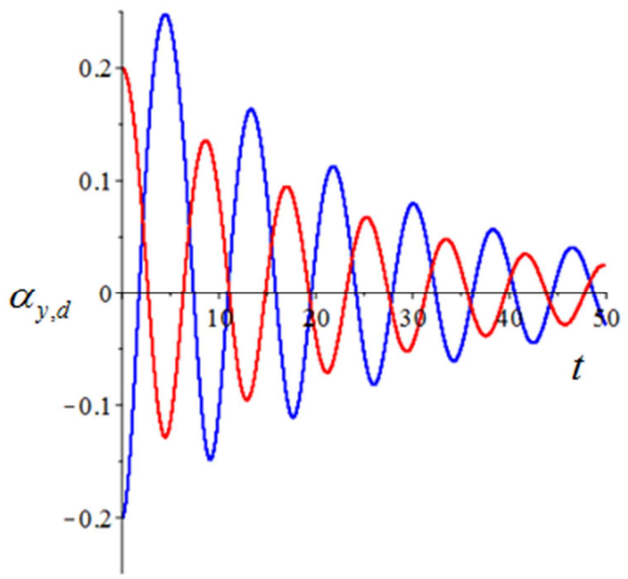

(c) Resposta $t \times \alpha_{y, d}: \Delta_{y}= \pm 0,2 h_{0}$

Figura 6.14: Resposta no tempo da treliça com carga vertical, $\theta=15^{\circ}$, posição de equilíbrio estático $(0,0,2,0,031)$ e $\Delta_{y}= \pm 0,05 h_{0}$ e $\Delta_{y}= \pm 0,2 h_{0}$.

Como mostra a Figura 6.14, as respostas para ambas as perturbações convergem para o mesmo ponto de equilíbrio estático $(0,0,2,0,031)$. A amplitude máxima da resposta para a trajetória em azul é maior que a amplitude da trajetória vermelha, considerando ambos os valores em módulo, devido à rigidez do modelo a tração ser maior que a do modelo à compressão. Em consequência disto, a perturbação necessária para instabilizar a treliça é menor quando esta aplicada no sentido negativo de $y$. Este comportamento é típico de 
estruturas com não linearidade quadrática, cuja resposta dinâmica apresenta esta assimetria.

O aumento da perturbação realça a não linearidade do sistema estrutural conforme visualizado na Figura 6.14d. Além da diferença em amplitude, o período entre as duas respostas ficam defasados. Isto se deve à variação da frequência de vibração com a amplitude, característica de sistemas dinâmicos não lineares (Nayfeh \& Mook, 2008). Neste caso observa-se um aumento do período (decréscimo da frequência) com a amplitude da vibração, característica de um sistema dinâmico com perda de rigidez (softening).

Da mesma forma que se fez uma previsão dos pontos de atração na Figura 6.12, é possível prever as perturbações na direção $+y$ que levam a treliça com $\theta=15^{\circ}$ a perder sua estabilidade quando submetida a uma carga estática.

Considere a treliça com carga vertical e $\theta=15^{\circ}$, na posição de equilíbrio estático dada por $(0,0,25,0,035)$ e submetida a três deslocamentos $\Delta_{y}$ crescentes $\left(0,1 h_{0}, 0,3 h_{0}\right.$ e $\left.0,39 h_{0}\right)$, sempre em relação à posição de equilíbrio estático. A Figura 6.15 apresenta as respostas de deslocamento e velocidade ao longo do tempo para as três situações.

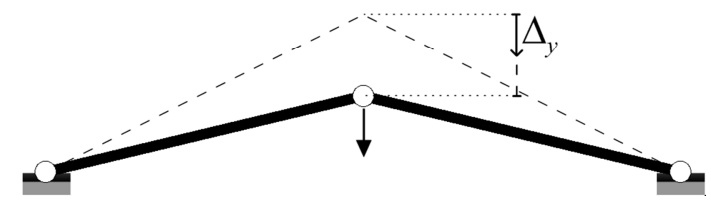

(a) Modelo.

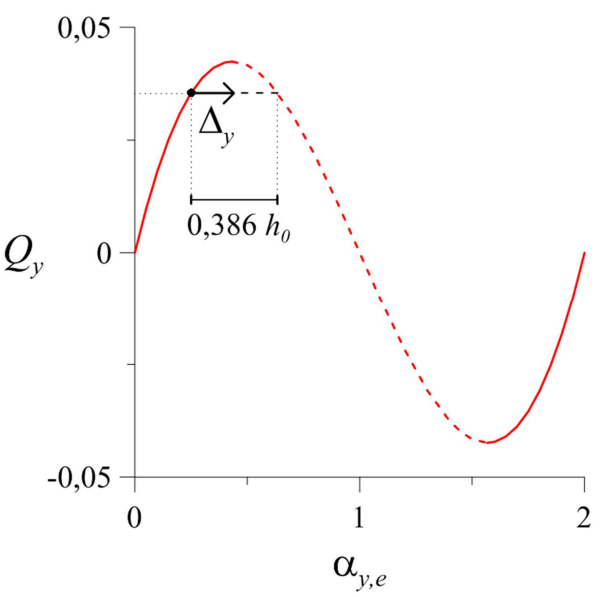

(b) Caminho fundamental de equilíbrio. 


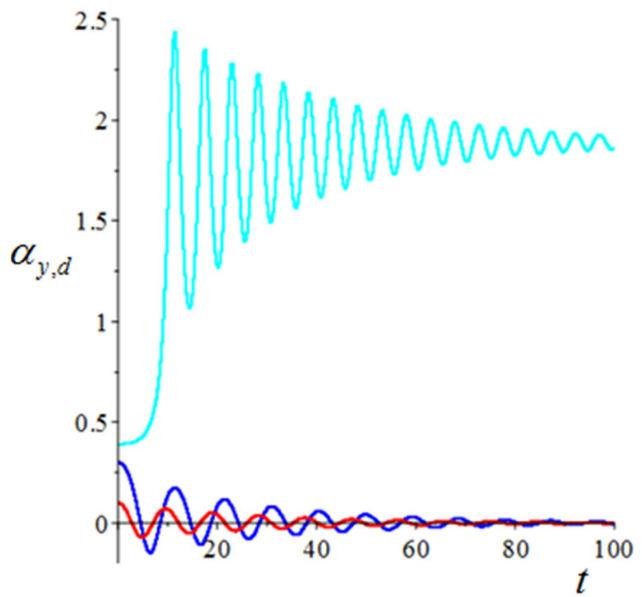

(c) Resposta $t \times \alpha_{y, d}$.

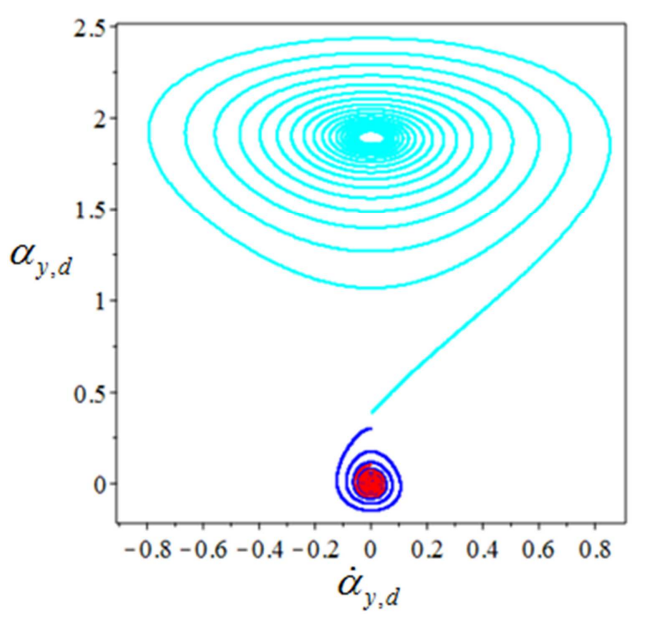

(c) Plano $\alpha_{y, d} \times \dot{\alpha}_{y, d}$.

Figura 6.15: Respostas no tempo da treliça com carga vertical, $\theta=15^{\circ}$, posição de equilíbrio estático $(0,0,25,0,035)$ e $\Delta_{y}=0,1 h_{0}, 0,3 h_{0}$ e $0,39 h_{0}$.

Na Figura 6.15b, marca-se no caminho de equilíbrio da treliça sua posição estática inicial, indicando o sentido dos deslocamentos aplicados e mostra-se o valor do deslocamento necessário para provocar instabilidade. $\mathrm{O}$ aumento do deslocamento de $0,1 h_{0}$ para $0,3 h_{0}$ provoca o aumento do período da estrutura durante os instantes iniciais e assim uma defasagem em relação à resposta de menor amplitude. Quando a perturbação aplicada é igual ou maior que a distância cotada no gráfico do caminho de equilíbrio da treliça $\left(0,39 h_{0}\right)$, a estrutura perde a estabilidade e diverge para a outra posição de equilíbrio. Após a divergência inicial, a estrutura passa a vibrar em torno da configuração pós-crítica e o período da oscilação diminui indicando o enrijecimento da estrutura, agora submetida à tração. O plano de fase $\alpha_{y, d} \times \dot{\alpha}_{y, d}$ ilustra a convergência das soluções para os dois atratores (posições de equilíbrio estável).

Quando a treliça possui um ângulo de abatimento superior ao crítico $\left(\theta_{\lim }=70,76^{\circ}\right)$, a energia dos pontos de selas simétricos é menor que a do ponto de sela central (Tabela 6.3), e assim a treliça perde a estabilidade lateralmente quando submetida a uma carga vertical.

$\mathrm{Na}$ análise da treliça com ângulo de abatimento de $15^{\circ}$, foram apresentadas as respostas no tempo dos deslocamentos e velocidade na direção vertical $y$, uma vez que o movimento da estrutura é predominantemente simétrico. Qualquer 
perturbação na direção horizontal decai rapidamente a zero. A Figura 6.16 ilustra essa situação para um deslocamento com componentes $0,06 b_{0}$ e $0,2 h_{0}$ nas direções $x$ e $y$, respectivamente.
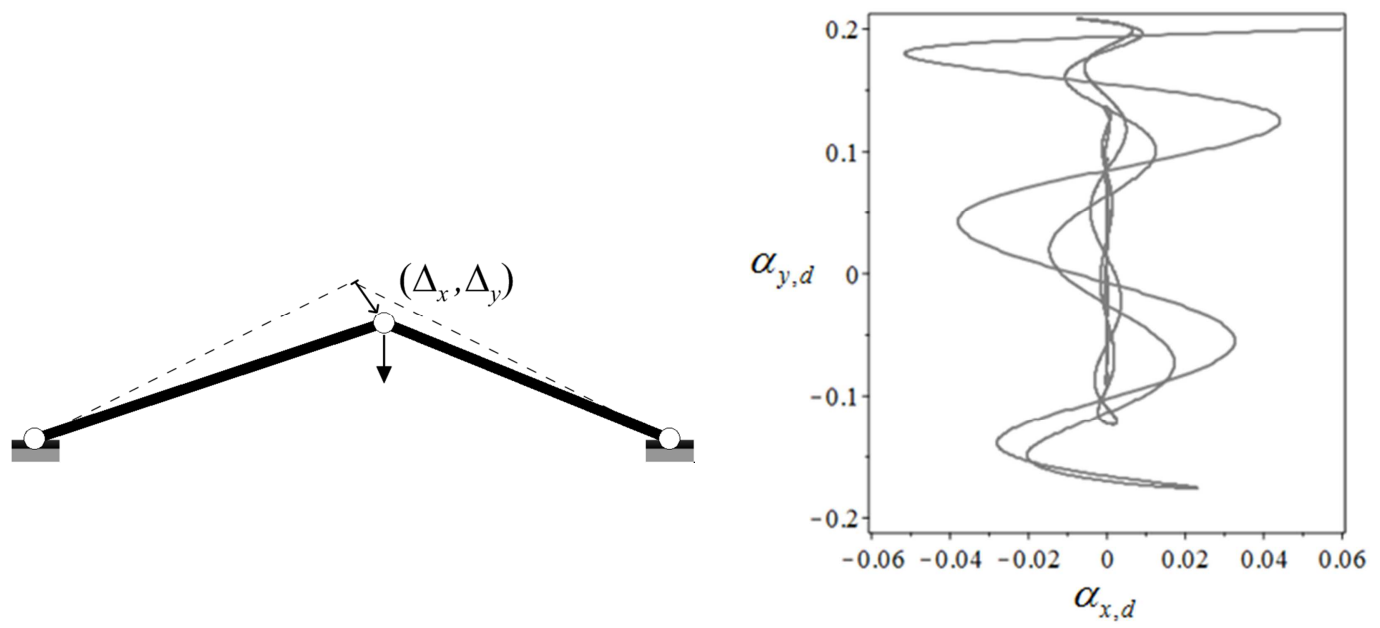

(a) Modelo.

(b) Plano $\alpha_{x, d} \times \alpha_{y, d}$.

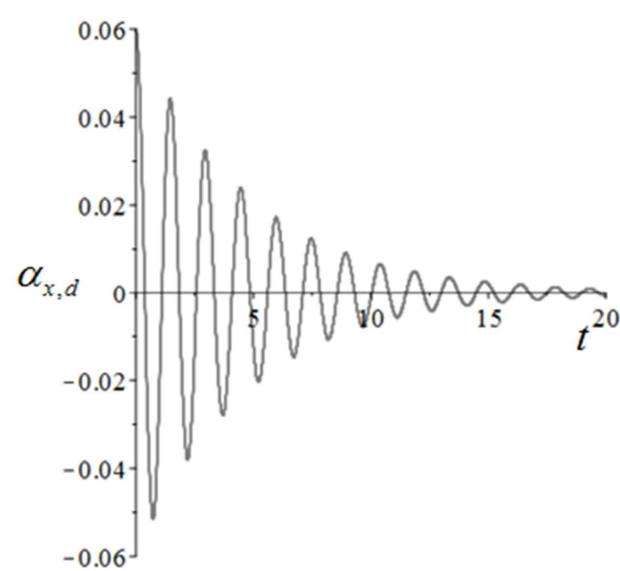

(c) Resposta $t \times \alpha_{x, d}$.

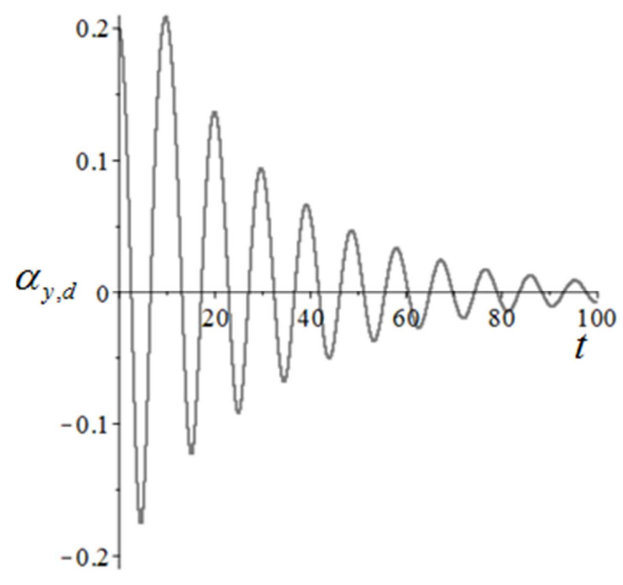

(d) Resposta $t \times \alpha_{y, d}$.

Figura 6.16: Respostas no tempo da treliça com carga vertical, $\theta=15^{\circ}$, posição de equilíbrio estático $(0,0,2,0,035)$ e $\left(\Delta_{x}, \Delta_{y}\right)=\left(0,06 b_{0}, 0,2 h_{0}\right)$.

Para ângulos superiores ao crítico, ambas as componentes de deslocamento influenciam na resposta da treliça quando submetida a perturbações horizontais. Inicia-se análise da treliça com $\theta=75^{\circ}$ impondo-se um deslocamento na direção $x$ de $1 b_{0}$ na treliça descarregada para os modelos com e sem imperfeição. A Figura 6.17 mostra a resposta ao longo do tempo dos deslocamentos $\alpha_{x, d}$ e $\alpha_{y, d}$ e de diferentes planos de fase. 


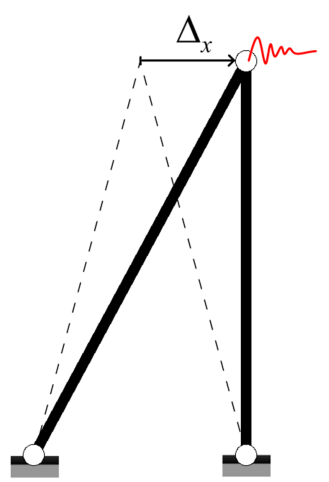

(a) Modelo perfeito.

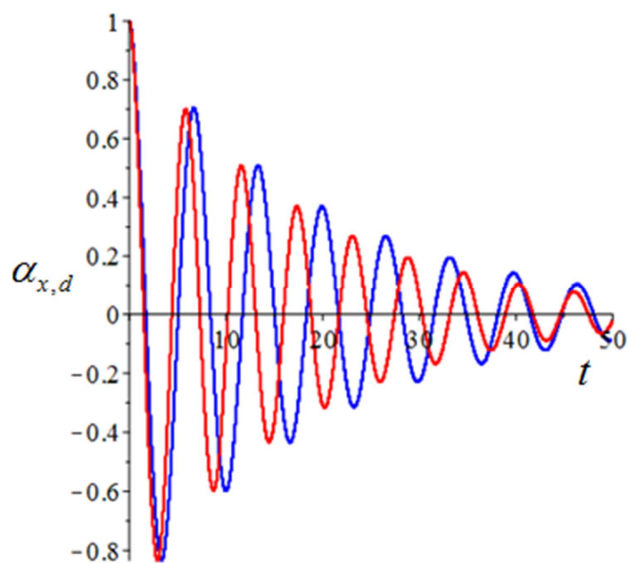

(c) Resposta $t \times \alpha_{x, d}$.

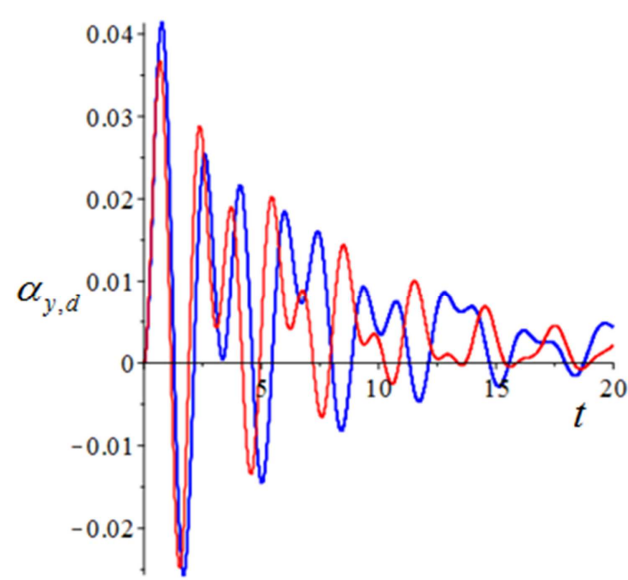

(e) Resposta $t \times \alpha_{y, d}$.

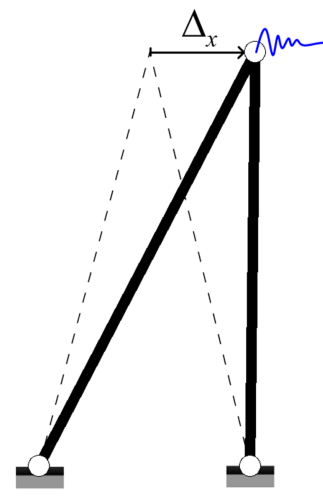

(b) Modelo imperfeito.

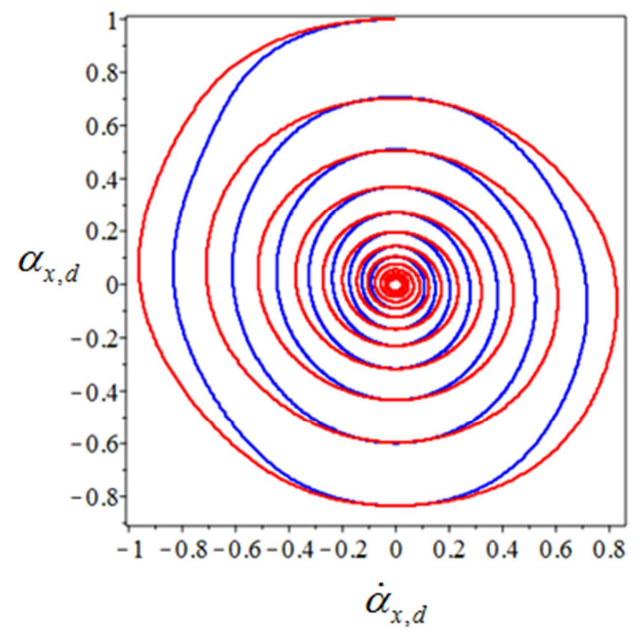

(d) Plano $\dot{\alpha}_{x, d} \times \alpha_{x, d}$.

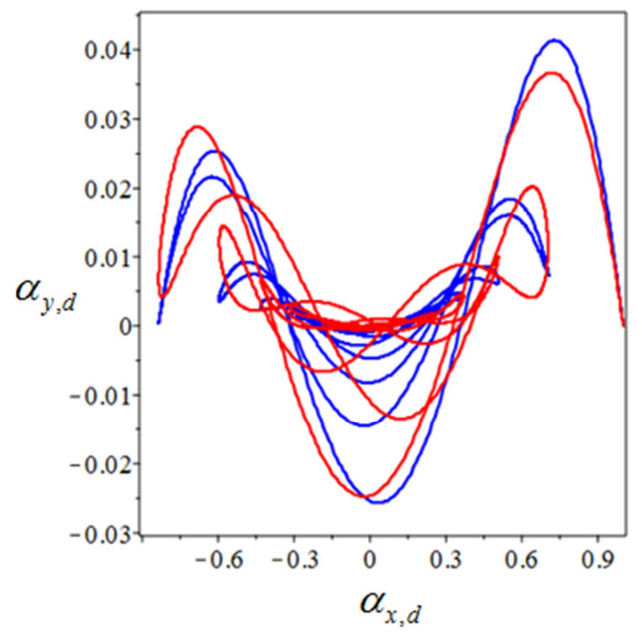

(f) Plano $\alpha_{x, d} \times \alpha_{y, d}$.

Figura 6.17: Resposta no tempo da treliça com e sem imperfeição, $\theta=75^{\circ}$, descarregada e $\Delta_{x}=1 b_{0}$. 
Diferentemente do que acontece na treliça abatida, a treliça com $\theta=75^{\circ}$ imperfeita é menos rígida do que o modelo perfeito. Assim o período dos deslocamentos na resposta $t \times \alpha_{x, d}$ é maior para a treliça com imperfeição (Figura 6.17c). Além da variação da frequência de vibração com a amplitude, observa-se também a não lineridade da resposta na direção $y$.

Analisa-se em seguida a treliça perfeita com carga vertical estática submetida a perturbações horizontais crescentes $\Delta_{x}$ em relação à posição de equilíbrio estático $(0,0,09,1,054)$, como ilustra a Figura 6.18 .

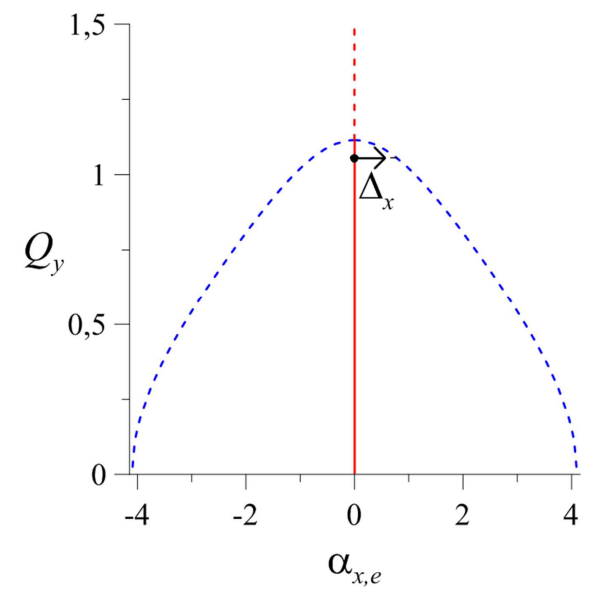

Figura 6.18: Localização da treliça com $\theta=75^{\circ}$ carregada em seu caminho de equilíbrio: posição inicial $(0,0,09,1,054)$.

A Figura 6.19 apresenta as respostas devido aos deslocamentos $\Delta_{x}=0,5 b_{0}$ (vermelho) e $\Delta_{x}=0,8 b_{0}(\mathrm{azul})$, a partir da posição de equilíbrio estático $(0,0,09,1,054)$.

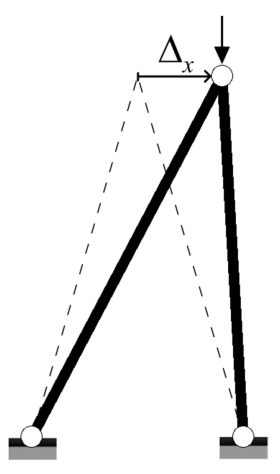

(a) Modelo.

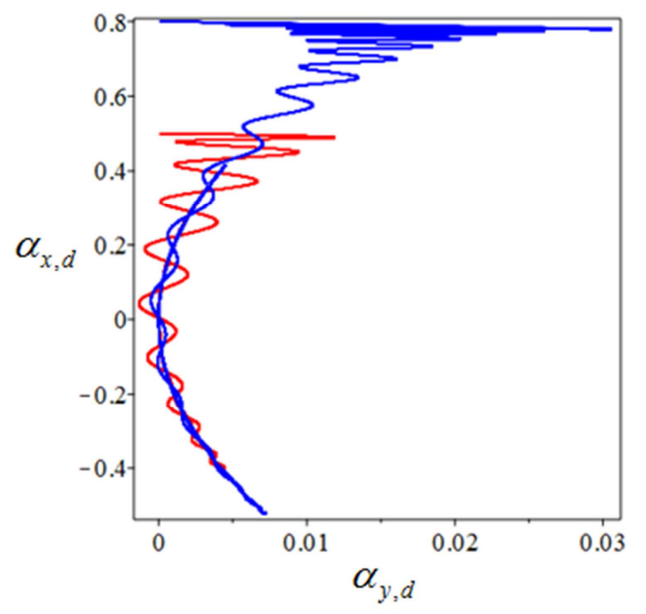

(b) Plano $\alpha_{y, d} \times \alpha_{x, d}$. 


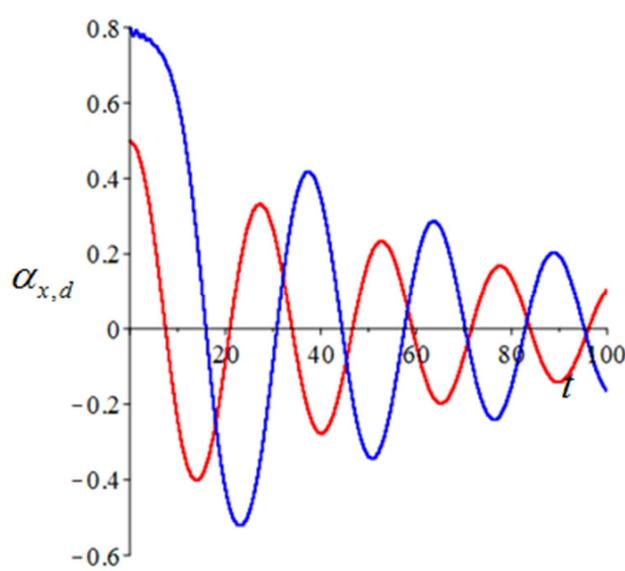

(c) Resposta $t \times \alpha_{x, d}$.

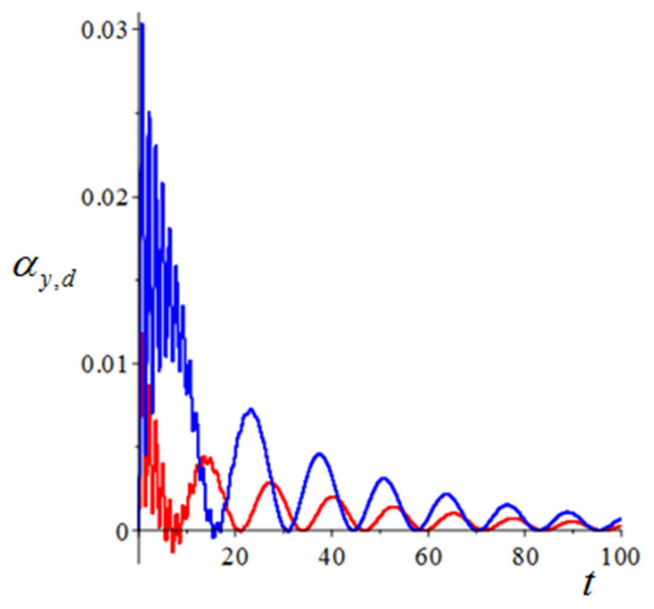

(e) Resposta $t \times \alpha_{y, d}$.

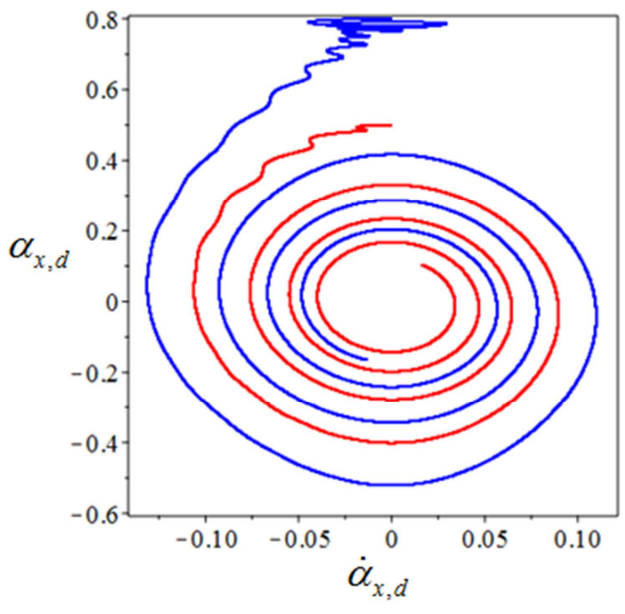

(d) Plano $\dot{\alpha}_{x, d} \times \alpha_{x, d}$.

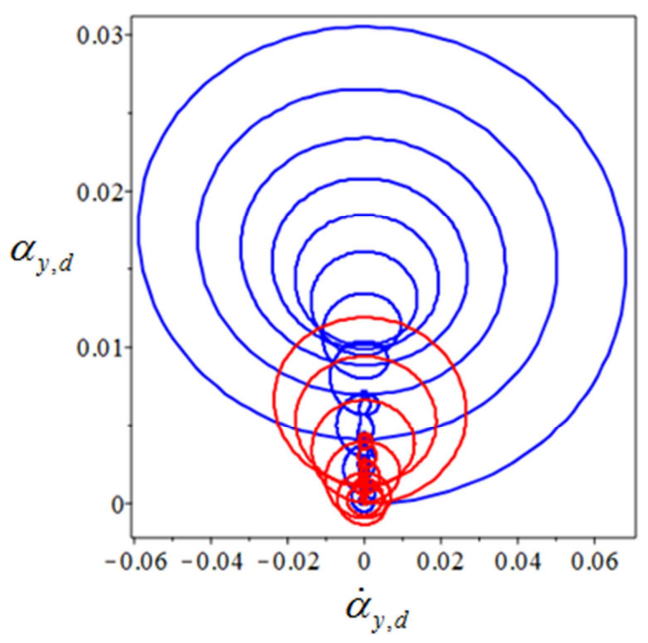

(f) Plano $\dot{\alpha}_{y, d} \times \alpha_{y, d}$.

Figura 6.19: Respostas no tempo da treliça com carga vertical, $\theta=75^{\circ}$, posição de equilíbrio estático $(0,0,09,1,054)$ e $\Delta_{x}=0,5 b_{0}$ e $0,8 b_{0}$.

Observa-se na Figura 6.19 que em ambos os casos, após as perturbações, a estrutura retorna assintoticamente a sua posição estática inicial.

No Capítulo 5 foram apresentadas as frequências naturais da estrutura submetida a uma carga vertical. Foi observado que próximo ao ponto de bifurcação há possibilidade de acoplamento modal. Conforme mostra a Figura 6.19, observa-se o acoplamento nos instantes iniciais em ambas as direções, assim como nos outros planos de fase. Nota-se também que o aumento da perturbação aumenta a não linearidade da resposta. 
A Figura 6.20 apresenta as respostas no tempo devido ao deslocamento horizontal necessário para a bifurcação da treliça $\left(\Delta_{x}=0,82 b_{0}\right)$, onde se observa a divergência da solução inicial e, posteriormente, a convergência para uma posição de equilíbrio pós-crítica. A visualização do processo de perda de estabilidade só é possível através da integração das equações não lineares de movimento, já que a perda de estabilidade é eminentemente um processo dinâmico.

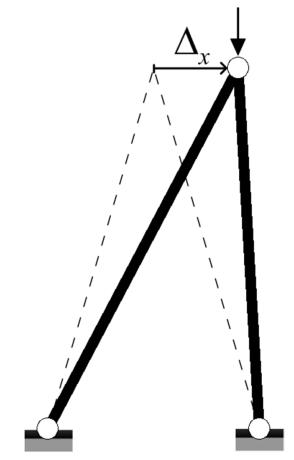

(a) Modelo.

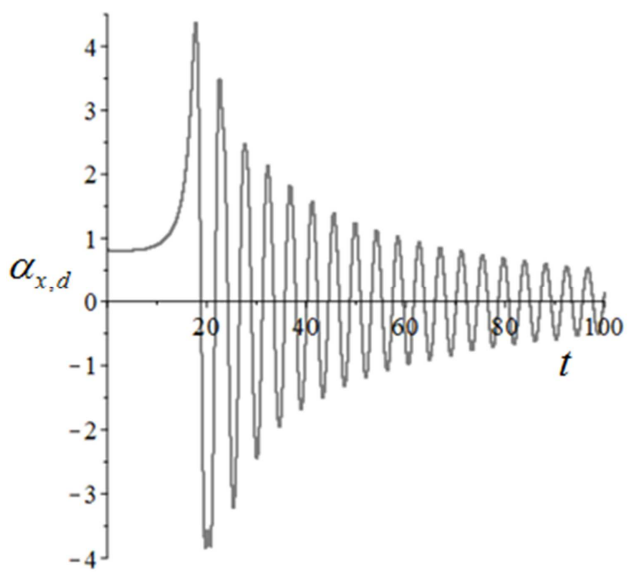

(c) Resposta $t \times \alpha_{x, d}$.

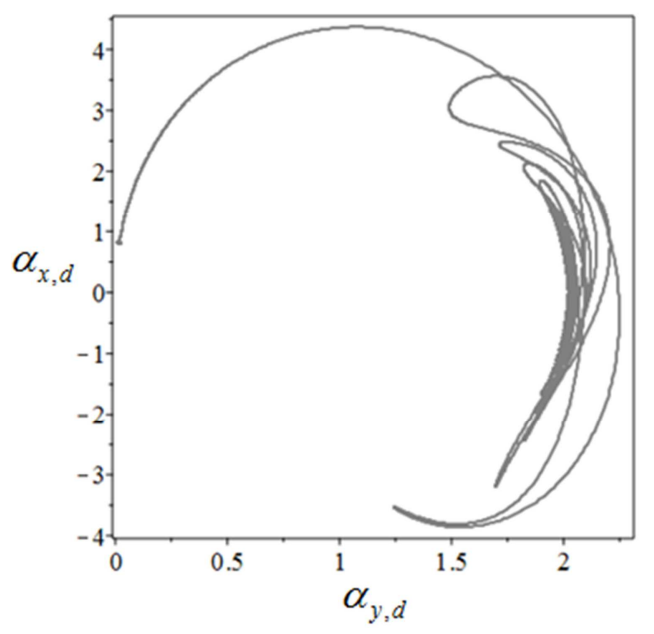

(b) Plano $\alpha_{y, d} \times \alpha_{x, d}$.

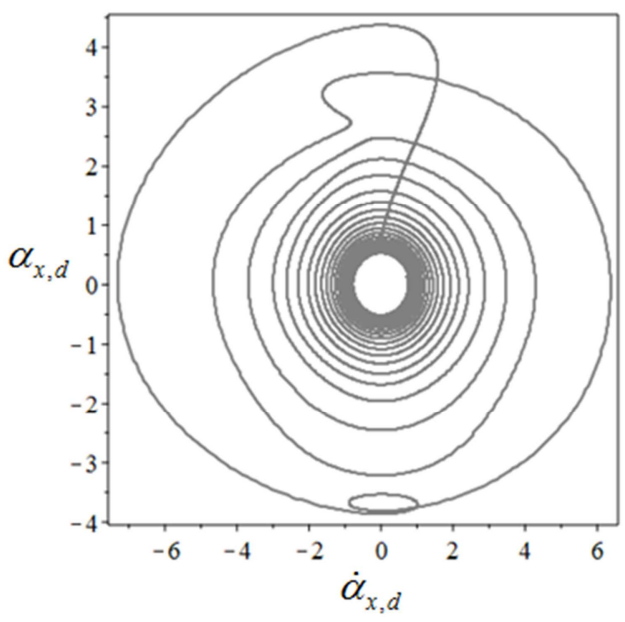

(d) Plano $\dot{\alpha}_{x, d} \times \alpha_{x, d}$. 


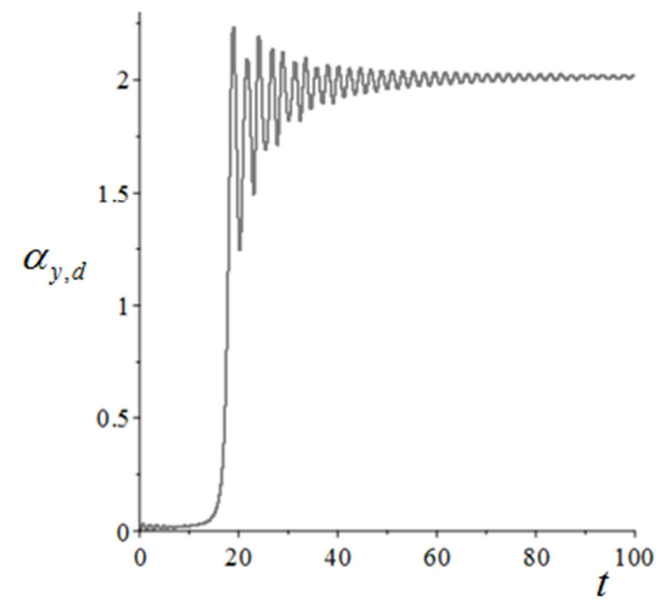

(e) Resposta $t \times \alpha_{y, d}$.

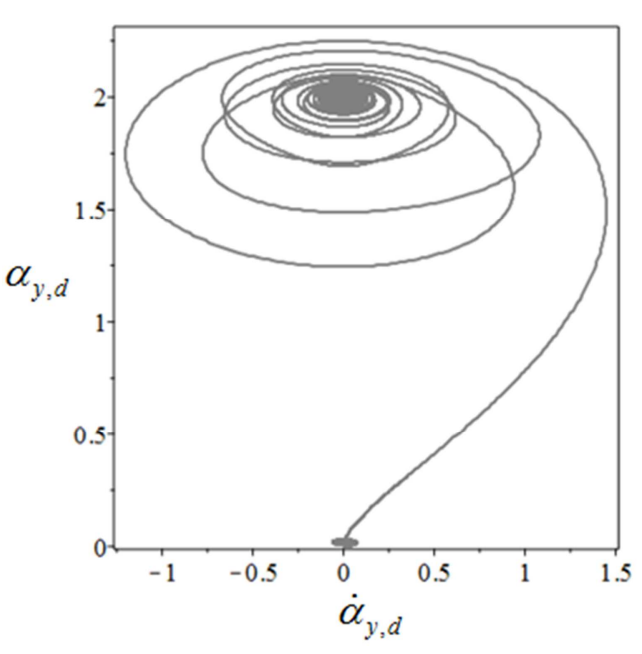

(f) Plano $\dot{\alpha}_{y, d} \times \alpha_{y, d}$.

Figura 6.20: Respostas no tempo da treliça com carga vertical, $\theta=75^{\circ}$, posição de equilíbrio estático $(0,0,09,1,054)$ e $\Delta_{x}=0,82 b_{0}$.

Conforme apresentado na Figura 6.17, a imperfeição na geometria ou de carga horizontal, como mostrado nos capítulos anteriores, diminui a rigidez horizontal da estrutura. Na Figura 6.21 visualiza-se a sensibilidade às imperfeições de carga (perturbação horizontal de $0,01 p_{y}$ ), em azul, e na geometria da estrutura (projeções das barras na direção $x$ são alteradas em 5\% ver Fig. 3.5), em vermelho, na resposta do tempo dessas estruturas em relação ao modelo perfeito, em preto, considerando um mesmo valor de carga estática.

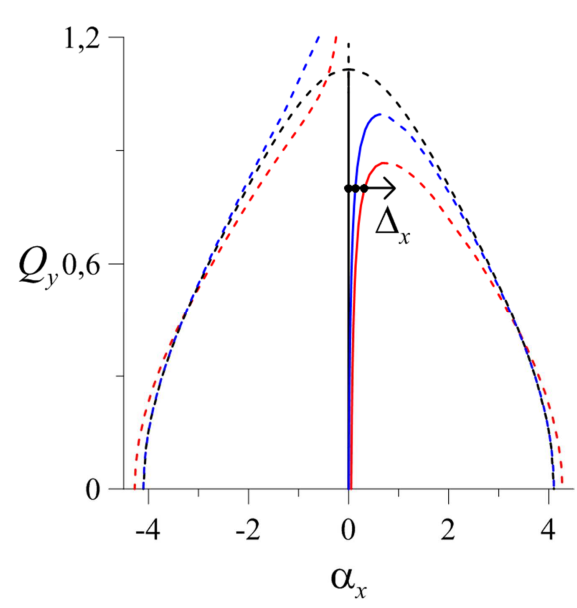

(a) Caminho fundamental de equilíbrio.

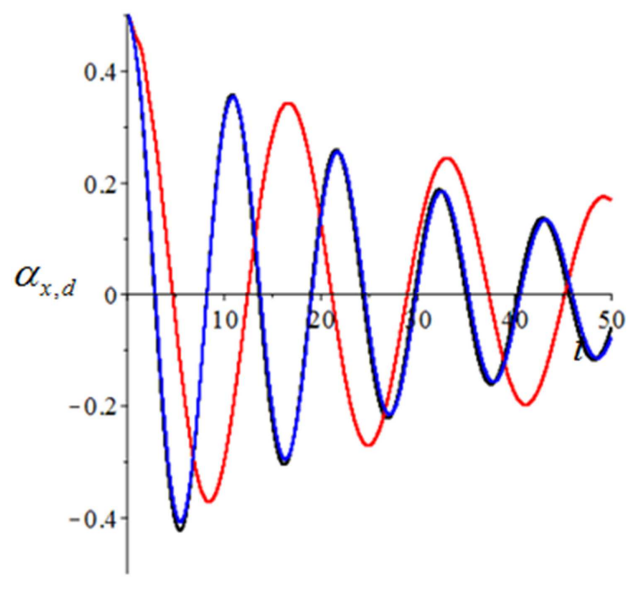

(b) Resposta $t \times \alpha_{x, d}$.

Figura 6.21: Respostas no tempo das treliças sem e com imperfeições (carga e geométrica) para carga vertical $Q_{y}=0,799, \theta=75^{\circ}$ e $\Delta_{x}=0,5 b_{0}$. 
A Figura 6.21 ilustra como as perturbações aplicadas influenciam no período da estrutura com um mesmo valor de carga estática $\left(Q_{y}=0,799\right)$.

A análise estática das treliças submetidas à carga horizontal demonstrou que o caminho fundamental de equilíbrio é estável até a treliça alcançar o ponto de bifurcação, localizado nas coordenadas $\alpha_{x, e}>1$ e $\alpha_{y, e}=1$. A Figura 6.22 apresenta os possíveis pontos de atração para as treliças com carga estática horizontal.

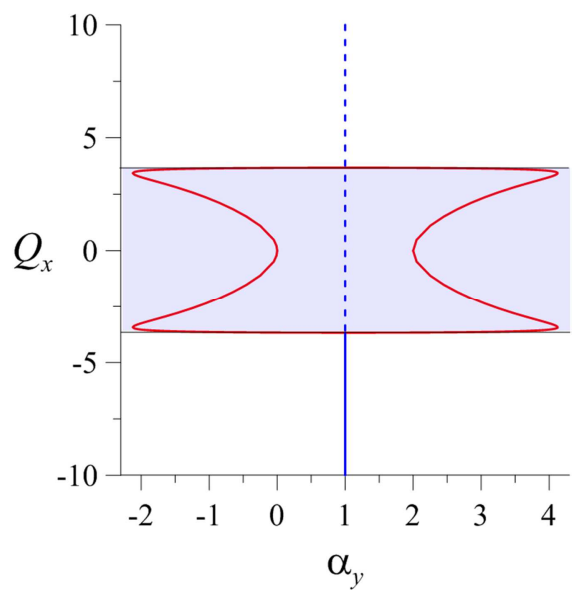

(a) $\theta=15^{\circ}$.

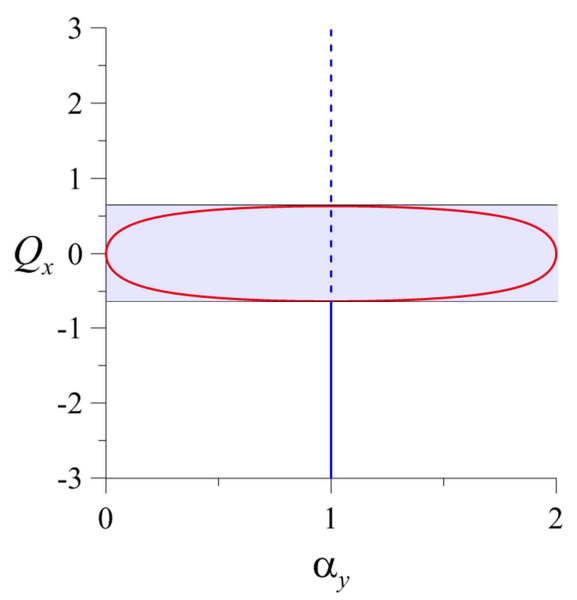

(b) $\theta=75^{\circ}$.

Figura 6.22: Pontos de atração para a treliça com carga estática horizontal.

$\mathrm{Na}$ Figura 6.22, as regiões hachuradas no caminho fundamental de equilíbrio das treliças submetidas a um carregamento estático horizontal indicam dois possíveis pontos atração. Apesar da estabilidade dos caminhos de equilíbrio e ambos dirigirem-se para a direção de $\alpha_{y, e}=1$ a variação da rigidez ao longo do caminho de equilíbrio na direção $y$ em ambas as treliças até esta coordenada é diferente.

Começando pela treliça com $\theta=15^{\circ}$, ilustra-se na Figura 6.23 a resposta da estrutura diante de uma perturbação vertical igual $0,5 h_{0}$ a partir de três posições diferentes listadas na Tabela 6.6. Mostram-se também as frequências e os modos de vibração referentes a estas posições. 
Tabela 6.6: Modos de vibração e frequências naturais para a treliça com $\theta=15^{\circ}$.

\begin{tabular}{ccc}
\hline$\left(\alpha_{x, e}, \alpha_{y, e}, Q_{x}\right)$ & $\omega_{1,2}{ }^{2} / w^{2}$ & Modos de vibração \\
\hline$(0,045,-0,05,0,482)$ & 1,$30 ; 16,70$ & $\left\{\begin{array}{c}-0,013 \\
1,000\end{array}\right\} ;\left\{\begin{array}{c}1,000 \\
0,186\end{array}\right\}$ \\
\hline$(0,309,-1,05,2,364)$ & 2,$51 ; 15,48$ & $\left\{\begin{array}{c}-0,167 \\
1,000\end{array}\right\} ;\left\{\begin{array}{c}0,43 \\
1,000\end{array}\right\}$ \\
\hline$(0,741,-2,00,3,256)$ & 1,$39 ; 16,61$ & $\left\{\begin{array}{c}-0,865 \\
1,000\end{array}\right\} ;\left\{\begin{array}{c}0,083 \\
1,000\end{array}\right\}$
\end{tabular}

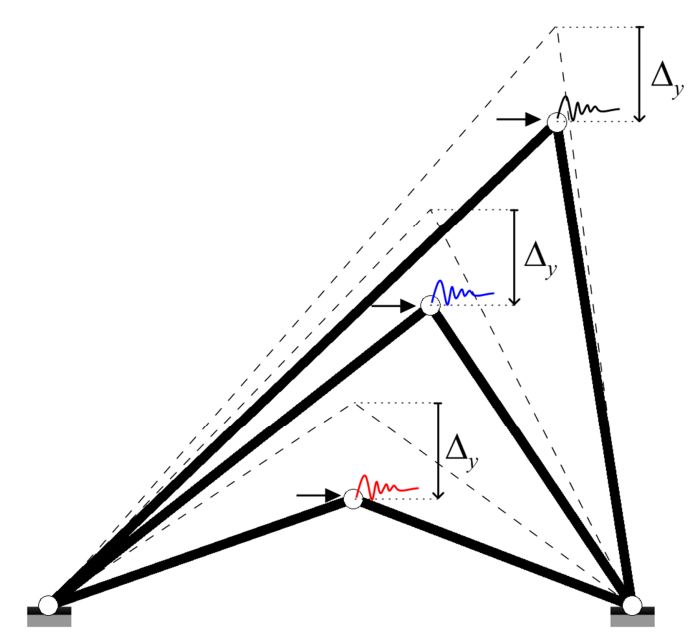

(a) Modelo.

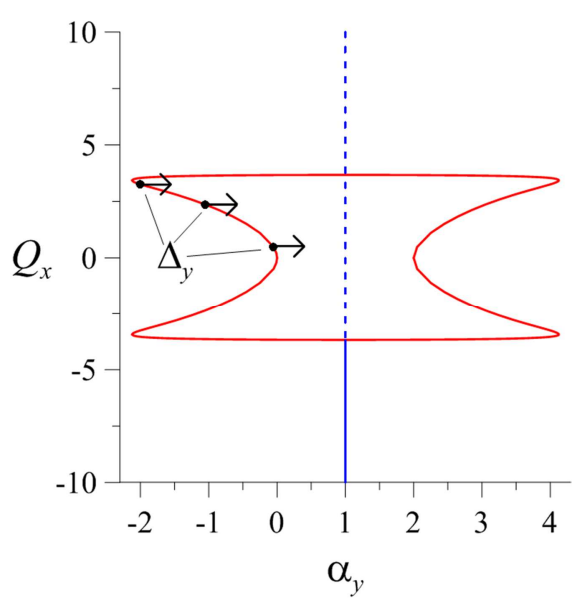

(b) Caminho fundamental de equilíbrio.

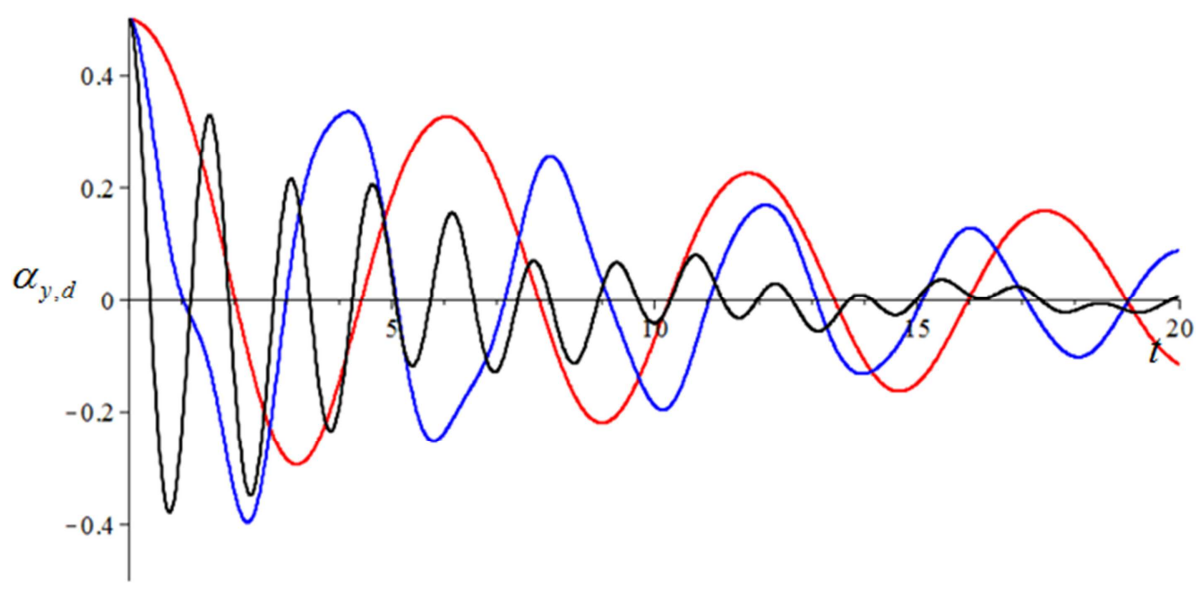

(c) Resposta $t \times \alpha_{y, d}$. 


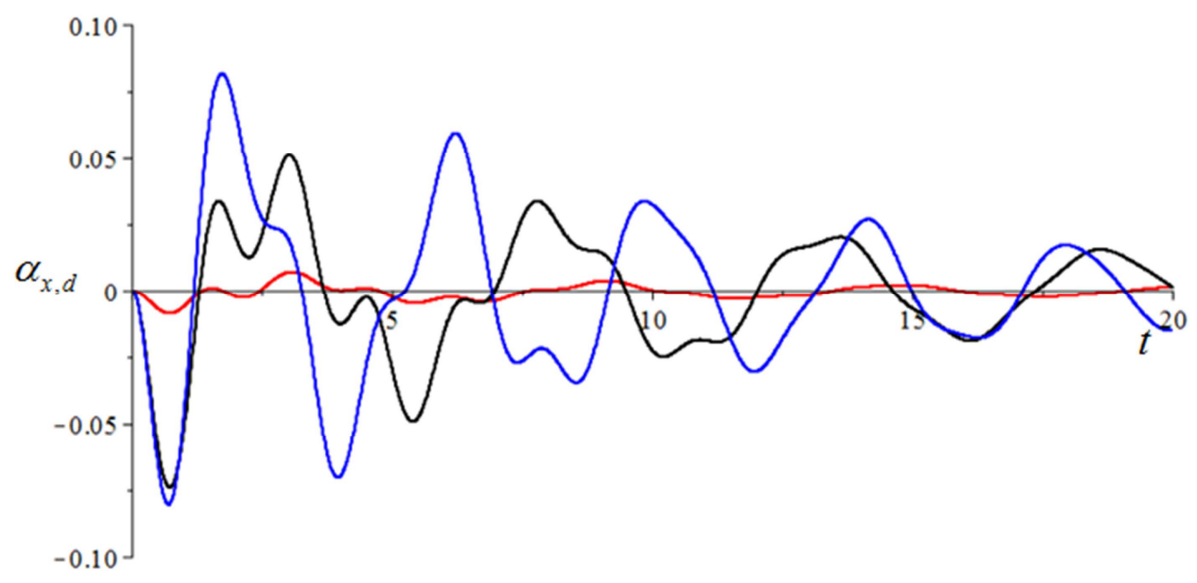

(d) Resposta $t \times \alpha_{x, d}$.

Figura 6.23: Respostas no tempo da treliça perfeita, carga horizontal, $\theta=15^{\circ} \mathrm{e}$ $\Delta_{y}=0,5 h_{0}$ para diferentes posições de equilíbrio estático.

A Figura 6.23 e a Tabela 6.6 permite uma visão geral do comportamento dinâmico não linear da estrutura nas duas direções ao longo do tempo diante da perturbação na direção $y$. Nota-se na resposta na direção $y$ que, para as respostas de cor vermelho e azul, o período da vibração é próximo do primeiro modo de vibração e para a treliça na posição mais carregada $(0,741,-2,00,3,256)$ visualiza-se a superposição dos dois modos de vibração e sua resposta decai rapidamente para zero. A resposta na direção $x$ mostra o acoplamento entre os dois modos de vibração.

A rigidez da treliça na direção $y$ na ausência da carga vertical aumenta e grandes perturbações são necessárias para que ocorra divergência. No Capítulo 4 mostrou-se que uma imperfeição de carga igual a $0,071 Q_{x}$ altera o caminho fundamental de equilíbrio da treliça abatida que passa a perder a estabilidade por ponto limite saltando entre os apoios da treliça. A fim de visualizar a resposta no tempo da treliça para esta situação aplica-se esta imperfeição $\left(0,071 Q_{x}\right)$. A Figura 6.24 apresenta a resposta dos deslocamentos na direção y para duas perturbações diferentes. 


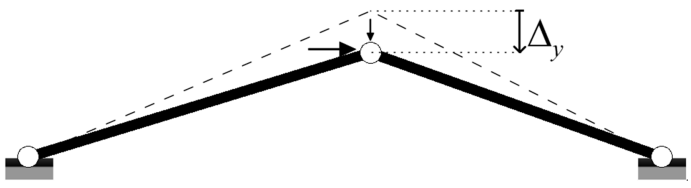

(a) Modelo.

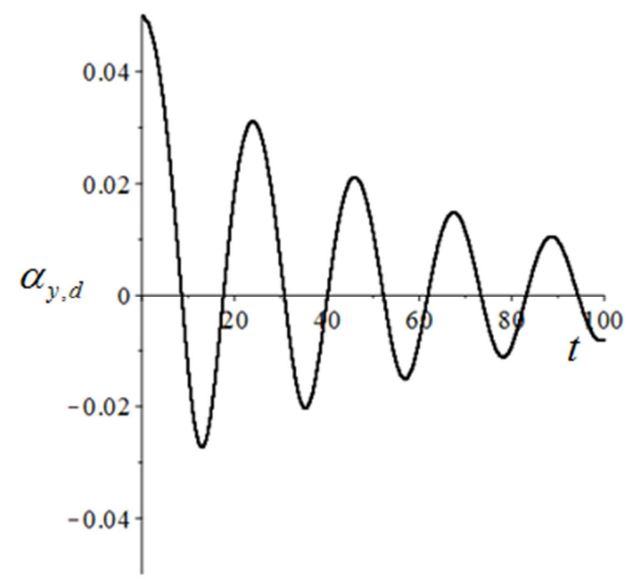

(c) Resposta $t \times \alpha_{y, d}: \Delta_{y}=0,05 h_{0}$.

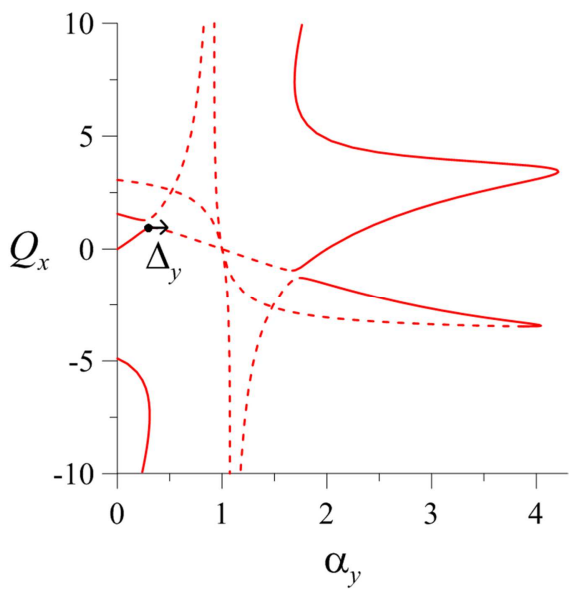

(b) Caminho de equilíbrio.

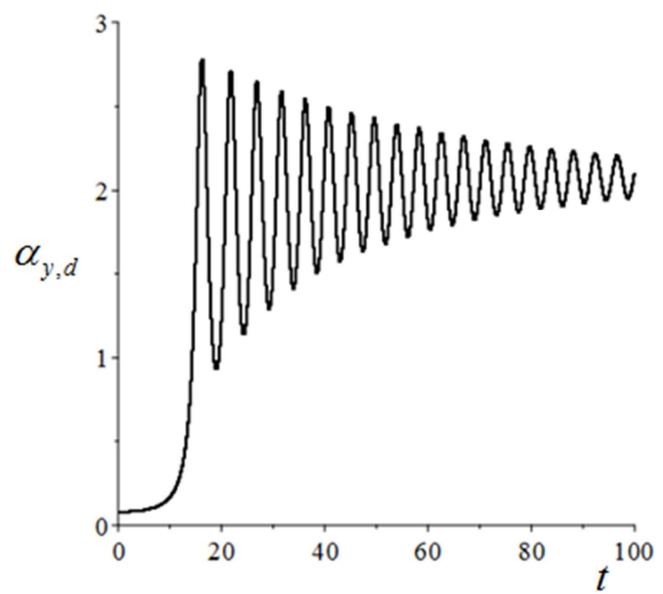

(d) Resposta $t \times \alpha_{y, d}: \Delta_{y}=0,08 h_{0}$.

Figura 6.24: Resposta no tempo da treliça com imperfeição de carga de $0,071 Q_{x}$, $\theta=15^{\circ}$ e posição de equilíbrio estático $(0,08,0,3,0,933)$.

Se for observada a carga limite na trajetória fundamental na Figura 6.12a $\left(Q_{y}=0,042\right)$ e comparada com a carga vertical da imperfeição de carga aplicada ao modelo da Figura $6.24\left(0,071 Q_{x}=0,071 \times 0,933=0,066\right)$, nota-se que a carga horizontal no modelo aumenta a capacidade de carga vertical da treliça. Ao mesmo tempo, comparando o período das respostas com o da Figura 6.14 percebe-se um período cerca de 2,5 vezes maior, anunciando que a estrutura está próxima de divergir para outra posição estável, conforme apresentado para uma perturbação superior de $\Delta_{y}=0,08 h_{0}$. 
Finalmente, a Figura 6.25 apresenta resposta da treliça com $\theta=75^{\circ}$ e carga estática horizontal para uma perturbação $\left(\Delta_{x}, \Delta_{y}\right)=\left(0,5 b_{0}, 0,15 h_{0}\right)$, a partir de duas posições de equilíbrio estático.

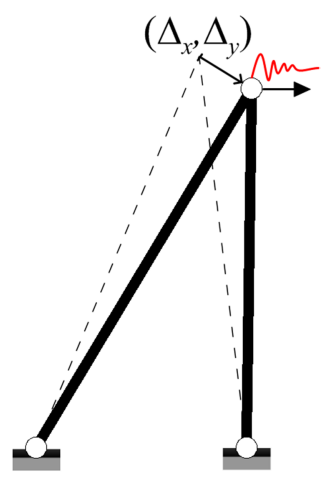

(a) Posição $(0,55,0,007,0,113)$

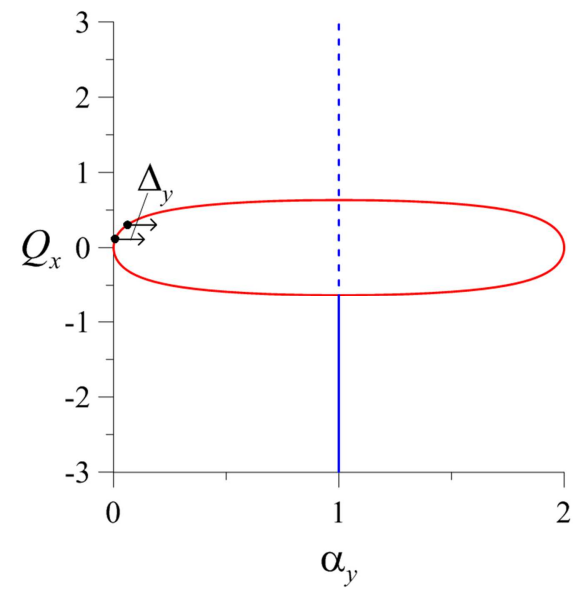

(c) Caminho de equilíbrio: $\alpha_{y} \times Q_{x}$

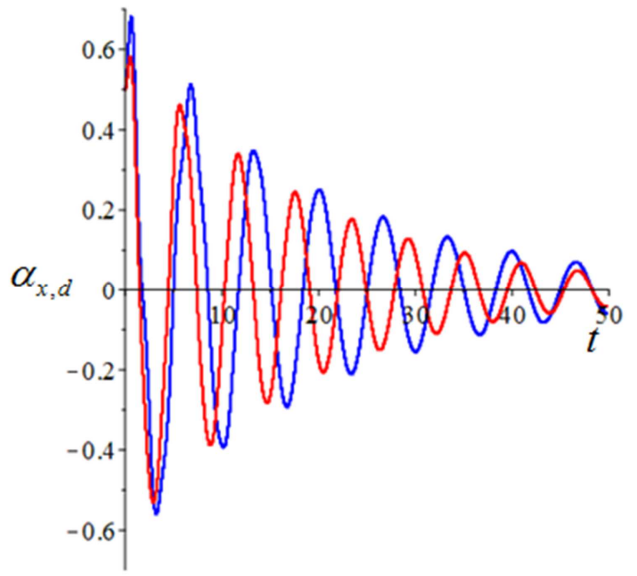

(e) Resposta $t \times \alpha_{x, d}$.

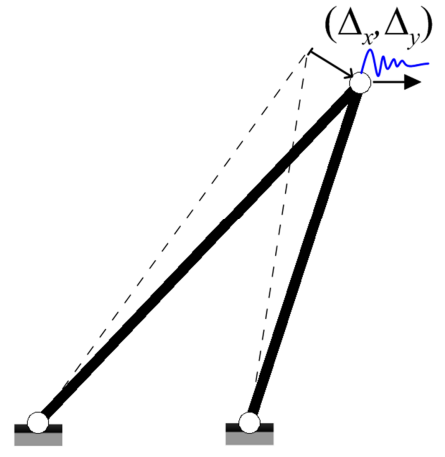

(b) Posição $(1,55,0,061,0,302)$

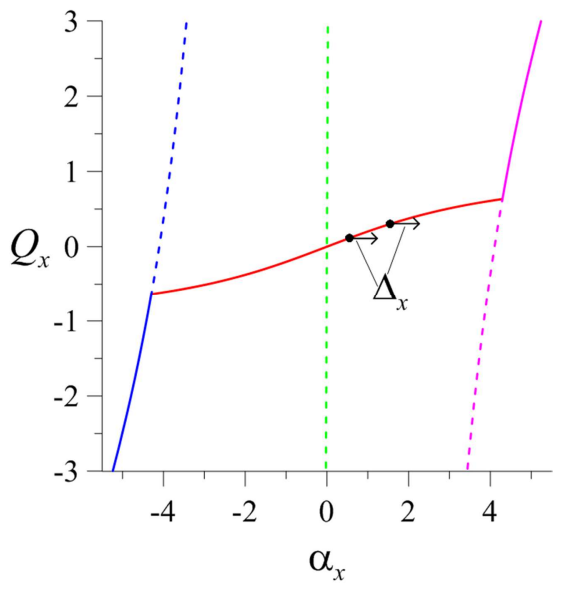

(d) Caminho de equilíbrio: $\alpha_{x} \times Q_{x}$

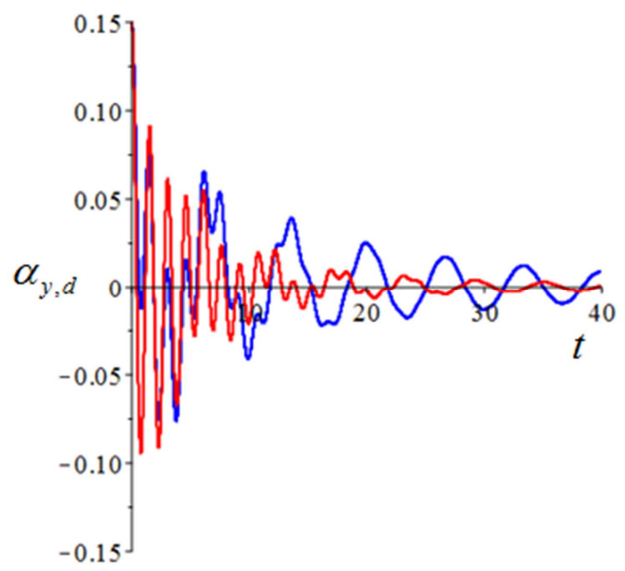

(f) Resposta $t \times \alpha_{y, d}$.

Figura 6.25: Resposta no tempo da treliça perfeita, $\theta=75^{\circ}$ para as posições de equilíbrio estático $(0,55,0,007,0,113)$ e $(1,55,0,061,0,302)$ diante de uma perturbação $\left(\Delta_{x}, \Delta_{y}\right)=\left(0,5 b_{0}, 0,15 h_{0}\right)$. 
De acordo com a Figura 6.25, a treliça na posição estática $(0,55,0,007,0,113)$ possui uma rigidez efetiva na direção $x$ superior e com isso um período inferior em relação à treliça da posição $(1,55,0,061,0,302)$. O mesmo comportamento observa-se para sua resposta na direção $y$. Nesse caso o acoplamento maior acontece na resposta da direção $y$.

Este exemplo finaliza a análise da vibração livre amortecida das treliças hiperelásticas, onde se observa que a não linearidade associada à coexistência de soluções estáveis leva a uma grande variabilidade da resposta no tempo em termos de amplitude e período de vibração. 


\section{7 \\ Conclusões e Sugestões}

Este trabalho investigou o comportamento não linear, a estabilidade e as vibrações de uma treliça neo-Hookeana. Uma análise paramétrica detalhada entre treliças com dois ângulos de abatimento $\left(15^{\circ}\right.$ e $\left.75^{\circ}\right)$ foi conduzida considerando a elasticidade em seu domínio não linear completo. Duas situações de carregamento foram consideradas: carga estática vertical e horizontal. A sensibilidade da estrutura a imperfeições foi estudada, considerando imperfeições de carga e na geometria de sua estrutura. Para isso, uma formulação geral baseada no modelo com imperfeição geométrica foi desenvolvida, o que possibilita a extensão deste estudo para treliças com diferentes ângulos de abatimento e imperfeições, ou até mesmo para diferentes materiais constitutivos. Dessa forma, todos os caminhos de equilíbrio são obtidos e sua estabilidade é investigada utilizando o princípio da energia potencial mínima. As frequências naturais e os modos de vibração são obtidos, confirmando a estabilidade das trajetórias de equilíbrio. Utilizando o princípio da conservação de energia, os retratos de fase da estrutura são exibidos, possibilitando a compreensão das várias soluções estáveis e instáveis coexistentes e de sua complexa superfície de energia potencial. E por fim realiza-se uma breve análise das vibrações livres amortecidas em cada sistema estrutural, permitindo visualizar algumas características dinâmicas desses sistemas.

A investigação da treliça iniciou-se com a análise de uma barra neoHookeana submetida a um carregamento axial, onde se mostrou a não linearidade física da barra hiperelástica, destacando-se a diferença no seu comportamento quando submetida à tração e compressão, que pode exibir deformações na compressão e na tração bastante distintas para um mesmo módulo de força.

A seguir, estudou-se o desenvolvimento das trajetórias de equilíbrio da treliça submetida a uma carga estática vertical. Demonstrou-se que a presença simultânea da não linearidade do material e geométrica geram novos caminhos de equilíbrio que não são esperados para os materiais elásticos lineares. Verificou-se que as treliças neo-Hookeanas, independentemente do seu ângulo de abatimento, 
apresentam cinco posições de equilíbrio na situação descarregada, sendo duas destas posições estáveis e as demais instáveis.

No estudo das trajetórias de equilíbrio, observaram-se dois tipos de cenários: três caminhos independentes e quatro caminhos que se interceptam, norteando a escolha dos ângulos de abatimento, $15^{\circ}$ e $75^{\circ}$, da análise paramétrica.

Quando submetidas a uma carga vertical, as treliças com ângulo de abatimento de $15^{\circ}$ apresentaram o comportamento não linear típico de estruturas abatidas. Ao longo do seu caminho fundamental, o sistema estrutural mantem sua simetria, à medida que a força compressiva cresce, diminui sua rigidez efetiva até tornar-se nula, exibindo uma bifurcação do tipo nó-sela (ponto limite), onde, ao atingir a carga limite, a estrutura perde sua estabilidade e salta para uma configuração pós-crítica estável. Além disto, foram identificados dois caminhos instáveis isolados associados a não linearidade do material.

Para a treliça com ângulo de abatimento de $75^{\circ}$ e carga vertical, ao longo de seu caminho fundamental a estrutura alcança a carga crítica e perde a estabilidade por uma bifurcação simétrica instável. Após esta bifurcação, a configuração fundamental torna-se instável até atingir outro ponto de bifurcação simétrica, representando a segunda carga crítica da treliça. Seguindo nesta trajetória a estrutura torna-se novamente estável até atingir o ponto limite onde corre um salto para uma configuração tracionada com concavidade invertida.

Uma comparação entre as soluções obtidas e a solução de von Mises é realizada, permitindo visualizar graficamente, para todos os ângulos de abatimentos, a diferença entre o comportamento de uma treliça elástica e uma hiperelástica, submetida à carga estática vertical, não só em termos das bifurcações, mas também em termos da capacidade de carga.

Traçaram-se as curvas de sensibilidade a imperfeições de carga e geométrica para esses sistemas estruturais. As estruturas $\operatorname{com} \theta=75^{\circ}$ são sensíveis aos dois tipos de imperfeições e as treliças com $\theta=15^{\circ}$ apresentaram pequena sensibilidade às imperfeições.

$\mathrm{Na}$ análise da treliça submetida à carga horizontal, a estabilidade dos caminhos de equilíbrio apresentou apenas um comportamento, sendo estável até o ponto de bifurcação para ambos os ângulos de abatimento. As treliças com $\theta=15^{\circ}$ apresentaram um comportamento inédito, possuindo rigidez negativa no início de sua trajetória fundamental, provocando um deslocamento do nó superior 
no sentido negativo do eixo $y$, mostrando a influência do modelo neo-Hookeano nos caminhos de equilíbrio.

Ao contrário da estrutura submetida à carga vertical, ambas as estruturas apresentam sensibilidade às imperfeições de carga e pequena sensibilidade às imperfeições geométricas.

As equações do movimento foram obtidas a partir das equações de EulerLagrange e utilizando os termos lineares da série de Taylor, linearizaram-se essas equações em torno da configuração deformada relativa a uma posição estática de equilíbrio genérica. Com isso, inicialmente, obteve-se a variação das frequências em função do ângulo de abatimento para as treliças descarregadas com e sem imperfeição geométrica, mostrando que a imperfeição acopla os modos de vibração próximos ao ângulo de abatimento de $45^{\circ}$, podendo levar a uma interação modal. Utilizando as trajetórias de equilíbrio, determinaram-se as frequências naturais da estrutura, identificando como estas variam ao longo dos caminhos de equilíbrio, mostrando a grande influência do carregamento estático nas frequências naturais da estrutura e servindo de base para análise das vibrações da estrutura.

O princípio da conservação da energia permitiu analisar o sistema estrutural para níveis crescentes de energia, considerando determinados conjuntos de condições iniciais e com o tempo de forma implícita, fazendo uma ligação entre a análise estática e a análise posterior das vibrações amortecidas. Uma abordagem focada nas posições iniciais descarregadas e nos pontos críticos foi desenvolvida permitindo uma compreensão das várias soluções estáveis e instáveis coexistentes dentro e na fronteira de suas bacias conservativas.

Um amortecimento de Rayleigh proporcional às matrizes de massa e de rigidez efetiva linear da estrutura carregada foi utilizado nas equações não lineares do movimento, possibilitando uma análise gradual da resposta dinâmica da estrutura em vibração livre diante de grandes perturbações e a visualização do processo de perda de estabilidade, onde foi aplicado o conceito de bacias de atração. Mostrou-se como o aumento da perturbação realça a não linearidade do sistema estrutural influenciando nas suas repostas ao longo do tempo. 
Os resultados deste trabalho permitiram caracterizar o comportamento não linear estático e dinâmico das treliças neo-Hookenas, um estudo inédito na literatura, que são estruturas potencialmente promissoras para aplicação na recente área que envolve a multiestabilidade de sistemas estruturais.

Explorando as treliças hiperelásticas, alguns trabalhos podem ser desenvolvidos como continuidade deste. As sugestões são apresentadas a seguir.

- Análise teórica e experimental das treliças hiperelásticas, caracterizando seu comportamento não linear estático e dinâmico, investigando a influência da viscoelasticidade diante de ações de natureza cíclica;

- adicionar a energia de flexão na formulação do sistema estrutural em treliça e realizar uma possível análise paramétrica com as estruturas treliçadas aqui apresentadas, considerando a instabilidade local das barras;

- explorar a rigidez negativa presente nos caminhos de equilíbrio apresentados para as treliças com ângulo de abatimento de $15^{\circ}$ submetidas à carga horizontal em estruturas inteligentes, podendo ser aplicada em mecanismos ou no aumento da capacidade de carga da estrutura;

- projetar e analisar estruturas ou materiais compostos por treliças hiperelásticas, desenvolvendo uma formulação que represente o comportamento desses arranjos estruturais, que podem exibir diferentes regimes, não lineares e lineares de deformação, explorando suas aplicações, por exemplo, como um mecanismo de absorção de energia;

- investigar a aplicação das treliças hiperelásticas na construção e análise de placas sanduíches, formando o núcleo destas estruturas. 


\section{8 Referências bibliográficas}

ARIO, I. Homoclinic bifurcation and chaos attractor in elastic two-bar truss. International Journal of Non-Linear Mechanics, v. 39, n. 4, p. 605-617, 2004.

ATTARD, M. M.; HUNT, G. W. Column buckling with shear deformations-a hyperelastic formulation. International Journal of Solids and Structures, v. 45, n. 14-15, p. 4322-4339, 2008.

BAZANT, Z. P., CEDOLIN, L. Stability of structures: elastic, inelastic, fracture and damage theories. World Scientific, 2010.

CASTRO, C. H. L. Vibrações não lineares e estabilidade de treliças piramidais abatidas. Dissertação de Mestrado. Pontifícia Universidade Católica do Rio de Janeiro, 2014.

CHEN, T.; MUELLER, J.; SHEA, K. Integrated design and simulation of tunable, multi-state structures fabricated monolithically with multi-material 3D printing. Scientific reports, v. 7, p. 45671, 2017.

COULAIS, C. et al. Discontinuous buckling of wide beams and metabeams. Physical review letters, v. 115, n. 4, p. 044301, 2015.

CROLL, J. G. A.; WALKER, A. C, Alastair Chalmers. Elements of structural stability. John Wiley \& Sons, 1972.

CUI, Y. Adaptive multistable flexible composite structures. 2015.

DAZIO, A. Course: Fundamentals of Structural Dynamics. An-Najah National University, 2013. 
FLORIJN, B.; COULAIS, C.; VAN HECKE, M. Programmable mechanical metamaterials. Physical review letters, v. 113, n. 17, p. 175503, 2014.

GONÇALVES, P. B.; PAMPLONA, D.; L., S. R. X. Finite deformations of an initially stressed cylindrical shell under internal pressure. International Journal of Mechanical Sciences, v. 50, n. 1, p. 92-103, 2008.

GONÇALVES, P. B.; SOARES, R. M.; PAMPLONA, D. Nonlinear vibrations of a radially stretched circular hyperelastic membrane. Journal of Sound and Vibration, v. 327, n. 1-2, p. 231-248, 2009.

GIOMI, L.; MAHADEVAN, L. Multi-stability of free spontaneously curved anisotropic strips. Proc. R. Soc. A, v. 468, n. 2138, p. 511-530, 2012.

KASSIMALI, A.; BIDHENDI, E. Stability of trusses under dynamic loads. Computers \& structures, v. 29, n. 3, p. 381-392, 1988.

KOITER, W. T. Current trends in the theory of buckling. In: Buckling of structures. Springer, Berlin, Heidelberg, 1976. p. 1-16.

KWASNIEWSKI, Leslaw. Complete equilibrium paths for Mises trusses. International Journal of Non-Linear Mechanics, v. 44, n. 1, p. 19-26, 2009.

LIGARO, S. S.; VALVO, P. S. Large displacement analysis of elastic pyramidal trusses. International journal of solids and structures, v. 43, n. 16, p. 48674887, 2006.

LEE, S. et al. Dynamic failure of metallic pyramidal truss core materialsexperiments and modeling. International Journal of Plasticity, v. 22, n. 11, p. 2118-2145, 2006.

LOPES, S. R. X. Comportamento Não-Linear e Instabilidade de Membranas e Cascas Hiperelásticas. 2003. Tese de Doutorado. PUC-Rio. 
MISES, R. V. Über die stabilitätsprobleme der elastizitätstheorie. ZAMMJournal of Applied Mathematics and Mechanics/Zeitschrift für Angewandte Mathematik und Mechanik, v. 3, n. 6, p. 406-422, 1923.

MISES, R. V.; RATZERSDORFER, J. Die Knicksicherheit von Fachwerken. ZAMM-Journal of Applied Mathematics and Mechanics/Zeitschrift für Angewandte Mathematik und Mechanik, v. 5, n. 3, p. 218-235, 1925.

MOONEY, M. A theory of large elastic deformation. Journal of applied physics, v. 11, n. 9 , p. 582-592, 1940.

NADKARNI, N.; DARAIO, C.; KOCHMANN, D. M. Dynamics of periodic mechanical structures containing bistable elastic elements: From elastic to solitary wave propagation. Physical Review E, v. 90, n. 2, p. 023204, 2014.

NAYFEH, A. H.; MOOK, D. T. Nonlinear oscillations. John Wiley \& Sons, 2008.

NAYFEH, A. H. Nonlinear interactions: analytical, computational and experimental methods. Wiley, 2000.

ORLANDO, D. Dinâmica Não-Linear, Instabilidade e Controle de Sistemas Estruturais com Interação Modal. 2010. Tese de Doutorado. PUC-Rio.

OGDEN, R. W. Large deformation isotropic elasticity-on the correlation of theory and experiment for compressible rubberlike solids. Proc. R. Soc. Lond. A, v. 328, n. 1567 , p. $567-584,1972$.

PASCON, J. P. Nonlinear analysis of hyperelastoplastic truss-like structures. Archive of Applied Mechanics, v. 86, n. 5, p. 831-851, 2016.

RAFSANJANI, A.; AKBARZADEH, A.; PASINI, D. Snapping mechanical metamaterials under tension. Advanced Materials, v. 27, n. 39, p. 5931-5935, 2015. 
SASSO, M. et al. Characterization of hyperelastic rubber-like materials by biaxial and uniaxial stretching tests based on optical methods. Polymer Testing, v. 27, n. 8, p. 995-1004, 2008.

SCHIOLER, T.; PELLEGRINO, S. A bistable structural element. Proceedings of the Institution of Mechanical Engineers, Part C: Journal of Mechanical Engineering Science, v. 222, n. 11, p. 2045-2051, 2008.

SCHMIED, J. U. et al. Toward structurally integrated locally resonant metamaterials for vibration attenuation. In: Active and Passive Smart Structures and Integrated Systems 2017. International Society for Optics and Photonics, 2017. p. 1016413.

SCHREURS, P. Material Models. Materials Technology, 2012.

SELVADURAI, A. P. S. Deflections of a rubber membrane. Journal of the Mechanics and Physics of Solids, v. 54, n. 6, p. 1093-1119, 2006.

SHAN, S. et al. Multistable architected materials for trapping elastic strain energy. Advanced Materials, v. 27, n. 29, p. 4296-4301, 2015.

SOARES, R. M. Análise dinâmica de membranas circulares hiperelásticas. 2009. Tese de Doutorado. PUC-Rio.

THOMPSON, J. M. T.; HUNT, G. W. Elastic instability phenomena. Chichester etc.: Wiley, 1984.

TRELOAR, L. R. G. The photo-elastic properties of rubber. Part I: Theory of the optical properties of strained rubber. Transactions of the Faraday Society, v. 43, p. 277-284, 1947.

TRELOAR, L. R. G. Stresses and birefringence in rubber subjected to general homogeneous strain. Proceedings of the Physical Society, v. 60, n. 2, p. 135, 1948. 
WANG, B. et al. Mechanical behavior of the sandwich structures with carbon fiber-reinforced pyramidal lattice truss core. Materials \& Design (1980-2015), v. 31, n. 5, p. 2659-2663, 2010.

WANG, P. et al. Harnessing buckling to design tunable locally resonant acoustic metamaterials. Physical review letters, v. 113, n. 1, p. 014301, 2014.

WIKIPEDIA. Arruda-Boyce model. Disponível em:

<https://en.wikipedia.org/wiki/Arruda\%E2\%80\%93Boyce_model > Acesso em: 27 de junho de 2018.

ZIRBEL, S. A. et al. Bistable mechanisms for space applications. PloS one, v. 11, n. 12, p. e0168218, 2016. 